\author{
Universidade de São Paulo \\ Instituto de Astronomia, Geofísica e Ciências Atmosféricas \\ Departamento de Ciências Amosféricas
}

Ana Maria Pereira Nunes

\title{
Estudo das tempestades noturnas no sudoeste da Amazônia
}

São Paulo, 2021 



\section{Estudo das tempestades noturnas no sudoeste da Amazônia}

Tese apresentada ao Departamento de Ciências Amosféricas do Instituto de Astronomia, Geofísica

e Ciências Atmosféricas da Universidade de São Paulo como requisito parcial para a obtenção do título de Doutora em Ciências.

Versão corrigida. O original encontra-se disponível na Unidade.

Área de Concentração: Ciências Amosféricas Orientador(a): Prof ${ }^{a}$. Dra ${ }^{a}$. Maria Assunção Faus da Silva Dias

São Paulo, 2021 

In memorian de Moacir Pereira Nunes 



\section{Agradecimentos}

Aos meus pais Moacir (in memorian) e Maria Cristina, e a minha irmã Maria da Graça por todo o apoio, carinho, compreensão e incentivo. Vocês são minha base, fundamentais nesta jornada.

À professora Dra. Maria Assunção Faus da Silva Dias, pela proposta de trabalho, por todos os anos de orientação, apoio, incentivo e puxões de orelha.

À professora Dra. Rosmeri Porfirio da Rocha, principalmente pelo suporte emocional durante minha etapa de exame de qualificação.

Ao apoio financeiro da Coordenação de Aperfeiçoamento de Pessoal de Nível Superior/CAPES (Código de financiamento 001) e seu Programa de Excelência Acadêmica (PROEX), e do Conselho Nacional de Desenvolvimento Científico e Tecnológico (CNPq), que tornou possível a realização desta pesquisa.

Aos colegas (The Remainings/Season Finale) que estiveram comigo ao longo destes anos em São Paulo e também ao ex-colega Dr. Glauber Camponogara por toda a paciência e auxílio com o modelo BRAMS.

Aos queridos técnicos de informática Djalma Melo, Samuel Reis e Sebastião Antônio Silva pelo suporte ao longo da minha trajetória no instituto, sempre muito prestativos e parceiros.

A todos os funcionários do instituto, desde o pessoal da limpeza à administração.

A minha amiga Mariana Turibio e sua família, absolutamente por tudo.

Por último e não menos importante um agradecimento especial aos meus gatos: Venâncio por aparecer de surpresa no momento mais crítico do meu doutorado, trazendo refúgio às minhas angústias e um companheirismo sem igual; e a minha gata Guilhermina Boulas que me ensinou sobre persistir e alcançar. 

"Adestrei-me com o vento e a minha festa é a tempestade."

Cecília Meireles 



\section{Resumo}

O presente estudo investiga as tempestades noturnas registradas na região sudoeste da Amazônia durante o período de 1998-2013. As tempestades foram identificadas utilizando dados obtidos pelo satélite TRMM através de uma série de critérios envolvendo sua profundidade vertical e área horizontal, volume de chuva associado e presença de raios. Os eventos noturnos encontrados aqui não correspondem totalmente a passagem de linhas de instabilidade, como sugerem estudos anteriores. As tempestades noturnas são analisadas sob o ponto de vista observacional, explorando diferentes bases de dados, e também da modelagem numérica através do modelo regional BRAMS. O conjunto de 97 tempestades noturnas foi classificado de acordo com sua severidade, identificada pela taxa de raios: cerca de $40 \%$ destes sistemas são intensos (> 32 raios $/ \mathrm{min}$ ) e $25 \%$ extremos (> $47 \mathrm{raios} / \mathrm{min}$ ). Resultados mostram que a maior parte das tempestades noturnas ocorre próximo ao sopé da cordilheira dos Andes, sugerindo um papel orográfico importante, e com preferência pelo trimestre de Outubro-Novembro-Dezembro. Dois padrões sinóticos de baixos níveis são observados durante estes eventos: P1, relacionado ao jato de baixos níveis da América do Sul (55 casos), e P2 relacionado a uma confluência NO-SE proveniente da passagem de sistemas frontais (42 casos). Composições de grande escala e anomalias baseadas na reanálise ERA5 enfatizam estes padrões, que já estão estabelecidos pelo menos 12 horas antes do registro das tempestades. A maioria das tempestades noturnas ocorre com suporte de sistemas sinóticos, porém, isoladas: apenas 7 delas são consideradas embebidas em frentes frias. O horário preferencial de início destes sistemas é entre 1800 e 0000 hora local, e eles duram por volta de 7,5 e 22,5 horas. São realizadas composições centradas nas tempestades intensas e não intensas em caixas de $6^{\circ} \times 6^{\circ}$ ao redor delas. Tempestades noturnas intensas apresentam confluência em baixos níveis, ambiente 
mais quente, com CAPE mais alto e aumentando no período pré-convectivo enquanto CIN diminui, maior contraste de umidade (horizontal e vertical, com fluxo mais seco sobreposto a fluxo mais úmido) e profundidade da parte quente da nuvem mais rasa quando comparadas às tempestades não intensas. O nível de $850 \mathrm{hPa}$ e o horário de 1800 UTC (dia anterior) parecem ser importantes para a previsibilidade destes sistemas no sudoeste da Amazônia. O papel das circulações locais associadas à cordilheira dos Andes é explorado através de simulações numéricas com modelo regional BRAMS. Resultados mostram que é possível capturar padrões de circulação observados nos campos de reanálise e também observar o desenvolvimento de circulações locais relacionadas à topografia, como fluxo descendo o terreno durante a noite e subindo o terreno o dia. A simulação da tempestade do dia 26/11/2001, terceira mais intensa na classificação de severidade, mostrou que um fluxo de ar em superfície é forçado a subir a inclinação da cordilheira, resultando em um sistema intenso, verticalmente desenvolvido, devido à confluência com fluxo que descende da montanha resultante do resfriamento noturno.

Palavras-chave: Tempestades noturnas. Amazônia. TRMM. BRAMS. 


\section{Abstract}

The present study investigates the nocturnal thunderstorms that occur in the southwest of Amazon region during the period 1998-2013. The thunderstorms were identified using data obtained by the TRMM satellite through a series of criteria involving vertical depth and horizontal area, rainfall volume, and lightning. The nocturnal cases found here do not fully correspond to the passage of squall lines, as suggested in previous studies. Here, the nocturnal thunderstorms are assessed from an observational viewpoint exploring several databases and numerical modeling through the BRAMS regional model. We classified the set of 97 NT according to their severity, identified by the lightning rate: about $40 \%$ of these systems are intense $(>32$ flashes $/ \mathrm{min})$ and $25 \%$ extreme $(>47$ flashes $/ \mathrm{min})$. Results show that most nocturnal thunderstorms occur near the foothills of the Andes mountain range, suggesting an important orographic role and preference for the October-NovemberDecember quarter. Two low-level synoptic patterns are observed during these events: P1, related to the South America low-level jet (55 cases), and P2 to a NW-SE confluence from the frontal system passage (42 cases). Large-scale composites and anomalies based on ERA5 reanalysis emphasize the patterns, which are already established at least $12 \mathrm{~h}$ in advance. Most of the nocturnal thunderstorms occur with synoptic systems support but in isolation, and only 7 are embedded in cold fronts. The preferable start time is between 1800-0000 local time, and they last about 7.5-22.5 h. Composite environmental fields relative to the thunderstorm centers in $6^{\circ} \times 6^{\circ}$ boxes for intense and not intense nocturnal thunderstorms are performed. Intense nocturnal thunderstorms present confluence at lowlevels, a warmer environment, with higher CAPE increasing in pre-convective period while CIN decreases, with a moisture contrast (horizontal and vertical, a drier flow overlapping on a wetter flow), and shallower warm cloud depth. The $850-\mathrm{hPa}$ level and the 1800 UTC 
time as indicated as important for the predictability of NT in the SW Amazon. The role of local circulations associated with the Andes mountain range is explored through numerical simulations using the BRAMS regional model. Results show that it is possible to capture circulation patterns observed in the reanalysis fields and also to observe the development of local circulations related to topography, such as downslope flow at night and upslope during the day. The simulation of the nocturnal thunderstorm recorded 26/11/2001, the third most intense in the severity ranking, showed that a surface air flows over the slope of the mountain range, resulting in an intense, vertically developed system, due to the confluence with downslope motion resulting from the cooling at the night.

Keywords: nocturnal thunderstorms, Amazon, TRMM, Andes mountain range, orographic precipitation. 


\section{Lista de Figuras}

2.1 Sub-regiões da área de estudo: AS, parte sul da Amazônia ocidental; WAN, parte norte da Amazônia ocidental; GS, Guiana Shield; CA, Amazônia central; EA, leste da Amazônia; SA: sul da Amazônia (adaptado de ter Steege et al., 2013). Contornos cinza claro indicam limites políticos para países e estados brasileiros. . . . . . . . . . . . . . . . . . . . . 38

2.2 Domínio de estudo ampliado identificado pelo retângulo preto onde a escala de cores representa a elevação do terreno em metros. . . . . . . . . . . . 39

2.3 Ilustração do indicador de severidade "warm cloud deph", onde $0^{\mathrm{O}} \mathrm{C}$ indica a isoterma de referente ao nível de congelamento e NCL o nível de condensação

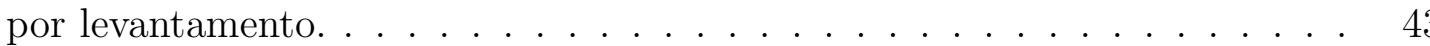

3.1 Posição das tempestades no horário de registro pelo satélite TRMM (símbolos pretos) dentro do domínio de estudo definido como região SW Amazônia. Escala de cores representa elevação do terre (em metros) . . . . . . . . . .

3.2 Distribuição geográfica das 97 tempestades noturnas na região SW Amazônia (símbolos brancos) entre 1998-2013, onde a escala de cores mostra o número de tempestades acumuladas por célula de grade com resolução espacial de

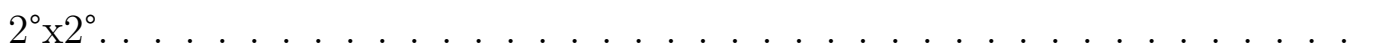

3.3 Distribuição geográfica (símbolos em vermelho) do acumulado trimestral das tempestades noturnas no SW Amazônia e acumulado mensal (barras em cinza, onde cada barra representa um mês do trimestre) para o período de 1998-2013, onde a) janeiro-fevereiro-março, b) abril-maio-junho, c) julhoagosto-setembro, d) outubro-novembro-dezembro. . . . . . . . . . . . 48

3.4 Distribuição anual de tempestades noturnas no SW Amazônia entre 1998-2013. 49 
3.5 Relação de dispersão entre chuva volumétrica das tempestades (mm h-1 $\mathrm{Km}-2)$ e elevação do terreno $(\mathrm{m})$ onde ocorreram . . . . . . . . . . 50

3.6 Histograma da elevação do terreno $(\mathrm{m})$ onde as tempestades noturnas foram registradas no SW Amazônia. . . . . . . . . . . . . . . . . . 50

3.7 Relação de dispersão entre área total $\left(\mathrm{km}^{2}\right)$ e a taxa de raios (raios $\left./ \mathrm{min}\right)$ das tempestades noturnas no SW Amazônia. Reta vermelha vertical destaca o limiar de $10000 \mathrm{~km}^{2}$ e reta vermelha horizontal o limiar de 32 raios/min. .

3.8 Relação de dispersão entre área total $\left(\mathrm{km}^{2}\right)$ e a taxa de raios (raios/min) das tempestades noturnas intensas no SW Amazônia. Símbolos em laranja destacam tempestades extremas. . . . . . . . . . . . . .

3.9 Histogramas das propriedades das tempestades noturnas onde a) taxa de raios (raios/min), b) hora de registro (UTC), c) área total $\left(\mathrm{Km}^{2}\right)$, d) área do núcleo $\left(\mathrm{Km}^{2}\right)$, e) mínima PCT85GHz $(\mathrm{K})$, f) mínima PCT37GHz, g) máxima taxa de precipitação na superfície $(\mathrm{mm} / \mathrm{h}), \mathrm{h})$ altura máxima do

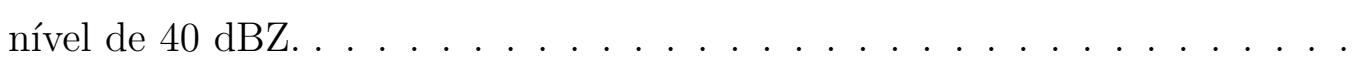

3.10 Altura máxima do nível de $40 \mathrm{dBZ}$ para as 97 tempestades noturnas (eixo y) em ordem decrescente de taxa de raios (eixo x) . . . . . . . . . . 60

3.11 MINPCT85GHz (linha contínua) e MINPCT37GHz (linha tracejada) para as 97 tempestades noturnas (eixo y), em ordem decrescente de taxa de raios $($ eixo $\mathrm{x}) \ldots \ldots \ldots \ldots \ldots \ldots \ldots \ldots \ldots \ldots \ldots \ldots \ldots \ldots \ldots \ldots \ldots \ldots \ldots \ldots$

3.12 MINPCT37GHz para as 23 tempestades noturnas extremas (eixo y), em ordem decrescente de taxa de raios $($ eixo $\mathrm{x}) \ldots \ldots \ldots$. . . . . . . 61

3.13 Topografia (escala de cores, em metros) e localização das tempestades a) com padrão de escoamento P1; b) com padrão P2. A localização é aquela dada durante a passagem do satélite TRMM. . . . . . . . . . . . . .

3.14 Composição do nível de 850 hPa para tempestades com padrão P1 de escoamento às a) 1200 UTC (dia anterior ao registro), b) 1800 UTC (dia anterior ao registro), c) 0000 UTC (dia de registro), d) 0600 UTC (dia de registro) onde escala de cores indica magnitude média do vento $(\mathrm{m} / \mathrm{s})$, vetores indicam vento horizontal e contornos em laranja mostram onde o cisalhamento do vento entre $700-850 \mathrm{hPa}$ é maior que $4 \mathrm{~m} / \mathrm{s} \ldots \ldots \ldots$. . . . . . . 
3.15 Composição do nível de 850 hPa para tempestades com padrão P2 de escoamento às a) 1200 UTC (dia anterior ao registro), b) 1800 UTC (dia anterior ao registro), c) 0000 UTC (dia de registro), d) 0600 UTC (dia de registro) onde escala de cores indica magnitude média do vento $(\mathrm{m} / \mathrm{s})$, vetores indicam vento horizontal e contornos em laranja mostram onde o cisalhamento do vento entre 700-850 hPa é maior que $4 \mathrm{~m} / \mathrm{s}$. . . . . . . . . . . .

3.16 Composição do nível de 950 hPa para tempestades com escoamento P1 (com JBN) às a) 1200 UTC - dia anterior, b) 1800 UTC - dia anterior, c) 0000 UTC, dia de registro e d) 0600 UTC do dia de registro. Escala de cores indica umidade específica $(\mathrm{g} / \mathrm{Kg})$, contornos representam temperatura $\left({ }^{\circ} \mathrm{C}\right)$ e vetores mostram vento horizontal. . . . . . . . . . . . . . .

3.17 Composição do nível de 950 hPa para tempestades com escoamento P2 (sem JBN) às a) 1200 UTC - dia anterior, b) 1800 UTC - dia anterior, c) 0000 UTC, dia de registro e d) 0600 UTC do dia de registro. Escala de cores indica umidade específica $(\mathrm{g} / \mathrm{Kg})$, contornos representam temperatura $\left({ }^{\circ} \mathrm{C}\right)$ e vetores mostram vento horizontal. . . . . . . . . . . . . . . . . 69 69

3.18 Composição do nível de $850 \mathrm{hPa}$ para o dia anterior às tempestades consideradas com escoamento padrão tipo P1 (com JBN) às a) 1200 UTC do dia anterior, b) 1800 UTC do dia anterior, c) 0000 UTC, dia de registro e d) 0600 UTC do dia de registro. Escala de cores indica umidade relativa (\%), contornos representam temperatura $\left({ }^{\circ} \mathrm{C}\right)$ e vetores mostram vento horizontal. 69

3.19 Composição do nível de 850 hPa para o dia anterior às tempestades consideradas com escoamento padrão tipo P2 (com JBN) às a) 1200 UTC do dia anterior, b) 1800 UTC do dia anterior, c) 0000 UTC, dia de registro e d) 0600 UTC do dia de registro. Escala de cores indica umidade relativa (\%), contornos representam temperatura $\left({ }^{\circ} \mathrm{C}\right)$ e vetores mostram vento horizontal. 70

3.20 Composição do nível de $700 \mathrm{hPa}$ para o dia anterior às tempestades consideradas com escoamento padrão tipo P1 (com JBN) às a) 1200 UTC do dia anterior, b) 1800 UTC do dia anterior, c) 0000 UTC, dia de registro e d) 0600 UTC do dia de registro. Escala de cores indica umidade relativa (\%), contornos representam temperatura $\left({ }^{\circ} \mathrm{C}\right)$ e vetores mostram vento horizontal. 71 
3.21 Composição do nível de $700 \mathrm{hPa}$ para o dia anterior às tempestades consideradas com escoamento padrão tipo P2 (com JBN) às a) 1200 UTC do dia anterior, b) 1800 UTC do dia anterior, c) 0000 UTC, dia de registro e d) 0600 UTC do dia de registro. Escala de cores indica umidade relativa (\%), contornos representam temperatura $\left({ }^{\circ} \mathrm{C}\right)$ e vetores mostram vento horizontal. 72

3.22 Composição do nível de $500 \mathrm{hPa}$ para o dia anterior às tempestades consideradas com escoamento padrão tipo P1 (com JBN) às a) 1200 UTC do dia anterior, b) 1800 UTC do dia anterior, c) 0000 UTC, dia de registro e d) 0600 UTC do dia de registro. Escala de cores indica umidade relativa (\%), contornos representam temperatura $\left({ }^{\circ} \mathrm{C}\right)$ e vetores mostram vento horizontal. 72

3.23 Composição do nível de $500 \mathrm{hPa}$ para o dia anterior às tempestades consideradas com escoamento padrão tipo P2 (com JBN) às a) 1200 UTC do dia anterior, b) 1800 UTC do dia anterior, c) 0000 UTC, dia de registro e d) 0600 UTC do dia de registro. Escala de cores indica umidade relativa (\%), contornos representam temperatura $\left({ }^{\circ} \mathrm{C}\right)$ e vetores mostram vento horizontal. 73

3.24 Climatologia de umidade específica $(\mathrm{g} / \mathrm{Kg})$ e vento $(\mathrm{m} / \mathrm{s})$ para dezembrojaneiro-fevereiro na América do Sul em a) 200 hPa, b) 500 hPa. Fonte: Romatschke e Houze (2010) . . . . . . . . . . . . . . 73

3.25 Composição de CAPE (escala de cores, J/Kg) e CIN (contornos, J/Kg) região SW Amazônia para tempestades com escoamento tipo P1 às a) 1200 UTC do dia anterior, b) 1800 UTC do dia anterior, c) 0000 UTC, dia de registro e d) 0600 UTC do dia de registro. . . . . . . . . . . 75

3.26 Composição de CAPE (escala de cores, J/Kg) e CIN (contornos, J/Kg) região SW Amazônia para tempestades com escoamento tipo P2 às a) 1200 UTC do dia anterior, b) 1800 UTC do dia anterior, c) 0000 UTC, dia de registro e d) 0600 UTC do dia de registro. . . . . . . . . . . . 75

3.27 Composição do cisalhamento vertical do vento horizontal em baixos níveis (escala de cores, m/s) e em médios níveis (contornos, m/s) para tempestades com escoamento tipo P1. . . . . . . . . . . . . . . 76

3.28 Composição do cisalhamento vertical do vento horizontal em baixos níveis (escala de cores, m/s) e em médios níveis (contornos, m/s) para tempestades com escoamento tipo $\mathrm{P} 2 \ldots \ldots \ldots \ldots \ldots \ldots$ 
3.29 Anomalia de umidade específica (g/Kg, escala de cores), vento (m/s, vetores) e temperatura $\left({ }^{\circ} \mathrm{C}\right.$, contornos) em $950 \mathrm{hPa}$ para o padrão $\mathrm{P} 1 \mathrm{em}$ relação à normal climatológica de 1981-2010 para os horários a) 1200 UTC (dia anterior), b) 1800 UTC (dia anterior), c) 0000 UTC, d) 0600 UTC. . .

3.30 Anomalia de umidade específica (g/Kg, escala de cores), vento (m/s, vetores) e temperatura $\left({ }^{\circ} \mathrm{C}\right.$, contornos) em $950 \mathrm{hPa}$ para o padrão $\mathrm{P} 1 \mathrm{em}$ relação à normal climatológica de 1981-2010 para os horários a) 1200 UTC (dia anterior), b) 1800 UTC (dia anterior), c) 0000 UTC, d) 0600 UTC. . .

3.31 Anomalia de umidade relativa (\%, escala de cores), vento (m/s, vetores) e temperatura $\left({ }^{\circ} \mathrm{C}\right.$, contornos) em $850 \mathrm{hPa}$ para o padrão $\mathrm{P} 1$ em relação à normal climatológica de 1981-2010 para os horários a) 1200 UTC (dia anterior), b) 1800 UTC (dia anterior), c) 0000 UTC, d) 0600 UTC. . . . .

3.32 Anomalia de umidade relativa (\%, escala de cores), vento (m/s, vetores) e temperatura $\left({ }^{\circ} \mathrm{C}\right.$, contornos) em $850 \mathrm{hPa}$ para o padrão $\mathrm{P} 2$ em relação à normal climatológica de 1981-2010 para os horários a) 1200 UTC (dia anterior), b) 1800 UTC (dia anterior), c) 0000 UTC, d) 0600 UTC. . . . .

3.33 Anomalia de umidade relativa (\%, escala de cores), vento (m/s, vetores) e temperatura $\left({ }^{\circ} \mathrm{C}\right.$, contornos) em $700 \mathrm{hPa}$ para o padrão $\mathrm{P} 1$ em relação à normal climatológica de 1981-2010 para os horários a) 1200 UTC (dia anterior), b) 1800 UTC (dia anterior), c) 0000 UTC, d) 0600 UTC. . . . .

3.34 Anomalia de umidade relativa (\%, escala de cores), vento (m/s, vetores) e temperatura $\left({ }^{\circ} \mathrm{C}\right.$, contornos) em $700 \mathrm{hPa}$ para o padrão $\mathrm{P} 2$ em relação à normal climatológica de 1981-2010 para os horários a) 1200 UTC (dia anterior), b) 1800 UTC (dia anterior), c) 0000 UTC, d) 0600 UTC. . . . .

3.35 Anomalia de umidade relativa (\%, escala de cores), vento (m/s, vetores) e temperatura $\left({ }^{\circ} \mathrm{C}\right.$, contornos) em $500 \mathrm{hPa}$ para o padrão $\mathrm{P} 1$ em relação à normal climatológica de 1981-2010 para os horários a) 1200 UTC (dia anterior), b) 1800 UTC (dia anterior), c) 0000 UTC, d) 0600 UTC. . . . .

3.36 Anomalia de umidade relativa (\%, escala de cores), vento (m/s, vetores) e temperatura $\left({ }^{\circ} \mathrm{C}\right.$, contornos) em $700 \mathrm{hPa}$ para o padrão $\mathrm{P} 2$ em relação à normal climatológica de 1981-2010 para os horários a) 1200 UTC (dia anterior), b) 1800 UTC (dia anterior), c) 0000 UTC, d) 0600 UTC. . . . . 
3.37 Ciclo de vida da tempestade noturna de 03-09-2009, registrada pelo satélite TRMM às 07:12 UTC em $15,98^{\circ} \mathrm{S}-65,66^{\circ} \mathrm{W}$ ilustrado pela temperatura de brilho $\left({ }^{\circ} \mathrm{C}\right)$ do conjunto GPM-MERGIR para: a) 2300 UTC (dia anterior); b) 0400 UTC; c) 0630 UTC; d) 0700 UTC (próximo ao horário de registro); e) 0900 UTC; f) 1430 UTC. Seta vermelha indica início das primeiras células. 84

3.38 Magnitude do vento (m/s, escala de cores) superior a $12 \mathrm{~m} / \mathrm{s}$ em $850 \mathrm{hPa}$ e cisalhamento vertical do vento horizontal entre 700-850 hPa (contornos em vermelho) acima de $6 \mathrm{~m} / \mathrm{s}$ para a tempestade noturna de 03-09-2009, registrada às $7,20 \mathrm{UTC}$ em $15,98^{\circ} \mathrm{S}-65,66^{\circ} \mathrm{W}$ (símbolo vermelho) para a) 1200 UTC (dia anterior ao registro); b) 1800 UTC (dia anterior ao registro); c) 0000 UTC (dia do registro); d) 0600 UTC (dia do registro). . . . . . . .

3.39 Ciclo de vida da tempestade noturna de 19-02-2004, registrada pelo satélite TRMM às 09:10 UTC em $15,35^{\circ} \mathrm{S}-66,16^{\circ} \mathrm{W}$ ilustrado pela temperatura de brilho $\left({ }^{\circ} \mathrm{C}\right)$ do conjunto GPM-MERGIR para: a) 0200 UTC; b) 0400 UTC; c) 0600 UTC; d) 0900 UTC (próximo ao horário de registro); e) 1200 UTC; f) 1900 UTC. . . . . . . . . . . . . . . . . . . . . . . . . . . . .

3.40 Magnitude do vento (m/s, escala de cores) superior a $12 \mathrm{~m} / \mathrm{s}$ em $850 \mathrm{hPa}$ e cisalhamento vertical do vento horizontal entre 700-850 hPa (contornos em vermelho) acima de $6 \mathrm{~m} / \mathrm{s}$ para a tempestade noturna de 19-02-2004, registrada às $09,17 \mathrm{UTC}$ em $15,35^{\circ} \mathrm{S}-66,16^{\circ} \mathrm{W}$ (símbolo vermelho) para a) 0000 UTC; b) 0600 UTC; c) 1200 UTC; d) 1800 UTC. . . . . . . . . . . .

3.41 Pressão a nível médio do mar (hPa, escala de cores) e vento horizontal em $10 \mathrm{~m}$ de altura (m/s, vetores) para a tempestade noturna de 19-02-2004, registrada às $09,17 \mathrm{UTC}$ em $15,35^{\circ} \mathrm{S}-66,16^{\circ} \mathrm{W}$ (símbolo vermelho) para a) 1200 UTC (dia anterior); b) 1800 UTC (dia anterior); c) 0000 UTC; d) 0600 UTC . . . . . . . . . . . . . . . . . . .

3.42 Precipitação (mm/dia) da tempestade noturna de 19-02-2004, registrada pelo satélite TRMM às $09,17 \mathrm{UTC}$ em $15,35^{\circ} \mathrm{S}-66,16^{\circ} \mathrm{W}$, posição indicada pelo símbolo preto, a) observada pelo satélite TRMM no conjunto de dados diário 3B42 e b) estimada pela reanálise ERA5. . . . . . . . . . . . . . 
3.43 Tempestades noturnas de 30-04-2008, registradas pelo satélite TRMM às $1,14 \mathrm{UTC}$ em $14,1^{\circ} \mathrm{S}-64,8^{\circ} \mathrm{W}$ e $1,13 \mathrm{UTC}$ em $15,9^{\circ} \mathrm{S}-66,3^{\circ} \mathrm{W}$ ilustradas pela temperatura de brilho $\left({ }^{\circ} \mathrm{C}\right)$ do conjunto GPM-MERGIR para: a) América do Sul; b) região SW Amazônia, ambas às 0100 UTC. . . . . . . . . . . . .

3.44 Ciclo de vida das tempestades noturnas de 30-04-2008, registradas pelo satélite TRMM por volta de 01:00 UTC em $14,1^{\circ} \mathrm{S}-64,8^{\circ} \mathrm{W}$ e $15,9^{\circ} \mathrm{S}-66,3^{\circ} \mathrm{W}$ ilustrado pela temperatura de brilho $\left({ }^{\circ} \mathrm{C}\right)$ do conjunto GPM-MERGIR para: a) 09:00 UTC (dia anterior ao registro); b) 11:30 UTC (dia anterior ao registro); c) 15:30 UTC (dia anterior ao registro); d) 19:00 UTC (dia anterior ao registro); e) 22:00 UTC (dia anterior ao registro); f) 01:00 UTC (horário aproximado do registro de ambas as tempestades); g) 03:00 UTC (dia de registro); h) 04:00 UTC (dia de registro); i) 05:00 UTC (dia de registro); j) 06:30 UTC (dia de registro); k) 10:30 UTC (dia de registro); l) 22:00 UTC (dia de registro)

3.45 Temperatura de brilho (GPM-MERGIR) na América do Sul ilustrando o avanço da frente fria a) 1200 UTC (29-04-2008); b) 1800 UTC (29-04-2008); c) 0000 UTC (30-04-2008); d) 16:00 UTC (30-04-2008) . . . . . . . . . .

3.46 Magnitude do vento (m/s, escala de cores) superior a $12 \mathrm{~m} / \mathrm{s}$ em $850 \mathrm{hPa}$ e cisalhamento vertical do vento horizontal entre $700-850 \mathrm{hPa}$ (contornos em vermelho) acima de $6 \mathrm{~m} / \mathrm{s}$ para as tempestades noturnas de 30-04-2008, registradas $\sim 01: 00 \mathrm{UTC}$ em $14,1^{\circ} \mathrm{S}-64,8^{\circ} \mathrm{W}$ e $15,9^{\circ} \mathrm{S}-66,3^{\circ} \mathrm{W}$ (símbolos em vermelho) para a) 1200 UTC (dia anterior ao registro); b) 1800 UTC (dia anterior ao registro); c) 0000 UTC (dia do registro); d) 0600 UTC (dia do registro.$\ldots \ldots \ldots \ldots \ldots$

3.47 Vento horizontal em $10 \mathrm{~m}$ (m/s, em vetores), pressão a nível médio do mar (hPa, escala de cores) e precipitação acima de $1 \mathrm{~mm}$ (contornos em azul) para as tempestades noturnas de 30-04-2008, registradas 01:00 UTC em $14,1^{\circ} \mathrm{S}-64,8^{\circ} \mathrm{W}$ e $15,9^{\circ} \mathrm{S}-66,3^{\circ} \mathrm{W}$ (símbolos em vermelho) para a) $1200 \mathrm{UTC}$ (dia anterior ao registro); b) 1800 UTC (dia anterior ao registro); c) 0000 UTC (dia do registro); d) 0600 UTC (dia do registro). . . . . . . . . . 
3.48 Ciclo de vida da tempestade noturna de 26-11-2001, registrada pelo satélite TRMM por $5,04 \mathrm{UTC}$ em $8,14^{\circ} \mathrm{S}-75,9^{\circ} \mathrm{W}$ ilustrado pela temperatura de brilho $\left({ }^{\circ} \mathrm{C}\right)$ do conjunto GPM-MERGIR para: a) 0000 UTC; b) 0100 UTC; c) 0130 UTC; d) 0300 UTC; e) 0400 UTC; f) 0500 UTC; g) 0730 UTC; h) 1000 UTC; i) 1300 UTC. . . . . . . . . . . . . . . . . . . . 95

3.49 Magnitude do vento (m/s, escala de cores) superior a $12 \mathrm{~m} / \mathrm{s}$ em $850 \mathrm{hPa}$ e cisalhamento vertical do vento horizontal entre 700-850 hPa (contornos em vermelho) acima de $6 \mathrm{~m} / \mathrm{s}$ para a tempestade noturna de 26-11-2001, registrada $\sim$ 05:00 $\mathrm{UTC}$ em 8,14 ${ }^{\circ} \mathrm{S}-75,9^{\circ} \mathrm{W}$ (símbolo em vermelho) para a) 1200 UTC (dia anterior ao registro); b) 1800 UTC (dia anterior ao registro); c) 0000 UTC (dia do registro); d) 0600 UTC (dia do registro). . . . . . . .

3.50 Magnitude do vento (m/s, escala de cores) superior a $12 \mathrm{~m} / \mathrm{s}$ em $500 \mathrm{hPa}$ para a tempestade noturna de 26-11-2001, registrada $\sim 0500 \mathrm{UTC}$ em $8,14^{\circ} \mathrm{S}$ - 75,9 $9^{\circ} \mathrm{W}$ (símbolo em vermelho) para a) 1200 UTC (dia anterior ao registro); b) 1800 UTC (dia anterior ao registro); c) 0000 UTC (dia do registro); d) 0600 UTC (dia do registro) . . . . . . . . . . . . . . . 97

3.51 Elevação do terreno ( $\mathrm{m}$, escala de cores) na região onde atua a tempestade 26-11-2001, registrada $\sim 0500 \mathrm{UTC}$ em $8,14^{\circ} \mathrm{S}-75,9^{\circ} \mathrm{W}$, baseada no conjunto de dados de alta resolução SRTM. Símbolo preto indica local de formação, símbolo vermelho local de registro.

3.52 Ciclo de vida da tempestade noturna de 20-10-2007, registrada pelo satélite TRMM às $00254 \mathrm{UTC}$ em $10,9^{\circ} \mathrm{S}-60,04^{\circ} \mathrm{W}$ ilustrado pela temperatura de brilho $\left({ }^{\circ} \mathrm{C}\right)$ do conjunto GPM-MERGIR para: a) 2100 UTC (dia anterior); b) 0000 UTC; c) 0200 UTC; d) 0300 UTC; e) 0500 UTC; f) 0700 UTC. . .

3.53 Magnitude do vento (m/s, escala de cores) superior a $12 \mathrm{~m} / \mathrm{s}$ em $850 \mathrm{hPa}$ e cisalhamento vertical do vento horizontal entre $700-850 \mathrm{hPa}$ (contornos em vermelho) acima de $6 \mathrm{~m} / \mathrm{s}$ para a tempestade noturna de 20-10-2007, registrada $\sim 0300 \mathrm{UTC}$ em $10,9^{\circ} \mathrm{S}-60,04^{\circ} \mathrm{W}$ (símbolo em vermelho) para a) 1200 UTC (dia anterior ao registro); b) 1800 UTC (dia anterior ao registro); c) $0000 \mathrm{UTC}$ (dia do registro); d) $0600 \mathrm{UTC}$ (dia do registro). . . . . . . 100 
3.54 Elevação do terreno ( $\mathrm{m}$, escala de cores) na região onde atua a tempestade 20-10-2007, registrada $\sim 0300 \mathrm{UTC}^{\mathrm{em}} 10,9^{\circ} \mathrm{S}-60,04^{\circ} \mathrm{W}$, baseada no conjunto de dados de alta resolução SRTM.

3.55 Ciclo de vida da tempestade noturna de 25-12-2013, registrada pelo satélite TRMM às $0150 \mathrm{UTC}$ em $16,16^{\circ} \mathrm{S}-63,42^{\circ} \mathrm{W}$ ilustrado pela temperatura de brilho $\left({ }^{\circ} \mathrm{C}\right)$ do conjunto GPM-MERGIR para: a) 1930 UTC (dia anterior); b) 2130 UTC (dia anterior); c) 0130 UTC; d) 0200 UTC (próximo ao horário de registro); e) 0330 UTC; f) 0630 UTC.

3.56 Campos médios do evento de ZCAS registrado entre 11 e 26-12-2013 de: a) Tb (GPM-MERGIR); b) linhas de corrente e divergência de umidade no nível de $850 \mathrm{hPa}\left(10^{-8} \mathrm{Kg} \mathrm{s}^{-1}\right)$; c) linhas de corrente e velocidade vertical em $\left.500 \mathrm{hPa}\left(10^{-3} \mathrm{~Pa}^{-1}\right) ; \mathrm{d}\right)$ precipitação acumulada $(\mathrm{mm})$. . . . . . . . . 103

3.57 Temperatura de brilho para horário aproximado do registro da tempestade noturna de 25-12-2013 (0200 UTC), registrada pelo satélite TRMM em $16,16^{\circ} \mathrm{S}-63,42^{\circ} \mathrm{W}$, indicada pela seta vermelha. . . . . . . . . . . . 104

3.58 Vento horizontal (vetores) em $500 \mathrm{hPa}$, umidade relativa (\%, escala de cores) e temperatura (contornos em branco) para a tempestade noturna de 25-122013, registrada $\sim 0150 \mathrm{UTC}$ em $16,16^{\circ} \mathrm{S}-63,42^{\circ} \mathrm{W}$ (símbolo preto) para a) 1200 UTC (dia anterior ao registro); b) 1800 UTC (dia anterior ao registro); c) 0000 UTC (dia do registro); d) 0600 UTC (dia do registro). . . . . . . . 105

3.59 Magnitude do vento (m/s, escala de cores) superior a $12 \mathrm{~m} / \mathrm{s}$ em $850 \mathrm{hPa}$ e cisalhamento vertical do vento horizontal entre 700-850 hPa (contornos em vermelho) acima de $6 \mathrm{~m} / \mathrm{s}$ para a tempestade noturna de 25-12-2013, registrada $\sim 0150 \mathrm{UTC}$ em $16,16^{\circ} \mathrm{S}-63,42^{\circ} \mathrm{W}$ (símbolo em vermelho) para a) 1200 UTC (dia anterior ao registro); b) 1800 UTC (dia anterior ao registro); c) 0000 UTC (dia do registro); d) 0600 UTC (dia do registro). . . . . . . . 106

3.60 Histograma da hora local de início das tempestades noturnas. . . . . . . . 108

3.61 Histograma do tempo de vida das tempestades noturnas. . . . . . . . . . 108

3.62 Temperatura de brilho (GPM-MERGIR) para a) 1900 UTC, dia 09-11-2011, seta vermelha indicando início do sistema; b) 2330 UTC, dia 09-11-2011; c) 0500 UTC, dia 10-11-2011; d) 21:00 UTC, dia 10-11-2011; e) 0300 UTC, dia 11-11-2011 e f) 0930 UTC, horário de registro, dia 11-11-2011. . . . . . . . 110 
3.63 Localização das tempestades noturnas intensas com padrão P1 (símbolos em preto), com padrão P2 (símbolos em vermelho) e dos focos de raios de Albrecht et al. (2016) pertencentes ao domínio do presente estudo (símbolos em azul) . . . . . . . . . . . . . . . . .

3.64 WCD (eixo y, em metros) calculado a partir da reanálise ERA5 para às 1200 UTC e 1800 UTC do dia anterior às tempestades e 0000 UTC do dia de registro das tempestades (linha azul, laranja e cinza, respectivamente). A disposição do eixo horizontal alinha-se à ordem de severidade (decrescente), onde 1 refere-se à tempestade mais intensa e 97 a menos intensa. . . . . . . 113

3.65 Ingredientes de severidade médios para tempestades não intensas (barras em preto) e intensas (barras em cinza), às 1200 UTC e 1800 UTC do dia anterior às tempestades e 0000 UTC do dia de registro das tempestades, sendo a) WCD (eixo y, em metros); b) CAPE (J/Kg); c) CIN (J/Kg); d) Cisalhamento em baixos níveis $(\mathrm{m} / \mathrm{s}) \ldots \ldots \ldots \ldots$

3.66 Composição de $950 \mathrm{hPa}$ centrada nas tempestades intensas onde escala de cores representa umidade específica $(\mathrm{g} / \mathrm{Kg})$, contornos a temperatura $\left({ }^{\circ} \mathrm{C}\right)$ e vetores o vento horizontal utilizando reanálise ERA5. . . . . . . . . . . 116

3.67 Composição de 950 hPa centrada nas tempestades não intensas onde escala de cores representa umidade específica $(\mathrm{g} / \mathrm{Kg})$, contornos a temperatura $\left({ }^{\circ} \mathrm{C}\right)$ e vetores o vento horizontal utilizando reanálise ERA5. . . . . . . . . 116

3.68 Composição de $850 \mathrm{hPa}$ centrada nas tempestades intensas onde escala de cores representa umidade relativa $(\%)$, contornos a temperatura $\left({ }^{\circ} \mathrm{C}\right)$ e vetores o vento horizontal utilizando reanálise ERA5. . . . . . . . . . . . 118

3.69 Composição de 850 hPa centrada nas tempestades não intensas onde escala de cores representa umidade relativa $(\%)$, contornos a temperatura $\left({ }^{\circ} \mathrm{C}\right) \mathrm{e}$ vetores o vento horizontal utilizando reanálise ERA5. . . . . . . . . . . . 118

3.70 Composição de $700 \mathrm{hPa}$ centrada nas tempestades intensas onde escala de cores representa umidade relativa $(\%)$, contornos a temperatura $\left({ }^{\circ} \mathrm{C}\right)$ e vetores o vento horizontal utilizando reanálise ERA5. . . . . . . . . . . . . . 119

3.71 Composição de 700 hPa centrada nas tempestades não intensas onde escala de cores representa umidade relativa $(\%)$, contornos a temperatura $\left({ }^{\circ} \mathrm{C}\right) \mathrm{e}$ vetores o vento horizontal utilizando reanálise ERA5. . . . . . . . . . . . . 119 
3.72 Composição de $500 \mathrm{hPa}$ centrada nas tempestades intensas onde escala de cores representa umidade relativa $(\%)$, contornos a temperatura $\left({ }^{\circ} \mathrm{C}\right)$ e vetores o vento horizontal utilizando reanálise ERA5. . . . . . . . . . . 120

3.73 Composição de $500 \mathrm{hPa}$ centrada nas tempestades não intensas onde escala de cores representa umidade relativa $(\%)$, contornos a temperatura $\left({ }^{\circ} \mathrm{C}\right)$ e vetores o vento horizontal utilizando reanálise ERA5. . . . . . . . . . . . . 120

3.74 Composição de CAPE e CIN $(\mathrm{J} / \mathrm{Kg})$ centrada nas tempestades intensas onde escala de cores representa CAPE e os contornos representam CIN, utilizando reanálise ERA5. . . . . . . . . . . . . . . . . . . . . . . . 122

3.75 Composição do cisalhamento em baixos (escala de cores, m/s) e médios níveis (contornos, m/s) para tempestades intensas, utilizando reanálise ERA5.122

3.76 Composição de CAPE e CIN (J/Kg) centrada nas tempestades não intensas onde escala de cores representa CAPE e os contornos representam CIN, utilizando reanálise ERA5. . . . . . . . . . . . . . . . . . . . 123

3.77 Composição do cisalhamento em baixos (escala de cores, m/s) e médios níveis (contornos, $\mathrm{m} / \mathrm{s}$ ) para tempestades não intensas, utilizando reanálise

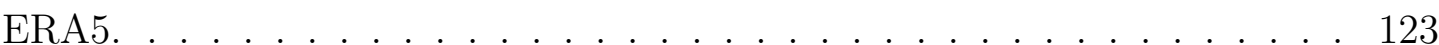

3.78 Domínios utilizados na simulação indicados pelos retângulos vermelhos. O ponto vermelho indica a localização da tempestade do dia 26/11/2001 simulada. . . . . . . . . . . . . . . . . . . . . 125

3.79 Comparação entre campos de reanalise em 850 hPa e a grade 2 da simulação numérica para a tempestade 26/11/2001 onde a escala de cores representa a umidade relativa (\%), vetores representam o vento horizontal $(\mathrm{m} / \mathrm{s})$ e contornos a temperatura $\left({ }^{\circ} \mathrm{C}\right)$ para a) 0010 UTC, grade 2 da simulação; ) 0000 UTC da reanálise ERA5; c) 0600 UTC, grade 2 da simulação; d) 0600 UTC da reanálise ERA5. . . . . . . . . . . . . . . . . . . . . . 127 
3.80 Resultado do campo de precipitação (totpcp, mm) e topografia (m) para a grade aninhada da simulação da tempestade noturna do dia 26/11/2001 onde a escala de cinza representa a elevação do terreno, os contornos a precipitação, os vetores mostram vento horizontal em 535 m de altura, símbolo em vermelho indica o centro da tempestade e a caixa preta a região onde a análise será realizada para a) 0530 UTC, início da precipitação; b) 0000 UTC, 27/11/2001, final da simulação. . . . . . . . . . . . . . . . . . 127

3.81 Corte vertical em $9,2^{\circ} \mathrm{S}$, entre $77,5^{\circ}-75^{\circ} \mathrm{W}$ para a grade 2 da simulação da tempestade registrada em 26/11/2001, onde a topografia é representada pela região preenchida por preto $(\mathrm{m})$, os vetores representam o vento vertical (componentes u e w, sendo que w está multiplicado por 10) e da razão de mistura do vapor é mostrada pelos contornos em a) 0000 UTC, b) 0010 UTC, c) 0220 UTC, d) 0320 UTC, e) 0500 UTC, f) 0620 UTC, g) 0810 UTC, h) 1000 UTC.

3.82 Corte vertical em $9,2^{\circ} \mathrm{S}$ entre $80^{\circ} \mathrm{W}-74^{\mathrm{O}} \mathrm{W}$, às 0500 UTC do dia $26 / 11 / 2001$, mostrando vento vertical $\left(\mathrm{u} ; \mathrm{w}^{*} 10\right)$, topografia $(\mathrm{m})$ e razão de mistura $(\mathrm{g} / \mathrm{Kg})$ de a) água de nuvem, b) condensado total, c) chuva, d) pristine, e) neve, f) graupel, g) agregados, h) granizo. . . . . . . . . . . . .

A.1 Normais climatológicas (1981-2010) para o nível de $950 \mathrm{hPa}$, onde vetores representam vento horizontal $(\mathrm{m} / \mathrm{s})$, escala de cores representa umidade específica $(\mathrm{g} / \mathrm{Kg})$ e contornos a temperatura $\left({ }^{\circ} \mathrm{C}\right)$ às a) 12:00 UTC, b) 18:00 UTC, c) 00:00 UTC, d) 06:00 UTC. . . . . . . . . . . . . . . . 162

A.2 Normais climatológicas (1981-2010) para o nível de $850 \mathrm{hPa}$, onde vetores representam vento horizontal $(\mathrm{m} / \mathrm{s})$, escala de cores representa umidade relativa $(\%)$ e contornos a temperatura $\left({ }^{\circ} \mathrm{C}\right)$ às a) 12:00 UTC, b) 18:00 UTC, c) 00:00 UTC, d) 06:00 UTC. . . . . . . . . . . . . . . . . . . . . . . . . . . .

A.3 Normais climatológicas (1981-2010) para o nível de 700 hPa, onde vetores representam vento horizontal $(\mathrm{m} / \mathrm{s})$, escala de cores representa umidade relativa $(\%)$ e contornos a temperatura $\left({ }^{\circ} \mathrm{C}\right)$ às a) 12:00 UTC, b) 18:00 UTC, c) 00:00 UTC, d) 06:00 UTC. . . . . . . . . . . . . . . . . . 163 
A.4 Normais climatológicas (1981-2010) para o nível de $500 \mathrm{hPa}$, onde vetores representam vento horizontal $(\mathrm{m} / \mathrm{s})$, escala de cores representa umidade relativa $(\%)$ e contornos a temperatura $\left({ }^{\circ} \mathrm{C}\right)$ às a) 12:00 UTC, b) 18:00 UTC, c) 00:00 UTC, d) 06:00 UTC. . . . . . . . . . . . . . . . . . . . . 163

A.5 Recorte da região SO da Amazônia mostrando anomalia do escoamento P1 para o nível de $950 \mathrm{hPa}$, onde vetores representam vento horizontal $(\mathrm{m} / \mathrm{s})$, escala de cores representa umidade específica $(\mathrm{g} / \mathrm{Kg})$ e contornos a temperatura $\left({ }^{\circ} \mathrm{C}\right.$ ) às a) 12:00 UTC, b) 18:00 UTC, c) 00:00 UTC, d) 06:00 UTC . . . . . . . . . . . . . . . . . . . . . 164

A.6 Recorte da região SO da Amazônia mostrando anomalia do escoamento P1 para o nível de $850 \mathrm{hPa}$, onde vetores representam vento horizontal (m/s), escala de cores representa umidade relativa (\%) e contornos a temperatura $\left({ }^{\circ} \mathrm{C}\right)$ às a) 12:00 UTC, b) 18:00 UTC, c) 00:00 UTC, d) 06:00 UTC. . . . . 164

A.7 Recorte da região SO da Amazônia mostrando anomalia do escoamento P1) para o nível de $700 \mathrm{hPa}$, onde vetores representam vento horizontal (m/s), escala de cores representa umidade relativa (\%) e contornos a temperatura $\left({ }^{\circ} \mathrm{C}\right)$ às a) 12:00 UTC, b) 18:00 UTC, c) 00:00 UTC, d) 06:00 UTC. . . . .

A.8 Recorte da região SO da Amazônia mostrando anomalia do escoamento P1 para o nível de $500 \mathrm{hPa}$, onde vetores representam vento horizontal $(\mathrm{m} / \mathrm{s})$, escala de cores representa umidade relativa (\%) e contornos a temperatura $\left({ }^{\circ} \mathrm{C}\right)$ às a) 12:00 UTC, b) 18:00 UTC, c) 00:00 UTC, d) 06:00 UTC. . . . . 165

A.9 Recorte da região SO da Amazônia mostrando anomalia do escoamento P2 para o nível de $950 \mathrm{hPa}$, onde vetores representam vento horizontal $(\mathrm{m} / \mathrm{s})$, escala de cores representa umidade específica $(\mathrm{g} / \mathrm{Kg})$ e contornos a temperatura $\left({ }^{\circ} \mathrm{C}\right.$ ) às a) 12:00 UTC, b) 18:00 UTC, c) 00:00 UTC, d) 06:00 UTC . . . . . . . . . . . . . . . . . . 166

A.10 Recorte da região SO da Amazônia mostrando anomalia do escoamento P2 para o nível de $850 \mathrm{hPa}$, onde vetores representam vento horizontal (m/s), escala de cores representa umidade relativa (\%) e contornos a temperatura $\left({ }^{\circ} \mathrm{C}\right)$ às a) 12:00 UTC, b) 18:00 UTC, c) 00:00 UTC, d) 06:00 UTC. . . . . 166 
A.11 Recorte da região SO da Amazônia mostrando anomalia do escoamento P2 para o nível de $700 \mathrm{hPa}$, onde vetores representam vento horizontal (m/s), escala de cores representa umidade relativa (\%) e contornos a temperatura $\left({ }^{\circ} \mathrm{C}\right)$ às a) 12:00 UTC, b) 18:00 UTC, c) 00:00 UTC, d) 06:00 UTC. . . . . 167

A.12 Recorte da região SO da Amazônia mostrando anomalia do escoamento P2 para o nível de $500 \mathrm{hPa}$, onde vetores representam vento horizontal $(\mathrm{m} / \mathrm{s})$, escala de cores representa umidade relativa (\%) e contornos a temperatura $\left({ }^{\circ} \mathrm{C}\right)$ às a) 12:00 UTC, b) 18:00 UTC, c) 00:00 UTC, d) 06:00 UTC. . . . . 167 


\section{Lista de Tabelas}

3.1 Percentis das taxas de raios (raios/min) para as tempestades noturnas no SW Amazônia registradas entre 1998-2013, respectiva classificação e total de tempestades em cada categoria. . . . . . . . . . . . 52

3.2 Classificação das 23 tempestades noturnas extremas através da taxa de raios, em ordem decrescente. Caso: ordem de classificação de severidade; Data: data de registro; TaxaR: taxa de raios (raios/min); Hora: horário de registro do sistema pelo satélite TRMM (UTC); Lat: latitude do sistema no horário de registro; Lon: longitude do sistema no horário de registro; $A_{T}$ : área total do sistema (número de pixels com $\mathrm{PCT} 85 \mathrm{GHz}<250 \mathrm{~K}^{*}$ área do pixel), em $\mathrm{Km}^{2} ; A_{N}$ : área do núcleo do sistema (número de pixels com PCT $85 \mathrm{GHz}<100 \mathrm{~K}^{*}$ área do pixel), em $\mathrm{Km}^{2} ; T_{85}$ : mínima temperatura de brilho do sistema no canal de $85 \mathrm{GHz}$ (MINPCT85GHZ), em K; $T_{37}$ : mínima temperatura de brilho do sistema no canal de 37 GHz (MINPCT37GHZ), em $\mathrm{K} ; P_{M}$ : máxima taxa de precipitação na superfície (MAXNSRAIN, mm/h); $H_{40}$ : máxima altura do nível de 40 dBZ (MAXHT40, Km) . . . . . . . . . 
3.3 Valores mínimos e máximos extraídos do conjunto das 97 tempestades. Caso: ordem de classificação de severidade; Data: data de registro; TaxaR: taxa de raios (raios/min); Hora: horário de registro do sistema pelo satélite TRMM (UTC); Lat: latitude do sistema no horário de registro; Lon: longitude do sistema no horário de registro; $A_{T}$ : área total do sistema, em $\mathrm{Km}^{2}$; $A_{N}$ : área do núcleo do sistema, em $\mathrm{Km}^{2} ; T_{85}$ : mínima temperatura de brilho do sistema no canal de $85 \mathrm{GHz}$ (MINPCT85GHZ), em K; $T_{37}$ : mínima temperatura de brilho do sistema no canal de $37 \mathrm{GHz}$ (MINPCT37GHZ), em $\mathrm{K} ; P_{M}$ : máxima taxa de precipitação na superfície (MAXNSRAIN, mm/h); $H_{40}$ : máxima altura do nível de $40 \mathrm{dBZ}($ MAXHT40, Km) . . . . . . . . .

3.4 Resumo das categorias de intensidade de tempestades comparáveis, baseadas em parâmetros do TRMM, citadas no texto onde $\operatorname{Taxa}_{R}$ representa a taxa de raios (raios/min), $T_{85}$ a MINPCT85GHz $(\mathrm{K}), T_{77}$ a MINPCT37GHz (K) e $H_{40}$ a MAXHT40.

3.5 Configurações principais da simulação da tempestade noturna ocorrida em 26/11/2001, localizada em $8,14^{\mathrm{o}} \mathrm{S}-75,9^{\mathrm{o}} \mathrm{W}$.

A.1 Classificação das 97 tempestades através da taxa de raios, em ordem decrescente. Coluna 1: ordem de classificação de severidade; Coluna 2: data de ocorrência; Coluna 3: taxa de raios (flashes/min); Coluna 4: horário de registro do sistema pelo satélite TRMM (UTC); Coluna 5: latitude do sistema no horário de registro; Coluna 6: longitude do sistema no horário de registro; Coluna 7: área total do sistema (número de pixels com PCT85GHzi250 $\mathrm{K}^{*}$ área do pixel), em $\mathrm{Km}^{2}$; Coluna 8: área do núcleo do sistema (número de pixels com PCT85GHz;100 K*área do pixel), em $\mathrm{Km}^{2}$; Coluna 9: mínima temperatura de brilho do sistema no canal de $85 \mathrm{GHz}$, em K; Coluna 10: mínima temperatura de brilho do sitema no canal de $37 \mathrm{GHz}$, em K; Coluna 11: máxima taxa de precipitação na superfície (mm/h); Coluna 12: máxima

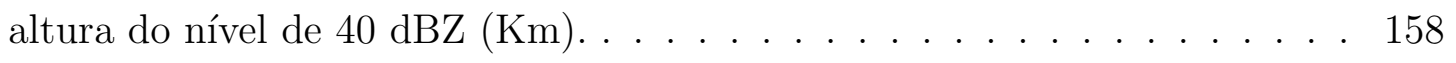

A.2 Continuação Tabela A.1 . . . . . . . . . . . . . . . . . 159

A.3 Continuação Tabela A.1 . . . . . . . . . . . . . . . . . . . . 160

A.4 Continuação Tabela A.1 . . . . . . . . . . . . . . . . . . . . . . . . . . 161 


\section{Sumário}

1. Introdução . . . . . . . . . . . . . . . . . . . . . 31

1.1 Tempestades na Amazônia . . . . . . . . . . . . . . . . . 31

1.2 Caracterização do problema . . . . . . . . . . . . . . . . 34

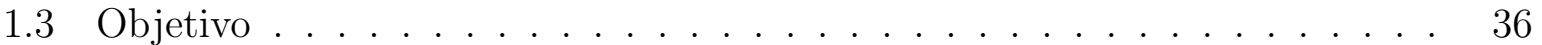

2. Dados e Métodos . . . . . . . . . . . . . . . . . . . . 37

2.1 Conjunto de dados Precipitation Features (PF) . . . . . . . . . . . . . 37

2.2 ERA5, GPM MERGIR, SRTM . . . . . . . . . . . . . . . 41

2.3 Modelo regional BRAMS . . . . . . . . . . . . . . . . . . . . 444

3. Resultados e discussão . . . . . . . . . . . . . . . . . . 45

3.1 Análise observacional . . . . . . . . . . . . . . . . . . . 45

3.1.1 Principais características das tempestades noturnas . . . . . . . 45

3.1 .2 Classificação de severidade . . . . . . . . . . . . . . . 50

3.1.3 Padrões sinóticos: jato de baixos níveis versus confluência . . . . . 61

3.1.4 Anomalias nos padrões de escoamento . . . . . . . . . . . . . 77

3.1.5 Sistemas sinóticos associados às tempestades noturnas . . . . . . 83

3.1 .6 Ciclo de vida . . . . . . . . . . . . . . . . . . . . . 106

3.1.7 Ingredientes de severidade: tempestades intensas e não intensas . . 109

3.2 Simulações numéricas . . . . . . . . . . . . . . . . . . . . . . 124

3.2.1 Cordilheira dos Andes e circulações locais . . . . . . . . . . . . . 124

4. Conclusões . . . . . . . . . . . . . . . . . . . . . . 133 
A. Apêndice A . . . . . . . . . . . . . . . . . . . . 157

A.1 Classificação de severidade das tempestades noturnas . . . . . . . . . 157

A.2 Normais climatológicas e anomalias . . . . . . . . . . . . . 161 
Capítulo 1

\section{Introdução}

\subsection{Tempestades na Amazônia}

Com cerca de $6.000 .000 \mathrm{~km}^{2}$ e localizada na região equatorial entre $5^{\circ} \mathrm{N}-18^{\circ} \mathrm{S}$ e $42^{\circ} \mathrm{W}$ $74^{\circ} \mathrm{W}$, a Amazônia é considerada a maior floresta tropical do mundo, estendendo-se por sete países: Brasil, Peru, Bolívia, Colômbia, Equador, Venezuela e Guiana. Devido a sua extensão territorial, abundância de umidade e intensa atividade convectiva ao longo da bacia, a Amazônia se destaca no cenário atmosférico global. Dentre os sistemas precipitantes que atuam na Amazônia podem ser citados as linhas de instabilidade (LI), a zona de convergência intertropical (ZCIT), a zona de convergência do Atlântico Sul (ZCAS) e os sistemas convectivos de mesoescala (SCM) - (Reboita et al., 2010). Estes sistemas distribuem-se de forma a organizar a marcha anual da estação chuvosa de sul durante o verão austral, entre dezembro a março, para o norte da bacia no inverno austral, entre junho a agosto - (Ratisbona, 1976; Salati et al., 1978; Kousky et al., 1984; Horel et al., 1989; Figueroa and Nobre, 1990; Nobre et al., 1991, entre outros).

A região da Amazônia andina, em particular, vem ganhando mais atenção de estudos relativamente recentes no âmbito das ciências atmosféricas como, por exemplo, Espinoza et al. (2009), Rasmussen and Houze (2011), Trachte et al. (2010), Halladay et al. (2012), Chavez and Takahashi (2017), Bendix et al. (2017) e Junquas et al. (2018). Em sua pesquisa Espinoza et al. (2009) analisaram os registros de 1446 pluviômetros distribuídos ao longo dos sete países que a floresta amazônica abrange e detalharam a grande variabilidade espacial pluviométrica da região andina, onde foram encontrados os valores de precipitação mais altos e também os mais baixos, evidenciando o importante papel do relevo na distribuição da chuva. Em termos de valores anuais estações próximas nesta região podem ter 
variação espacial de $58 \mathrm{~mm} / \mathrm{km}$ (Equador) a $73 \mathrm{~mm} / \mathrm{km}$ (Bolívia).

Ao longo das últimas décadas as regiões com terreno complexo vêm sendo relacionadas com grande ocorrência de atividade elétrica, granizo e convecção severa em geral (Frisby and Sansom, 1967; Rasmussen and Houze, 2011; Cecil and Blankenship, 2012; Romatschke and Houze, 2010, 2011a, 2011b; Albrecht et al., 2016, entre outros). A relação entre tempestades intensas e o relevo está ligada ao conceito de "chuva orográfica", que se refere à intensificação ou o disparo de sistemas precipitantes que se aproximam ou cruzam barreiras montanhosas (Houze, 2012), como resultado da combinação da microfísica envolvida no crescimento das partículas da nuvem, do comportamento dinâmico do fluxo que se aproxima do terreno e da termodinâmica do ar úmido.

Ainda segundo a revisão bibliográfica que Houze (2012) traz sobre o tema, existem pelo menos doze mecanismos reconhecíveis através dos quais o relevo afeta nuvens precipitantes. Dentre eles destacam-se: 1) a forçante diurna, no qual o aquecimento das encostas e do terreno elevado induzem uma circulação local no sentido montanha acima durante o dia com convergência no topo da montanha; e um fluxo no sentido montanha abaixo durante o resfriamento noturno do terreno, que, quando converge com um fluxo de ar instável na base da montanha pode resultar em convecção noturna no vale; 2) fluxo de ar se aproximando de uma elevação que, dependendo da sua estabilidade e da altura do terreno, pode desencadear convecção a barlavento e/ou sotavento, geralmente associado com a intensificação de um sistema pré-existente como frentes frias ou SCM.

Observações remotas feitas por satélites têm sido muito úteis para estudos de tempestades, uma vez que é praticamente impossível ter registro observacional de todas as tempestades que ocorrem ao redor do globo. A missão do satélite TRMM (Tropical Rainfall Measuring Mission), em particular, foi de grande sucesso ao buscar estimar distribuição de precipitação e fluxo de calor latente nos trópicos e subtrópicos. Lançado em 1997 e com planejamento inicial de três anos de duração (Simpson et al., 1988), teve seu tempo de vida prolongado até ser completamente desativado em 2015 (National Aeronautics and Space Administration, 2014; National Aeronautics and Space Administration, 2015). Seus diversos instrumentos, tais como radar de precipitação, radiômetro de microonda, radiômetro no visível e infravermelho e sensor de imageamento de relâmpagos (Kummerow et al., 1998) forneceram informações valiosas. A base de dados Precipitation Features (PF) organiza os dados do satélite TRMM através da definição de regiões contíguas de precipitação, como 
descrito em Nestbitt et al (2000). Zipser et al. (2006) utilizaram estas informações para identificar as tempestades mais intensas do globo através de parâmetros de intensidade, revelando que a maior frequência relativa de convecção severa ocorre, de fato, próximo a elevações montanhosas como no sudeste da América do Sul (Serras de Córdoba/Argentina e sul da Cordilheira dos Andes), no centro dos Estados Unidos (Montanhas Rochosas), na África equatorial (Cordilheira Mitumba) e na Cordilheira do Himalaia (subcontinente indiano). Este trabalho mostra que também há ocorrência de eventos considerados extremos ao longo de toda a região amazônica, embora esta não seja uma região preferencial do globo.

Albrecht et al. (2016) utilizando dados orbitais em alta resolução do sensor LIS (Lightning Imaging Sensor) a bordo do TRMM identificaram os lugares com maior ocorrência de raios ao redor do globo, um dos critérios associados com severidade de tempestades. Dos trinta primeiros focos apenas seis não ocorrem sobre regiões montanhosas, sendo que o lugar mais intenso de cada continente é próximo ou relacionado a terrenos complexos, com exceção da Oceania. Além disso, o estudo mostra a hora local de maior ocorrência de raios e, para a região da Amazônia andina observa-se que eles ocorrem mais à noite, entre 0 e 6 horas local, o que corrobora com resultados obtidos por Nunes et al. (2016).

Nunes et al. (2016) elaboraram uma climatologia de tempo severo na floresta amazônica para o período entre 1998-2012, também utilizando a base de dados PF, citada anteriormente. Os casos considerados severos no estudo possuem $2000 \mathrm{~km}^{2}$ ou mais com temperatura polarizada corrigida (do inglês polarization-corrected temperature, a partir daqui referida como PCT) na frequência de $85 \mathrm{GHz}(\mathrm{PCT} 85 \mathrm{GHz})$ menor que $250 \mathrm{~K}$, um núcleo mais frio de pelo menos $25 \mathrm{Km}^{2}$ com PCT85GHz $<100 \mathrm{~K}$, volume de chuva convectiva maior do que $1000 \mathrm{~mm} / \mathrm{h} \mathrm{Km}^{2}$ e pelo menos um registro de raio. A PCT é definida como uma combinação linear das polarizações horizontal e vertical da temperatura de brilho ( $\mathrm{Tb}$ ) para reduzir os efeitos das emissividades das superfícies de fundo - terra, água para que áreas de chuva sejam mais facilmente delineadas (Spencer, 1986). Através desse critério Nunes et al. (2016) identificaram um total de 1560 casos, sendo que a primavera se destaca como sendo a estação com maior número de casos severos (581), e o inverno o segundo maior número (350). A estação com menor ocorrência é o verão (281 casos), seguida pelo outono (348 casos). A maioria dos sistemas severos tem área total de até $10000 \mathrm{Km}^{2}$, área do núcleo mais frio de até $200 \mathrm{Km}^{2}$ e taxa de raio de 30 raios/min, para 
todos os meses. As taxas de raios aumentam nos meses em que a ocorrência é maior. O estudo, ainda, separou a Amazônia em seis sub-regiões baseado em Steege et al. (2013): parte sul da Amazônia ocidental, parte norte da Amazônia ocidental, escudo das Guianas, Amazônia central, Amazônia oriental e sul da Amazônia, do inglês: Southern part of Western Amazonia - WAS, Northern part of Western Amazonia - WAN, Guyana Shield GS, Central Amazonia - CA, Eastern Amazonia - EA, Southern Amazonia - SA, respectivamente. Esta sub-divisão pode ser vista na Figura 2.1 do próximo capítulo, na seção 2.1 dos Dados e Métodos. O horário local de ocorrência dos casos severos foi analisado, e a partir daí a região WAS chamou atenção pelo grande número de casos ocorridos no período noturno (considerado até então entre 0 e 5 horas local), que não são totalmente explicados por passagens de LI como sugere o estudo de convecção noturna de Rickenbach (2004).

\subsection{Caracterização do problema}

A convecção noturna e matinal no centro e sudoeste da Amazônia é relatada em diversos estudos (Machado et al., 2004; Rickenbach, 2004; Tang et al., 2016) e costuma ser associada com propagação de LI. Rickenbach (2004), por exemplo, examinou a região de Rondônia e sua conclusão geral é de que a convecção profunda gerada à tarde contribui para um máximo de nebulosidade e precipitação pós meia noite, e que a maior parte destes sistemas são causados pelas grandes LI que se propagam da costa nordeste do Brasil para oeste.

Cohen, Silva Dias e Nobre (1989) e Cohen (1989), que analisaram a passagem de LI durante o período de 1979-1986, constataram que as LI podem ser observadas durante todo o ano, mas com maior frequência entre os meses de abril e agosto. Já Santos Neto (2004) analisou o período de 1979-2002 e concluiu que: 1) a maior ocorrência de LI é entre maio e agosto e a menor em janeiro (maior frequência das LI ocorre no período em que a ZCIT está bem organizada perto da costa da América do Sul); 2) as LIC (linhas de instabilidade costeiras, que se propagam continente adentro, até no máximo 170 km) são mais frequentes em outubro, novembro e dezembro e 3) as LIP (linha de instabilidade que se propaga além de $170 \mathrm{~km}$ ) são mais frequentes entre os meses de maio e agosto e menos frequentes em dezembro. De acordo com estes autores, novembro somente é preferencial para as LIC, porém elas estão confinadas à região costeira e não correspondem à área 
atuação dos eventos de tempestades noturnas da Amazônia andina.

Angelis, MCGregor e Kidd (2004a) hipotetizam que, na verdade, uma LI se desenvolva da convergência de vento catabático frio que desce os Andes à noite com o ar quente e úmido presente no sopé da cordilheira e avance para o interior da bacia, dada a identificação de uma banda de precipitação nos campos do radar do TRMM movendo-se neste sentido. Angelis, MCGregor e Kidd (2004b) também encontram indícios de que a convecção originada na costa nordeste da Amazônia não consiga alcançar a cordilheira dos Andes. Mais recentemente, Anselmo et al. (2021) estudando características do ciclo de vida e propagação de sistemas convectivos durante o experimento de campo GoAmazon (Observations and Modeling of Green Ocean Amazon, Martin et al. 2016) mostram que, de fato, é relativamente raro que um sistema convectivo tenha início na costa nordeste e consiga se propagar $1500 \mathrm{~km}$ para o interior da bacia alcançando o centro ou sudeste da região amazônica, ao invés disso, maioria dos sistemas observados na região central tem início local.

Além disso, Anselmo et al. (2020) discutem o papel de um jato de baixos níveis noturno da Amazônia na reativação da convecção de mesoescala a centenas de quilômetros onde os sistemas que vêm da costa nordeste se dissipam, que pode se dar através de advecção de umidade em níveis médios ou por associação com ondas de gravidade internas. Levando em consideração os trabalhos supracitados, acredita-se que os casos noturnos encontrados por Nunes et al. (2016), que têm pico de ocorrência entre outubro e dezembro, não correspondem inteiramente à passagem das grandes LI que alcançam esta região, dado que o pico de ocorrência é diferente. Somando isto às hipóteses de Angelis, MCGregor e Kidd (2004a, 2004b) e aos recentes resultados de Anselmo et al. (2021) há necessidade de investigação das tempestades noturnas no sudoeste da Amazônia. 


\subsection{Objetivo}

Até o presente momento, a revisão bibliográfica levantada não encontrou um estudo específico a respeito de tempestades na Amazônia andina, embora a região venha sendo mais estudada como citado anteriormente. O objetivo do presente documento consiste em ampliar o estudo das tempestades noturnas identificadas por Nunes et al. (2016) ocorridas na região sudoeste da Amazônia, que inclui a Amazônia andina, especialmente sob o ponto de vista observacional e, em segundo plano, da modelagem numérica.

As principais perguntas a serem respondidas aqui são:

1. Sob qual configuração sinótica essas tempestades noturnas ocorrem?

2. Estão embebidas em sistemas maiores ou acontecem de forma isolada?

3. Quais são as características comuns entre elas?

4. Quais seriam os ingredientes importantes para sua intensidade e previsibilidade?

5. Qual o papel dos Andes na formação dessas tempestades severas?

O documento está organizado da seguinte forma: a seção 2 apresenta os dados e a metodologia de análise, a seção 3 os resultados divididos em análise observacional e identificação do papel dos Andes através de simulações numéricas, e 4 as conclusões. 
Capítulo 2

\section{Dados e Métodos}

\subsection{Conjunto de dados Precipitation Features (PF)}

O banco de dados Precipitation Features (daqui para frente abreviado como PF) é baseado nos dados do satélite TRMM, organizado e armazenado pela Universidade de Utah. Sua estrutura é detalhada em Liu et al. (2008), sendo que o conceito de "características de precipitação" envolve regiões contíguas de precipitação, como descrito por Nesbitt et al. (2000). Nunes et al. (2016) sintetizam a organização desta base de dados que possui basicamente três níveis de dados, onde o Nível 1 refere-se ao arranjo das observações dos diversos instrumentos do satélite dentro da grade do radar de precipitação, o Nível 2 agrupa as PF de acordo com diferentes definições (sendo possível também obter uma série de informações a respeito de cada sistema como, por exemplo, hora de registro, localização, tamanho, volume de precipitação, altura do nível de 40 dBZ, número de raios, dentre inúmeras outras) e o Nível 3 apresenta as características das nuvens individuais e sistemas precipitantes do Nível 2 em uma grade com resolução espacial de $1^{\circ} \mathrm{x} 1^{\circ}$, incorporando estimativas de precipitação de outras fontes. Liu et al. (2008) sugerem que o Nível 2 desta base de dados seja uma ferramenta de busca por sistemas com determinadas características e/ou eventos históricos, e Nunes et al. (2016) utilizam parte deste conjunto para elaborar uma climatologia de tempo severo para a Amazônia.

A primeira etapa do presente estudo refere-se a uma nova filtragem das tempestades noturnas neste banco de dados, mantendo a metodologia e os critérios de seleção de Nunes et al. (2016). Uma vez que os autores chamam atenção para a ocorrência de sistemas noturnos na sub-região WAS aqui amplia-se este domínio para $78^{\circ} \mathrm{W}-60^{\circ} \mathrm{W}$ e $18^{\circ} \mathrm{S}-8^{\circ} \mathrm{S}$, que passa a ser considerado como região sudoeste da Amazônia no presente estudo e referido 
como SW Amazônia. As Figuras 2.1 e 2.2 mostram, respectivamente, a subdivisão da Amazônia nas seis sub-regiões citadas anteriormente e o novo domínio de estudo, ampliado a sub-região WAS. Além disso, o período de filtragem estende-se para 1998-2013 e o horário de seleção de casos para 0000 UTC - 1000 UTC. Embora o satélite tenha sido desativado por completo somente em 2015, seu descomissionamento teve início em 2014 sua órbita entrou em processo de descida tendo alguns de seus sensores desligados (National Aeronautics and Space Administration, 2014; National Aeronautics and Space Administration, 2015), introduzindo incertezas, justificando a limitação do período do presente estudo até 2013 .

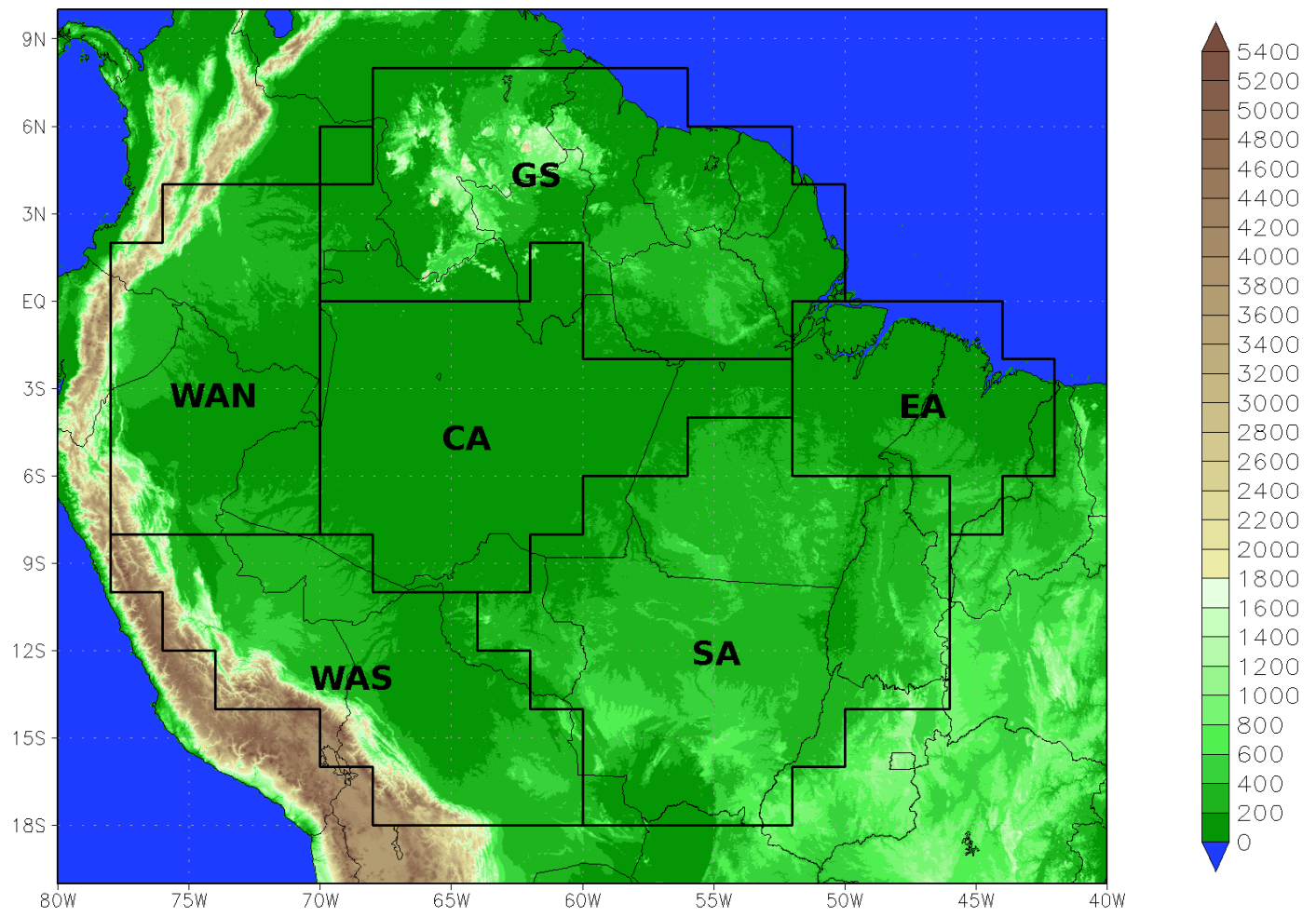

Figura 2.1: Sub-regiões da área de estudo: AS, parte sul da Amazônia ocidental; WAN, parte norte da Amazônia ocidental; GS, Guiana Shield; CA, Amazônia central; EA, leste da Amazônia; SA: sul da Amazônia (adaptado de ter Steege et al., 2013). Contornos em cinza indicam limites políticos dos estados brasileiros e países vizinhos.

Os critérios de seleção são originalmente baseados na metodologia de Mohr e Zipser (1996), que utilizam o limiar de $250 \mathrm{~K}$ da PCT85GHz do sensor de microonda Special Sensor Microwave/Imager, precursor ao radiômetro de microonda do TRMM, para obter 


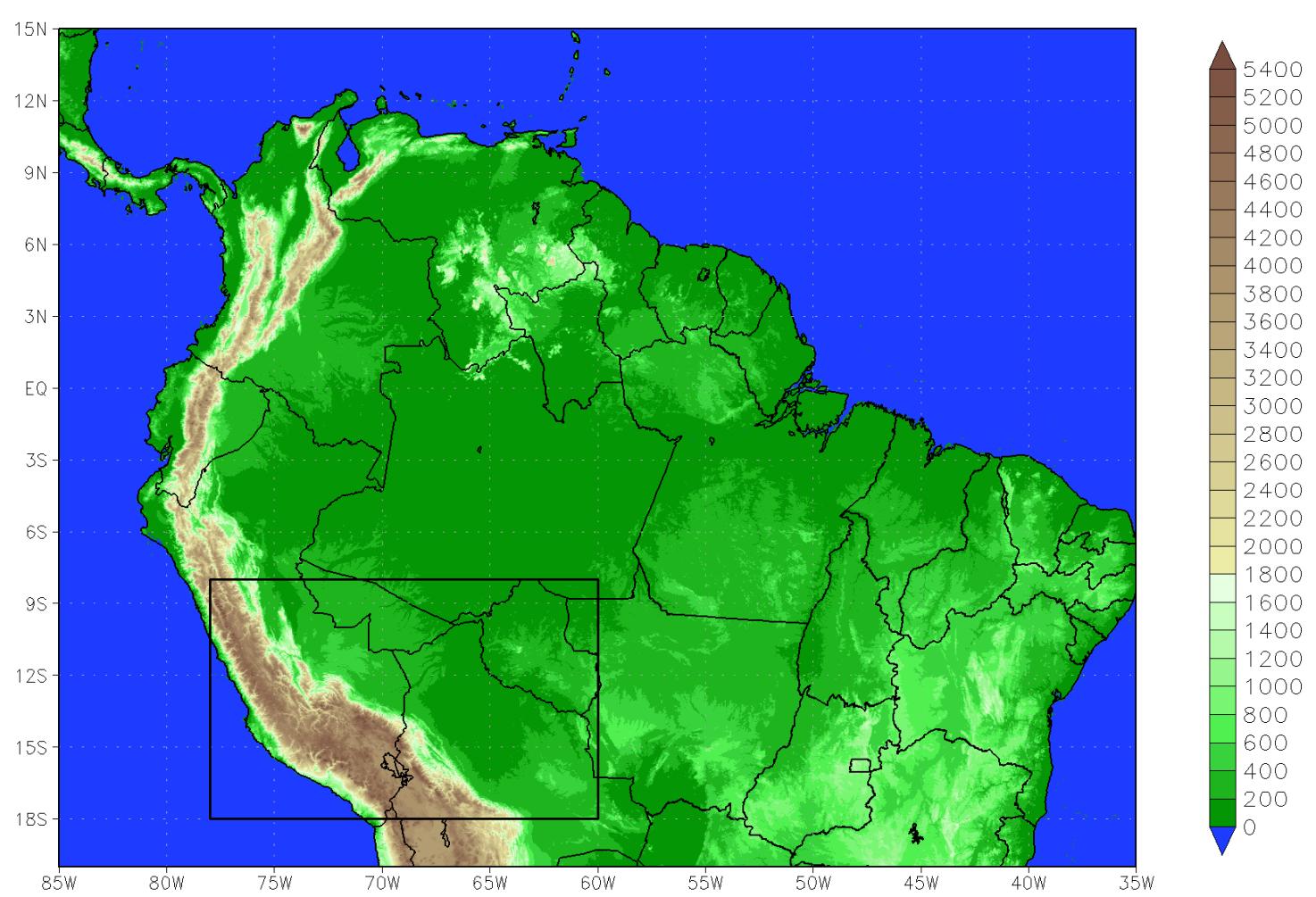

Figura 2.2: Domínio de estudo ampliado identificado pelo retângulo preto onde a escala de cores representa a elevação do terreno em metros.

uma amostra de SCM com espalhamento de gelo. A PCT, do inglês Polarization Corrected Temperature, é combinação linear das polarizações horizontal e vertical da temperatura de brilho que, segundo Spencer et al. (1989), serve para amenizar os efeitos das diferentes emissividades das superfícies de fundo que podem ser confundidas com áreas de chuva. O sensor TMI (TRMM Microwave Imager) a bordo do satélite TRMM é um sensor de microonda passivo, ou seja, mede a quantidade de energia emitida pela terra, superfícies de água, nuvens, etc, sendo capaz de quantificar vapor d’água, água de nuvem e intensidade de precipitação (Kummerow et al., 1998, 2000). Ele opera em cinco frequências (10.7, 19.4, 21.3, 37 e $85.5 \mathrm{GHz}$ ), sendo que as micro-ondas de alta frequência (85.5 GHz e 37 $\mathrm{GHz}$ ) são fortemente espalhadas pelo gelo presente no topo de muitas nuvens com chuva, como indicam os estudos de sensibilidade de modelo de Smith et al. (1992) e Mugnai et al. (1993) por exemplo, impactando e "resfriando" a temperatura de brilho emitida.

Então, como em Nunes et al. (2016), a seleção das tempestades noturnas no SW 
Amazônia é feita pela filtragem de sistemas no subconjunto PCTF (Polarization Corrected Temperature Features) do Nível 2 do banco de dados PF, buscando sistemas que possuam $2000 \mathrm{~km}^{2}$ ou mais com PCT85GHz $\leq 250 \mathrm{~K}$, um núcleo mais frio de pelo menos $25 \mathrm{~km}^{2}$ com PCT85GHz $\leq 100 \mathrm{~K}$, volume de chuva convectiva maior do que $1000 \mathrm{~mm} / \mathrm{h} \mathrm{km}^{2}$ e pelo menos um registro de raio. A nova filtragem resulta em um conjunto de 97 tempestades, sendo que as mais extremas são apresentadas na Seção 3.1 e o conjunto completo no Apêndice A.

Segundo Fisher (2004) erros de amostragem são intrísecos ao processo de medição do satélite TRMM uma vez que dependem das características orbitais do satélite. O TRMM tem uma órbita baixa, inicialmente cerca de $350 \mathrm{~km}$ de altura (Kummerow et al., 1998) e posteriormente elevada para 402,5 km, inclinada a $35^{\mathrm{O}}$. Desta forma, uma órbita completa ao redor do planeta é realizada a cada 96 minutos aproximadamente, sendo que para visitar o mesmo lugar no mesmo horário local pode levar no mínimo 23 dias (Angelis, MCGregor e Kidd, 2004a). Imaoka e Spencer (2000), por exemplo, encontraram que o satélite levou 48 dias para visitar o mesmo lugar no mesmo horário local, resultando em um número máximo de 15 amostras para determinado horário e local (em oceano tropical) no período de 1 ano. É de fundamental importância considerar o número de passagens e o tempo de observação dos sensores sobre determinadas regiões na construção e comparação de mapas de distribuições geográficas, como em Anselmo (2015), que estima que o satélite passou 10 mil vezes mais nas latitudes extratropicais do que nas tropicais entre 1998-2011, como um efeito decorrente da região onde a máxima latitude é atingida. Negri et al. (2002) sugerem técnicas para minimizar efeitos de baixa amostragem, como não utilizar regiões de estudo menores que $12^{\mathrm{O}}$ e utilizar médias a cada 4 horas para descrever o ciclo diurno da precipitação estimada tanto pelo radar de precipitação quanto pelo radiômetro de microonda. Assim, é necessário reconhecer a possibilidade do resultado da filtragem das tempestades noturnas conter algum erro relacionado à amostragem, embora o presente estudo utilize um domínio suficientemente grande e que o viés da amostragem diurna tornese mínimo ao utilizar duas décadas de dados (Chuntao Liu, em comunicação pessoal por correspondência eletrônica, em junho de 2021).

Existem diversas formas de representar severidade de tempestades, como através da altura do nível de $40 \mathrm{dBZ}$, limiares de temperatura de brilho mínima, taxa de raios, velocidade das rajadas de vento, presença e tamanho de granizo, intensidade de precipitação, 
etc. Aqui utiliza-se a taxa de raios, definida em Cecil et al. (2005) como o quociente entre o número de relâmpagos registrado pelo LIS/TRMM e o tempo médio de observação pelo satélite:

Taxa de raios $=(\text { Número de relâmpagos/Tempo médio de observação })^{*} 60$ [min-1 ]

Aumentos abruptos na taxa de raios total estão associados com condições de severidade como precipitação de granizo, rajadas de vento e tornados (MacGorman et al., 1989; Carey and Rutledge, 1998; Williams et al., 1999; Gatlin and Goodman, 2010; Schultz et al., 2011), além disso, quanto maior a taxa de raios atingida em um sistema maior será sua severidade (Zipser et al., 2006). A classificação por ordem de severidade e as principais informações das tempestades são mostradas na seção 3 .

\subsection{ERA5, GPM MERGIR, SRTM}

Utiliza-se a reanálise ERA5 (Hersbach et al. 2018), a quinta geração de reanálises atmosféricas do European Centre for Medium-Range Weather Forecasts (ECMWF) lançada pelo Copernicus Climate Change Service - (C3S), para analisar as características atmosféricas associadas com as tempestades noturnas. ERA5 possui $0.25^{\circ} \times 0.25^{\circ}$ de resolução espacial e 1 h de resolução temporal, disponível desde 1979 até o presente em 37 níveis de pressão e também para a superfície. Padronizou-se os horários de análise para 1200 UTC e 1800 UTC do dia anterior ao registro dos sistemas, considerado como o período pré-convectivo, e 0000 UTC e 0600 UTC do dia do registro.

Realizou-se dois tipos de composições de campos médios:

1. Composições dos campos de grande escala para avaliar padrões sinóticos no domínio de $35^{\circ} \mathrm{S}-0^{\circ}$ e $80^{\circ} \mathrm{W}-40^{\circ} \mathrm{W}$, onde a reanálise ERA5 no formato de média mensal horária foi utilizada para calcular as normais climatológicas anuais (1981-2010) a fim de identificar as anomalias dos padrões de grande escala que conduziram ao desenvolvimento de tempestades noturnas na região;

2. Composições centradas nas tempestades, em caixas de $6^{\circ} \times 6^{\circ}$ ao redor delas, buscando avaliar o ambiente de desenvolvimento das tempestades intensas e não intensas. 
Variáveis do estado base da atmosfera em níveis de pressão (como temperatura, altura geopotencial, vento horizontal, umidade relativa, etc.) foram utilizadas para caracterizar a configuração sinótica de grande escala. Além disso, foram obtidos da reanálise a energia convectiva potencial disponível (CAPE), a energia de inibição convectiva (CIN) e as variáveis necessárias para os cálculos dos parâmetros como profundidade da parte quente da nuvem (do inglês warm cloud depth - WCD) e o cisalhamento em baixos e médios níveis (700-1000 hPa e 400-1000 hPa, respectivamente). Em algumas análises estes valores são apresentados espacializados e em outras no ponto de grade mais próximo à localização das tempestades.

O WCD é definido como a distância vertical entre a altura do nível de condensação por levantamento (NCL) e a altura da isoterma de $0^{\circ} \mathrm{C}$ (o nível de congelamento), como esquematizado na Figura 2.3. A altura da base da nuvem dada pelo NCL já vem sendo discutida há mais tempo como um índice importante para a eletrificação das nuvens, uma vez que um NCL mais elevado pode aumentar a concentração de água de nuvem na fase mista, permitindo que água superresfriada seja utilizada em processos de crescimento de hidrometeoros sólidos (acreção) que, ao colidirem separam suas cargas e eletrificam as nuvens (Williams et al., 2005). Além disso, um NCL mais alto consequentemente torna o WCD mais raso o que, por sua vez, também afeta a microfísica das gotículas: uma trajetória mais curta na fase quente da nuvem resulta em menor coalescência e menor chance de precipitação antes das gotículas alcançarem a fase mista da nuvem. Logo, maior conteúdo de umidade alcança a região de fase mista permitindo congelamento de gotas grandes e carregamento por colisão de partículas de gelo (Rosenfeld e Woodley, 2003; Carey e Buffalo, 2007; Stolz et. al, 2015; Liu et. al, 2019).

Já o cisalhamento vertical do vento horizontal é um parâmetro que está relacionado com o nível de organização do sistema convectivo, podendo influenciar o desenvolvimento de células de duração curta, sistemas multicelulares ou supercélulas (Weisman e Klemp, 1984).

Para verificar sistemas de escala sinótica relacionados às tempestades noturnas e ciclo de vida (horário de início e duração) foram utilizados dados binários globais de Tb no canal infravermelho, com resolução espacial de $4 \mathrm{~km}$ e temporal de trinta minutos, do conjunto GPM-MERGIR (National Centers for Environmental Prediction/Climate Prediction Center - NCEP/CPC - Janowiak, Joyce and Xie, 2017), que combina dados 


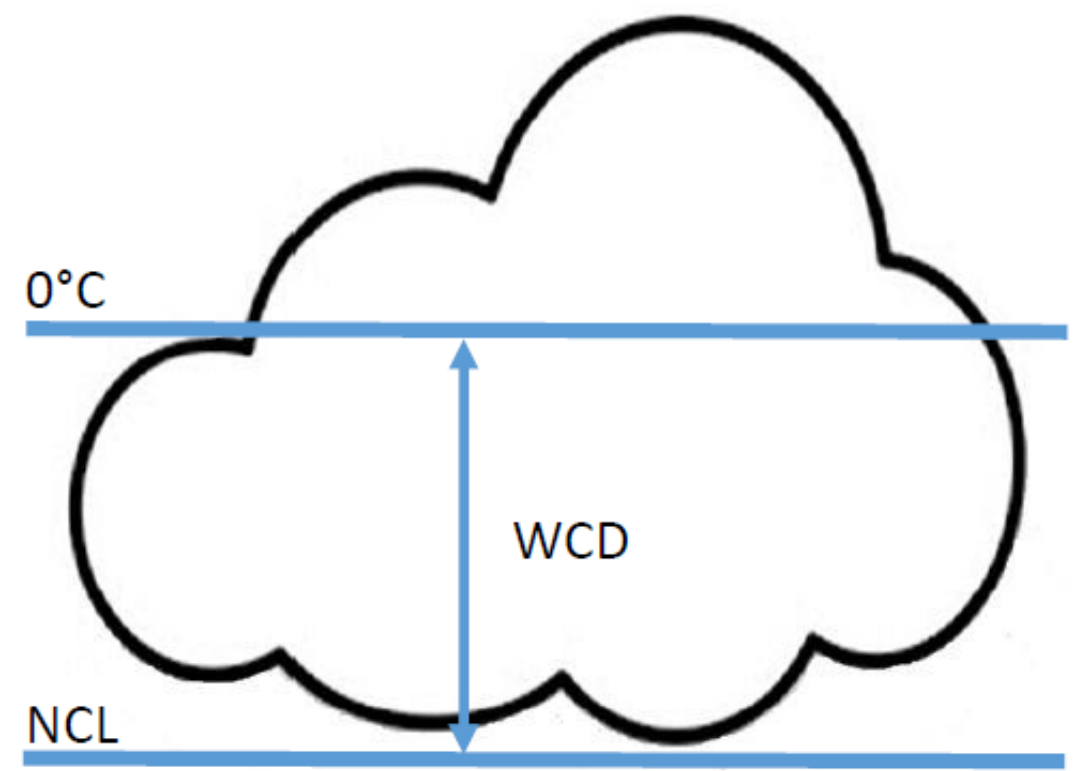

Figura 2.3: Ilustração do indicador de severidade "warm cloud deph", onde $0^{\circ} \mathrm{C}$ indica a isoterma de referente ao nível de congelamento e NCL o nível de condensação por levantamento.

dos satélites geoestacionários europeus, japoneses e norte-americanos, disponível no site https://disc.gsfc.nasa.gov/datasets/GPM_MERGIR_1/summary. O rastreamento dos sistemas nas imagens de Tb é feito manualmente, na contramão dos importantes estudos que desenvolvem métodos automáticos de rastreamento de sistemas com determinadas características como, por exemplo, Machado et al., 1998; Williams e Houze, 1987; Mapes e Houze, 1993. Isso se deve ao fato de que tempestades noturnas foram previamente filtradas utilizando critérios específicos na base PF, sendo necessário identificá-las uma a uma nas imagens de satélite para então estimar hora de início e duração. Boletins Climanálise (CPTEC-INPE) também foram usados como suporte à identificação e contabilização de sistemas sinóticos.

Em todas as figuras onde há representação da topografia em escala de cores é utilizada a base de dados de alta resolução $(1 \mathrm{~km}$ x $1 \mathrm{~km})$ do Shuttle Radar Topographic Mission - SRTM (Jarvis et al. 2008, disponível em https://srtm.csi.cgiar.org). Entretanto, quando se menciona a elevação onde uma tempestade noturna foi registrada, trata-se da informação proveniente da observação do satélite TRMM. 


\subsection{Modelo regional BRAMS}

O Brazilian Regional Atmospheric System (BRAMS) é um modelo numérico regional de previsão, desenvolvido originalmente pela parceria entre a Atmospheric, Meteorological, and Environmental Solutions (ATMET/USA, http://www . atmet.com), o Centro de Previsão de Tempo e Estudos Climáticos/Instituto Nacional de Meteorologia (CPTEC/INPE), e os institutos de Matemática e Estatística e de Astronomia, Geofísica e Ciências Atmosféricas da Universidade de São Paulo (IME-USP, IAG-USP). É considerado o melhor modelo operacional do INPE para a América do Sul (http://www.inpe.br/noticias/ noticia.php?Cod_Noticia=3493).

Seu desenvolvimento é baseado no modelo RAMS (Regional Atmospheric Modeling System), que utiliza o conjunto de equações não-hidrostáticas quasi-Boussinesq descritas por Tripoli e Cotton (1982) e Pielke et al. (1992). O modelo permite aninhamento múltiplo de grades que podem interagir em via de mão dupla (two-way) ou mão única (one-way), onde a grade com resolução mais grosseira alimenta a(s) grade(s) mais refinada(s). Diversas alterações foram introduzidas no BRAMS para produzir uma simulação mais realista dos processos físicos fundamentais nos trópicos, tais como interação terra/superfície e o papel dos aerossóis na radiação de onda curta (Souto et. al., 2015). A complexidade de umidade do modelo permite desde simulações secas, eliminando processos que influenciam ou são influenciados por qualquer fase da umidade, até a ativação da parametrização microfísica bulk, que inclui água de nuvem, chuva, gelo puro, neve, agregados, granizo e granizo, incluindo precipitação. Foi utilizada a versão 4.3 do modelo, e a descrição da simulação encontra-se na seção 3.2.1. 
Capítulo 3

\section{Resultados e discussão}

A análise dos resultados está dividida em duas partes, onde a primeira se refere à análise observacional (seção 3.1) e a segunda à modelagem numérica (seção 3.2).

\subsection{Análise observacional}

Neste tópico serão abordadas as principais características das tempestades baseadas nas propriedades do conjunto de dados PF, a classificação da severidade, os padrões sinóticos identificados, as composições dos campos médios do ambiente sinótico e respectivas anomalias, os sistemas sinóticos associados e o ciclo de vida das tempestades, composições centradas nas tempestades intensas e não intensas, mostrando campos médios para o ambiente em que os sistemas estão embebidos, bem como os ingredientes de severidade para tempestades intensas e não intensas. A partir daqui refere-se aos pontos cardeais norte, sul, leste, oeste, noroeste, nordeste, sudoeste, sudeste através das abreviações N, S, E, W, NW, NE, SW, SE, respectivamente.

\subsubsection{Principais características das tempestades noturnas}

O conjunto de dados PF fornece dezenas de informações acerca dos sistemas observados pelo satélite, podendo ser utilizadas tanto para localizar sistemas com determinadas características ou então para descrevê-los através de suas propriedades. Utilizando, portanto, estas informações, observa-se que as 97 tempestades noturnas identificadas pela nova filtragem no domínio de estudo para o período de 1998-2013 distribuem-se ao longo do Brasil, Peru e Bolívia, com a maior parte localizada no sopé da Cordilheira dos Andes. Esta distribuição geográfica pode ser vista na Figura 3.1, que mostra a elevação do terreno 
(escala de cores, em metros, proveniente da base de dados SRTM) e a posição das tempestades no horário em que foram registradas pelo satélite TRMM (símbolos em preto). A Figura 3.2 evidencia a concentração das tempestades próximo à Cordilheira mostrando o acumulado destes sistemas numa grade de $2^{\circ} \times 2^{\circ}$, onde a escala de cores indica o número de tempestades em cada célula da grade. Rehbein, Ambrizzi e Mechoso (2018) estudaram aspectos climatológicos de SCMs que tiveram alguma etapa de seu ciclo de vida sobre a bacia amazônica entre 2000 e 2013, sob a perspectiva de imagens de Tb no infravermelho de alta resolução temporal e espacial. Seus resultados mostram que a encosta da cordilheira dos Andes tem destaque para a gênese de SCMs de curta (entre 3 e 5,5 horas) e longa duração (superior a 6 horas): SCMs de curta duração ocorrem próximo de $10^{\circ} \mathrm{S}-75^{\circ} \mathrm{W}$ entre a primavera e o outono e próximo de $14^{\circ} \mathrm{S}-71^{\circ} \mathrm{W}$ nos meses mais quentes do ano $\left(3^{\circ}\right.$ e $5^{\circ}$ locais preferenciais, respectivamente); já os de longa duração têm início por volta de $14^{\circ} \mathrm{S}-75^{\circ} \mathrm{W}$ e em $16^{\circ} \mathrm{S}-65^{\circ} \mathrm{W}$ nos meses mais quentes do ano $\left(5^{\circ}\right.$ e $6^{\circ}$ locais preferenciais, respectivamente).

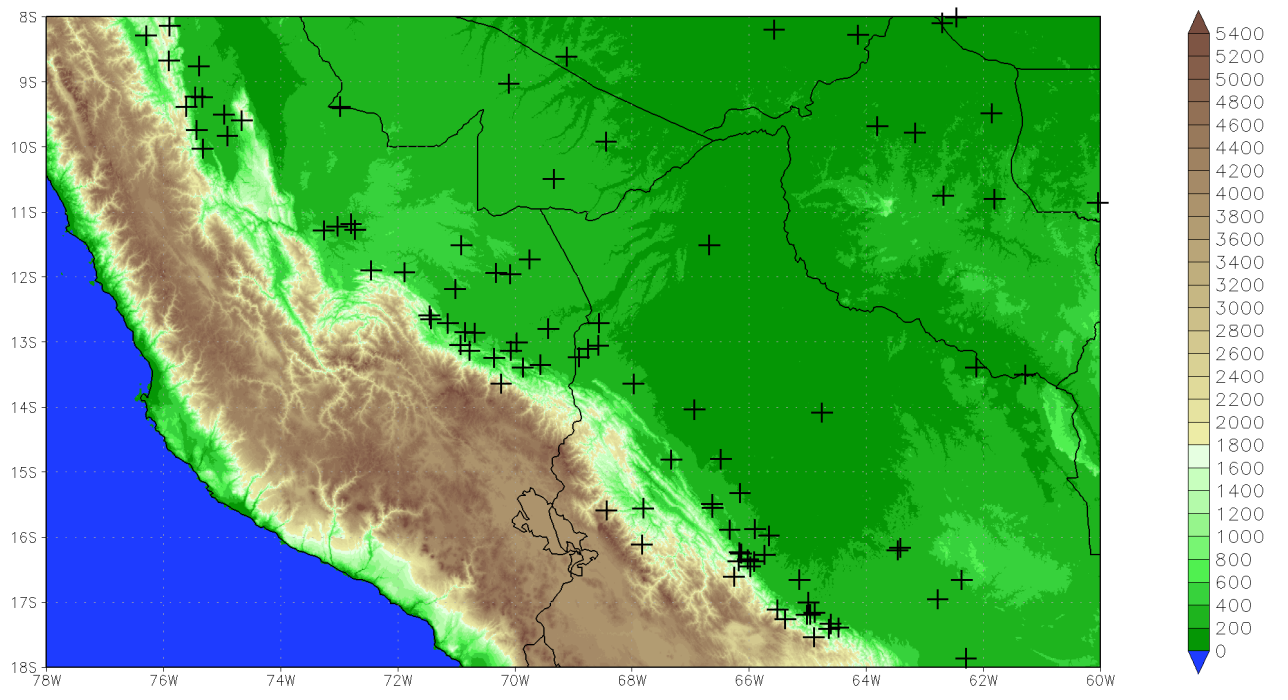

Figura 3.1: Símbolos em preto indicam a posição das tempestades no horário em que foram registradas pelo satélite TRMM dentro do domínio de estudo ampliado definido como região SW Amazônia, onde a escala de cores representa a elevação do terreno (em metros).

O ciclo anual das tempestades é mostrado na Figura 3.3. Os símbolos em vermelho mostram a distribuição geográfica das tempestades acumuladas por trimestres (janeirofevereiro-março, abril-maio-junho, julho-agosto-setembro e outubro-novembro-dezembro - 
JFM, AMJ, JAS, OND - Fig. 3.3 a, b, c, d, respectivamente) enquanto os gráficos de barras exibem o número de tempestade ocorridas em cada mês do respectivo trimestre. $\mathrm{O}$ pico de tempestades noturnas ocorre no trimestre de OND (Figura 3.3 d), totalizando 47 casos bem distribuídos ao longo do domínio do estudo. O menor número de tempestades ocorre em JAS (Figura $3.3 \mathrm{c}$ ), com apenas 7 casos confinados mais ao $\mathrm{S}$ da bacia. $\mathrm{O}$ segundo trimestre com maior número de casos noturnos é JFM (Figura 3.3 a), com 27 tempestades localizadas mais próximo ao sopé da cordilheira, seguido de AMJ (Figura 3.3 b), que contabiliza 16 eventos noturnos, o mês de abril representa um segundo máximo, com 14 tempestades noturnas.

Tempestades naturnas 1998-2013
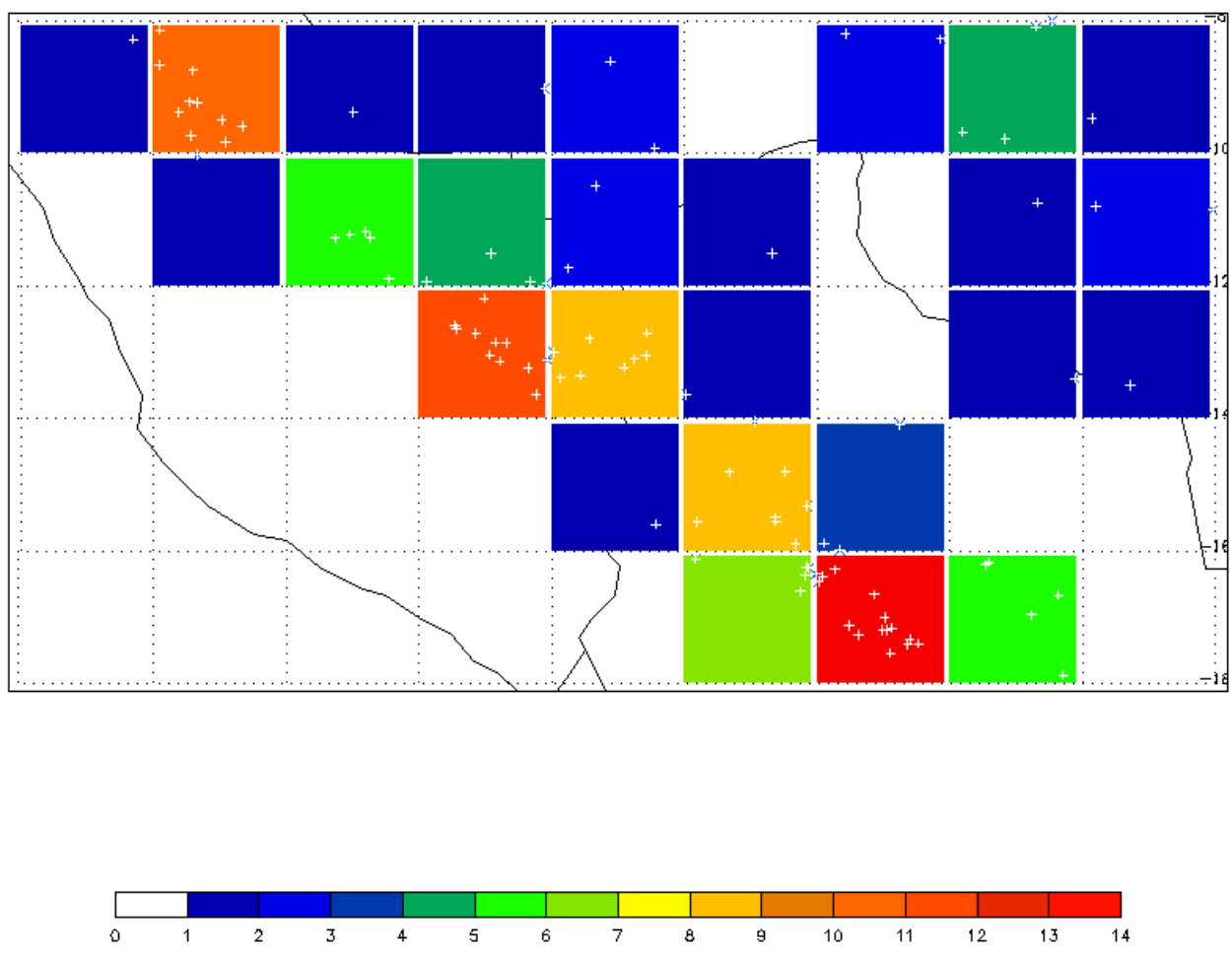

Figura 3.2: Distribuição geográfica das 97 tempestades noturnas na região SW Amazônia (símbolos brancos) entre 1998-2013, onde a escala de cores mostra o número de tempestades acumuladas por célula de grade com resolução espacial de $2^{\circ} \times 2^{\circ}$.

Destaca-se que a ocorrência de tempestades noturnas no SW Amazônia está intimamente ligada ao ciclo anual das chuvas na região. Apesar da precipitação ser heterogênea 
no tempo e no espaço ao longo da bacia (Nobre et al., 2009) existe uma marcha da anual da estação chuvosa entre o S e o $\mathrm{N}$ da bacia, com uma defasagem de seis meses: a estação chuvosa tem início no S da bacia entre os meses de abril e outubro (período de transição), com pico entre novembro e março, quando a ZCIT alcança sua posição mais ao $\mathrm{S}$ e o sistema de monção sul americana se estabelece. A partir de então, juntamente com a migração da ZCIT para N, a estação chuvosa migra também e, nos meses de inverno austral (maio a setembro), enquanto a maior parte da bacia tem estabelecida sua estação seca, na porção N-NW, na América Central e Oceano Pacífico adjacente, ocorre o período chuvosa (Figueroa e Nobre, 1990; Fish et al. 1998; Horel, Hahmann e Geisler; 1989, por exemplo).

[a]
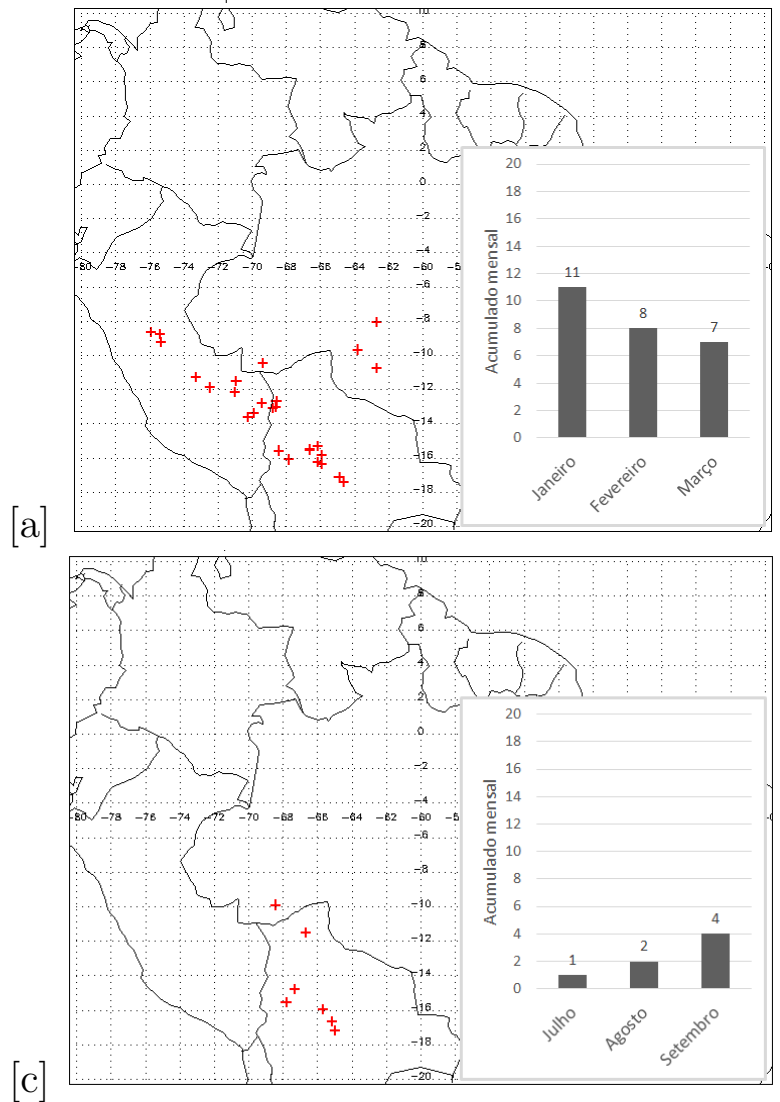

$[\mathrm{b}]$
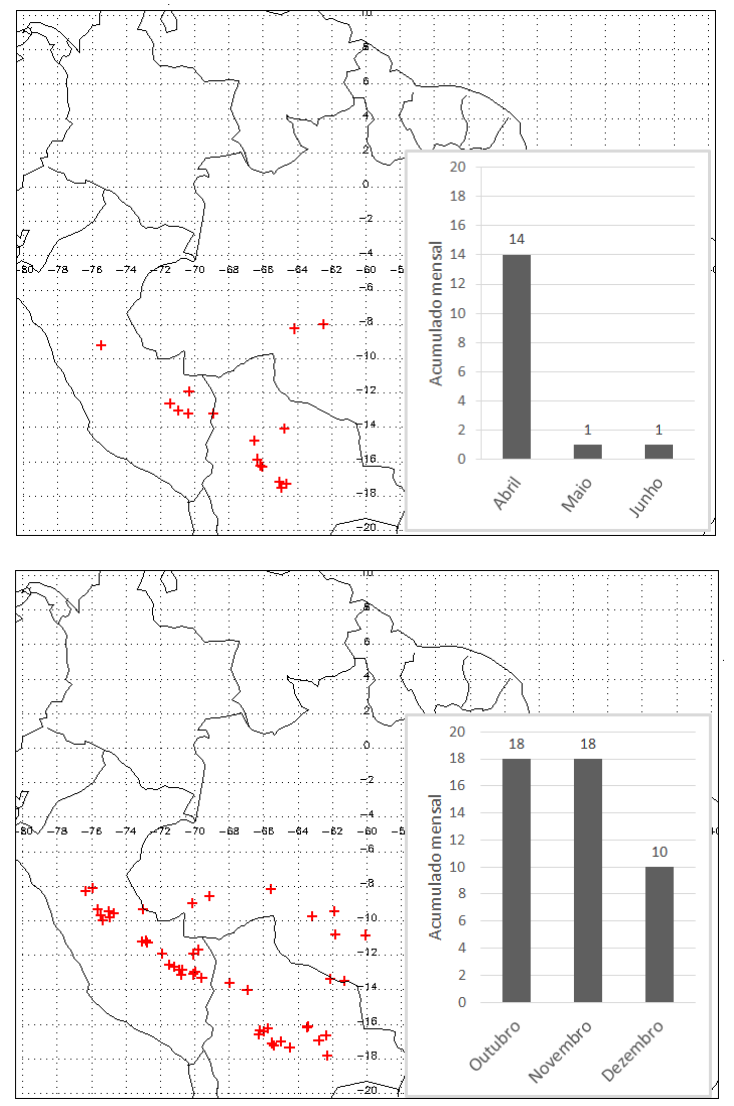

Figura 3.3: Distribuição geográfica (símbolos em vermelho) do acumulado trimestral das tempestades noturnas no SW Amazônia e acumulado mensal (barras em cinza, onde cada barra representa um mês do trimestre) para o período de 1998-2013, onde a) janeiro-fevereiro-março, b) abril-maio-junho, c) julhoagosto-setembro, d) outubro-novembro-dezembro.

A distribuição anual dentro do período entre 1998-2013 (Figura 3.4) destaca o ano de 2006 como o mínimo absoluto, com registro de apenas uma tempestade noturna, enquanto 2001, 2008 e 2012 destacam-se com picos máximos, com 9 tempestades em cada. 


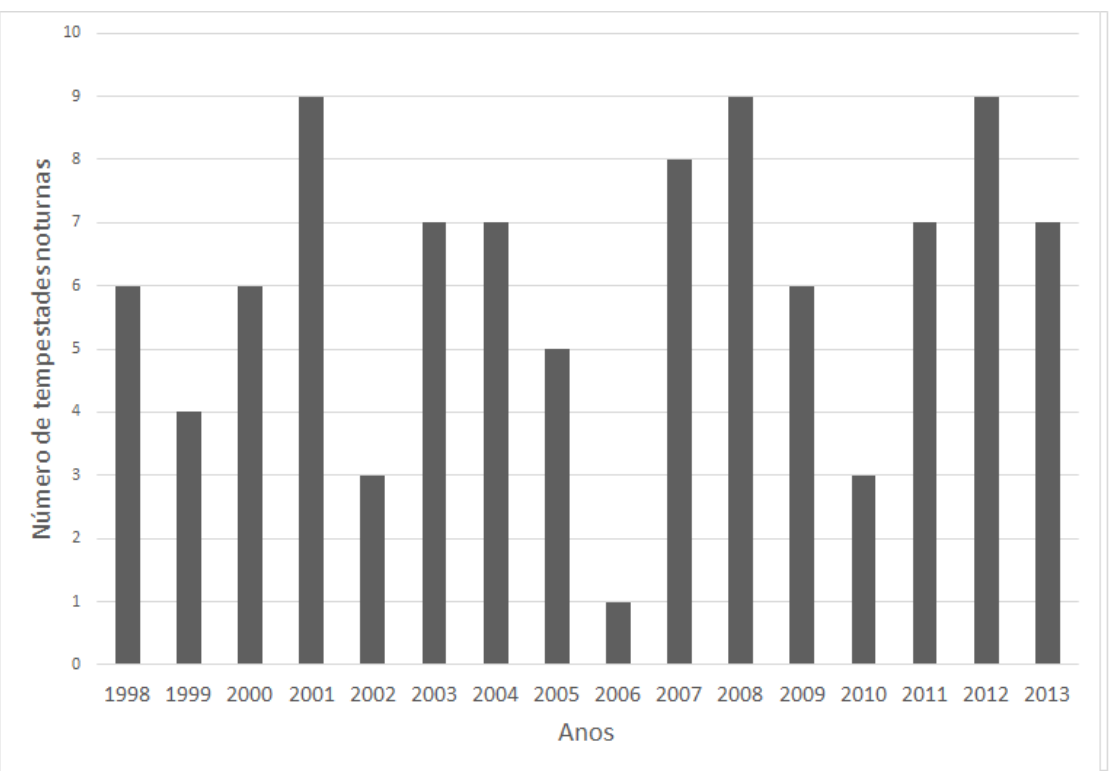

Figura 3.4: Distribuição anual de tempestades noturnas no SW Amazônia entre 1998-2013.

Através da relação de dispersão entre elevação do terreno e volume de precipitação (Figura 3.5) observa-se que os maiores totais ocorrem essencialmente em altitudes menos elevadas (abaixo de $600 \mathrm{~m}$ ). Embora que tempestades severas não necessariamente registrem recordes de acumulado de chuva, este resultado corrobora com a avaliação da precipitação para a Amazônia andina de Espinoza et al. (2009). Segundo os autores as maiores precipitações anuais na região localizam-se em estações abaixo de $1.500 \mathrm{~m}$. Eles relacionam a chuva mais abundante em baixas elevações devido à condensação de alta quantidade de vapor sobre a primeira inclinação oriental dos Andes. A menor elevação do terreno onde foi registrada uma tempestade noturna é de apenas $60 \mathrm{~m}$, enquanto a maior ocorreu em 3350 m, segundo as informações extraídas do conjunto de dados PF, chamando atenção para a complexidade do terreno na região e sua possível influência no disparo dos sistemas. O histograma da Figura 3.6 mostra que mais de $\%$ das tempestades ocorrem em elevações de até $500 \mathrm{~m}$ e $25 \%$ ocorrem acima de $1000 \mathrm{~m}$, sendo que três casos se desenvolveram acima de $3000 \mathrm{~m}$. 


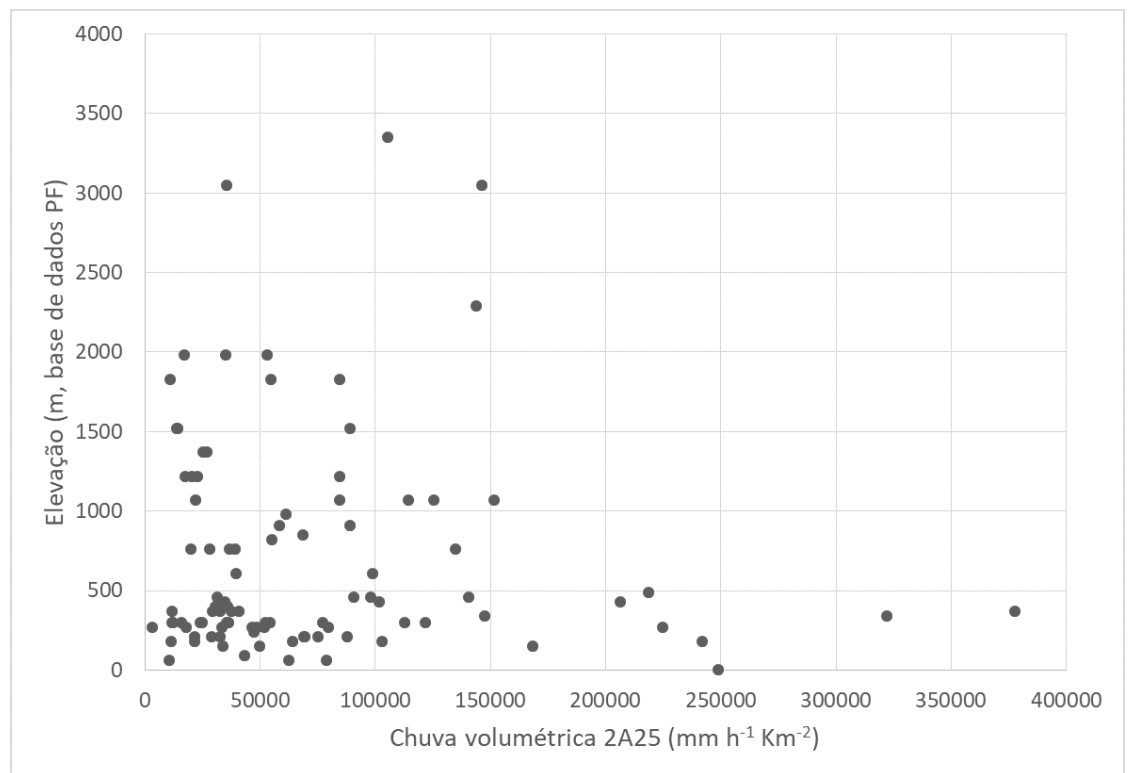

Figura 3.5: Relação de dispersão entre chuva volumétrica das tempestades (mm h-1 Km-2) e elevação do terreno.

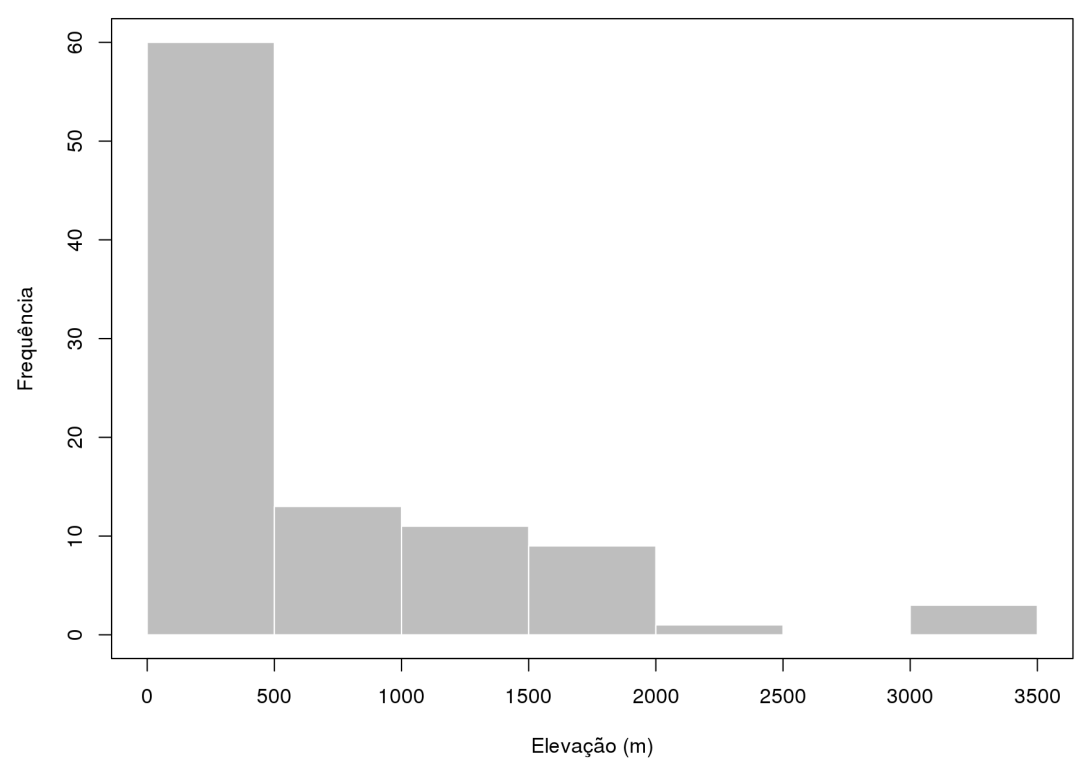

Figura 3.6: Histograma da elevação do terreno (m) onde as tempestades noturnas foram registradas no SW Amazônia.

\subsubsection{Classificação de severidade}

A severidade é um critério arbitrário que leva em consideração os impactos que um sistema pode causar social e economicamente (Nascimento, 2005). Alguns conjuntos de 
critérios de tempo severo são bastante difundidos na literatura científica, como aqueles Johns e Doswell (1992) e Mills e Colquhoun (1998), que estabelecem valores mínimos para velocidade de rajada de vento, tamanho de granizo, presença de tornado e inundação, ambos para latitudes médias. Nas latitudes tropicais ainda há uma lacuna neste sentido, no entanto, uma estratégia que permite estimar a severidade de sistemas convectivos é utilizar indicadores de severidade, uma vez que é quase impossível ter registros observacionais dos impactos de todas as tempestades que acontecem ao redor do globo. Como mencionado anteriormente, aqui utiliza-se a taxa de raios para classificar a severidade das tempestades noturnas, em virtude de ela estar relacionada com a velocidade das correntes ascendentes: fisicamente, quanto maior a taxa de raios mais poderosas as correntes ascendentes convectivas, logo, produzem e elevam grandes partículas de gelo para o topo das tempestades eletrificando-as (Zipser et al., 2006). Este e outros indicativos de severidade baseados em observações do satélite TRMM podem ser encontrados no estudo de Zipser et al. (2006) sobre as tempestades mais intensas da Terra.

Assim como as formas de estimar severidade variam, os limiares também. Anselmo (2015) realizou um estudo da morfologia das tempestades elétricas na América do Sul, concluindo que taxas de raio superior a 47,2 raios/min representam as tempestades extremas. Recentemente Liu et al. (2019) consideraram tempestades com 32 raios/min como intensas e Liu et al. (2020) definiram tempestades com altas taxas de raio como aquelas com mais do que $50 \mathrm{raios} / \mathrm{min}$. Aqui, as taxas de raios de $32 \mathrm{raios} / \mathrm{min}$ e $47 \mathrm{raios} / \mathrm{min}$ correspondem, respectivamente, aos percentis de $60 \%$ e $75 \%$ e utiliza-se ambos limiares: o primeiro para representar as tempestades noturnas intensas e o segundo as extremas. Estatisticamente um percentil de $60 \%$ significa que $60 \%$ dos valores do conjunto estão abaixo daquele limiar e, complementarmente, $40 \%$ acima. Portanto, tem-se que $40 \%$ do conjunto de tempestades noturnas são intensas e $25 \%$ extremas (39 e 23 casos, respectivamente).

A Tabela 3.1 mostra a categorização das tempestades em oito grupos, de acordo com os percentis da taxa de raios, e o número de tempestades em cada categoria. Estes percentis foram calculados para as taxas mais significativas ( $>32$ raios $/ \mathrm{min}$ ). Para cada percentil (por ordem crescente) nomeou-se categorias que vão de Não intensa (<percentil 60\%, portanto, <32 raios/min), Intensa 0 a 2 e Extrema de 0 a 4, para facilitar a comparação com outros estudos. 
Tabela 3.1 - Percentis das taxas de raios (raios/min) para as tempestades noturnas no SW Amazônia registradas entre 1998-2013, respectiva classificação e total de tempestades em cada categoria.

\begin{tabular}{c|c|c|c}
\hline Percentil & Raios/min & Categoria & № de tempestades \\
\hline $95 \%$ & 117,92 & Extrema-4 & 5 \\
$90 \%$ & 71,78 & Extrema-3 & 5 \\
$85 \%$ & 63,41 & Extrema-2 & 5 \\
$80 \%$ & 51,94 & Extrema-1 & 5 \\
$75 \%$ & 46,39 & Extrema-0 & 5 \\
$70 \%$ & 43,30 & Intensa-2 & 4 \\
$65 \%$ & 38,02 & Intensa-1 & 6 \\
$60 \%$ & 32,73 & Intensa-0 & 4 \\
$<60 \%$ & $<32$ & Não intensas & 58 \\
\hline
\end{tabular}

O gráfico de dispersão da Figura 3.7 mostra relação entre a taxa de raios e a área total das tempestades noturnas. Observa-se que a maior parte das tempestades têm área total inferior a $10000 \mathrm{~km}^{2}$ (valor destacado pela reta vertical em vermelho), sendo que a maior parte apresenta taxas raio inferior a $32 \mathrm{raios} / \mathrm{min}$ (categoria Não intensa, destacado pela reta horizontal em vermelho). Além disso, pode-se inferir que das 97 tempestades noturnas, 37 têm área total superior a $10000 \mathrm{Km}^{2}(38 \%)$, das quais 21 são intensas ( 57\%), sendo 15 delas extremas (41\%). Tempestades com valores máximos para área total e taxa de raios têm os rótulos destacados no gráfico: a maior tempestade $\left(67075 \mathrm{~km}^{2}\right)$ tem taxa de $70,88 \mathrm{raios} / \mathrm{min}$, e a tempestade mais extrema (275,15 raios/min) tem área de $8375 \mathrm{~km}^{2}$.

Concentrando essa análise para as tempestades intensas, a Figura 3.8 mostra a relação de dispersão entre área total e taxa de raios, com símbolos em laranja destacando as tempestades extremas. Das 39 tempestades intensas do conjunto, 21 têm área total superior a $10000 \mathrm{~km}^{2}(\sim 54 \%)$ e das 23 tempestades extremas, 15 têm área total superior a $10000 \mathrm{~km}^{2}$ $(\sim 65 \%)$. Desta forma, apesar da área total explicar apenas $9 \%$ da variância da taxa de raios (coeficiente de determinação $\mathrm{R}^{2}=0,0971$ ) as tempestades com maiores taxas de raios estão relacionadas a tempestades maiores em área, principalmente aquelas consideradas extremas, embora a tempestade mais extrema esteja associada a uma área relativamente pequena. 


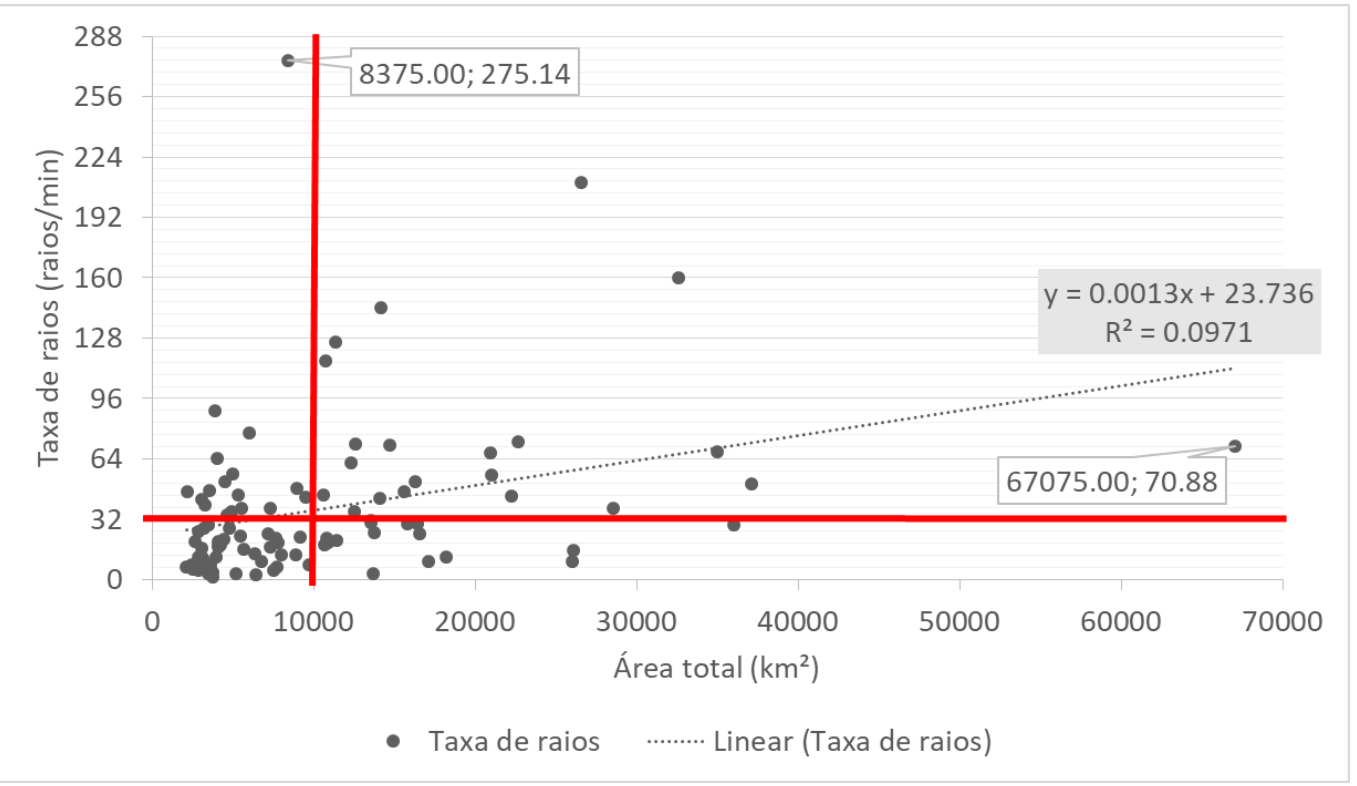

Figura 3.7: Relação de dispersão entre área total $\left(\mathrm{km}^{2}\right)$ e a taxa de raios (raios/min) das tempestades noturnas no SW Amazônia. Reta vermelha vertical destaca o limiar de $10000 \mathrm{~km}^{2}$ e reta vermelha horizontal o limiar de 32 raios/min.

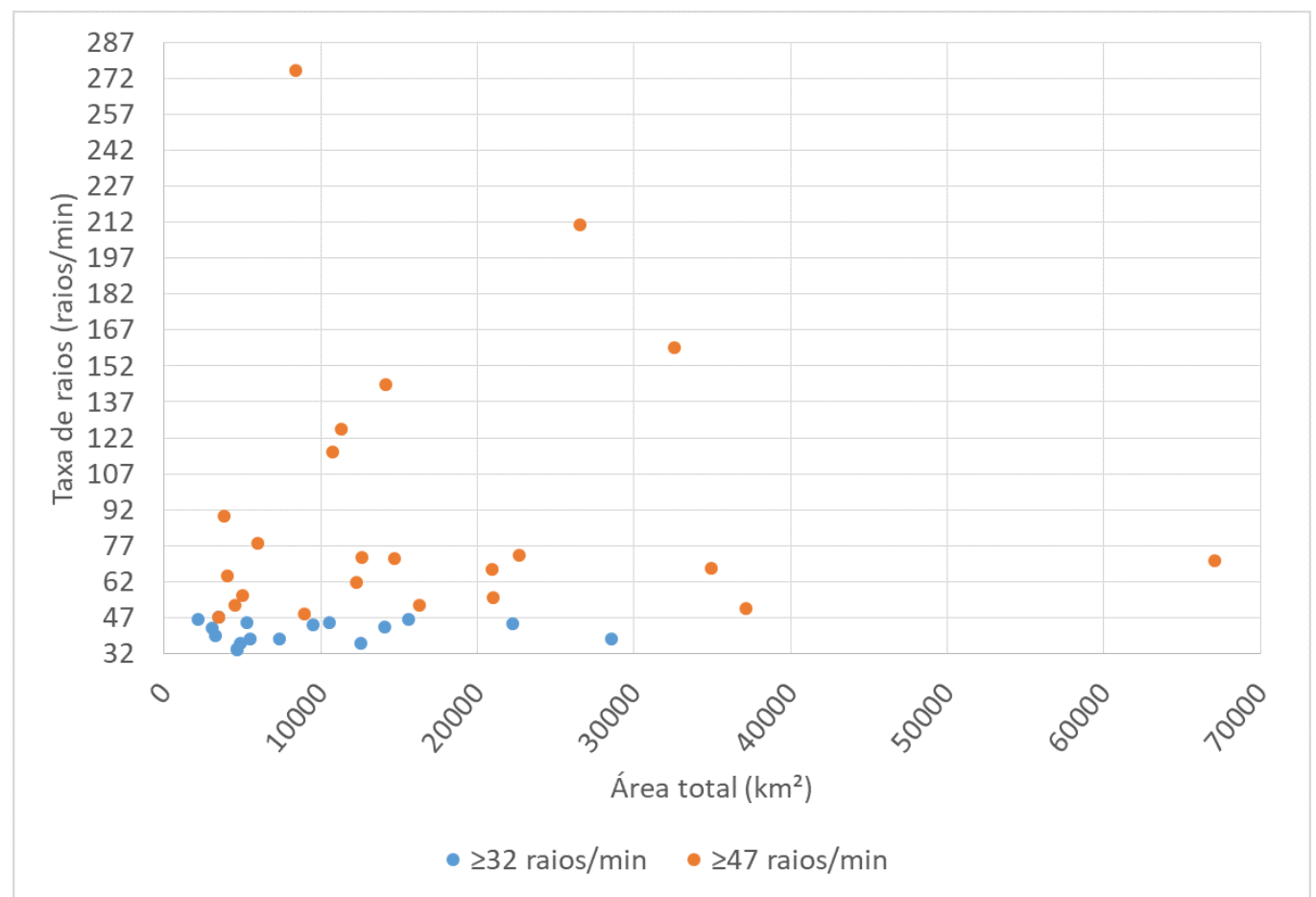

Figura 3.8: Relação de dispersão entre área total $\left(\mathrm{km}^{2}\right)$ e a taxa de raios (raios/min) das tempestades noturnas no SW Amazônia. Símbolos em laranja destacam tempestades extremas.

A Tabela 3.2 apresenta as principais propriedades observadas pelo TRMM para as tempestades noturnas extremas. A coluna "Caso" indica a posição da tempestade na clas- 
sificação de severidade, "Data" o dia em que ela foi registrada, "Hora"indica o horário de registro pelo satélite (UTC), "Lat" representa a latitude do sistema e "Lon" a longitude, " $A_{T}$ " refere-se a uma estimativa da área total do sistema (número de pixels com PCT85GHz $<250 \mathrm{~K}^{*}$ área do pixel), em $\mathrm{Km}^{2}$, " $A_{N}$ " é a estimativa para a área do núcleo do sistema (número de pixels com PCT85GHz<100 K*área do pixel), em $\mathrm{Km}^{2}$, " $T_{85}$ " referese à propriedade MINPCT85GHZ, a mínima temperatura de brilho do sistema no canal de $85 \mathrm{GHz}$, em $\mathrm{K}$, enquanto " $T_{37}$ " à MINPCT37GHZ, a mínima temperatura de brilho do sistema no canal de $37 \mathrm{GHz}$, em $\mathrm{K}$, " $P_{M}$ " refere-se à máxima taxa de precipitação na superfície (MAXNSRAIN, mm/h) e " $H_{40}$ " a máxima altura do nível de 40 dBZ (MAXHT40, $\mathrm{Km}$ ). Todas essas propriedades são instantâneas, registradas no momento da passagem do satélite.

Ao considerar o conjunto total de tempestades noturnas observa-se, através dos histogramas da Figura 3.9, que a maior parte dos sistemas noturnos possui:

1. Taxas de raio de até 50 raios/min, sendo que quanto mais extrema a tempestade menor sua frequência (Fig 3.9 ,a);

2. Horário de registro quase uniforme ao longo do período entre 0000-1000 UTC com ligeira preferência pelo intervalo entre 0700-0800 UTC, o que corresponde a 0200-0300 hora local (Fig, 3.9, b);

3. Área total de até $20.000 \mathrm{Km}^{2}$ (Fig.3.9. c);

4. Área do núcleo mais frio de até $200 \mathrm{Km}^{2}$ (Fig. 3.9, d);

5. Mínima temperatura de brilho na frequência de 85 GHz entre 80-100 K (Fig.3.9.e);

6. Mínima temperatura de brilho na frequência de 37 GHz entre 200-230 K (Fig 3.9.f);

7. Taxas máximas de precipitação na superfície entre 50-100 mm/h (Fig 3.9.g);

8. Altura máxima do nível de 40 dBZ entre 6 e 11 km (Fig,3.9,h). 
Tabela 3.2 - Classificação das 23 tempestades noturnas extremas através da taxa de raios, em ordem decrescente. Caso: ordem de classificação de severidade; Data: data de registro; TaxaR: taxa de raios (raios/min); Hora: horário de registro do sistema pelo satélite TRMM (UTC); Lat: latitude do sistema no horário de registro; Lon: longitude do sistema no horário de registro; $A_{T}$ : área total do sistema (número de pixels com PCT85GHz<250 $\mathrm{K}^{*}$ área do pixel), em $\mathrm{Km}^{2} ; A_{N}$ : área do núcleo do sistema (número de pixels com $\mathrm{PCT} 85 \mathrm{GHz}<100 \mathrm{~K}^{*}$ área do pixel), em $\mathrm{Km}^{2} ; T_{85}$ : mínima temperatura de brilho do sistema no canal de $85 \mathrm{GHz}$ (MINPCT85GHZ), em K; $T_{37}$ : mínima temperatura de brilho do sistema no canal de 37 GHz (MINPCT37GHZ), em K; $P_{M}$ : máxima taxa de precipitação na superfície (MAXNSRAIN, mm/h); $H_{40}$ : máxima altura do nível de 40 dBZ (MAXHT40, Km).

\begin{tabular}{|c|c|c|c|c|c|c|c|c|c|c|c|}
\hline Caso & Data & $\operatorname{Taxa}_{R}$ & Hora & Lat & Lon & $\mathrm{A}_{T}$ & $\mathrm{~A}_{N}$ & $\mathrm{~T}_{85}$ & $\mathrm{~T}_{37}$ & $\mathrm{P}_{M}$ & $\mathrm{H}_{40}$ \\
\hline $1^{\mathrm{O}}$ & $25 / 12 / 2013$ & 275,14 & 1,84 & 16,16 & 63,42 & 8375 & 275 & 89,41 & 189,35 & 85,60 & 12,50 \\
\hline $2^{\mathrm{O}}$ & $24 / 10 / 2007$ & 210,71 & 0,77 & $-16,27$ & $-65,74$ & 26575 & 850 & 70,56 & 163,41 & 110,60 & 10,75 \\
\hline $3^{\mathrm{O}}$ & $26 / 11 / 2001$ & 159,80 & 5,04 & $-8,14$ & $-75,90$ & 32550 & 200 & 84,55 & 198,82 & 105,10 & 9,25 \\
\hline $4^{\mathrm{O}}$ & 09/08/2013 & 144,34 & 8,29 & $-17,19$ & $-64,96$ & 14125 & 125 & 86,56 & 195,57 & 138,30 & 10,00 \\
\hline $5^{\mathrm{O}}$ & $30 / 11 / 2012$ & 125,65 & 7,31 & $-17,00$ & $-64,99$ & 11325 & 1250 & 66,95 & 169,95 & 194,90 & 9,75 \\
\hline $6^{\underline{\mathrm{O}}}$ & 03/09/2009 & 115,99 & 7,20 & $-15,98$ & $-65,66$ & 10725 & 375 & 81,77 & 177,15 & 80,50 & 9,25 \\
\hline $7^{\underline{O}}$ & $22 / 11 / 2001$ & 89,57 & 7,18 & $-16,46$ & $-65,98$ & 3850 & 50 & 83,65 & 212,23 & 54,80 & 10,50 \\
\hline $8^{\mathrm{O}}$ & $24 / 10 / 2012$ & 77,97 & 2,16 & $-9,38$ & $-75,62$ & 6000 & 450 & 69,19 & 195,32 & 96,60 & 13,50 \\
\hline $9^{\underline{0}}$ & $03 / 11 / 2009$ & 72,81 & 9,67 & $-13,13$ & $-70,07$ & 22675 & 125 & 82,79 & 208,71 & 105,80 & 9,25 \\
\hline $10^{\mathrm{o}}$ & $11 / 10 / 2003$ & 72,17 & 4,24 & $-12,59$ & $-71,46$ & 12600 & 300 & 90,98 & 213,89 & 271,60 & 9,00 \\
\hline $11^{\mathrm{O}}$ & $30 / 10 / 2008$ & 71,52 & 3,79 & $-16,96$ & $-62,78$ & 14675 & 75 & 95,90 & 199,67 & 82,50 & 10,25 \\
\hline $12^{\mathrm{O}}$ & $12 / 11 / 2004$ & 70,88 & 8 & $-11,18$ & $-72,80$ & 67075 & 75 & 7,74 & 206,65 & 90 & 8,25 \\
\hline $13^{\mathrm{O}}$ & $10 / 11 / 2003$ & 67,66 & 2,73 & $-9,78$ & $-63,17$ & 34950 & 175 & 57 & 206,64 & 117,20 & 6,75 \\
\hline $14^{\mathrm{O}}$ & $21 / 10 / 2009$ & 67,01 & 6,95 & $-12,86$ & $-70,69$ & 20950 & 150 & 83,86 & 212,47 & 194,20 & 8,00 \\
\hline $15^{\mathrm{o}}$ & $25 / 09 / 2003$ & 64,44 & 2,71 & $-14,80$ & $-67,33$ & 4000 & 175 & 81,33 & 216,95 & 53,60 & 10,50 \\
\hline $16^{\mathrm{o}}$ & $20 / 10 / 2007$ & 61,86 & 2,89 & $-10,85$ & $-60,04$ & 12275 & 50 & 95,08 & 212,95 & 51,60 & 7,75 \\
\hline $17^{\mathrm{o}}$ & 10/09/1999 & 56,06 & 0,17 & $-15,56$ & $-67,81$ & 4975 & 75 & 99,97 & & 126,60 & 11,00 \\
\hline $18^{\underline{O}}$ & $03 / 02 / 2013$ & 55,42 & 7,72 & $-13,10$ & $-68,76$ & 21025 & 225 & 88,94 & 209,60 & 133,70 & 11,25 \\
\hline $19^{\underline{O}}$ & $10 / 10 / 2000$ & 52,19 & 1,78 & $-17,26$ & $-65,38$ & 4525 & 25 & 97,68 & 193,10 & 99,10 & 9,25 \\
\hline $20^{\mathrm{O}}$ & $12 / 11 / 2007$ & 52,19 & 6,17 & $-11,22$ & $-73,04$ & 16275 & 275 & 95,30 & 216,40 & 78,10 & 9,50 \\
\hline $21^{\mathrm{O}}$ & $16 / 02 / 2007$ & 50,90 & 7,76 & $-13,05$ & $-68,58$ & 37125 & 150 & 94,97 & 209,30 & 131,00 & 7,25 \\
\hline $22^{\mathrm{O}}$ & $22 / 11 / 2001$ & 48,33 & 7,16 & $-13,35$ & $-69,57$ & 8950 & 200 & 70,81 & 219,90 & 121,60 & 10,50 \\
\hline $23^{\mathrm{O}}$ & $28 / 10 / 2012$ & 47,04 & 0,12 & $-11,73$ & $-69,75$ & 3500 & 300 & 89,43 & 228,91 & 36,70 & 8,00 \\
\hline
\end{tabular}




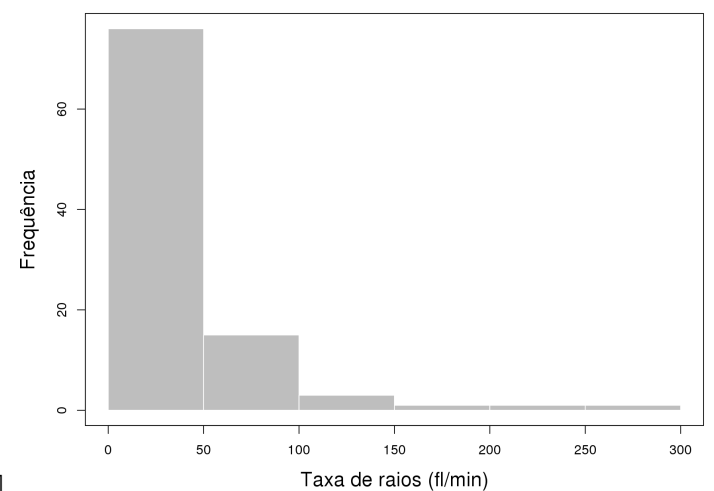

[a]

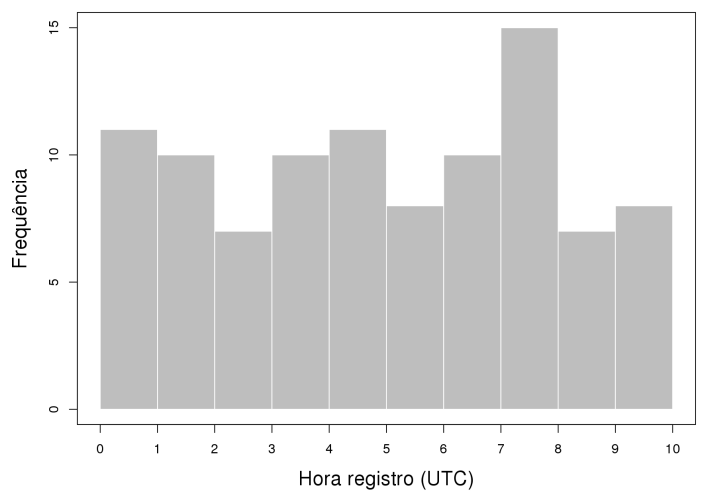

$[\mathrm{b}]$
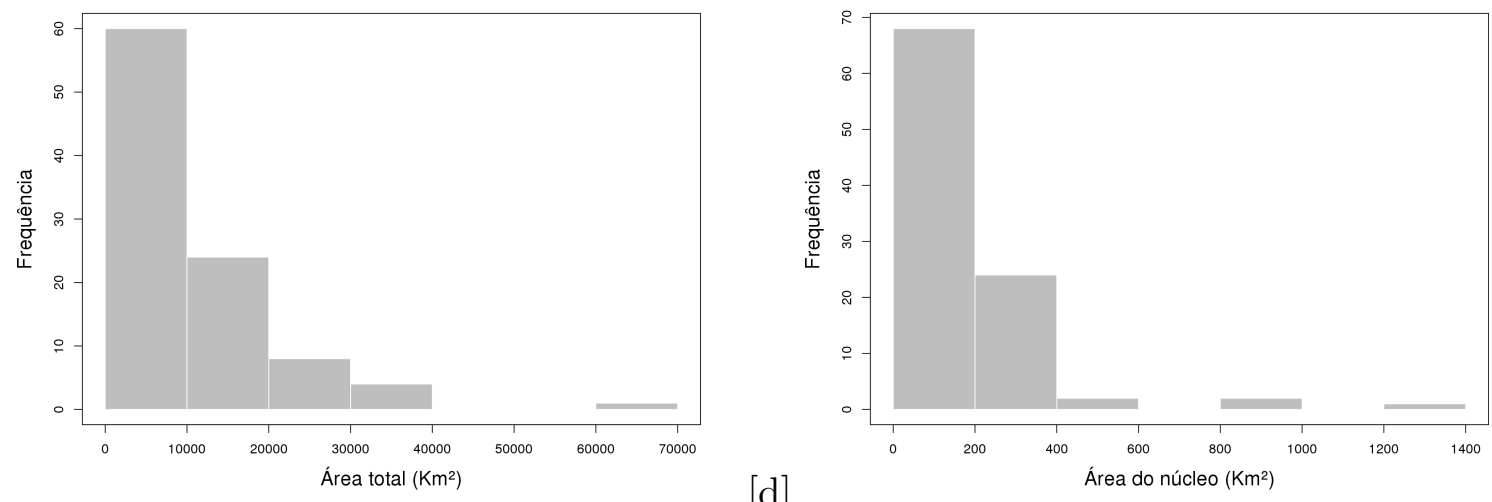

[d]

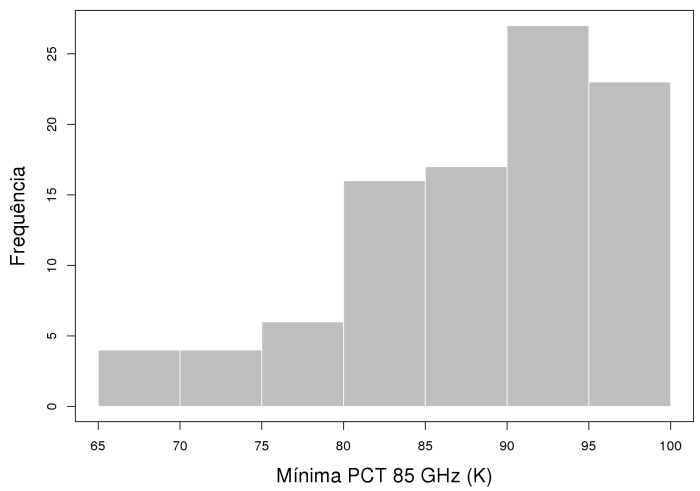

[e]
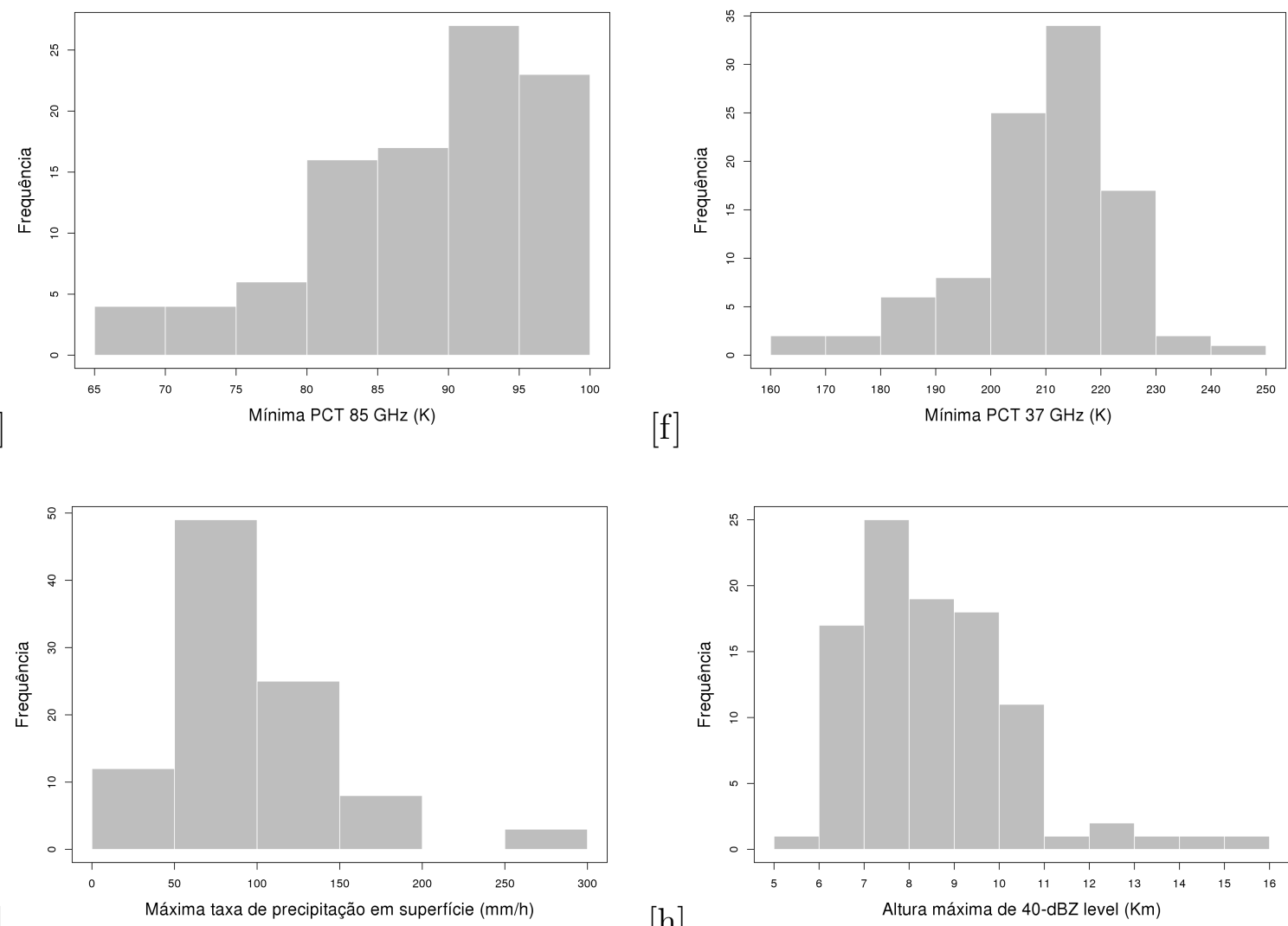

[g]

Máxima taxa de precipitação em superfície $(\mathrm{mm} / \mathrm{h}$ )

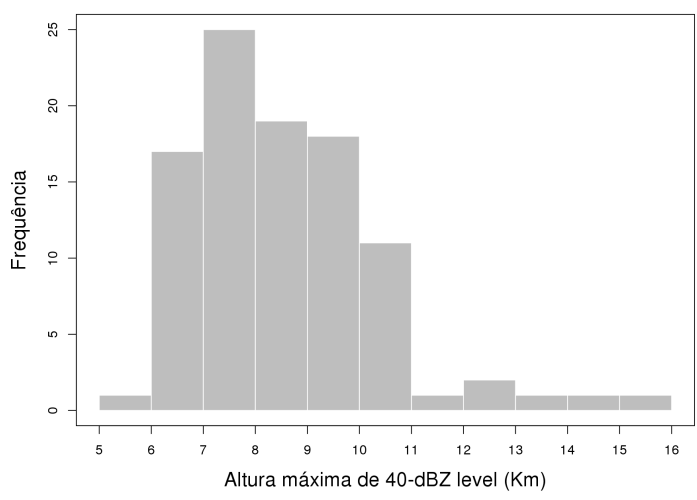

[h]

Figura 3.9: Histogramas das propriedades das tempestades noturnas onde a) taxa de raios ( $\mathrm{raios} / \mathrm{min})$, b) hora de registro (UTC), c) área total $\left(\mathrm{Km}^{2}\right)$, d) área do núcleo $\left(\mathrm{Km}^{2}\right)$, e) mínima PCT85GHz (K), f) mínima PCT37GHz, g) máxima taxa de precipitação na superfície $(\mathrm{mm} / \mathrm{h}), \mathrm{h})$ altura máxima do nível de $40 \mathrm{dBZ}$. 
A Tabela 3.3 destaca valores extremos das principais propriedades encontrados para o conjunto de tempestades noturnas onde nota-se que há dois grupos de variáveis com comportamentos opostos e complementares: 1) maiores valores de taxa de raios $\left(\operatorname{Taxa}_{R}\right)$, área total $\left(A_{T}\right)$, área do núcleo $\left(A_{N}\right)$, máxima taxa de precipitação na superfície $\left(P_{M}\right)$ e máxima altura do nível de $40 \mathrm{dBZ}\left(H_{40}\right)$ estão associados com tempestades mais severas na classificação (ordem de classificação indicada pela coluna "CASO"), enquanto valores menores aparecem nas tempestades que estão nas posições mais inferiores da classificação; 2) já para as variáveis MINPCT85GHz $\left(T_{85}\right)$ e MINPCT37GHz $\left(T_{37}\right)$ acontece o contrário, aqui os valores menores é que estão associados a tempestades no topo da classificação, e maiores a tempestades menos intensas. Este é um padrão esperado e sua discussão será elaborada ao longo deste capítulo.

Tabela 3.3 - Valores mínimos e máximos extraídos do conjunto das 97 tempestades. Caso: ordem de classificação de severidade; Data: data de registro; TaxaR: taxa de raios (raios/min); Hora: horário de registro do sistema pelo satélite TRMM (UTC); Lat: latitude do sistema no horário de registro; Lon: longitude do sistema no horário de registro; $A_{T}$ : área total do sistema, em $\mathrm{Km}^{2} ; A_{N}$ : área do núcleo do sistema, em $\mathrm{Km}^{2} ; T_{85}$ : mínima temperatura de brilho do sistema no canal de $85 \mathrm{GHz}$ (MINPCT85GHZ), em K; $T_{37}$ : mínima temperatura de brilho do sistema no canal de $37 \mathrm{GHz}$ (MINPCT37GHZ), em K; $P_{M}$ : máxima taxa de precipitação na superfície (MAXNSRAIN, mm/h); $H_{40}$ : máxima altura do nível de 40 dBZ (MAXHT40, Km).

\begin{tabular}{c|c|c|c|c|c|c} 
& MÁXIMO & DATA & CASO & MÍNIMO & DATA & CASO \\
\hline Taxa $_{R}$ & 275,14 & $25 / 12 / 2013$ & $\left(1^{\circ}\right)$ & 1,29 & $14 / 04 / 2011$ & $\left(97^{\circ}\right)$ \\
HORA & 9,78 & $11 / 11 / 2011$ & $\left(75^{\circ}\right)$ & 0,12 & $28 / 10 / 2012$ & $\left(23^{\circ}\right)$ \\
LAT & $-8,00$ & $11 / 04 / 2008$ & $\left(93^{\circ}\right)$ & $-17,86$ & $21 / 12 / 2013$ & $\left(32^{\circ}\right)$ \\
LON & $-60,04$ & $20 / 10 / 2007$ & $\left(16^{\circ}\right)$ & $-76,30$ & $13 / 10 / 2007$ & $\left(79^{\circ}\right)$ \\
$A_{T}$ & 67075,00 & $12 / 11 / 2004$ & $\left(12^{\circ}\right)$ & 2100,00 & $17 / 10 / 2012$ & $\left(86^{\circ}\right)$ \\
$A_{N}$ & 1250,00 & $30 / 11 / 2012$ & $\left(5^{\circ}\right)$ & 25,00 & 3 casos & $\left(19^{\circ}, 73^{\circ}, 97^{\circ}\right)$ \\
$T_{85}$ & 99,97 & $10 / 09 / 1999$ & $\left(17^{\circ}\right)$ & 66,95 & $30 / 11 / 2012$ & $\left(5^{\circ}\right)$ \\
$T_{37}$ & 244,16 & $20 / 04 / 2001$ & $\left(96^{\circ}\right)$ & 163,41 & $24 / 10 / 2007$ & $\left(2^{\circ}\right)$ \\
$P_{M}$ & 300,00 & $02 / 04 / 2010$ & $\left(26^{\circ}\right)$ & 16,40 & $17 / 10 / 2012$ & $\left(86^{\circ}\right)$ \\
$H_{40}$ & 15,50 & $26 / 10 / 2012$ & $\left(31^{\circ}\right)$ & 5,75 & $21 / 12 / 2013$ & $\left(95^{\circ}\right)$ \\
\hline
\end{tabular}

Cecil et al. (2005) analisaram globalmente os três primeiros anos da base de dados PF dividindo os sistemas em cinco categorias de severidade baseado na taxa de raios, com valores variando de 0 a 297 raios/min. Conforme seus resultados, no SW Amazônia ocorrem sistemas de Categoria 2 e 3 (2,2-30,9 raios/min e 39,9-122,0 raios/min, respectivamente). Zipser et al. (2006), por sua vez, avaliaram os seis primeiros anos do mesmo conjunto de 
dados em busca das tempestades mais severas do globo, utilizando como indicadores de intensidade a taxa de raios, altura máxima de 40 dBZ, mínimas PCT85GHz e PCT37GHz. Seus resultados mostram que na região SW Amazônia ocorrem tempestades nas categorias 0,9\%, 0,09\% , e 0,009\% mais extremas do globo (2,9-32,9 raios/min, 32,9-126,7 raios/min e 126,7-314,7 raios/min, respectivamente), embora a Amazônia como um todo não seja uma região preferencial destes sistemas. A única categoria não registrada para a Amazônia é a 0,001\% mais extrema, com taxa de raio superior a 314,7 raios/min, altura máxima de 40 dBZ maior que 16,75 Km, MINPCT85GHz menor que 59,3 K e MINPCT37GHz menor que 138,4 K. Quando se compara taxas de raios das tempestades noturnas mais extremas (categoria Extremas-4, 125,65 a 275,14 raios/min) há correspondência com a Categoria 4 de Cecil et al. (2005), com taxas entre 122-296 raios/min, e com as 0,009\% mais extremas de Zipser et al. (2006).

Para uma melhor visualização do exposto acima, a Tabela 3.4 sintetiza valores das categorias comparáveis entre o presente estudo (Tempestades Noturnas), Cecil et al. (2005) e Zipser et al. (2006). Cecil et al. (2005) não avalia MAXH40 e estes valores ausentes aparecem representados por um traço. Na seção das tempestades noturnas são indicados apenas os valores máximos e mínimos dentre as categorias Intensa-0 e Extrema-4 para as variáveis MINPCT85GHz, MINPCT37GHz, MAXHT40, uma vez que elas não variam linearmente de acordo com os intervalos de taxas de raios utilizados na categorização e/ou variam muito pouco dentro dos percentis.

De acordo com Zipser et al. (2006) a informação mais precisa do radar de precipitação do TRMM é a altura máxima alcançada por determinados valores de refletividade, uma vez que para a conversão destes valores em precipitação são necessárias diversas correções de atenuação dentro dos algoritmos. Valores altos de refletividade em uma camada profunda podem indicar sistemas convectivos com correntes ascendentes vigorosas e o limiar de refletividade de $40 \mathrm{dBZ}$ é conhecido na literatura como um indicador de precipitação convectiva (Steiner et al., 1995, Awaka et al., 1997), estando associado a uma eletrificação rápida das tempestades (Dye et al., 1989). Correntes ascendentes intensas dentro das tempestades favorecem o crescimento dos hidrometeoros na região de fase mista das nuvens e consequentemente a colisão entre eles, gerando troca de cargas e carregamento da nuvem, ou seja, a eletrificação das tempestades e a microfísica estão intimamente relacionadas.

Houze et al. (2007), Romatschke et al. (2010) e Romatschke and Houze (2010) uti- 
lizaram o limiar de 40 dBZ para definir três tipos mais extremos de convecção: núcleos convectivos profundos (ecos convectivos 3D contínuos $>40 \mathrm{dBZ}$ estendendo-se acima de $10 \mathrm{Km}$ de altura), núcleos convectivos amplos (ecos convectivos contínuos > $40 \mathrm{dBZ}$ sobre uma área horizontal superior a $1000 \mathrm{Km}^{2}$ ) e grandes regiões estratiformes (ecos estratiformes contínuos sobre uma área maior que $50000 \mathrm{Km}^{2}$ ). Quando se analisa a altura máxima do nível de 40 dBZ nas tempestades noturnas por ordem decrescente de severidade (Figura 3.10), observa-se que os sistemas mais severos possuem alturas maiores, sendo que esta propriedade explica cerca de $31 \%$ da variância da taxa de raios $\left(\mathrm{R}^{2}=0,3084\right)$. Dos 97 sistemas noturnos estudados aqui, 22 possuem altura do nível de $40 \mathrm{dBZ}$ superior a $10 \mathrm{~km}$, sendo que 10 estão entre os $25 \%$ mais extremos. O valor máximo de 15,5 $\mathrm{Km}$ de altura foi registrado dia 26/10/2012, $31^{\circ}$ tempestade no ranking de severidade, enquanto o mínimo de apenas 5,5 Km dia 21/12/2013, antepenúltimo da classificação, como pode ser visto na síntese da Tabela 3.3 .

Tabela 3.4 - Resumo das categorias de intensidade de tempestades comparáveis, baseadas em parâmetros do TRMM, citadas no texto onde $\operatorname{Taxa}_{R}$ representa a taxa de raios (raios/min), $T_{85}$ a $\mathrm{MINPCT} 85 \mathrm{GHz}$ (K), $T_{77}$ a MINPCT37GHz $(\mathrm{K})$ e $H_{40}$ a MAXHT40.

\begin{tabular}{c|c|c|c|c|c}
\hline & CATEGORIA & Taxa $_{R}$ & $T_{85}$ & $T_{37}$ & $H_{40}$ \\
\hline & Intensa-0 & $33,51-36,08$ & & & \\
& Intensa-1 & $38,02-43,17$ & & & \\
Tempestades & Intensa-2 & $43,82-45,11$ & & & \\
noturnas & Extrema-0 & $46,39-50,90$ & $99,97-66,95$ & $228,91-163,41$ & $6,75-15,50$ \\
& Extrema-1 & $52,19-61,86$ & & & \\
& Extrema-2 & $64,44-71,52$ & & & \\
& Extrema-3 & $72,17-115,99$ & & & \\
& Extrema-4 & $125,65-275,14$ & & & - \\
Cecil et al. & Cat-2 & $2,20-30,90$ & $160,00-106,00$ & $253,0-219,0$ & - \\
& Cat-3 & $30,90-122,00$ & $105,00-74,00$ & $219,0-177,0$ & - \\
& Cat-4 & $122,00-296,00$ & $74,00-57,00$ & $177,0-135,0$ & - \\
\hline Zipser et al. & $0,90 \%$ & $2,90-32,90$ & $159,70-105,70$ & $254,60-220,60$ & $6,75-10,25$ \\
& $0,09 \%$ & $32,90-126,70$ & $105,70-75,10$ & $220,60-178,00$ & $10,50-14,00$ \\
& $0,009 \%$ & $126,70-314,70$ & $75,10-59,30$ & $178,00-138,40$ & $14,25-16,50$ \\
\hline
\end{tabular}

As variáveis MINPCT85GHz e MINPCT37GHz representadas respectivamente por $T_{85}$ e $T_{37}$ na Tabela 3.2, representam as menores PCTs identificadas em cada sistema extremo nas frequências de 85 GHz e 37 GHz. Zipser et al. (2006) também utilizam estas variáveis 


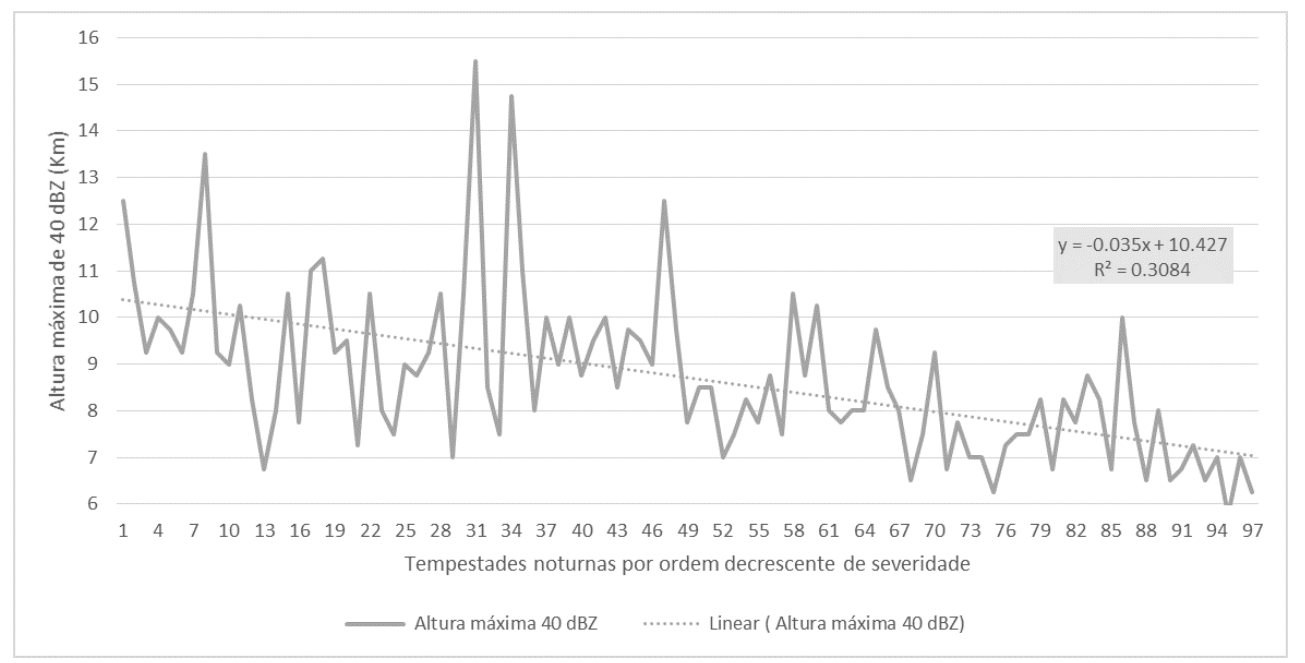

Figura 3.10: Altura máxima do nível de $40 \mathrm{dBZ}$ para as 97 tempestades noturnas (eixo y) em ordem decrescente de taxa de raios (eixo $\mathrm{x}$ ).

como indicadores de severidade: quanto mais baixos os valores de $\mathrm{Tb}$ alcançados nestas frequências, mais intensas as tempestades. Tempestades noturnas com maior número de raios tendem, ligeiramente, a ter PCTs mais baixas nas duas frequências, como pode ser visto na Figura 3.11, que mostra no eixo y os valores de MINPCT85GHz (linha sólida) e MINPCT37GHz (linha pontilhada) para as 97 tempestades noturnas por ordem decrescente de severidade (eixo x). Isso fica mais evidente ao para a MINPCT73GHZ das tempestades extremas (Figura 3.12). Os histogramas de MINPCT85GHz e MINPCT37GHz (Figura 3.9 e,f) mostram uma minoria de tempestades com valores mais baixos de temperatura mínima em ambas frequências, sendo a maior parte entre 80-100 K na frequência de 85 GHz e entre 200-230 K em $37 \mathrm{GHz}$. O menor valor de MINPCT85GHZ foi de 66,95 K durante a tempestade do dia 30/11/2012 ( $5^{\circ}$ caso mais severo), o que corresponderia às categorias mais extremas de Cecil et al. (2005) e de Zipser et al. (2006); enquanto o menor valor de MINPCT37GHZ de 163,41 K no evento noturno de 24/10/2007 (2 caso mais severo) estaria na segunda categoria mais extrema em ambos estudos. Diversos estudos como Zipser et al. (2006) e Mohr et al. (1996) apontam que as tempestades convectivas na Amazônia são mais fracas do que em outras áreas continentais tropicais, com características mais oceânicas, o que justifica o emprego do termo "green ocean" para Amazônia na literatura científica (Williams et al., 2002, Silva Dias et al., 2002). Isso ajuda a entender o fato de que nem todas as tempestades noturnas do conjunto têm valores marcantes de índices de severidade. 


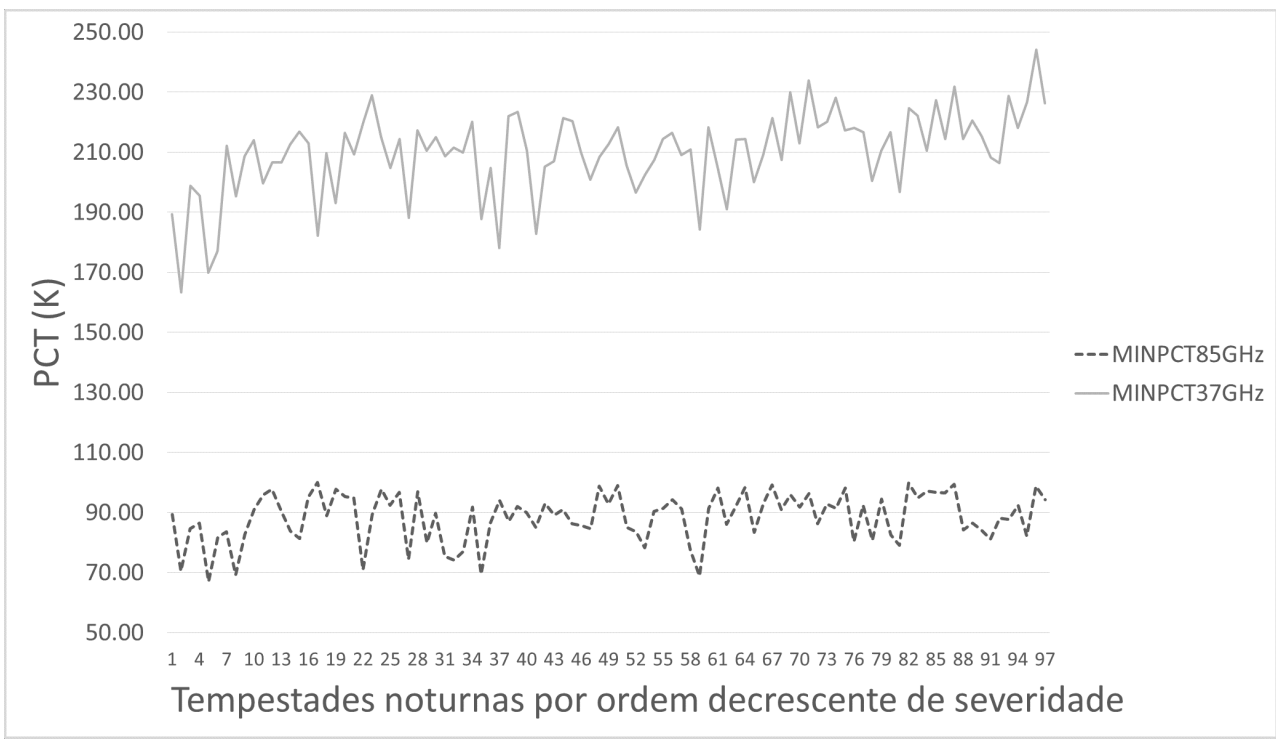

Figura 3.11: MINPCT85GHz (linha contínua) e MINPCT37GHz (linha tracejada) para as 97 tempestades noturnas (eixo y), em ordem decrescente de taxa de raios (eixo x).

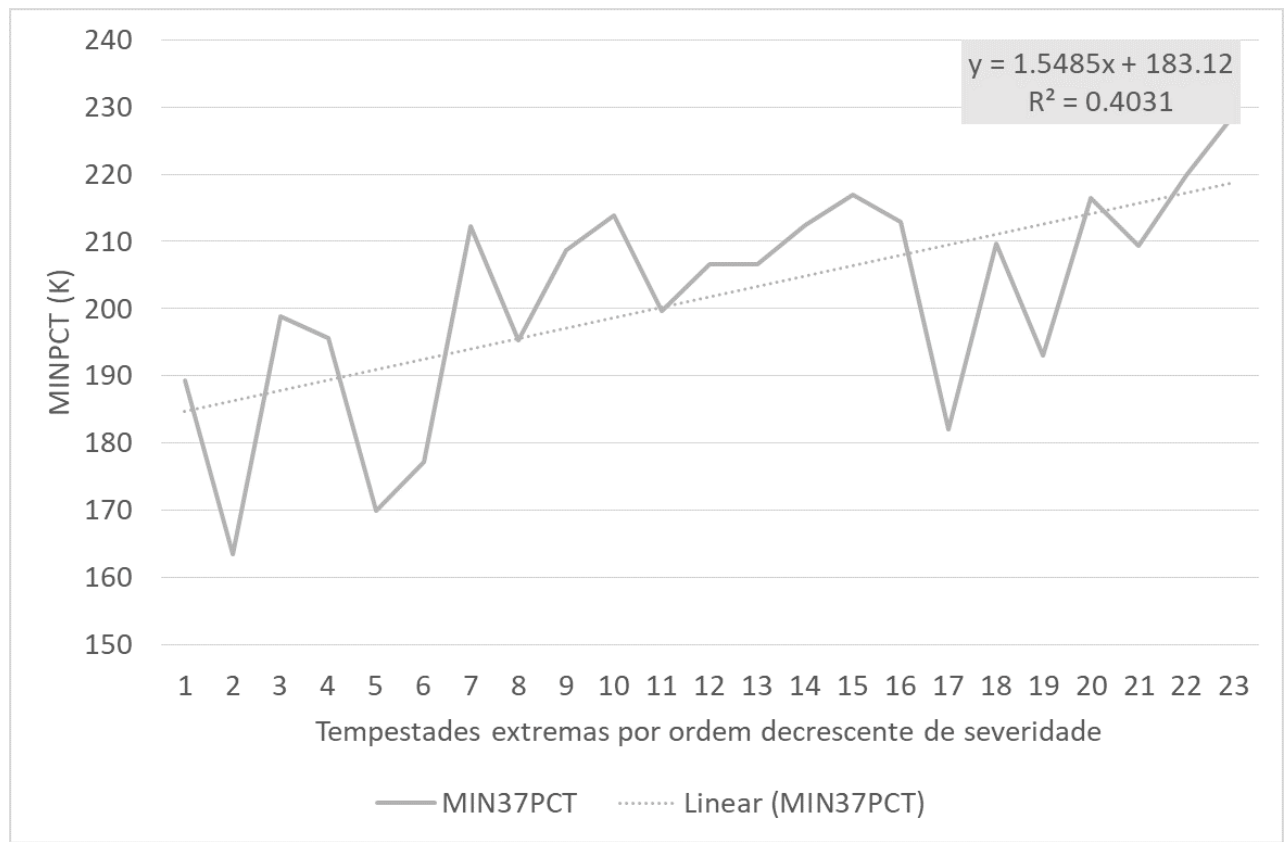

Figura 3.12: MINPCT37GHz para as 23 tempestades noturnas extremas (eixo y), em ordem decrescente de taxa de raios (eixo $\mathrm{x}$ ).

\subsubsection{Padrões sinóticos: jato de baixos níveis versus confluência}

Jatos de baixos níveis ocorrem em diversas regiões do globo associados a terrenos complexos como cadeias montanhosas, eles desempenham papel especialmente importante no transporte de umidade e na conveç̧ão profunda, como Stensrud (1996) elucida em sua 
revisão bibliográfica sobre o tema. Na presente análise identifica-se como recorrente nos campos sinóticos das tempestades noturnas um escoamento de NW em baixos níveis (850 hPa), sugerindo uma característica pré-frontal na formação das tempestades com atuação do jato de baixos níveis da América do Sul (JBNAS). De fato, como será melhor explorado no próximo tópico, sistemas frontais estiveram atuando principalmente nas regiões Sul e Sudeste do Brasil na maioria dos dias em que os eventos foram registrados, embora não necessariamente tenham afetado diretamente os sistemas aqui avaliados.

O JBNAS se desenvolve quando há uma intensificação no escoamento de $\mathrm{N}$ em baixos níveis ao longo da face oriental da cordilheira dos Andes, com máximas velocidades geralmente sobre a Bolívia e N do Paraguai (Marengo et al., 2004; Vera et al., 2006) às 0600 UTC. O transporte substancial de umidade entre as bacias amazônica e do Prata, no S da América do Sul, é conhecido por influenciar convecção profunda e precipitação na região subtropical (Marengo et al., 2002; Vera et al. 2006; Nascimento et al., 2016; Oliveira et al., 2018). Ao longo deste percurso, o levantamento orográfico do jato na cordilheira é um mecanismo clássico de disparo de tempestades, principalmente para aquelas situadas próximas a $16^{\circ} \mathrm{S}-65^{\circ} \mathrm{W}$ no final da orientação NW-SE dos Andes, onde a própria configuração da montanha atua como uma barreira natural do escoamento (Albrecht et al. 2016; Vera et al. 2006). Embora Salio, Nicolini e Zipser (2007) tenham verificado uma menor ocorrência de SCMs na região tropical quando o JBNAS está atuando, não quer dizer que eles não ocorram.

Surge, portanto, não somente o interesse como a necessidade de avaliar a presença do JBNAS nos eventos de tempestades noturnas, que pode ser definido segundo o critério de Bonner (1968) modificado (Saulo, Nicolini e Chou, 2000; Marengo et al., 2004), que leva em conta: 1) velocidade do vento, igual ou superior a $12 \mathrm{~m} / \mathrm{s}$ em $850 \mathrm{hPa}, 2$ ) cisalhamento vertical do vento horizontal de pelo menos $6 \mathrm{~m} / \mathrm{s}$ entre $700-850 \mathrm{hPa}$ e 3 ) a componente meridional do escoamento maior do que a componente zonal com ventos de $\mathrm{N}$ suficientemente intensos para anular o escoamento de S. Aqui considerou-se que o jato esteve atuando quando cumpriu, em uma mesma região, os critérios de velocidade, cisalhamento e orientação (N ou NW), às 0000 UTC ou 0600 UTC nos dias em que houve registro de tempestades noturnas.

Verificando o escoamento em $850 \mathrm{hPa}$ fica claro que a maioria das tempestades noturnas se desenvolve em escoamento de NW e/ou próximas a uma confluência de escoamentos 
NW-SE/S, sendo o primeiro padrão associado ao escoamento JBNAS e o segundo ao deslocamento de sistemas frontais. A partir daqui refere-se ao padrão onde há atuação do JBNAS como P1 e onde, não há, como P2. Na maioria dos casos de P2 observa-se a confluência NW-SE/S na metade sul do domínio de estudo, todavia, nele também estão contidos casos em que não há jato nem confluência. O padrão P1 contabiliza 55 eventos noturnos (dos quais 19 são intensos e 13 extremos) enquanto na maioria dos 42 casos com padrão P2 (20 intensos e 10 extremos) observa-se a confluência.

A Figura 3.13. a mostra a localização (símbolos pretos) das tempestades pertencentes ao padrão P1 em relação à topografia (escala de cores, em metros), enquanto a Figura 3.13.b àquelas pertencentes ao padrão P2. A posição é aquela registrada durante a observação do TRMM. Destaca-se que quando há JBNAS configurado as tempestades parecem ligeiramente mais confinadas no sopé da cordilheira dos Andes. Quando não há atuação de JBNAS a maioria das tempestades também está próxima aos Andes, porém, em comparação ao P1, há mais casos afastados da cordilheira, no E e SE do domínio. Estatísticas baseadas nas propriedades do conjunto PF indicam que as tempestades do padrão P2 (P1) ocorrem em média mais cedo (tarde) próximo a 0430 UTC (0515 UTC), em altitudes mais baixas (altas) em torno de $650 \mathrm{~m}(740 \mathrm{~m})$ e mais a SE (NW), em torno de $13,18^{\circ} \mathrm{S}-67,94^{\circ} \mathrm{W}$ $\left(13^{\circ} \mathrm{S}-68,4^{\circ} \mathrm{W}\right)$.

$[\mathrm{a}]$

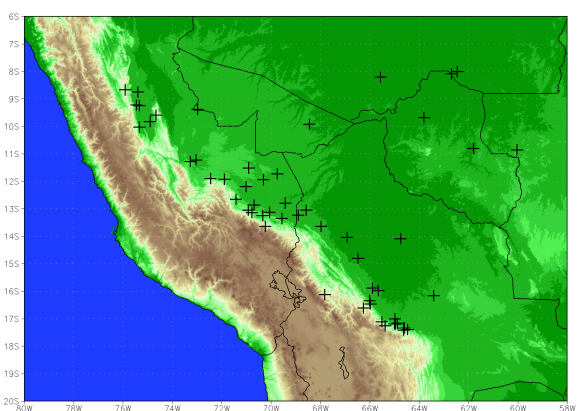

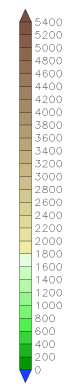

[b]
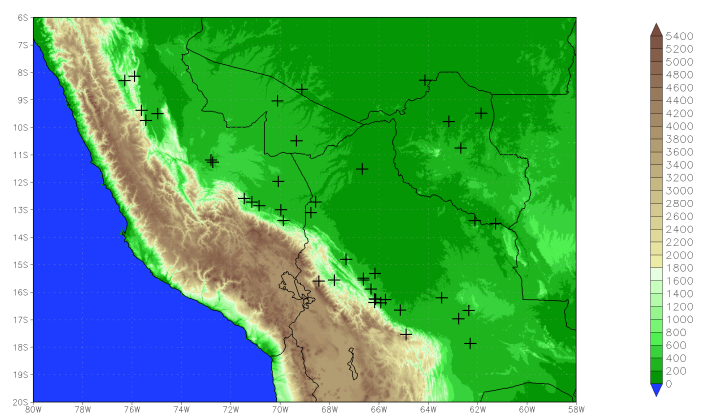

Figura 3.13: Topografia (escala de cores, em metros) e localização das tempestades a) com padrão de escoamento P1; b) com padrão P2. A localização é aquela dada durante a passagem do satélite TRMM.

Para enfatizar as características sinóticas dos dois padrões, foram feitas composições de grande escala dos campos de vento em $850 \mathrm{hPa}$ com os casos identificados dentro do padrão P1 e com os casos do padrão P2 (Figura 3.14 e Figura 3.15, respectivamente). Ambos painéis mostram horários considerados pré-convectivos (1200 UTC e 1800 UTC 
do dia anterior ao registro) e os primeiros horários do dia de registro (0000 UTC e 0600 UTC), onde a escala de cores representa magnitude média do vento em $\mathrm{m} / \mathrm{s}$ no nível de $850 \mathrm{hPa}$ e os contornos em laranja cisalhamento médio entre 700-850 hPa superior a 4 m/s. Importante destacar que valores médios aparecem suavizados, não sendo possível visualizar os mínimos correspondentes ao critério do JBNAS.

a) P1 - 12:00 UTC - dia-1

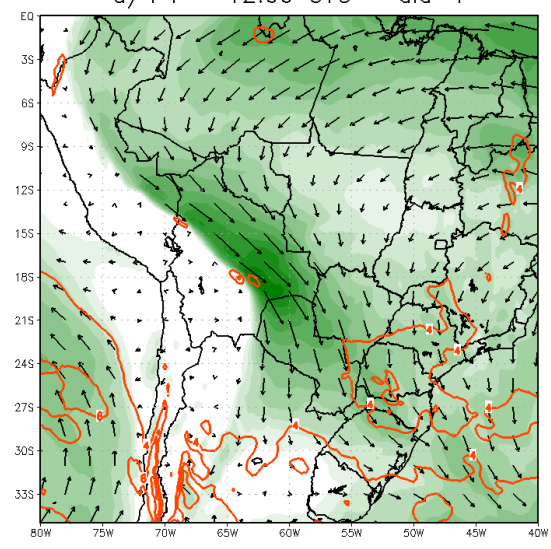

c) P1 - 00:00 UTC $\overrightarrow{-{ }^{12} \mathrm{dia}}$

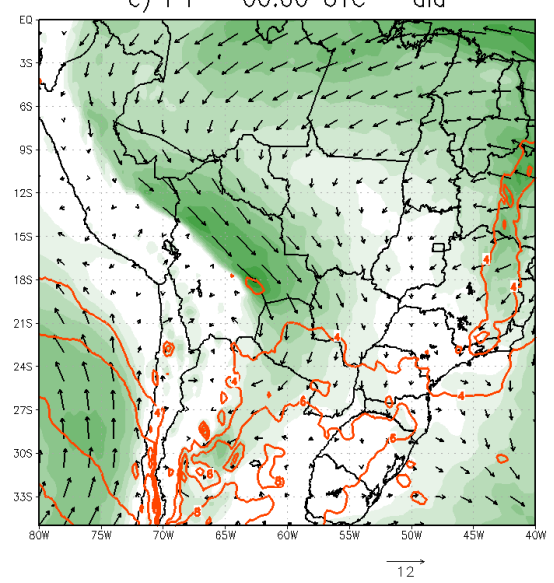

b) P1 - 18:00 UTC - dia-1

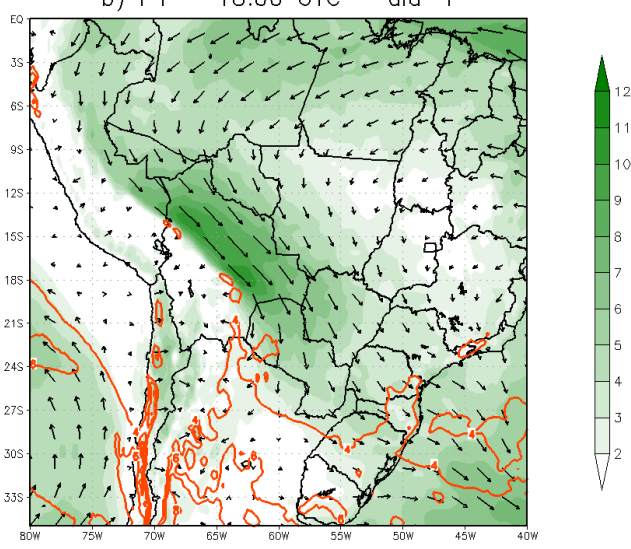

d) P1 - 06:00 UTC $\overrightarrow{-{ }^{12} \mathrm{dia}}$

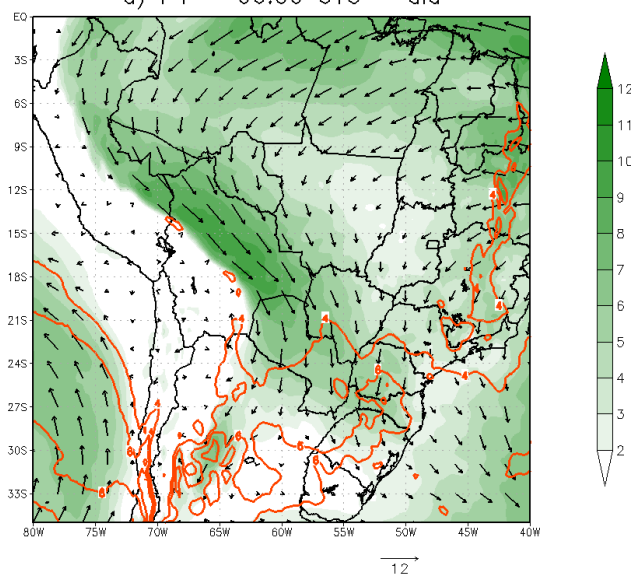

Figura 3.14: Composição do nível de 850 hPa para tempestades com padrão P1 de escoamento às a) 1200 UTC (dia anterior ao registro), b) 1800 UTC (dia anterior ao registro), c) 0000 UTC (dia de registro das tempestades), d) 0600 UTC (dia de registro das tempestades). Escala de cores indica magnitude média do vento $(\mathrm{m} / \mathrm{s})$, vetores indicam vento horizontal e contornos em laranja mostram onde o cisalhamento do vento entre 700-850 hPa é maior que $4 \mathrm{~m} / \mathrm{s}$.

Como pode ser observado nas composições dos horários pré-convectivos (painéis a e b das Fig. 3.14 e 3.15), ambos padrões já estão estabelecidos com pelo menos 12 horas de antecedência, reforçando a provável importância do nível de $850 \mathrm{hPa}$ na previsibilidade das tempestades noturnas no SW Amazônia. A magnitude média do JBNAS, inclusive, destaca-se às 1200 UTC do dia anterior, podendo ser esperada atuação deste evento, pelo 
menos, doze horas antes do registro de uma tempestade noturna. O padrão observado no período pré-convectivo de P1 também remete a um tipo de evento particular do JBNAS: o jato de baixos níveis do Chaco (Nicolini e Saulo, 2000; Saulo, Nicolini e Chou, 2000; Salio, Nicolini e Saulo, 2002; Nicolini e Saulo, 2006, entre outros), que é quando o JBNAS estende-se ao sul de $25^{\circ} \mathrm{S}$. A presente avaliação não distinguiu eventos de JBNAS de eventos de jato do Chaco, mas provavelmente eles também estiveram atuando em alguns casos. A confluência de ventos de NW-SE/S também é observada às 1200 UTC do dia anterior por volta de $18^{\circ} \mathrm{S}-64^{\circ} \mathrm{W}$. Neste horário a magnitude média do vento de NW é mais intensa que o escoamento de SE/S e nos horários seguintes diminui, conforme a confluência avança para a região o escoamento de SE se fortalece. O deslocamento da confluência também é suavizado pela composição.

a) P2 - 12:00 UTC - dia-1

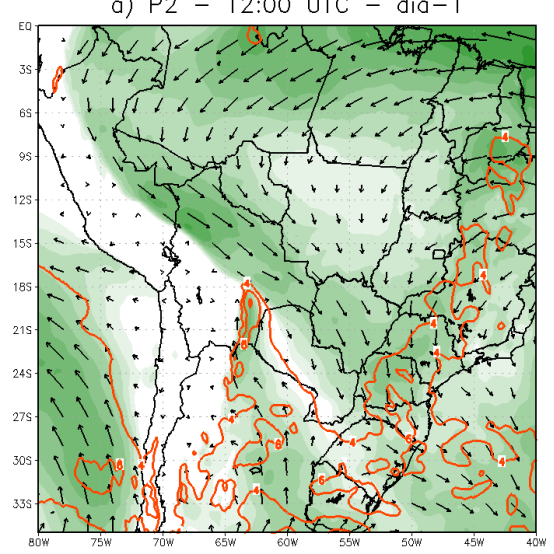

c) P2 - 00:00 UTC $\overrightarrow{-{ }^{12} \mathrm{dia}}$

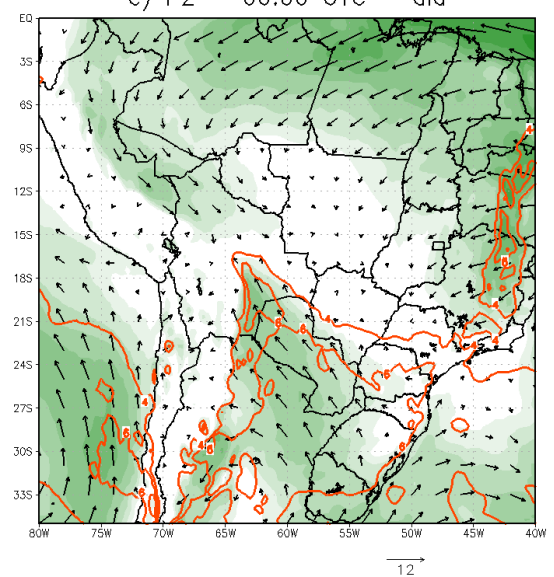

b) P2 - 18:00 UTC - dia-1

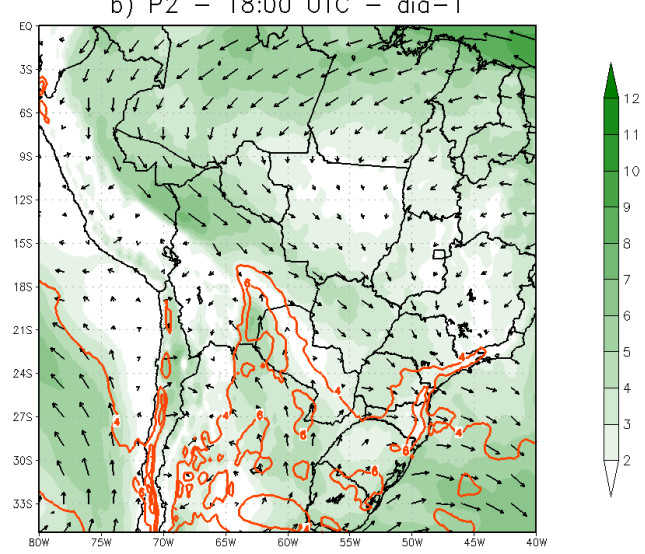

d) P2 - 06:00 UTC $\overrightarrow{-{ }^{12} \text { dia }}$

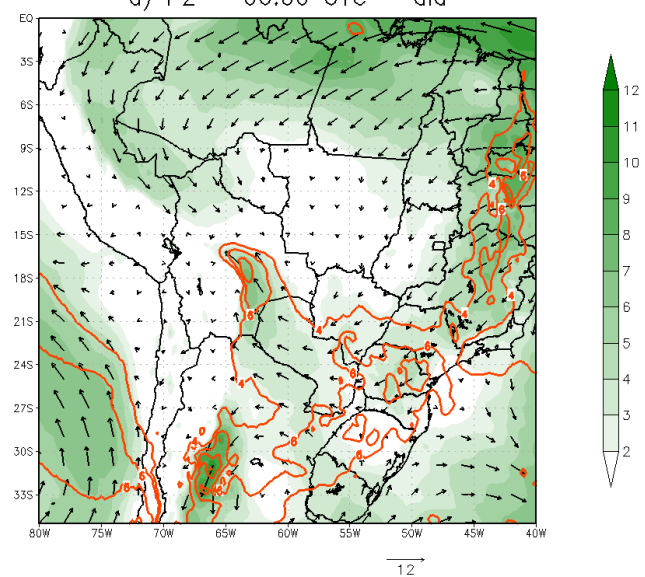

Figura 3.15: O mesmo que na Figura 3.14 para tempestades com padrão P2 de escoamento.

Outras diferenças destacam-se entre os padrões: 1) o vento de NW, presente em ambos, tem maior magnitude média em P1 do que em P2 e 2) o cisalhamento médio entre 700-850 
hPa alcança maiores magnitudes escoamento de SE, na região da confluência (P2), do que o cisalhamento na região de atuação do JBNAS (P1). Enquanto o escoamento de P1 se assemelha ao escoamento normal, mas intensificado, sendo relacionado ao JBNAS, o escoamento em P2 observado na composição da Figura 3.15 remete a um padrão característico de friagem (Longo et al., 2004), onde é possível notar no E do Estado do Rio Grande do Sul vestígio da circulação ciclônica associada à frente fria e, na sua retaguarda, uma circulação anticiclônica associada à alta pós-frontal. A componente de SE/S que avança em direção à Amazônia é resultado intersecção das bordas ocidental e oriental duas circulações, respectivamente. O termo friagem é definido tradicionalmente como uma onda de frio que alcança o sul da Amazônia derrubando as temperaturas (Marengo et al., 1997). Recentemente este termo foi flexibilizado para incluir avanço de massas de ar frio e queda diária brusca da temperatura máxima na região Centro-Oeste brasileira pelo estudo de Escobar et al. (2019). Os autores obtêm como primeiro padrão de circulação em superfície, a partir de análise de componentes principais, um anticiclone pós-frontal migratório movendo-se do Oceano Pacífico para o continente, com ventos de SE/S alcançando latitudes em torno de $15^{\circ} \mathrm{S}$, levando a frente fria e sua massa de ar associada a latitudes mais baixas. Ainda segundo Escobar et al. (2019) este padrão corrobora com àqueles encontrados nos estudos de incursões de ar frio na América do Sul (Girardi,1983; Garreaud, 2000), eventos de geada no Pampa Argentino (Müller et al., 2003), ondas de frio no estado de São Paulo (Escobar et al., 2004), friagem na Amazônia (Ricarte, 2012) e ondas frias no S do estado de Minas Gerais (Reboita et al., 2015). Embora o presente estudo não avalie friagem sob a perspectiva da temperatura do ar e sim pela configuração sinótica do escoamento do vento, há registro de friagem durante quatro eventos de tempestades noturnas de acordo com o Boletim Climanálise (CPTEC/INPE), que utiliza a definição clássica de mudança de tempo na região Norte, e diversos outros episódios de queda de temperatura nas regiões Sudeste e Centro-Oeste. As datas de ocorrência das tempestades noturnas nas quais houve registro de friagem foram 26/09/2005, 30/04/2008 (duas tempestades neste dia) e 09/08/2013.

Liu et al. (2020) pesquisaram globalmente por ambientes de grande escala favoráveis a tempestades com as mais altas taxas de raio, utilizando 16 anos de características convectivas (do inglês convective features - CF) do TRMM, um subconjunto do banco de dados PF. Arbitrariamente eles definiram o limiar de taxa de raios de 50 raios/min para identificar as tempestades mais intensas e avaliaram o ambiente de grande escala através da 
reanálise ERA-Interim $\left(0,75^{\circ}\right.$ x $0,75^{\circ}$ de resolução), realizando composições em caixas de $30^{\circ} \times 30^{\circ}$ centradas nas $\mathrm{CF}$ sobre regiões tropicais e subtropicais. Os campos analisados foram umidade específica (q), temperatura (T) e vento horizontal $\left(V_{H}\right)$ para a superfície (considerada como $1 \mathrm{Km}$ acima do solo para as CFs próximas a terrenos complexos, a fim de evitar ruídos dos campos de vento); umidade relativa (UR), T e $V_{H}$ para $850 \mathrm{hPa}$, $700 \mathrm{hPa}$ e $500 \mathrm{hPa}$; bem como CAPE, CIN e cisalhamento do vento. De acordo com os autores, as tempestades mais intensas geralmente têm CAPE grande (>1000 J/Kg), CIN pequeno-moderado, convergência de umidade vigorosa (associada com jatos de baixos níveis) e cisalhamento do vento maior do que tempestades com pequenas taxas de raio, mas as diferenças são pequenas em regiões tropicais.

Inspirado neste trabalho, aqui realizou-se composições adicionais dos campos de grande escala para padrões P1 e P2, a partir da reanalise ERA5. Ao invés de utilizar caixas centradas nas tempestades como Liu et al. (2020), avaliou-se o domínio entre $35^{\circ} \mathrm{S}-0^{\circ}$ e $80^{\circ} \mathrm{W}-40^{\circ} \mathrm{W}$, o mesmo onde os padrões foram identificados (Figura 3.14 e 3.15). Em alguns casos para melhor visualização o resultado é mostrado para a região SW Amazônia $\left(18^{\circ} \mathrm{S}\right.$ $\left.8^{\circ} \mathrm{S}, 80^{\circ} \mathrm{W}-60^{\circ} \mathrm{W}\right)$. As figuras a seguir mostram resultados das composições para P1 e P2, respectivamente, para os campos de q (escala de cores), T (contornos) e $V_{H}$ (vetores) em 950 hPa, aqui considerado como a representação da superfície (Figura 3.16/Figura 3.17), UR (escala de cores), T (contornos), $V_{H}$ (vetores), em 850 hPa (Figura 3.18/Figura 3.19), 700 hPa (Figura 3.20/Figura 3.21) e 500 hPa (Figura 3.22/Figura 3.23); CAPE (escala de cores) e CIN (contornos) - Figura 3.25/Figura 3.26), bem como cisalhamento de baixos níveis (escala de cores) e cisalhamento de níveis médios (contornos) - Figura 3.27/Figura 3.28 .

A composição do nível de 950 hPa para as tempestades do padrão P1 (Fig 3.16) mostra um vento de N-NW na região SW Amazônia trazendo umidade para esta região. Valores máximos de q (superiores a $16 \mathrm{~g} / \mathrm{Kg}$ ) encontram-se nesta região nos quatro horários analisados. A T aumenta cerca de 2 a $4^{\circ} \mathrm{C}$ entre 1200 UTC e 1800 UTC do dia anterior das tempestades, enquanto a umidade específica é mais generalizada no SW Amazônia às 0000 UTC (superior a $17 \mathrm{~g} / \mathrm{Kg}$, não mostrado). Em comparação à composição do padrão P2 neste mesmo nível (Fig. 3.17) o comportamento de q e T são semelhantes, destacando como diferença a menor magnitude do vento de N-NW no SW Amazônia e a confluência com o escoamento de S-SE, que já aparece ao S de $18^{\circ} \mathrm{S}$ às $1200 \mathrm{UTC}$ anterior. Este esco- 
amento avança até $15^{\circ} \mathrm{S}$ nos horários seguintes e tem maior intensidade que o escoamento de NW principalmente às 0000 UTC e 0600 UTC.

No nível de 850 hPa o vento é predominantemente de NW no padrão P1 (Fig. 3.18) no E da cordilheira dos Andes e a UR é máxima neste mesmo lugar em todos os horários. A T também aumenta cerca de $2^{\circ} \mathrm{C}$ entre 1200 UTC e 1800 UTC. Às 0600 UTC uma maior UR na região SW Amazônia deve ser efeito da própria convecção. Novamente ao comparar com a composição de P2 (Fig. 3.19) o comportamento de UR e T são similares, destacando-se que o vento permanece de NW e mais intenso em P1 em todos os horários, enquanto em P2 ele começa a desintensificar no SE da região SW Amazônia às 1800 UTC do dia anterior às tempestades, quando às 0000 UTC e 0600 UTC há confluência com o escoamento de SE por volta de $16^{\circ} \mathrm{S}$. Embora o vento de NW desintensifique conforme a confluência avança em direção à Amazônia, permanece mais intenso que o vento de SE, ao contrário do que ocorre em 950 hPa. O local da confluência é consistente com a posição média mais das tempestades do padrão P2, mais a sudeste da bacia como mencionado anteriormente.
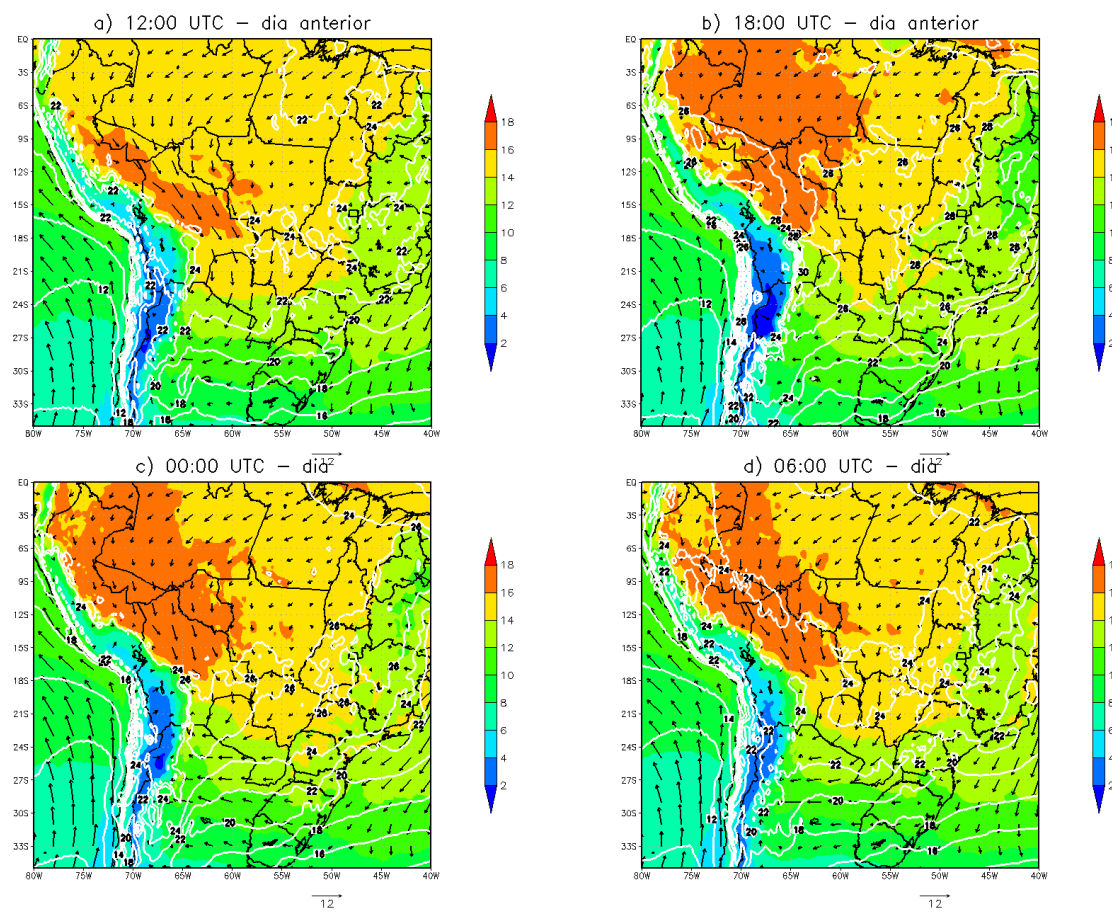

d) 06:00 UTC - di $\overrightarrow{\hat{a}^{2}}$

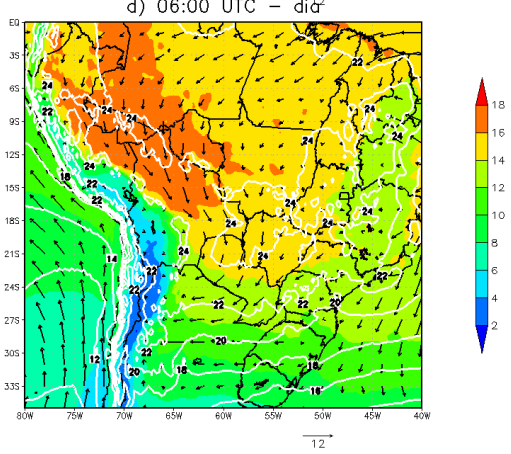

Figura 3.16: Composição do nível de $950 \mathrm{hPa}$ para tempestades com escoamento P1 (sem JBN) às a) 1200 UTC - dia anterior, b) 1800 UTC - dia anterior, c) 0000 UTC, dia de registro e d) 0600 UTC do dia de registro. Escala de cores indica umidade específica (g/Kg), contornos representam temperatura $\left({ }^{\circ} \mathrm{C}\right)$ e vetores mostram vento horizontal. 

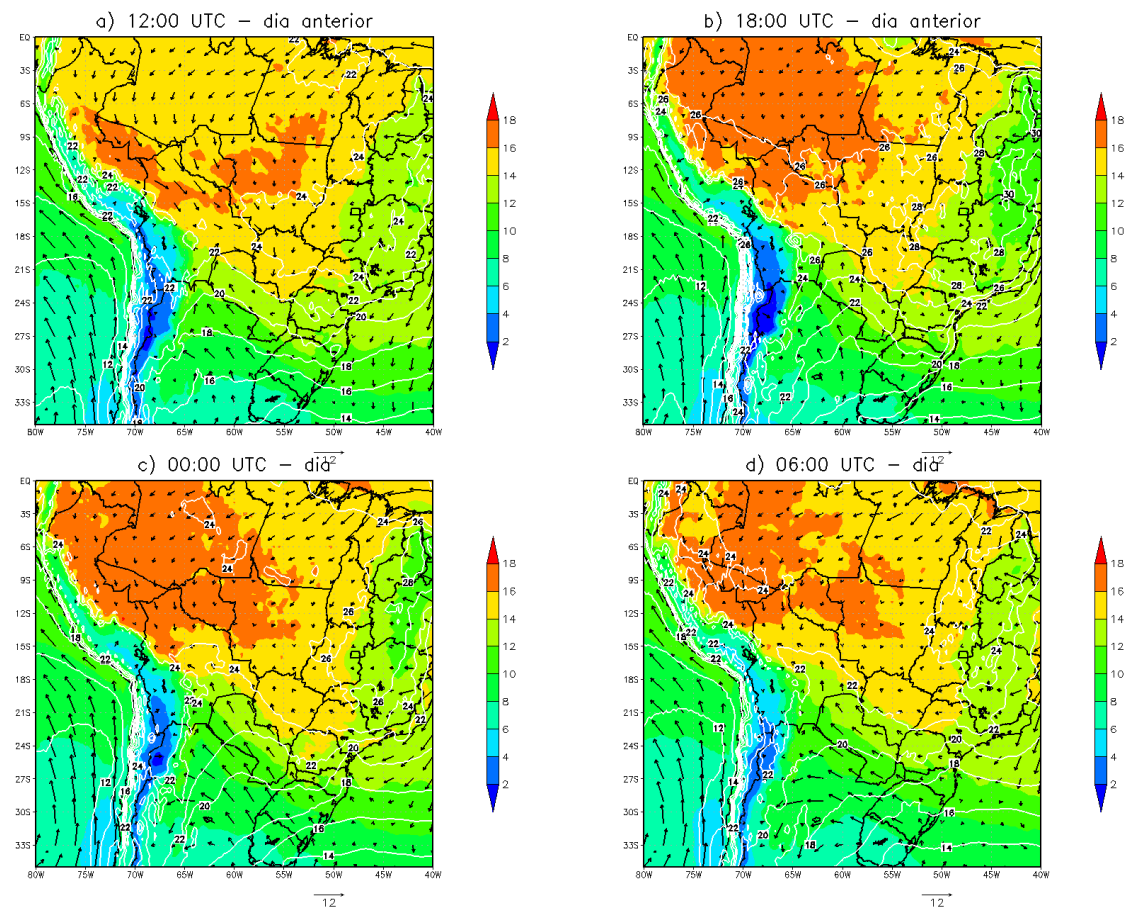

Figura 3.17: O mesmo que na Figura 3.16 mas para tempestades com escoamento P2.
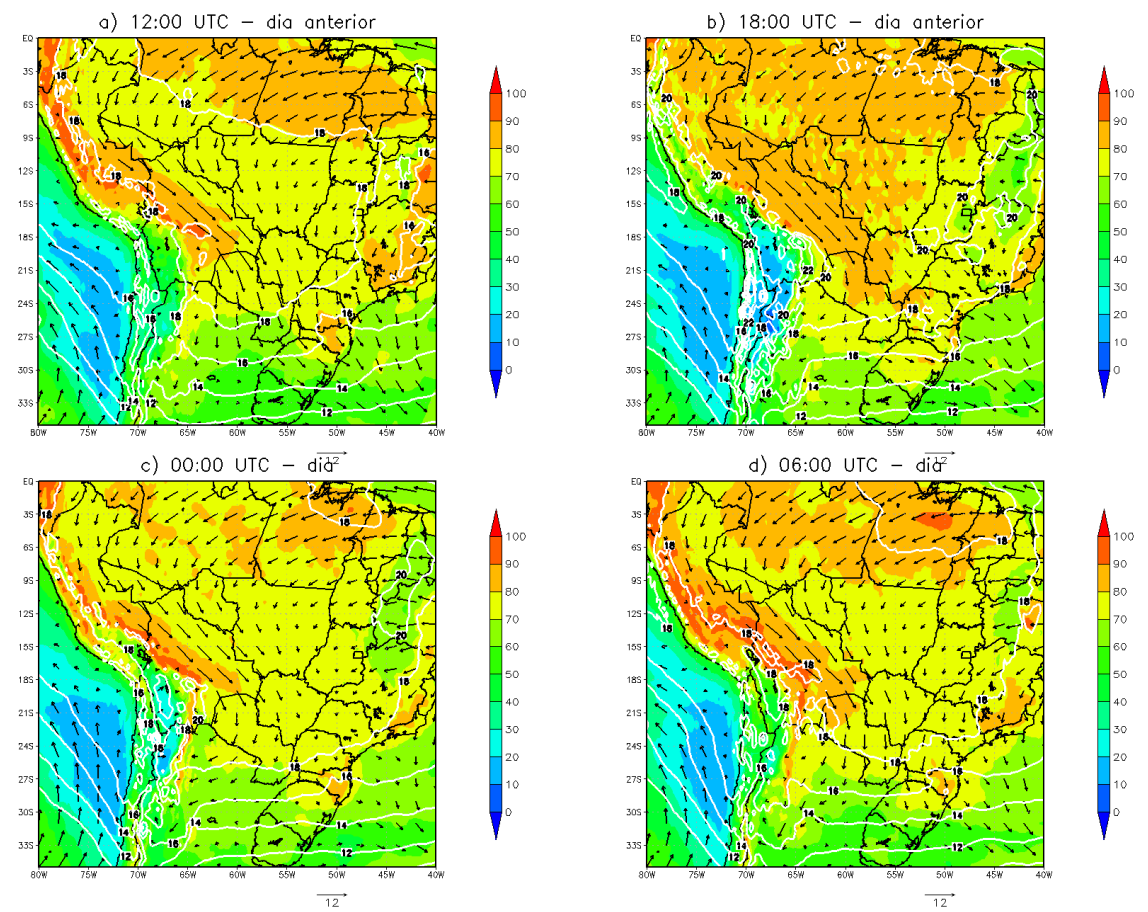

Figura 3.18: Composição do nível de $850 \mathrm{hPa}$ para o dia anterior às tempestades consideradas com escoamento padrão tipo P1 (com JBN) às a) 1200 UTC do dia anterior, b) 1800 UTC do dia anterior, c) 0000 UTC, dia de registro e d) 0600 UTC do dia de registro. Escala de cores indica umidade relativa (\%), contornos representam temperatura $\left({ }^{\circ} \mathrm{C}\right)$ e vetores mostram vento horizontal. 

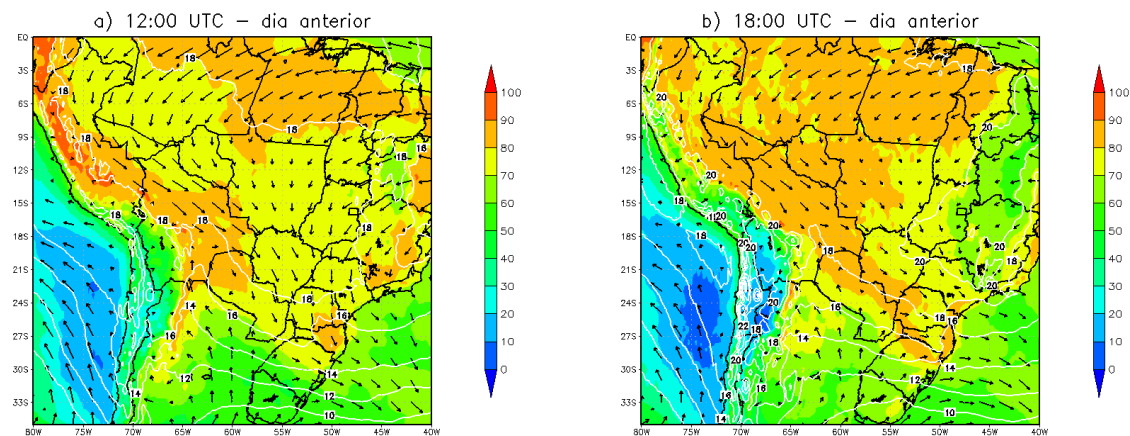

c) 00:00 UTC - di $\overrightarrow{\dot{a}^{2}}$

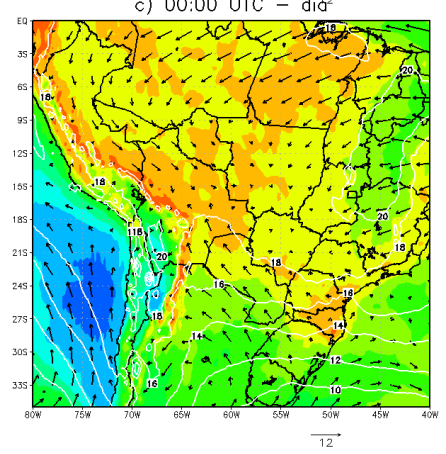

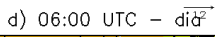

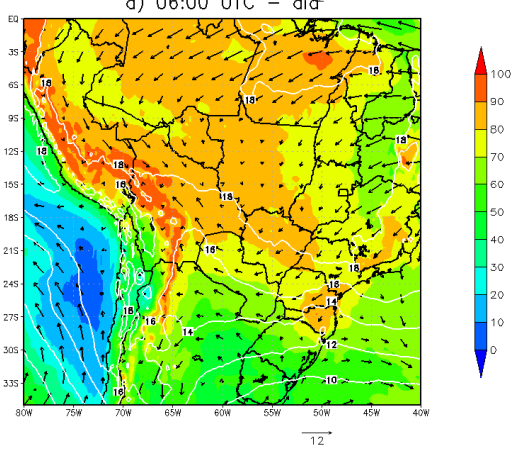

Figura 3.19: O mesmo que na Figura 3.18 mas para tempestades com escoamento P2.

As composições do ambiente pré-convectivo no nível de 700 hPa mostram campos de vento e UR similares entre P1 e P2 (Figura 3.20 e 3.21) do SW Amazônia, com escoamento de NW e UR acima de $60 \%$ no ambiente pré-convectivo. Às 0000 UTC o padrão P1 tem vento mais intenso e é relativamente mais seco em comparação à P2 (maior área com UR mais baixa). Escoamento de ar seco em 700 hPa sobreposto a escoamento úmido em 850 hPa, com direções diferentes, é uma configuração clássica encontrada em locais com tempo severo como, por exemplo, na Argentina e Centro-Sul dos EUA (Romatschke e Houze, 2010, Rasmussen e Houze, 2016, Liu et al. 2020, entre outros). Aqui não se observa mais o vento de SE em P2, permitindo concluir que a confluência é rasa, o que é consistente com uma alta fria pós-frontal.

Romatschke e Houze (2010) analisam convecção extrema no verão na América do Sul e em uma sub-região denominada sopé norte dos Andes centrais, bastante coincidente com o domínio do presente estudo. Em sua climatologia os padrões de vento de ar superior mostram que o anticiclone em $200 \mathrm{hPa}$ centrado ao longo do leste dos Andes centrais (a Alta da Bolívia), tem reflexo em $500 \mathrm{hPa}$, onde é possível observar um anticiclone centrado na cordilheira, a W do centro da Alta da Bolívia (Figura 3.24 a, b, respectivamente). Neste nível e próximo da borda oriental da Alta da Bolívia há um transporte de ar de S 
para N com baixo teor de umidade, como uma configuração típica de verão, que também é capturada em $500 \mathrm{hPa}$ para as tempestades noturnas, como pode ser visto nas Figuras 3.22 e 3.23 . Apesar de enfraquecida, provavelmente porque o estudo não considera apenas meses de verão, o escoamento pode ser considerado mais seco quando comparado às suas vizinhanças às 1200 UTC e, principalmente, às 0000 UTC. Já Escobar et al. (2019) discutem um padrão importante de ar superior que favorece o direcionamento dos sistemas migratórios de superfície para latitudes mais baixas: uma crista com orientação N-S entre o oceano Pacífico e a costa do Chile e um cavado no oceano Atlântico. Aqui são observados sinais bastante modestos desta configuração na composição de $\mathrm{P} 2$, um pouco mais pronunciados às 0000 UTC e 0600 UTC (Fig. $3.23 \mathrm{c}, \mathrm{d})$. Estes sinais ficam mais aparentes nos campos de anomalias, no próximo tópico.

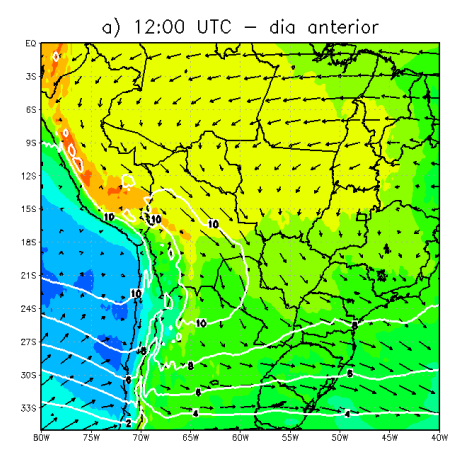

c) 00:00 UTC - di $\overline{\mathrm{ia}^{2}}$

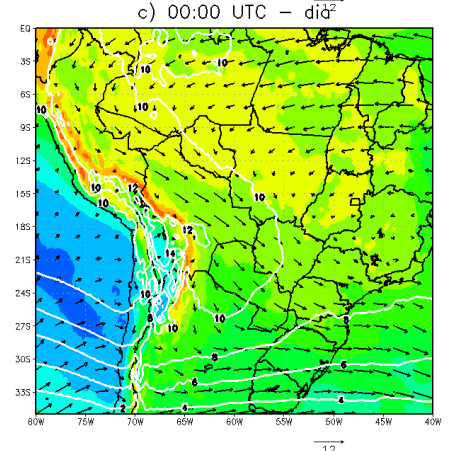

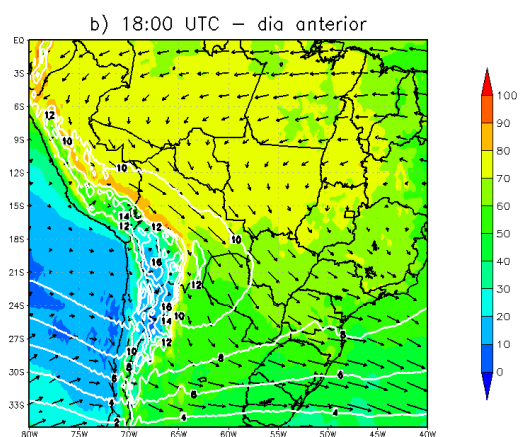

d) 06:00 UTC - di $\overline{i^{2}}$

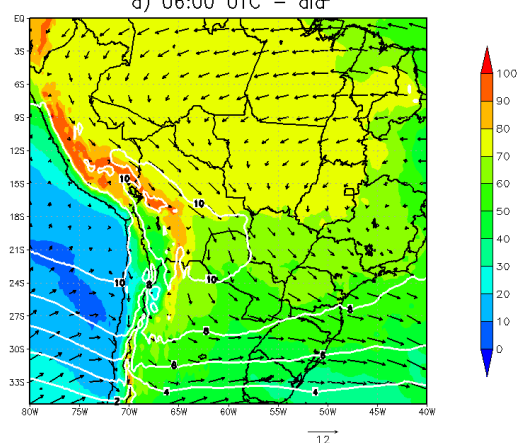

Figura 3.20: Composição do nível de $700 \mathrm{hPa}$ para o dia anterior às tempestades consideradas com escoamento padrão tipo P1 (com JBN) às a) 1200 UTC do dia anterior, b) 1800 UTC do dia anterior, c) 0000 UTC, dia de registro e d) 0600 UTC do dia de registro. Escala de cores indica umidade relativa $(\%)$, contornos representam temperatura $\left({ }^{\circ} \mathrm{C}\right)$ e vetores mostram vento horizontal. 

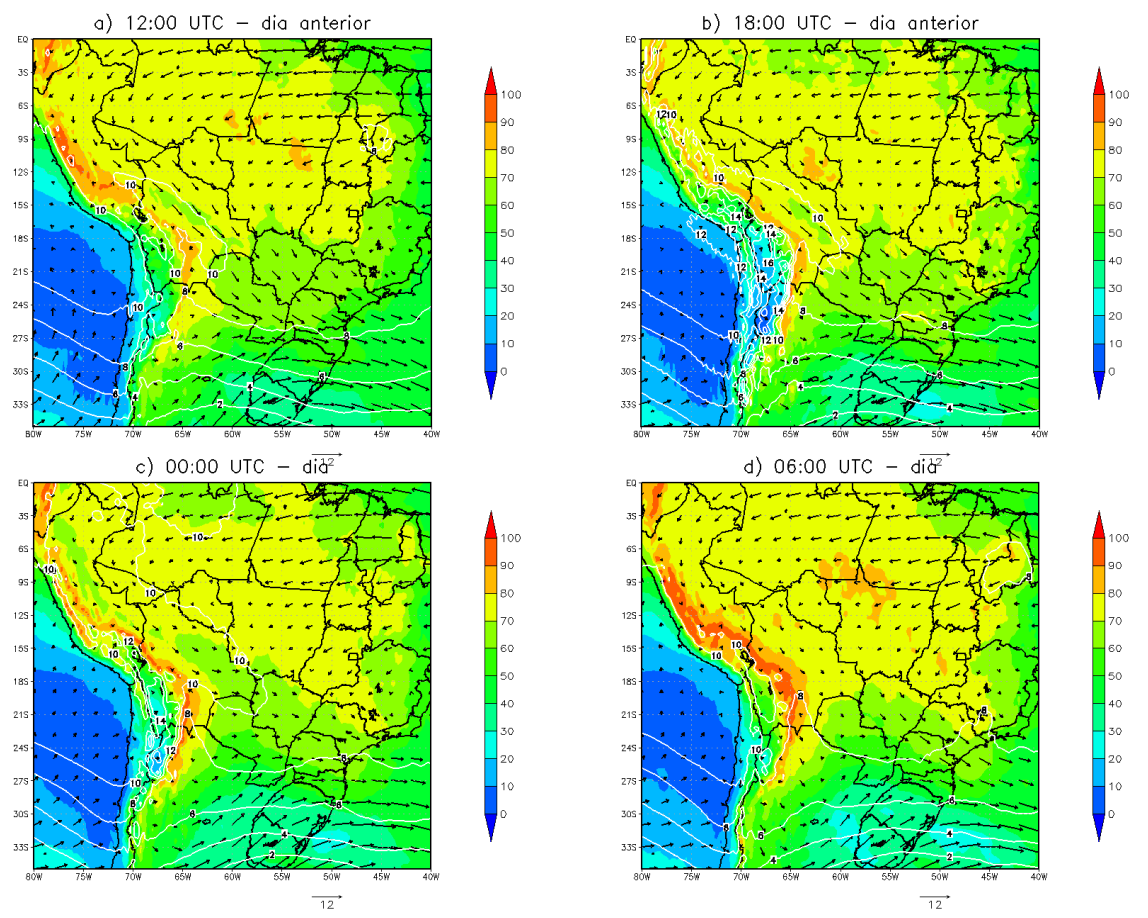

Figura 3.21: O mesmo que na Figura 3.20 mas para tempestades com escoamento P2.
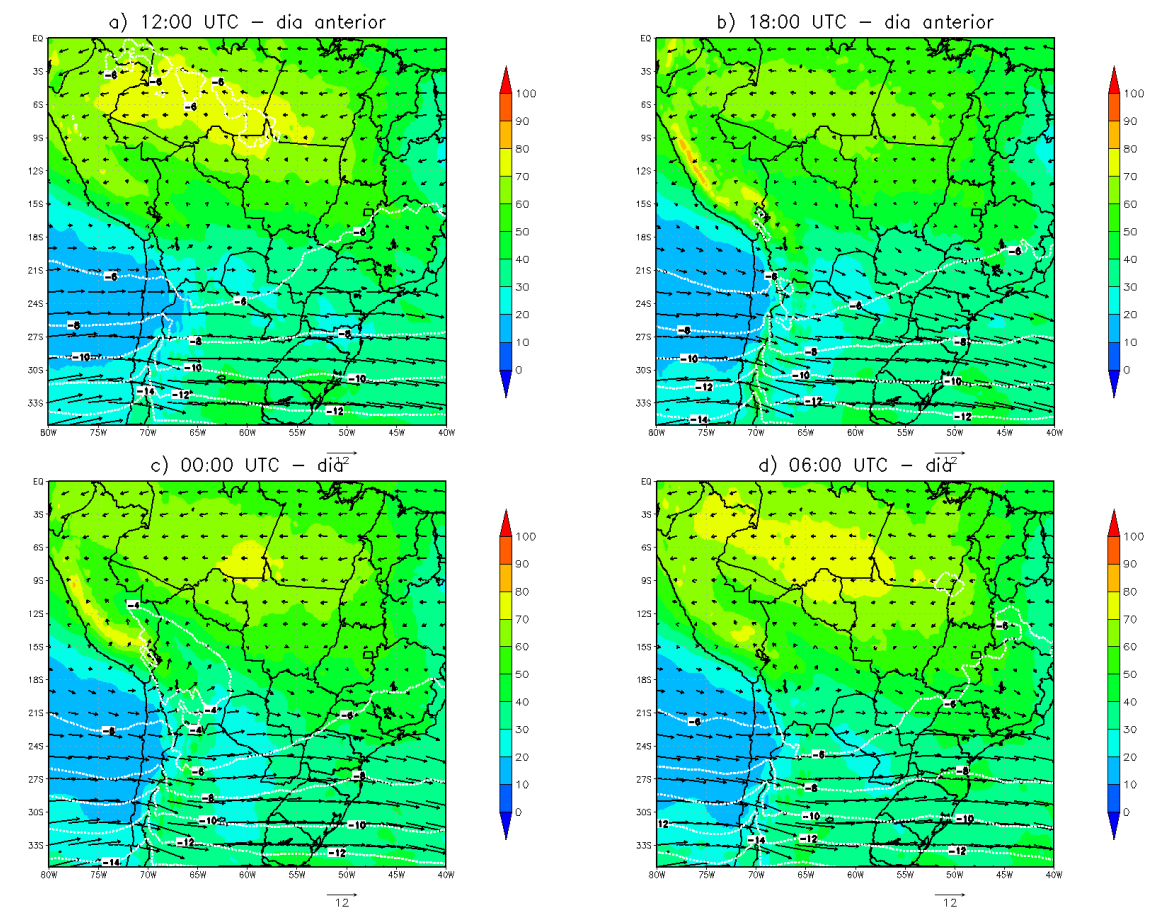

Figura 3.22: Composição do nível de $500 \mathrm{hPa}$ para o dia anterior às tempestades consideradas com escoamento padrão tipo P1 (com JBN) às a) 1200 UTC do dia anterior, b) 1800 UTC do dia anterior, c) 0000 UTC, dia de registro e d) 0600 UTC do dia de registro. Escala de cores indica umidade relativa $(\%)$, contornos representam temperatura $\left({ }^{\circ} \mathrm{C}\right)$ e vetores mostram vento horizontal. 

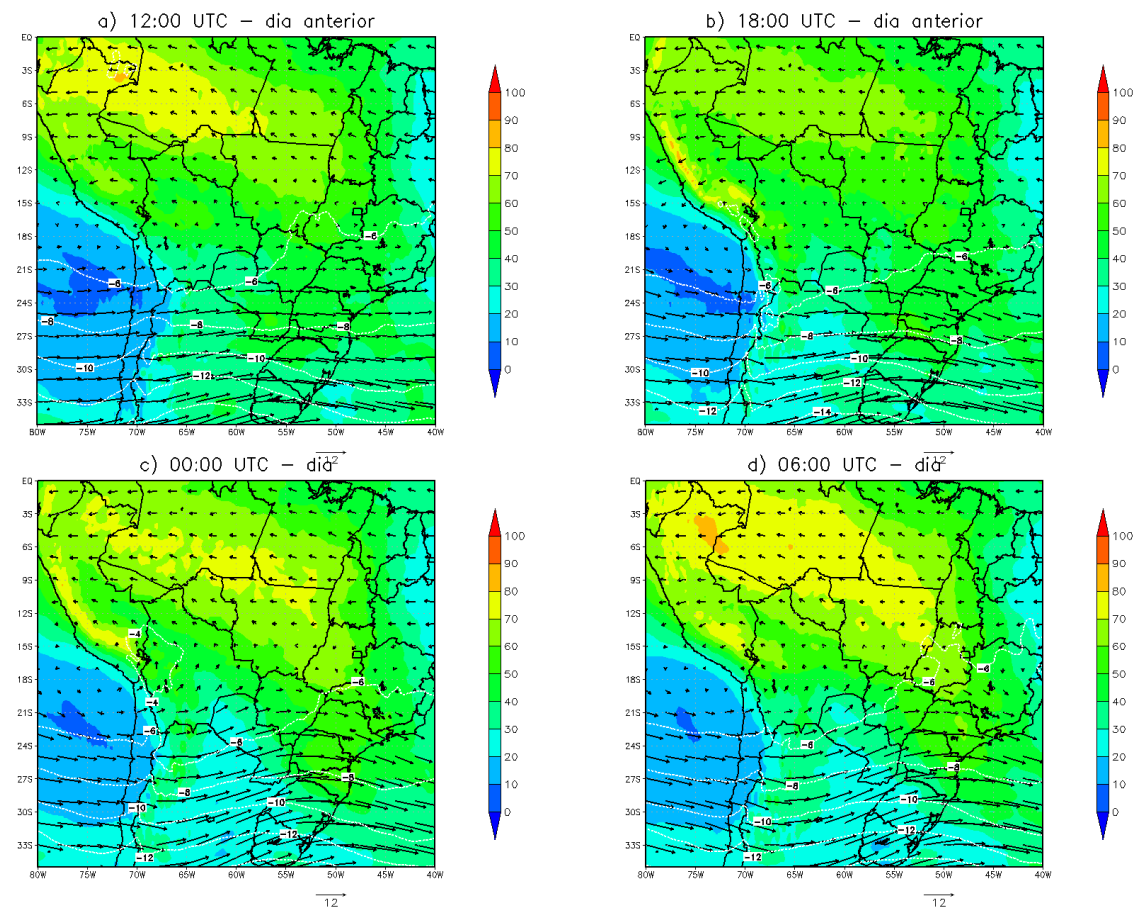

Figura 3.23: O mesmo que na Figura 3.35 mas para tempestades com escoamento P2.
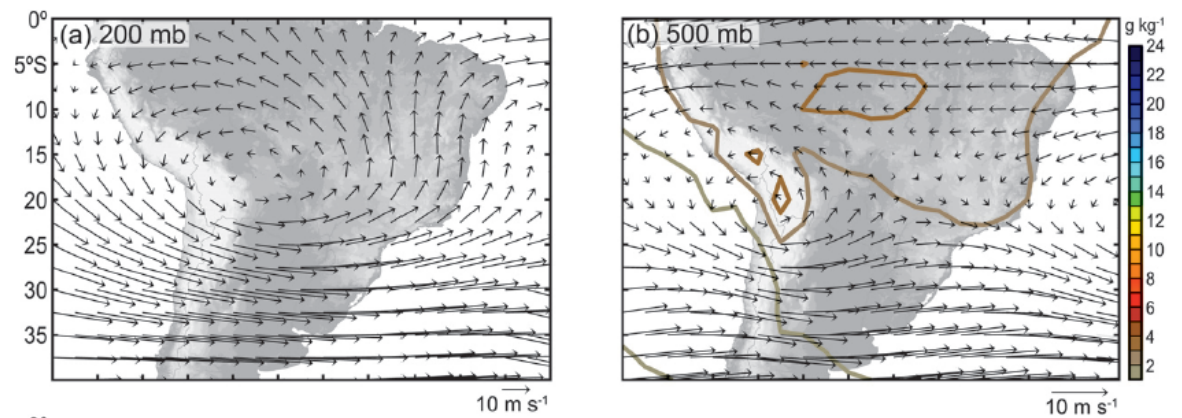

Figura 3.24: Climatologia de umidade específica $(\mathrm{g} / \mathrm{Kg})$ e vento $(\mathrm{m} / \mathrm{s})$ para dezembrojaneiro-fevereiro na América do Sul em a) 200 hPa, b) 500 hPa. Fonte: Romatschke e Houze (2010).

Variáveis como CAPE e CIN tem sido centro de diversas discussões na comunidade científica pois são medidas que incorporam diversas suposições (Stolz et al., 2015) que, por sua vez, influenciam o resultado final dos cálculos. Devido a diferentes resultados encontrados por diferentes métodos de cálculo, aqui utilizou-se os campos fornecidos pela própria reanálise ERA5 para avaliar CAPE e CIN, sempre reconhecendo que são apenas estimativas acerca do potencial da convecção profunda. A ERA5 fornece o CAPE da camada mais instável, calculado considerando parcelas de ar em ascensão partindo de 
diversos níveis do modelo, abaixo de $350 \mathrm{hPa}$ (Hersbach et al., 2018,b), assumindo que a parcela de ar não se mistura com o ar ambiente e que a ascensão é pseudo-adiabática (onde toda a água condensada precipita).

A ascensão do ar nas camadas inferiores da atmosfera é a essência do processo de convectivo severo (Johnson e Mapes, 2001), então medidas de flutuabilidade como CAPE são importantes para o processo de rompimento da inibição convectiva (CIN). Este último pode ter um papel de dualidade: ora inibindo a convecção quando apresenta valores muito altos, ora auxiliando a convecção intensa, de forma que sua barreira permite a atmosfera local acumular calor até que um gatilho leve a um rompimento explosivo da inibição. As composições de CAPE e CIN para os padrões P1 e P2 são mostradas nas Figuras 3.25 e 3.26, respectivamente. Ambos apresentam comportamento: um aumento em torno de 1000 J/Kg no ambiente pré-convectivo, entre 1200 e 1800 UTC, onde valores médios máximos são alcançados, de $\sim 3000 \mathrm{~J} / \mathrm{Kg}$ em localizações pontuais e similares entre os dois padrões. CIN médio, embora com valores altos entre 100-250 J/Kg, parece diminuir entre 1200 e 1800 UTC, permitindo que a energia potencial quebre a barreira de inibição convectiva para o disparo dos sistemas, quando novamente aumenta às 0000 UTC. A magnitude de CAPE neste trabalho está de acordo com aquelas encontradas para regiões tropicais em Liu et al. (2020), onde valores médios variam de $1161 \mathrm{~J} / \mathrm{Kg}$ nas tempestades menos intensas no NW do México a $2611 \mathrm{~J} / \mathrm{Kg}$ para tempestades mais intensas na Colômbia, enquanto CIN parece superestimado pela reanalise ERA5.

Ao comparar cisalhamento vertical do vento horizontal em baixos (700 - $1000 \mathrm{hPa}$, escala de cores) e médios níveis $(400$ - 1000 hPa, contornos) nos padrões P1 e P2 (Figura 3.25 e 3.28, respectivamente) mais uma vez as magnitudes médias são similares, porém, em P1 há área mais generalizada com valores mais altos. Valores médios de cisalhamento em ambos os padrões são coerentes por aqueles encontrados por Liu et al. (2020) nas regiões tropicais $(5,1 \mathrm{~m} / \mathrm{s}$ para tempestades menos intensas e $11,7 \mathrm{~m} / \mathrm{s}$ para mais intensas), e mais baixos do que nas regiões subtropicais (13-17 m/s para Argentina e Centro-Sul dos EUA). É importante ressaltar que, além destes valores serem suavizados pela média, a convecção severa tropical é diferente da subtropical (Romatschke e Houze, 2010, Houze et al. 2015, Liu et al. (2020), dentre vários outros autores). Como propriamente Liu et al. (2020) concluem, tanto convecção intensa quanto fraca pode ocorrer em ambientes semelhantes nas regiões tropicais. 

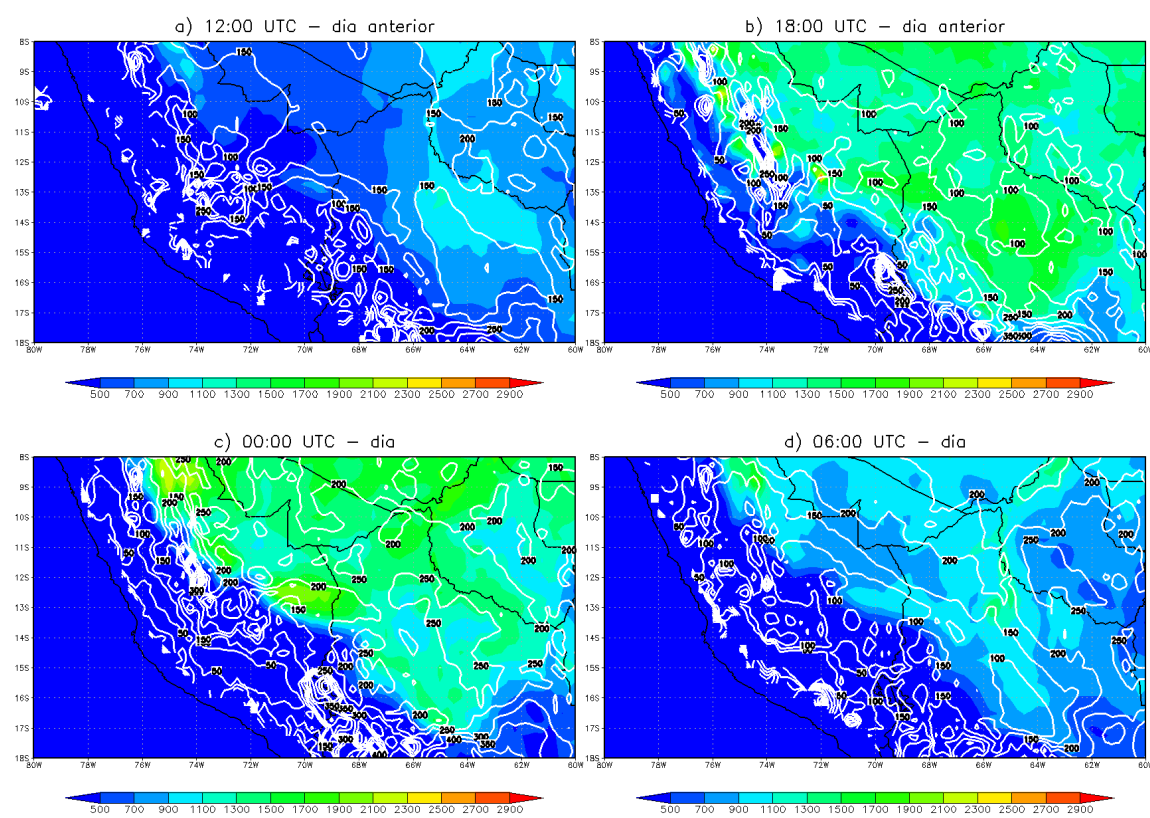

Figura 3.25: Composição de CAPE (escala de cores, J/Kg) e CIN (contornos, J/Kg) região SW Amazônia para tempestades com escoamento tipo P1 às a) 1200 UTC do dia anterior, b) 1800 UTC do dia anterior, c) 0000 UTC, dia de registro e d) 0600 UTC do dia de registro.
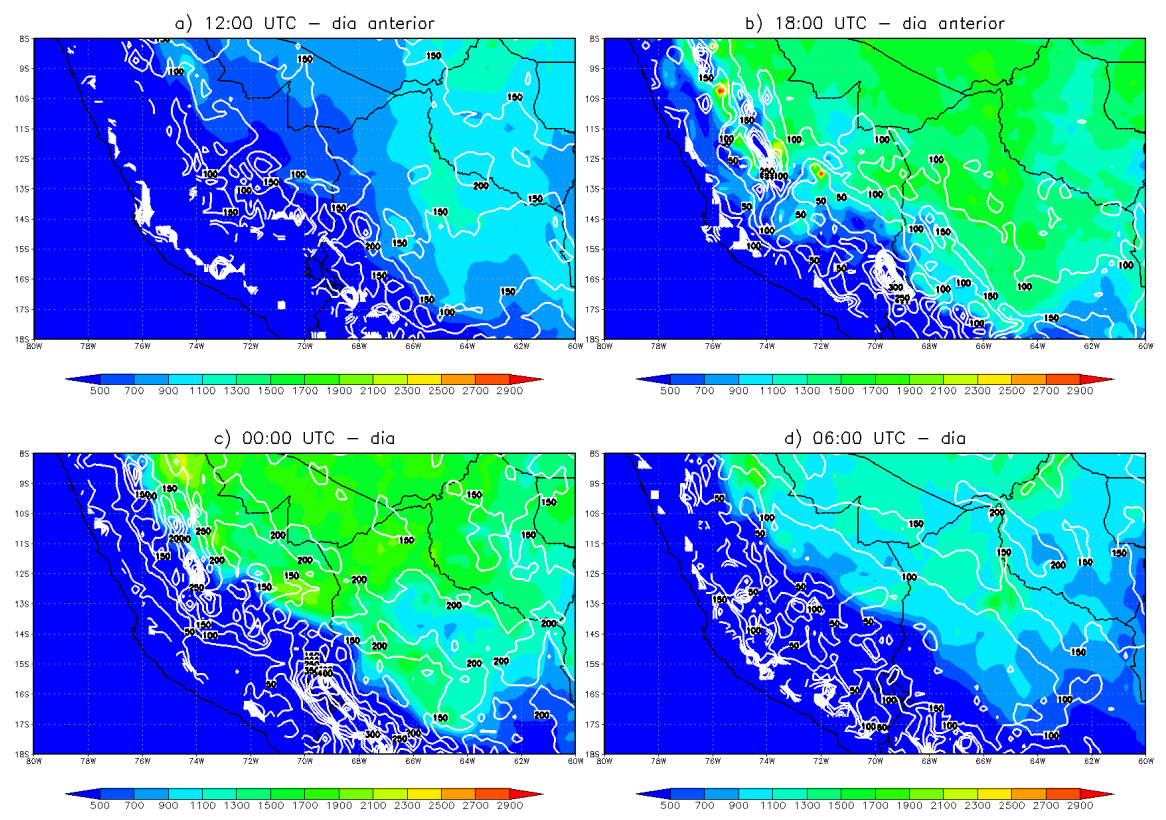

Figura 3.26: O mesmo que na Figura 3.25. mas para tempestades com escoamento P2. 

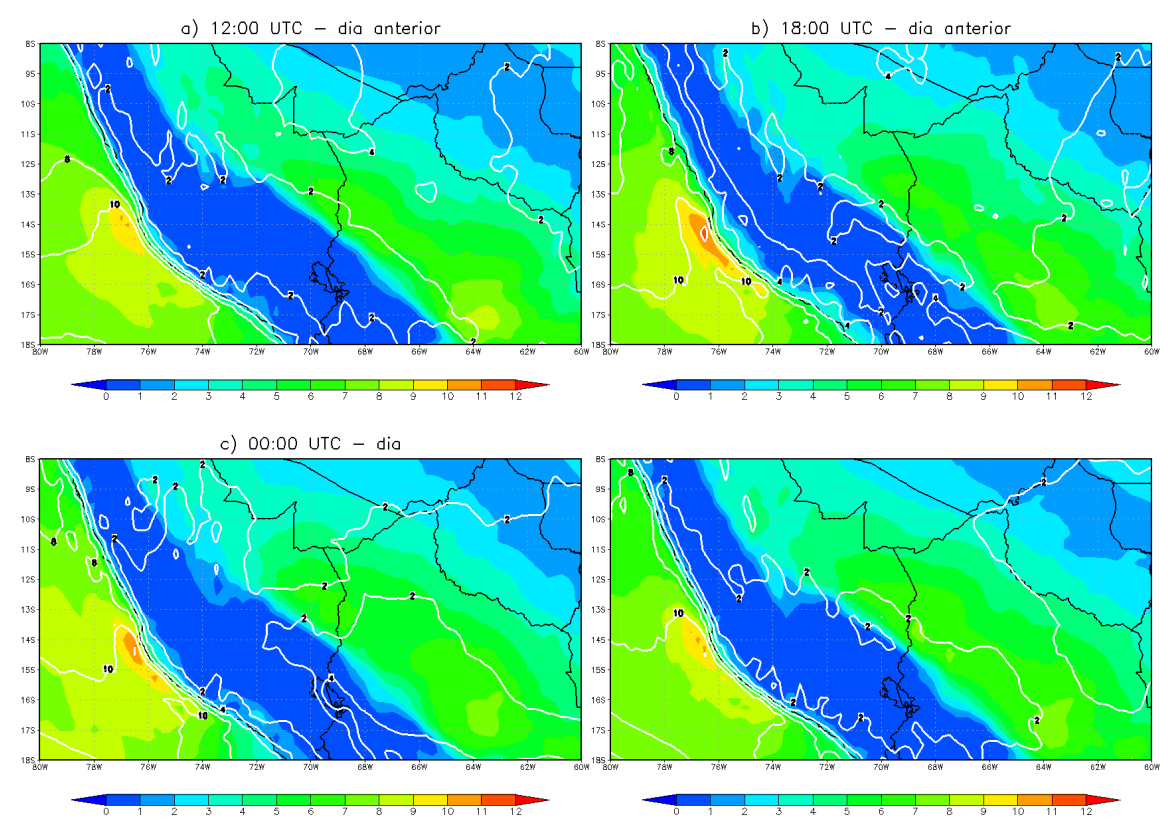

Figura 3.27: Composição do cisalhamento vertical do vento horizontal em baixos níveis (escala de cores, $\mathrm{m} / \mathrm{s}$ ) e em médios níveis (contornos, $\mathrm{m} / \mathrm{s}$ ) para tempestades com escoamento tipo P1.
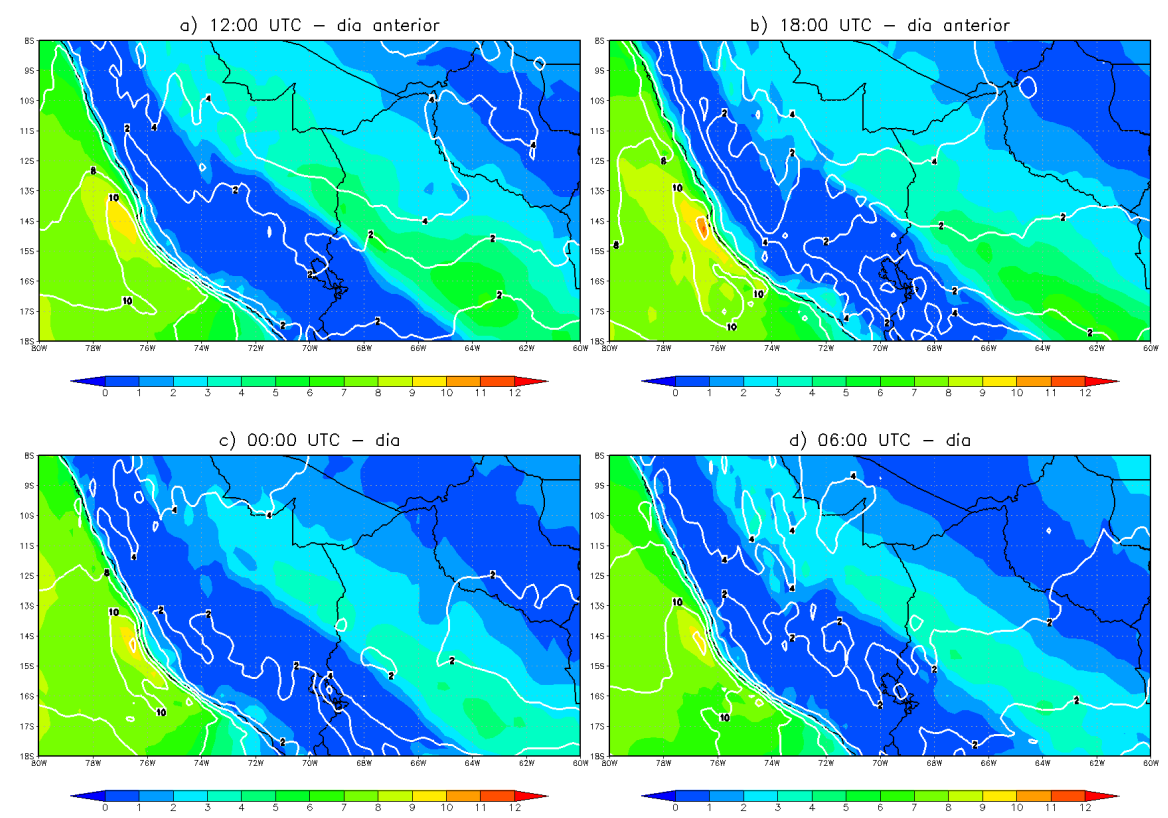

Figura 3.28: O mesmo que na Figura 3.27 mas para tempestades com escoamento P2.

Sintetiza-se que o ambiente de grande escala favorável às tempestades noturnas na região SW Amazônia destaca as seguintes combinações: 
- Atuação do JBNAS; entre 1200 e 1800 UTC (ambiente pré-convectivo) T aumenta até $4^{\circ} \mathrm{C}$ em $950 \mathrm{hPa}$, a umidade específica é alta e abundante em toda a região, CAPE também é alto e salta $\sim 1000 \mathrm{~J} / \mathrm{Kg}$ enquanto CIN reduz cerca de $\sim 50 \mathrm{~J} / \mathrm{Kg}$; escoamento persistente de NW se estende até 700 hPa; a circulação anticiclônica em $500 \mathrm{hPa}$ levando escoamento de ar relativamente seco de $\mathrm{S}$ para $\mathrm{N}$ especialmente às 0000 UTC;

- Confluência NW-SE/S em baixos níveis associada com passagem de sistema frontal, desde às 1200 UTC em $950 \mathrm{hPa}$ (onde o vento de SE é mais intenso que aquele de NW) e a partir de 1800 UTC em 850 hPa (vento de NW mais intenso que o de SE); o avanço da confluência em direção ao SW Amazônia é favorecido por configuração de crista próximo à costa do Chile e cavado no Sul do Brasil em 500 hPa; aumento de T, CAPE e redução de CIN tem mesma magnitude daquelas em P1.

\subsubsection{Anomalias nos padrões de escoamento}

Buscando quantificar o quão anômalos os padrões P1 e P2 são em relação ao escoamento normal, calculam-se as normais climatológicas anuais considerando o período de 1981-2010 para então determinar as anomalias utilizando as composições do item anterior. A seguir são discutidas as anomalias, e os campos normais são mostrados no Apêndice A2.

No campo de 950 hPa ambos padrões são anômalos, uma vez que neste nível os ventos na região amazônica são normalmente mais fracos. Em P1, portanto, o escoamento de NW é anomalamente mais intenso especialmente na região de estudo, juntamente com uma anomalia positiva de $\mathrm{T}$ entre 1 e $2^{\circ} \mathrm{C}$ no período pré-convectivo e de até $3 \mathrm{~g} / \mathrm{Kg}$ de q (Figura 3.29). O padrão dos ventos em P2 (Figura 3.30) também mostra escoamento de NW intensificado na região amazônica e pronunciada anomalia S-SE que reverte o sentido normal do vento e conduz à confluência observada anteriormente. Escoamento de NW é relativamente mais úmido e de SE mais seco. Às 1200 UTC (Fig 3.30,a) a anomalia de S é observada ao sul de $18^{\circ} \mathrm{S}$ e a partir das 1800 UTC é notada no SW Amazônia, quando às 0600 UTC está presente em $\sim 14^{\circ} \mathrm{S}$ (Fig 3.30, b,d, respectivamente). Anomalias positivas de até $3,5 \mathrm{~g} / \mathrm{Kg}$ de q são observadas no $\mathrm{SE}$ da região de estudo às $1200 \mathrm{UTC}$ e até $2^{\circ} \mathrm{C}$ na parte central às 1800 UTC (Fig. 3.30 a, b, respectivamente).

Em $850 \mathrm{hPa}$, nível onde os padrões foram identificados, o escoamento de P1 se asse- 
melha ao escoamento normal, com os alísios vindo do oceano Atlântico e virando para sul ao encontrar a barreira dos Andes. A anomalia de vento mostra uma componente mais marcante de NW em grande parte da região tropical (Figura 3.31). Novamente a anomalia de T é positiva em toda a região de estudo para os quatro horários analisados, com maior magnitude às $1800 \mathrm{UTC}\left(1,5^{\circ} \mathrm{C}\right.$, Fig. $\left.3.31 \mathrm{~b}\right)$ na encosta da cordilheira. Destaque para região com anomalia negativa de UR no $\mathrm{N}$ do domínio de estudo e positiva na parte S. No padrão P2 (Figura 3.32) destacam-se a intensa anomalia S-SE, que novamente reverte o sentido do escoamento normal do nível, a sul de $15^{\circ} \mathrm{S}$, e o contraste de umidade relativa onde o escoamento de NW é anomalamente mais seco principalmente no $\mathrm{N}$ da Amazônia e na cordilheira central às 1200 UTC (Fig. 3.32 a). Anomalias de T são positivas de até $1,5^{\circ} \mathrm{C}$ no ambiente pré-convectivo no domínio de estudo, e negativa no sul do continente.

O escoamento normal em 700 hPa é similar ao do nível de 850 hPa, mas intensificado. Campos de anomalia de P1 (Figura 3.33) são suaves e quase neutras na região SW Amazônia, reforçando a semelhança de P1 ao escoamento normal. Observa-se uma componente mais de $\mathrm{W}$ no vento na região amazônica e anomalias positivas modestas de $\mathrm{T}$ e UR. Em P2, pelo contrário, as anomalias são bastante significativas principalmente no escoamento úmido de SE/S oriundo do sul do continente que alcança o SW Amazônia. Ao sul de $18^{\circ} \mathrm{S}$ a anomalia de $\mathrm{T}$ é negativa, com magnitude da ordem de $1,5^{\circ} \mathrm{C}$ e na região de estudo onde há confluência é positiva em até $1^{\circ} \mathrm{C}$, assim como a anomalia de UR (com exceção de parte da cordilheira).

Climatologicamente o nível de $500 \mathrm{hPa}$ tem escoamento mais zonal na região equatorial (de E) e subtropical (de W), com uma circulação anticiclônica interligando estes escoamentos às 1200 e $1800 \mathrm{UTC}$, centrada próximo de $13^{\circ} \mathrm{S}-60^{\circ} \mathrm{W}$. Nesta região observa-se uma leve anomalia ciclônica em P1, área onde há maior anomalia positiva de umidade. Na região da Amazônia andina a anomalia de UR é negativa nos três primeiros horários e a de vento tem componente de SE (Figura 3.35). Para P2 a anomalia é ainda mais meridional, especialmente ao longo dos Andes, com componente de vento de SE no SW Amazônia onde também se observa anomalia negativa de UR às 1200 e 1800 UTC. Neste campo pode ser observado o padrão de circulação de crista-cavado comentado anteriormente: há circulação anticiclônica no oceano, próximo à costa do Chile e ciclônica no S do Uruguai e do Estado do Rio Grande do Sul estendendo um cavado até $\sim 24^{\circ} \mathrm{S}$, dando suporte ao avanço de sistemas frontais e massas de ar frio para latitudes mais baixas. 
a) 12:00 UTC - dia anterior

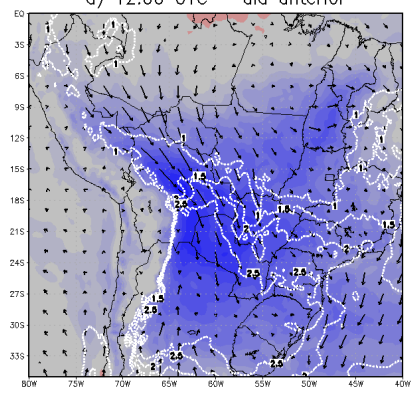

c) 00:00 UTC - di़्र

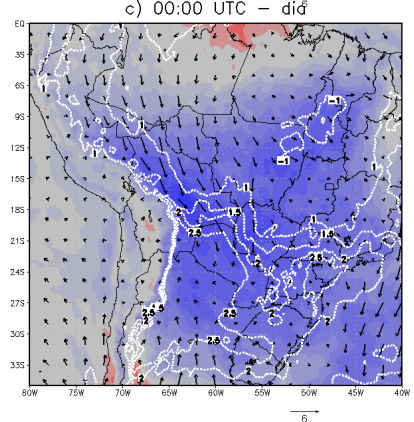

b) 18:00 UTC - dia anterior

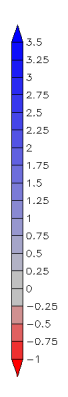

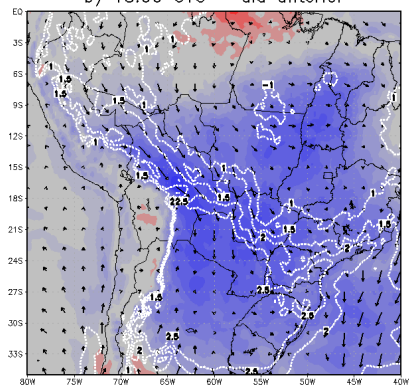

d) 06:00 UTC - di़्व
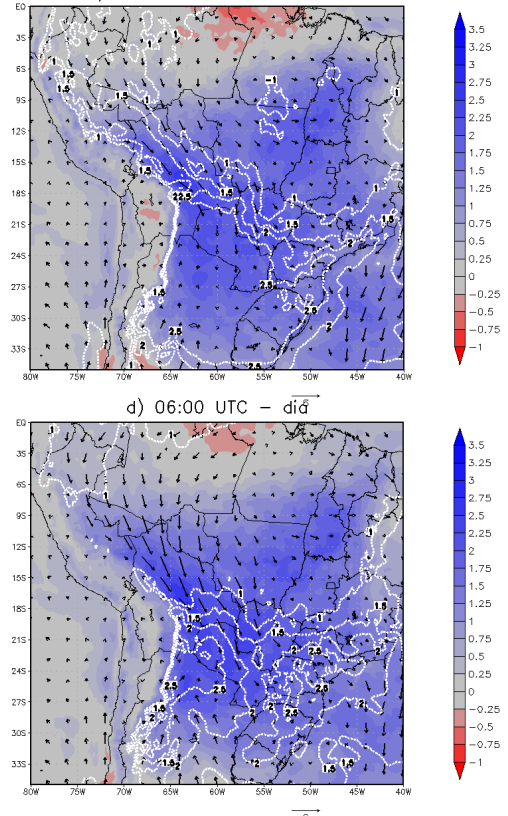

Figura 3.29: Anomalia de umidade específica (g/Kg, escala de cores), vento (m/s, vetores) e temperatura ( ${ }^{\circ} \mathrm{C}$, contornos) em $950 \mathrm{hPa}$ para o padrão $\mathrm{P} 1 \mathrm{em}$ relação à normal climatológica de 1981-2010 para os horários a) 1200 UTC (dia anterior), b) 1800 UTC (dia anterior), c) 0000 UTC, d) 0600 UTC.

a) 12:00 UTC - dis anterio

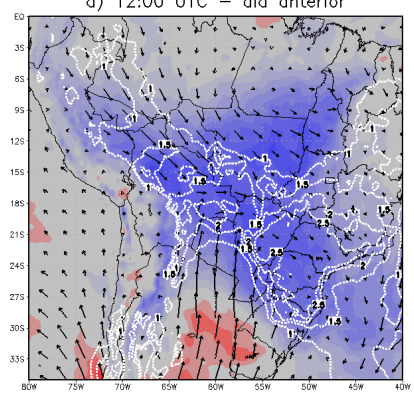

c) 00:00 UTC - diक्ष

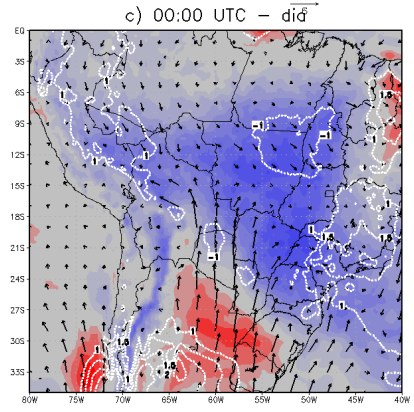

b) 18:00 UTC - dia anterior
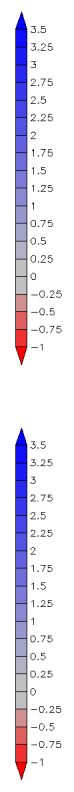

d) 06:00 UTC - diक्ष
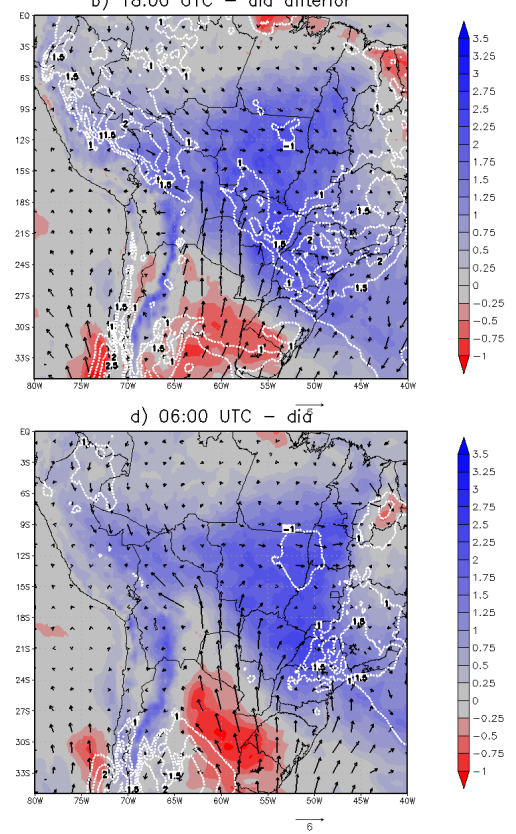

Figura 3.30: O mesmo que na Figura 3.29. mas para padrão P2. 
a) 12:00 UTC - dia anterio

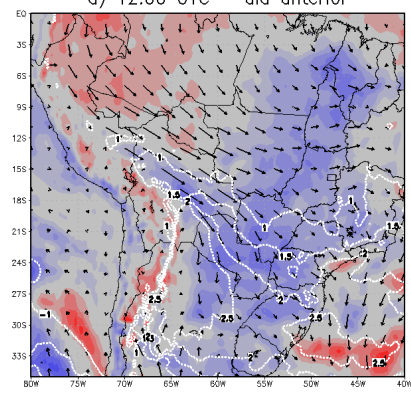

c) 00:00 UTC - diơ

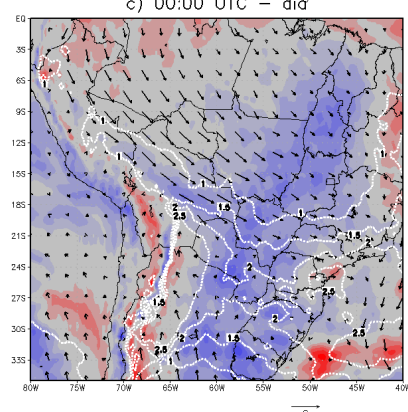

b) 18:00 UTC - dia anterior

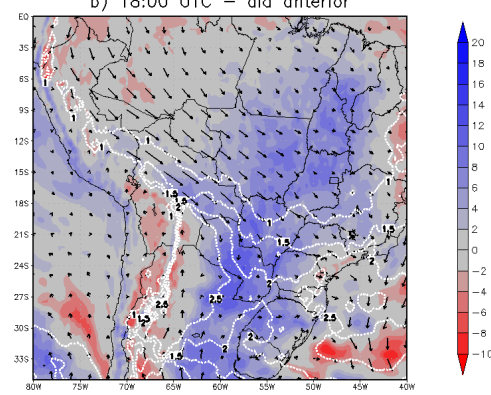

d) 06:00 UTC - diơ

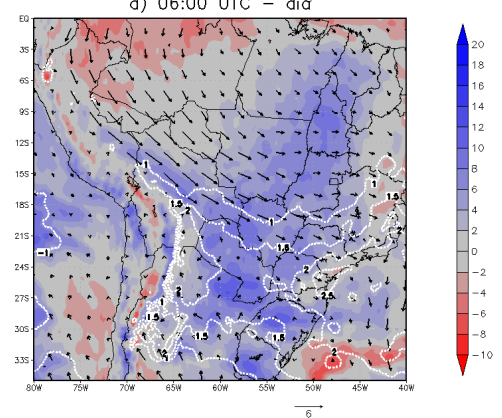

Figura 3.31: Anomalia de umidade relativa (\%, escala de cores), vento $(\mathrm{m} / \mathrm{s}$, vetores) e temperatura $\left({ }^{\circ} \mathrm{C}\right.$, contornos) em $850 \mathrm{hPa}$ para o padrão $\mathrm{P} 1$ em relação à normal climatológica de 1981-2010 para os horários a) 1200 UTC (dia anterior), b) 1800 UTC (dia anterior), c) 0000 UTC, d) 0600 UTC.

a) 12:00 UTC - dia anterior

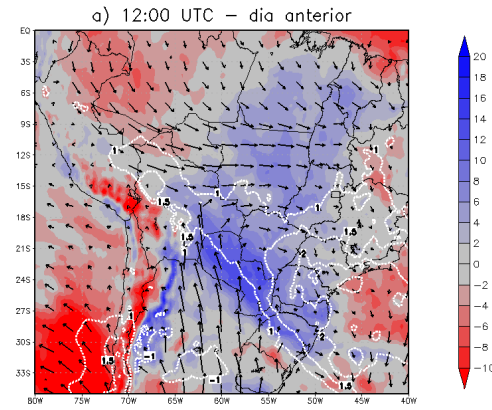

c) 00:00 UTC - diỡ

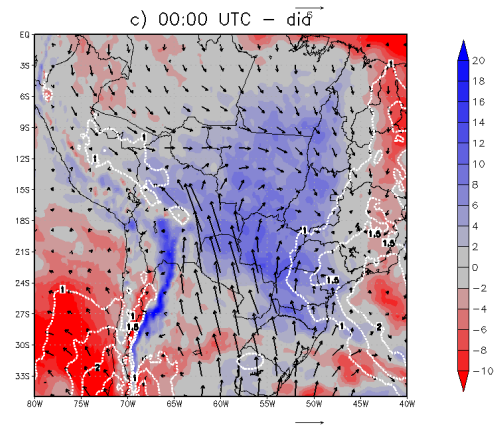

b) 18.00 UTC - dis anterior

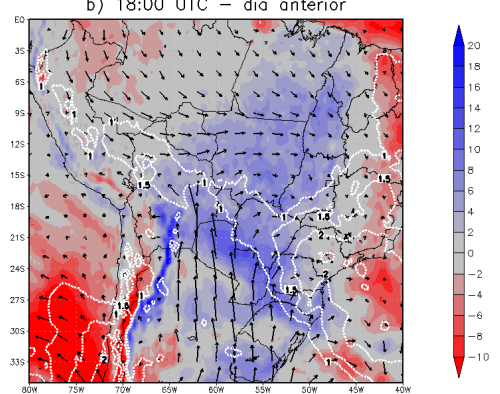

d) 06:00 UTC - diô

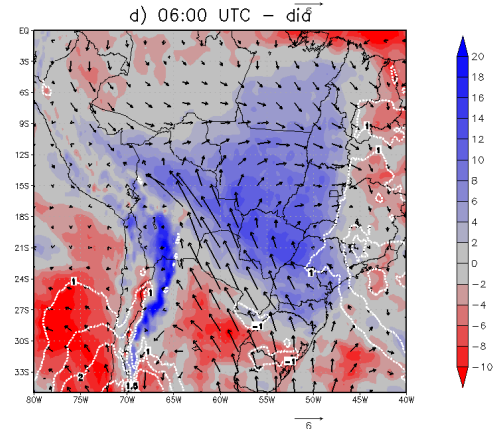

Figura 3.32: O mesmo que na Figura 3.31. mas para padrão P2. 
a) 12:00 UTC - dia anterior

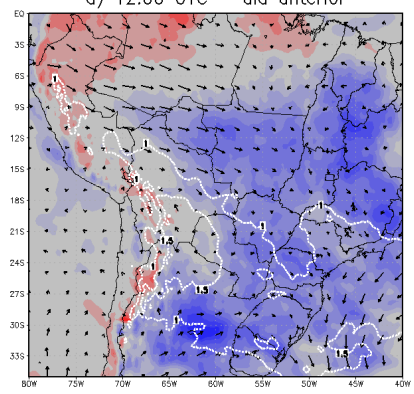

c) 00:00 UTC - di़्र

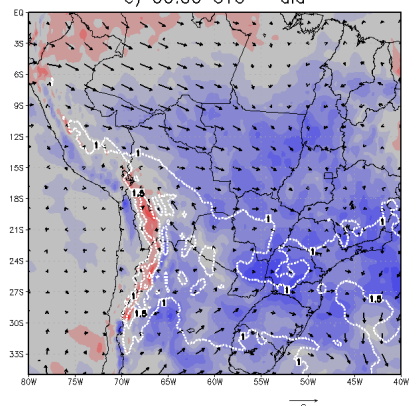

18:00 UTC - dia anterior

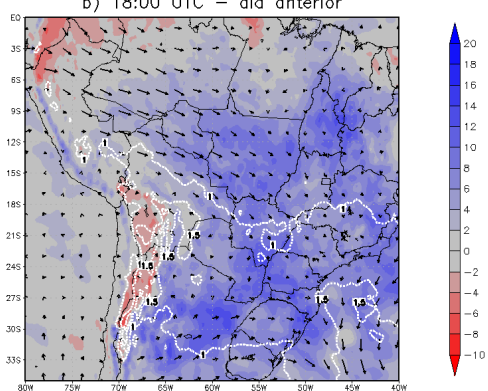

d) 06:00 UTC - di̊

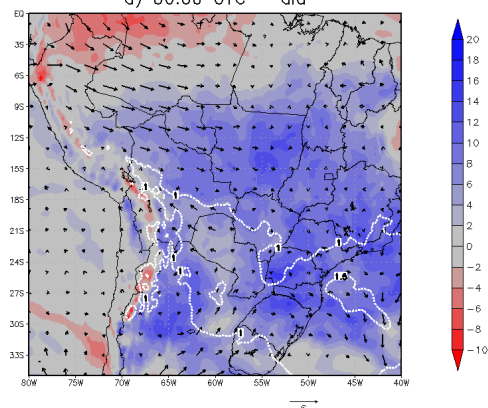

Figura 3.33: Anomalia de umidade relativa (\%, escala de cores), vento (m/s, vetores) e temperatura $\left({ }^{\circ} \mathrm{C}\right.$, contornos) em $700 \mathrm{hPa}$ para o padrão $\mathrm{P} 1$ em relação à normal climatológica de 1981-2010 para os horários a) 1200 UTC (dia anterior), b) 1800 UTC (dia anterior), c) 0000 UTC, d) 0600 UTC.

a) 12:00 UTC - dia anterior

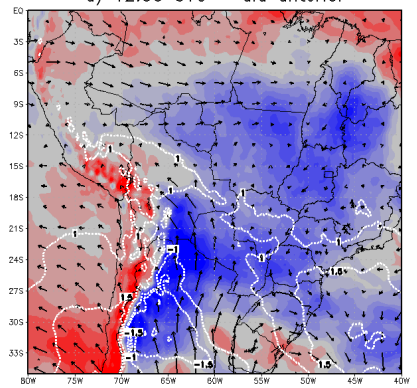

c) 00:00 UTC - diơ

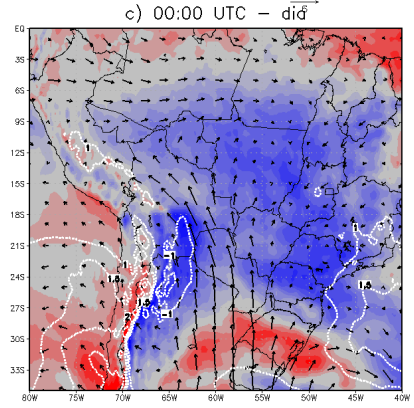

$\longrightarrow$ b) 18.00 UTC - dia anterio

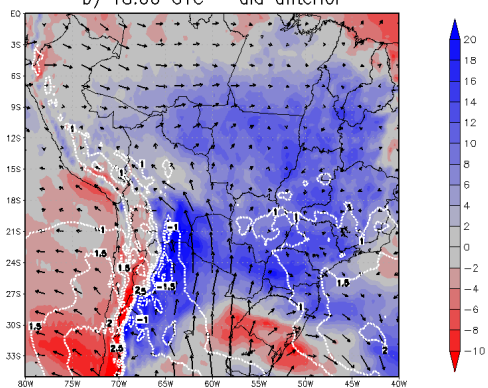

d) 06:00 UTC - diâ

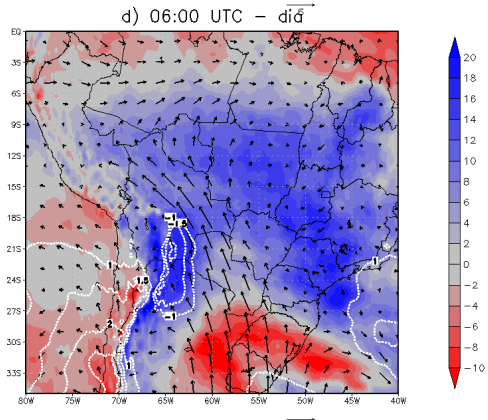

Figura 3.34: O mesmo que na Figura 3.33. mas para padrão P2. 
a) 12:00 UTC - dia anterior

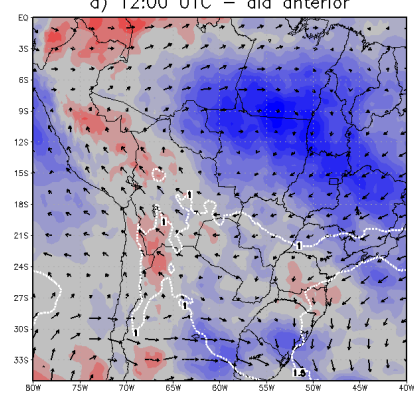

c) 00:00 UTC - diỡ

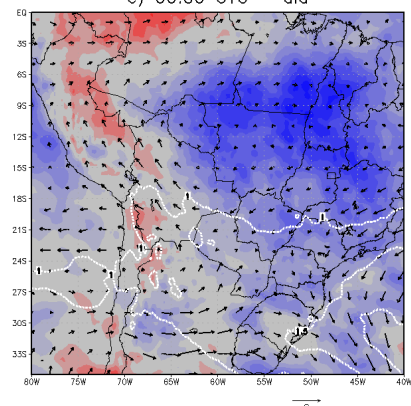

b) 18:00 UTC - dia anterior

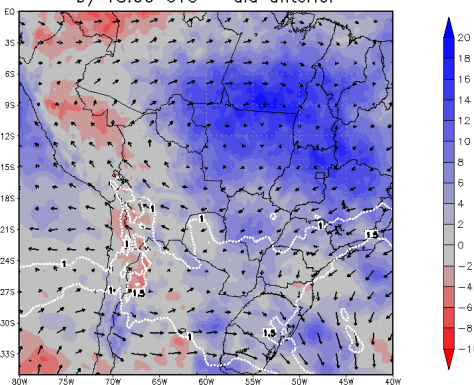

d) 06:00 UTC - dis

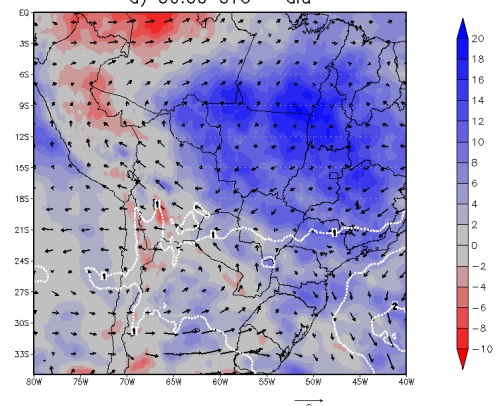

Figura 3.35: Anomalia de umidade relativa (\%, escala de cores), vento (m/s, vetores) e temperatura $\left({ }^{\circ} \mathrm{C}\right.$, contornos) em $500 \mathrm{hPa}$ para o padrão $\mathrm{P} 1$ em relação à normal climatológica de 1981-2010 para os horários a) 1200 UTC (dia anterior), b) 1800 UTC (dia anterior), c) 0000 UTC, d) 0600 UTC.

a) 12:00 UTC - dia anterior

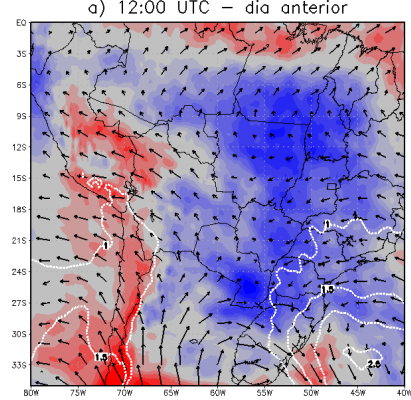

c) 00:00 UTC - diỡ

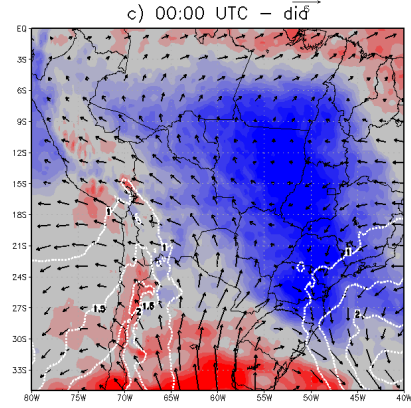

b) 18.00 UTC - dio anterio

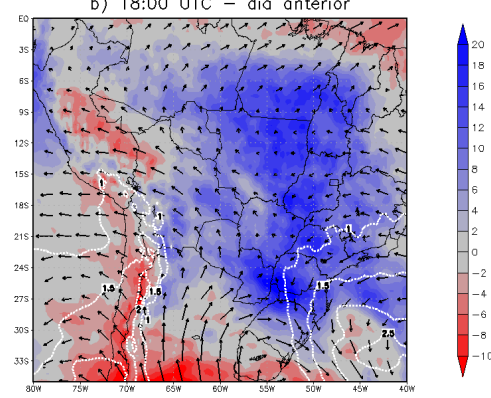

d) 06:00 UTC - diấ

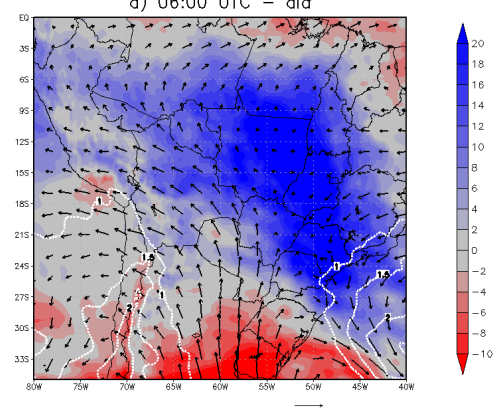

Figura 3.36: O mesmo que na Figura 3.33. mas para padrão P2. 


\subsubsection{Sistemas sinóticos associados às tempestades noturnas}

Tendo sido exploradas as características gerais das tempestades e os principais padrões sinóticos, é importante avaliar se estes eventos acontecem de forma isolada onde, pelas características geográficas do relevo podem ter um disparo orográfico, ou conectados a sistemas de grande escala como frentes frias, linhas de instabilidade ou mesmo ZCAS.

Diferentemente de Machado et al. (1998) e diversos outros autores (por exemplo, Williams e Houze, 1987; Mapes e Houze, 1993; Chen, 1996) que utilizaram métodos automatizados para rastrear sistemas convectivos nas imagens de Tb no infravermelho e então estudar suas propriedades, aqui há necessidade de localizar sistemas específicos já filtrados na base PF. Então, as tempestades noturnas foram manualmente rastreadas nos campos de Tb do conjunto GPM-MERGIR a fim de, juntamente com campos sinóticos e informações dos Boletins Climanálise (CPTEC-INPE), verificar se elas ocorrem de forma isolada ou em associação com sistemas sinóticos.

Sistemas frontais estiveram atuando principalmente no Sul e Sudeste do Brasil em 69 dias que houve registro de eventos de tempestades noturnas, incluindo 3 eventos de friagem, enquanto a ZCAS (ou zonas de convergência de umidade - ZCON) em 16. Embora o escoamento destes sistemas sinóticos tenha dado suporte às configurações que levaram a ocorrência da maioria das tempestades noturnas, considera-se que apenas 7 eventos estiveram embebidos ou disparados (pré-frontal) por frentes frias e nenhum foi registrado como parte da linha de nebulosidade associado à ZCAS/ZCON, totalizando 90 sistemas isolados.

A avaliação individual dos sistemas noturnos revela fundamentalmente seis tipos eventos: 1) isolados, no escoamento de NW relacionado ao JBNAS; 2) isolados, em região onde há confluência NW-SE/S em baixos níveis, relacionada ao escoamento de sistema frontal; 3) embebidos ou disparados por sistemas frontais; 4) isolados no NW do domínio onde os ventos alísios sofrem levantamento na cordilheira dos Andes, antes de defletirem para S; 5) isolados, no escoamento dos alísios mas no NE do domínio, longe da cordilheira e 6) isolados com suporte do escoamento relacionado a ZCAS/ZCON. Exemplos destes tipos de eventos são mostrados a seguir.

Uma tempestade isolada se desenvolveu em escoamento de JBNAS e foi registrada dia 03-09-2009 pelo TRMM às 07:12 UTC, em $15,98^{\circ} \mathrm{S}-65,66^{\circ} \mathrm{W}$. A Tb no painel da Figura 
3.37 ilustra o ciclo de vida deste sistema, considerado o $6^{\underline{0}}$ caso mais severo do conjunto, com 115,99 raios/min.

Tb (C)/GPM MERGIR 23Z02SEP2009

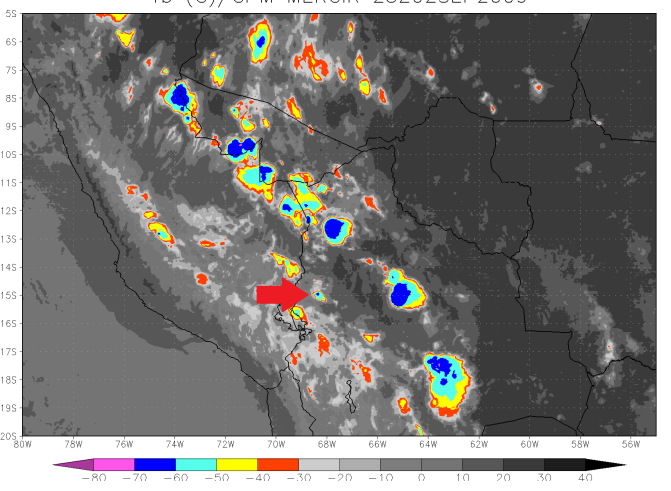

$[\mathrm{b}]$

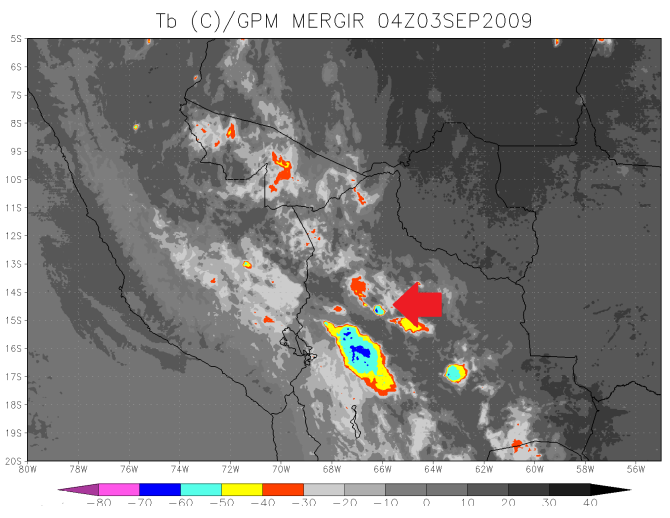

Tb (C)/GPM MERGIR 06:30Z03SEP2009
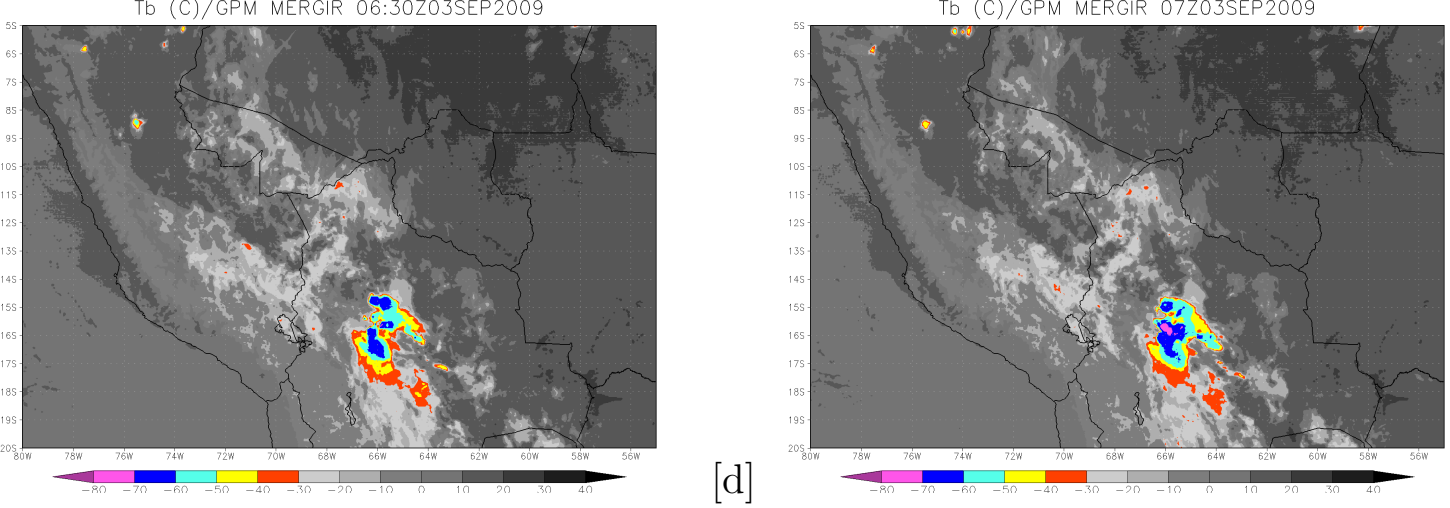

$[c]$

Tb (C)/GPM MERGIR 09Z03SEP2009
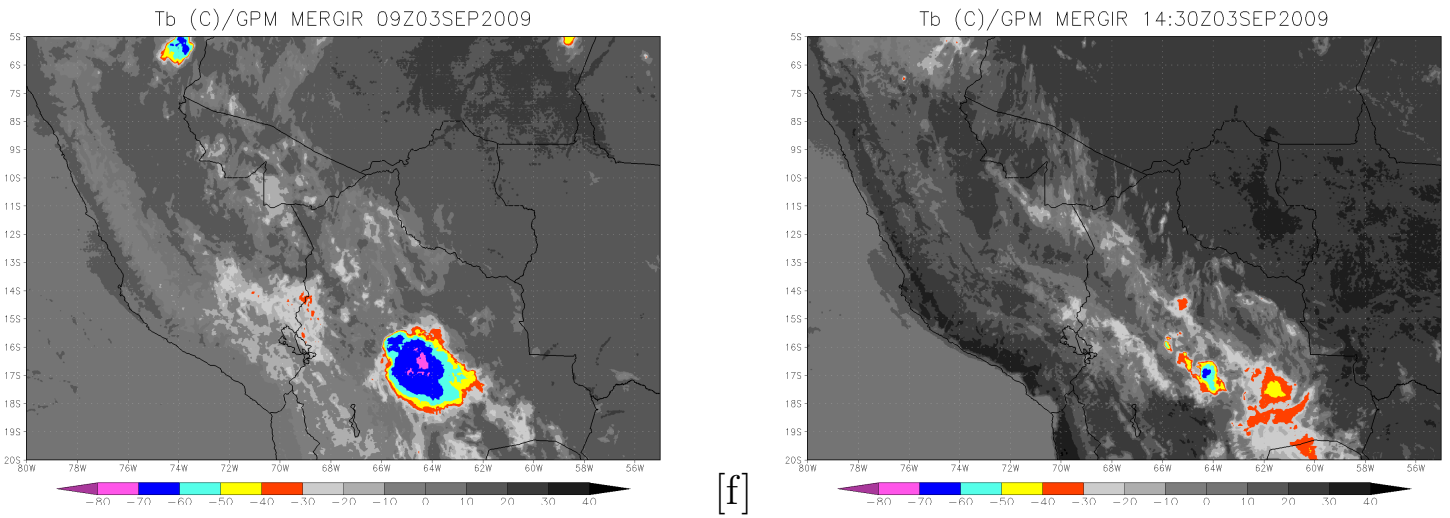

Figura 3.37: Ciclo de vida da tempestade noturna de 03-09-2009, registrada pelo satélite TRMM às 07:12 UTC em $15,98^{\circ} \mathrm{S}-65,66^{\circ} \mathrm{W}$ ilustrado pela temperatura de brilho $\left({ }^{\circ} \mathrm{C}\right)$ do conjunto GPM-MERGIR para: a) 2300 UTC (dia anterior); b) 0400 UTC; c) 0630 UTC; d) 0700 UTC (próximo ao horário de registro); e) 0900 UTC; f) 1430 UTC. Seta vermelha indica início das primeiras células.

A tempestade noturna se forma da união de células menores que têm início às 23:00 UTC do dia anterior e às 04:00 UTC (locais indicados por setas vermelhas em Fig. 3.37 a, b, respectivamente). Estas células avançam para SE e unem-se por volta de 06:30 UTC (Fig. 3.37 c) formando a tempestade que é registrada pelo TRMM cujo horário 
aproximado é mostrado na Figura 3.37 d. A máxima extensão é alcançada por volta de 09:00 UTC e a partir de então decai até estar descaracterizada às 14:30 UTC (Fig. 3.37 e, f, respectivamente), totalizando 16,6 h de duração.

O campo sinótico em $850 \mathrm{hPa}$ mostra intenso escoamento de NW na região onde o sistema se desenvolve, cumprindo critérios de JBNAS, o que pode ser observado tanto no período pré-convectivo (1200 e 1800 UTC do dia anterior ao registro) quanto no dia de observação do evento pelo satélite (0000 e 0600 UTC) - Figura 3.38 a, b, c, d, respectivamente.

a) $12 Z 02 \mathrm{SEP} 2009$

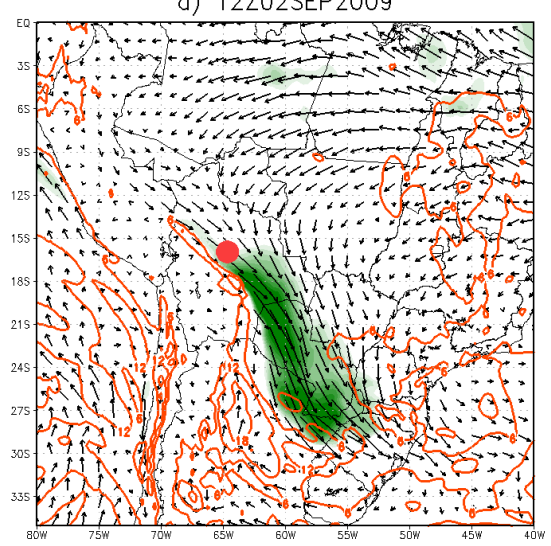

c) 00Z03SEP $200 \overrightarrow{9}^{2}$

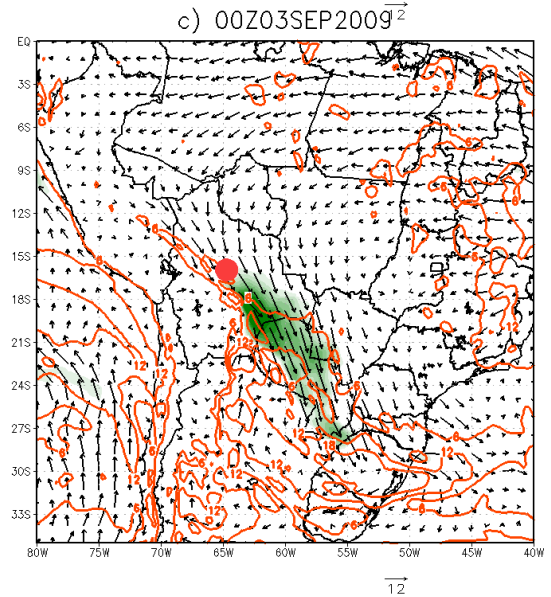

b) $18202 \mathrm{SEP} 2009$

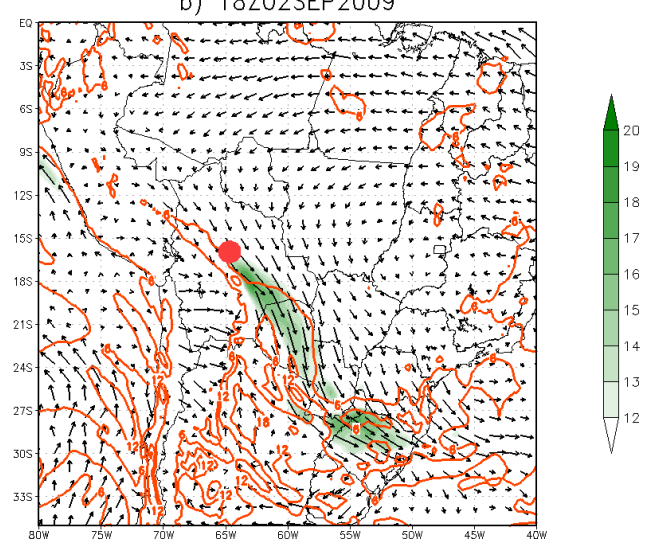

d) 06Z03SEP2009 $\overrightarrow{g^{2}}$

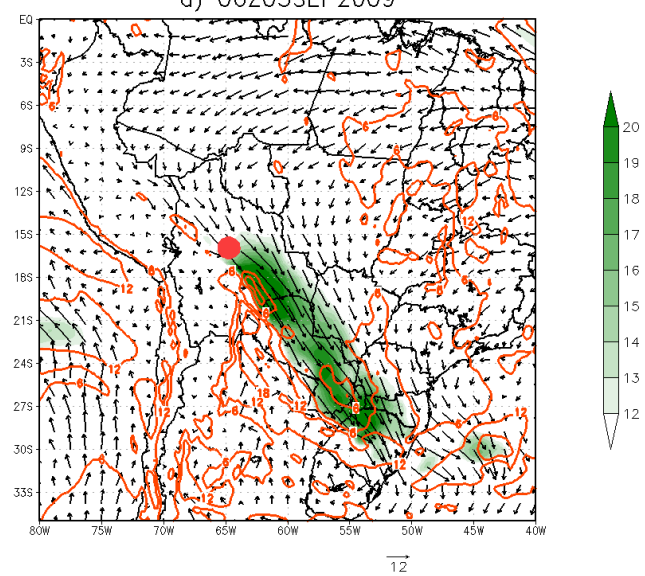

Figura 3.38: Magnitude do vento (m/s, escala de cores) superior a $12 \mathrm{~m} / \mathrm{s}$ em $850 \mathrm{hPa}$ e cisalhamento vertical do vento horizontal entre 700-850 hPa (contornos em vermelho) acima de $6 \mathrm{~m} / \mathrm{s}$ para a tempestade noturna de 03-09-2009, registrada às 7,20 UTC em $15,98^{\circ} \mathrm{S}$ $65,66^{\circ} \mathrm{W}$ (símbolo vermelho) para a) $1200 \mathrm{UTC}$ (dia anterior ao registro); b) 1800 UTC (dia anterior ao registro); c) 0000 UTC (dia do registro); d) 0600 UTC (dia do registro).

Os campos da Figura 3.38 apresentam magnitude do vento em $850 \mathrm{hPa}$ superior a 12 $\mathrm{m} / \mathrm{s}$ na escala de cores, cisalhamento vertical do vento em $3 \mathrm{Km}$ de 6 a $18 \mathrm{~m} / \mathrm{s}$ em contornos vermelhos e o círculo vermelho denota o centro da tempestade no horário de registro. Sua 
formação ocorre basicamente na região de entrada do JBNAS, que está dando suporte a uma frente fria no S do Rio Grande do Sul (não mostrado).

A Tb ilustrada na Figura 3.39 mostra a evolução de uma tempestade isolada que se desenvolveu em confluência de escoamentos de NW-SE em baixos níveis, registrada pelo satélite TRMM dia 19-02-2004, às 09:10 UTC em $15,35^{\circ} \mathrm{S}-66,16^{\circ} \mathrm{W}, 40^{\circ}$ posição na lista de severidade, com 31,57 raios/min (a primeira fora da classificação de tempestades intensas, considerando o limiar de $32 \mathrm{raios} / \mathrm{min})$.

Tb (C)/GPM MERGIR O2Z19FEB2004

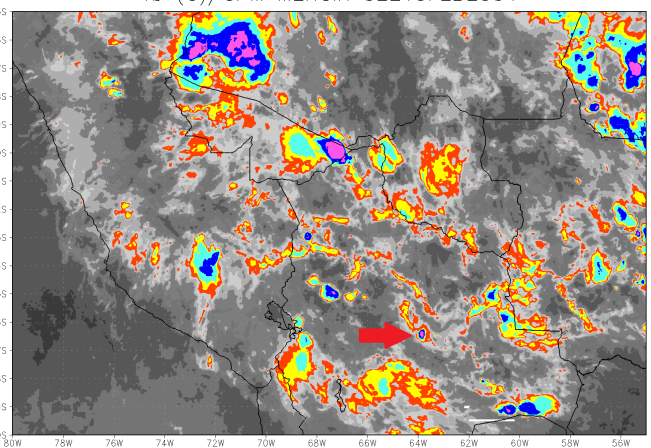

[a]

Tb (C)/GPM MERGIR O6Z19FEB2004

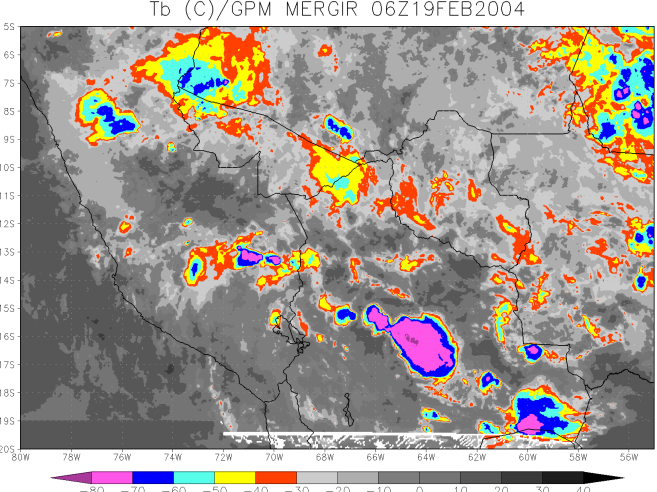

Tb (C)/GPM MERGIR 12Z19FEB2004

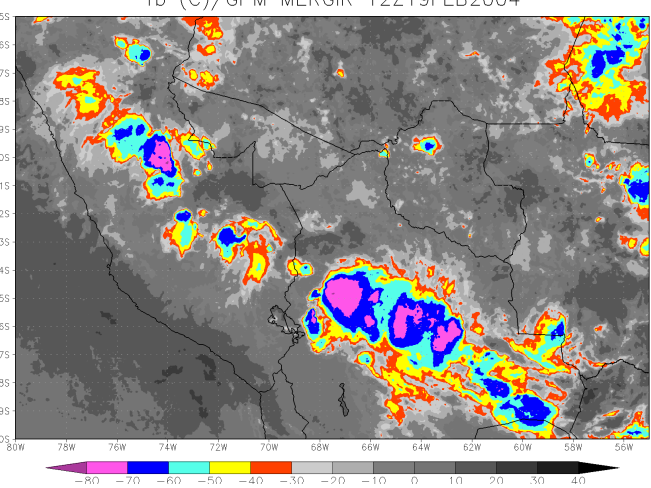

Tb (C)/GPM MERGIR 04Z19FEB2004

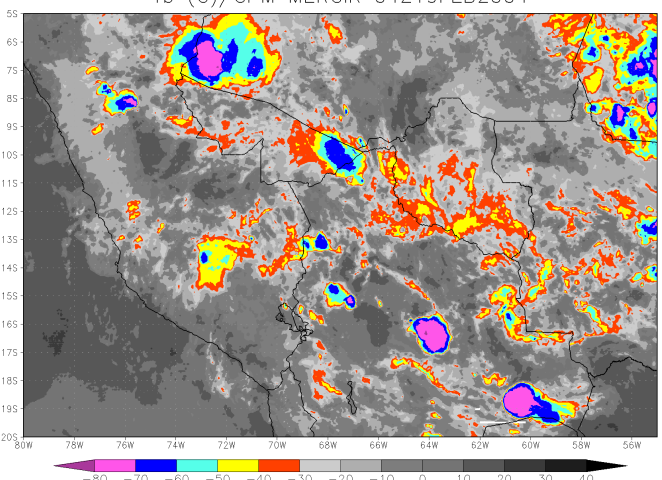

Tb (C)/GPM MERGIR 09Z19FEB2004

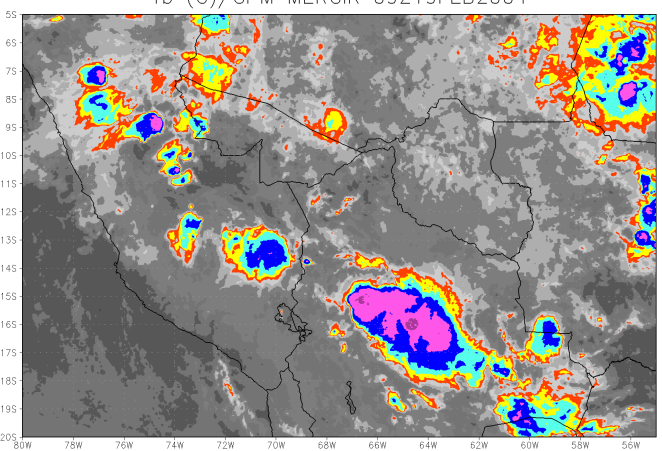

$[\mathrm{d}]$

Tb (C)/GPM MERGIR 19Z19FEB2004

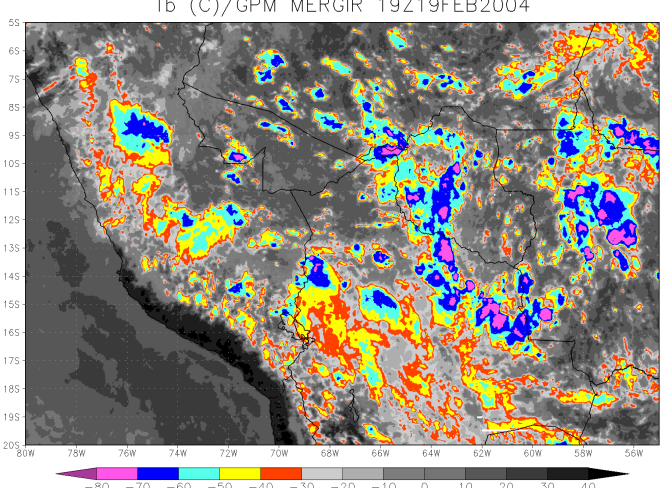

Figura 3.39: Ciclo de vida da tempestade noturna de 19-02-2004, registrada pelo satélite TRMM às 09:10 UTC em $15,35^{\circ} \mathrm{S}-66,16^{\circ} \mathrm{W}$ ilustrado pela temperatura de brilho $\left({ }^{\circ} \mathrm{C}\right)$ do conjunto GPM-MERGIR para: a) 0200 UTC; b) 0400 UTC; c) 0600 UTC; d) 0900 UTC (próximo ao horário de registro); e) 1200 UTC; f) 1900 UTC. 
Dentre a atividade convectiva na região pode-se observar início da célula da tempestade às $0200 \mathrm{UTC}$ por volta de $16,5^{\circ} \mathrm{S}-64^{\circ} \mathrm{W}$ (seta vermelha, Fig. 3.39 a), que evolui em tamanho e passa a incorporar células menores na sua vizinhança (Fig. 3.39 c), até ser registrada pelo satélite aproximadamente às 0900 UTC (Fig. 3.39 d). Às 1200 UTC, em fase de dissipação, tem seu núcleo dividido, e às 1900 UTC está totalmente descaracterizada (Fig. 3.39 e, f, respectivamente), totalizando $17 \mathrm{~h}$ de tempo de vida.

Similarmente à Figura 3.38, verifica-se o campo de vento em 850 hPa o dia 19-02-2004. A Figura 3.40 mostra que durante os quatro horários de observação do dia do registro do evento não há configuração de JBNAS, mas sim uma confluência de ventos NW-SE próximo onde a tempestade atua. Às 0000 UTC (Fig. 3.40 a, horário pré-convectivo neste caso) é possível observar confluência de ventos imediatamente a SE do símbolo vermelho, que indica posição onde a tempestade foi registrada. Isto é coerente com localização das primeiras células do sistema, mostrado na Figura 3.39,a. O escoamento de SE se intensifica e avança para NW, ao mesmo tempo que a tempestade evolui nesta direção.
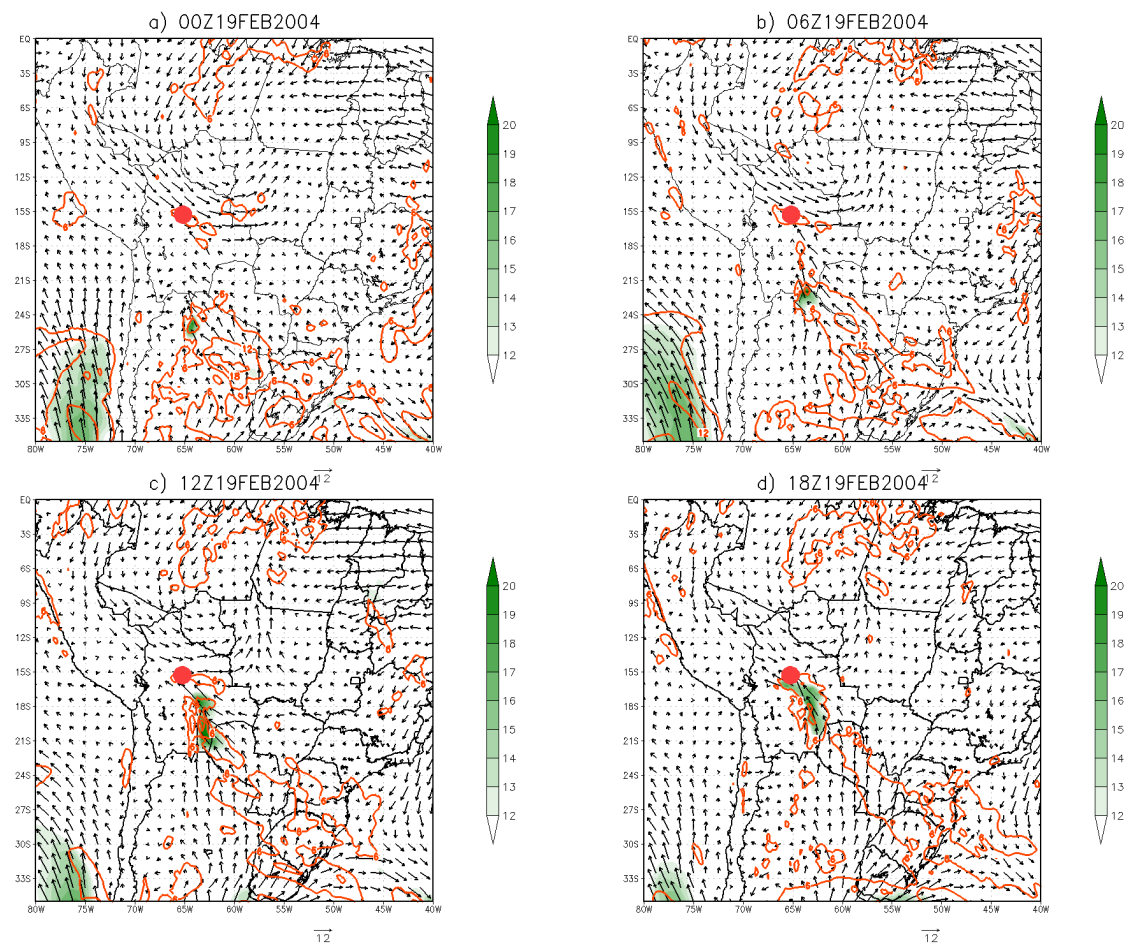

Figura 3.40: Magnitude do vento (m/s, escala de cores) superior a $12 \mathrm{~m} / \mathrm{s}$ em $850 \mathrm{hPa}$ e cisalhamento vertical do vento horizontal entre 700-850 hPa (contornos em vermelho) acima de $6 \mathrm{~m} / \mathrm{s}$ para a tempestade noturna de 19-02-2004, registrada às 09,17 UTC em $15,35^{\circ} \mathrm{S}$ $66,16^{\circ} \mathrm{W}$ (símbolo vermelho) para a) 0000 UTC; b) 0600 UTC; c) 1200 UTC; d) 1800 UTC. 
Como é mostrado nos campos de superfície da Figura 3.41 (vetores de vento horizontal em 10 m de altura e pressão a nível médio do mar - hPa, escala de cores), esta confluência está relacionada à passagem de um sistema frontal no Sul do Brasil. A frente fria localizase Estado do Paraná, e está conectada a um ciclone no oceano Atlântico com seu centro fora do domínio da figura. Um anticiclone pós-frontal com centro de pressão acima de 1022 hPa move-se do Pacífico para o continente atrás do sistema frontal e está bem definido próximo de $31^{\circ} \mathrm{S}-64^{\circ} \mathrm{W}$ às $1800 \mathrm{UTC}$ do dia anterior ao registro da tempestade (Fig. $3.41 \mathrm{~b}$ ). Os ventos de SE/S da sua borda oriental alcançam o SW Amazônia, levando à confluência observada na região da tempestade. Assim o evento noturno é considerado isolado de sistemas sinóticos mas relacionado ao escoamento de uma frente fria, pois se desenvolveu em confluência com escoamento de SE do anticiclone pós-frontal.

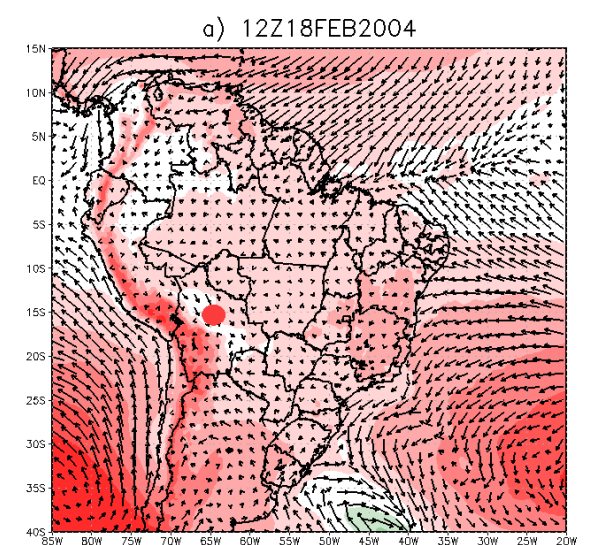

c) $00219 \mathrm{FEB} 2004^{\overrightarrow{10}}$

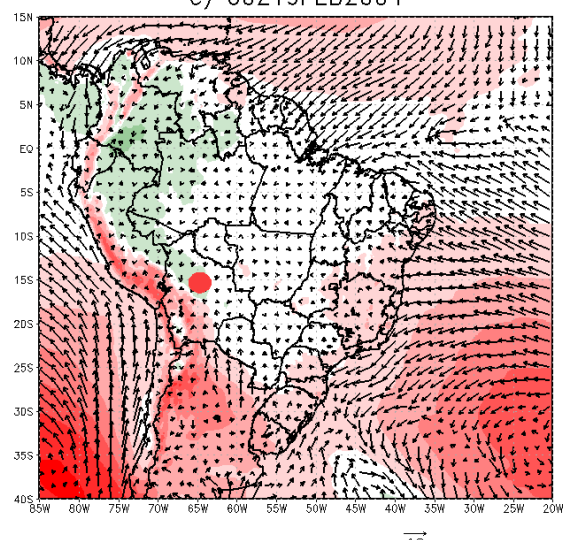

b) $18 \mathrm{Z} 18 \mathrm{FEB} 2004$

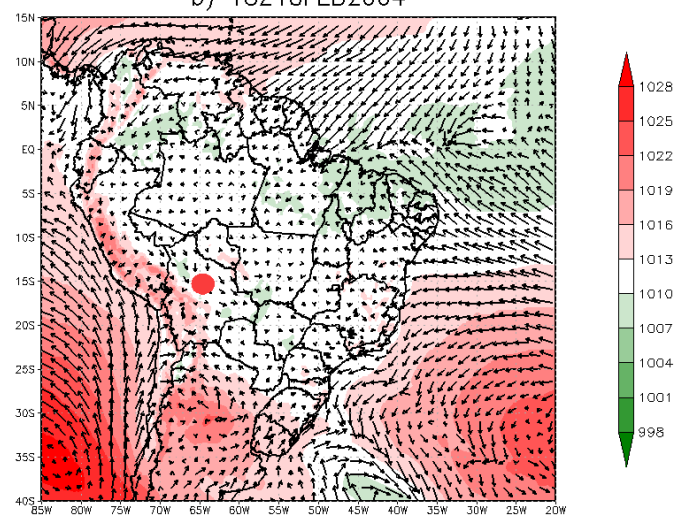

d) $06 Z 19 \mathrm{FEB} 2004^{\overrightarrow{10}}$

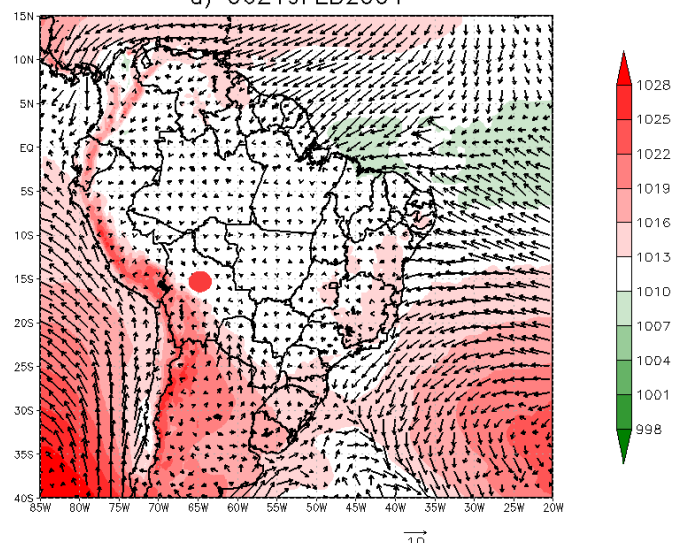

$\overrightarrow{10}$

Figura 3.41: Pressão a nível médio do mar (hPa, escala de cores) e vento horizontal em $10 \mathrm{~m}$ de altura (m/s, vetores) para a tempestade noturna de 19-02-2004, registrada às 09,17 UTC em $15,35^{\circ} \mathrm{S}-66,16^{\circ} \mathrm{W}$ (símbolo vermelho) para a) $1200 \mathrm{UTC}$ (dia anterior); b) $1800 \mathrm{UTC}$ (dia anterior); c) 0000 UTC; d) 0600 UTC.

A Figura 3.42 mostra a precipitação associada a este evento noturno observada pelo 
satélite TRMM (produto diário 3B42-TRMM, Fig. 3.42 a) em comparação àquela estimada pela reanálise ERA5 (Fig. 3.42 b). Como se pode notar através das escalas de cores (em $\mathrm{mm} /$ dia), a reanálise subestima a precipitação, que também aparece deslocada a SE da área de atuação da tempestade (posição de registro indicada pelo círculo preto em ambas as figuras). Apesar dos valores e localização diferentes, a tempestade noturna pode ser observada através do campo de precipitação da reanálise ERA5.

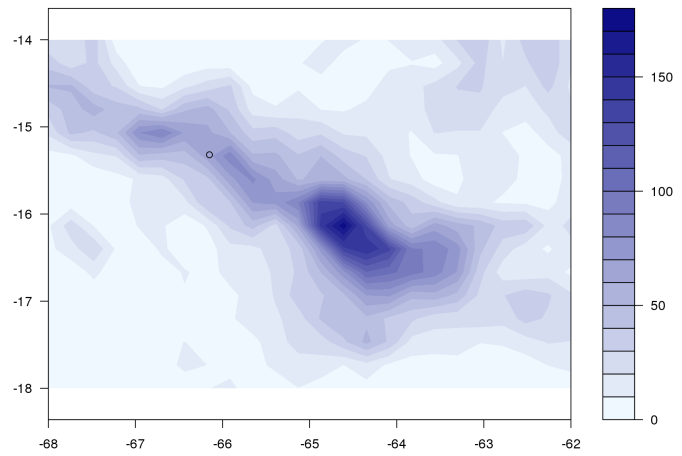

$[\mathrm{a}]$

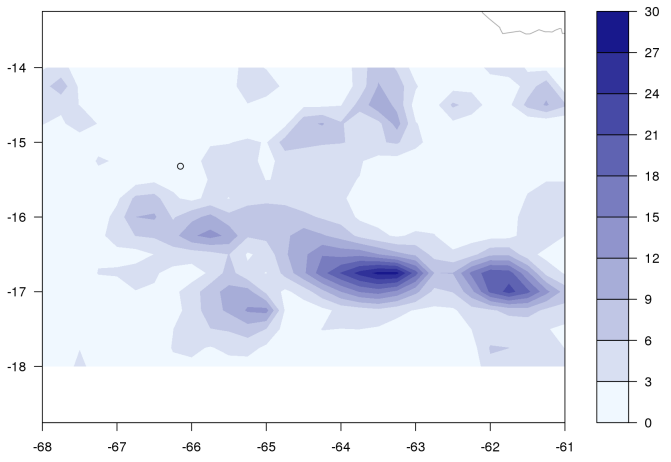

$[\mathrm{b}]$

Figura 3.42: Precipitação (mm/dia) da tempestade noturna de 19-02-2004, registrada pelo satélite TRMM às 09,17 UTC em $15,35^{\circ} \mathrm{S}-66,16^{\circ} \mathrm{W}$, posição indicada pelo símbolo preto, a) observada pelo satélite TRMM no conjunto de dados diário $3 \mathrm{~B} 42$ e b) estimada pela reanálise ERA5.

O dia 30-04-2008 é bastante interessante pois além de cumprir os critérios de JBNAS também apresenta confluência com escoamento de $\mathrm{S}$ proveniente do avanço um sistema frontal que, mais tarde, veio a culminar num evento de friagem, de acordo com o Boletim Climanálise (CPTEC-INPE). Houve registro de dois sistemas noturnos por volta de 0100 UTC, um em escoamento de SE e, portanto, considerado embebido no sistema frontal e outro no escoamento de NW do JBNAS (intenso, 29ํㅜ caso da classificação de severidade), considerado isolado e pré-frontal. A Figura 3.43 ilustra através da Tb as duas tempestades no horário aproximado do registro, uma em $\sim 14,1^{\circ} \mathrm{S}-64,8^{\circ} \mathrm{W}$ e outra em $\sim 15,9^{\circ} \mathrm{S}-$ $66,3^{\circ} \mathrm{W}$ (indicadas pelas setas vermelhas na Fig. 3.43 b), tanto no contexto sinótico evidenciando a atuação da frente fria, como um recorte no domínio SW Amazônia (Fig. 3.43,a,b, respectivamente).

A tempestade embebida no sistema frontal tem início por volta de 0900 UTC do dia anterior ao registro em $\sim 18,8^{\circ} \mathrm{S}-63^{\circ} \mathrm{W}$ (seta vermelha, Figura 3.44 a), muito próximo de onde ocorre a confluência em baixos níveis. Este sistema cresce, se intensifica, e avança 
para NO junto com a confluência, incorporando células menores durante sua trajetória (Fig. 3.44 b-e) até que 0100 UTC é registrado pelo satélite (Fig. 3.44 f). Às 0300 UTC ele parece estar em processo de decaimento mas no horário seguinte aparece regenerado imediatamente a NO (Fig. $3.44 \mathrm{~g}, \mathrm{~h}$, respectivamente). Às 0630 UTC ele se une à segunda tempestade, e segue avançando para NW até estar descaracterizado às 2200 UTC (Fig. 3.44 j-l). Esta tempestade desloca-se $~ 1200 \mathrm{Km}$ para NW, comparando a posição das primeiras células com o decaimento, e duração de cerca de 37 h. O segundo caso de tempestade noturna tem início por volta de $2200 \mathrm{UTC}, \sim 14,5^{\circ} \mathrm{S}-65^{\circ} \mathrm{W}$ (seta vermelha, Fig. 3.44. e). Nos horários seguintes cresce em tamanho, intensidade, e embora se desenvolva no escoamento do JBNAS avança com a confluência para NO até unir-se com o primeiro sistema e decair (Fig. 3.44), contabilizando cerca de 24 horas de vida e deslocamento de $1040 \mathrm{Km}$ para NW.

$[a]$
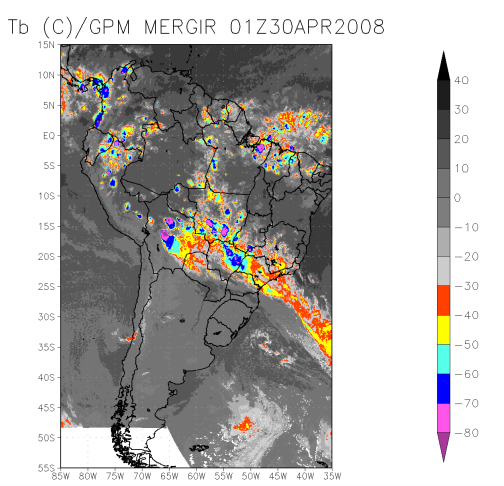

$[\mathrm{b}]$

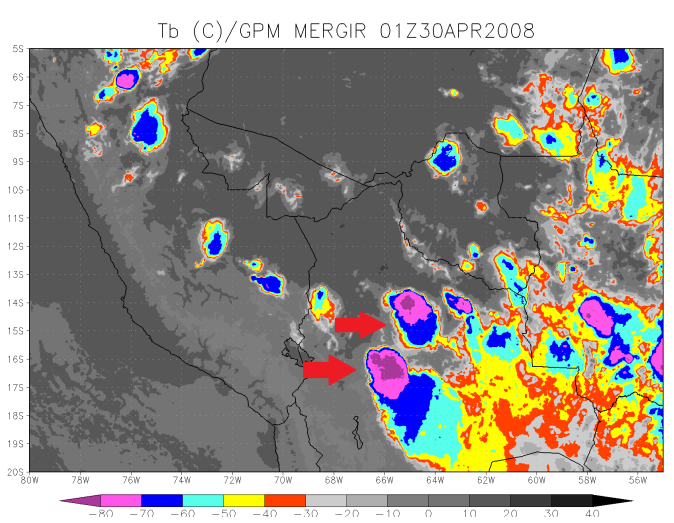

Figura 3.43: Tempestades noturnas de 30-04-2008, registradas pelo satélite TRMM às 1,14 UTC em $14,1^{\circ} \mathrm{S}-64,8^{\circ} \mathrm{W}$ e $1,13 \mathrm{UTC}$ em $15,9^{\circ} \mathrm{S}-66,3^{\circ} \mathrm{W}$ ilustradas pela temperatura de brilho $\left({ }^{\circ} \mathrm{C}\right)$ do conjunto GPM-MERGIR para: a) América do Sul; b) região SW Amazônia, ambas às 0100 UTC.

Olhando para a Tb no contexto da América do Sul, observa-se a frente fria atuando desde oceano Atlântico Sul, Sul do Brasil, Paraguai e S da Bolívia às 1200 UTC (29-042008), e avançando para NE quando às 0600 UTC (30-04-2008) alcança o S da Amazônia (Fig. 3.45 a-d).

A Figura 3.46 mostra o campo de vento horizontal em $850 \mathrm{hPa}$ e o cisalhamento em baixos níveis para as tempestades noturnas registradas no dia 30/04/2008, onde a escala de cores representa magnitude do vento $(\mathrm{m} / \mathrm{s})$ no nível e os contornos em laranja o cisalhamento em baixos níveis (m/s). Observa-se a atuação do JBNAS bem configurado, principalmente às 1200 UTC (dia anterior ao registro) mas também às 0000 e 0600 UTC 
(, Fig. 3.46 a, c, d, respectivamente), e um intenso escoamento de SE/S proveniente da passagem da frente fria, com a confluência NO-SE/S avançando em direção à Amazônia.

$[\mathrm{a}]$
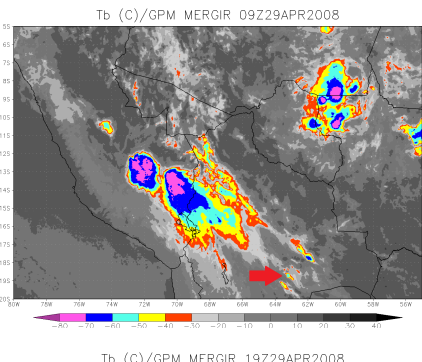

[d]
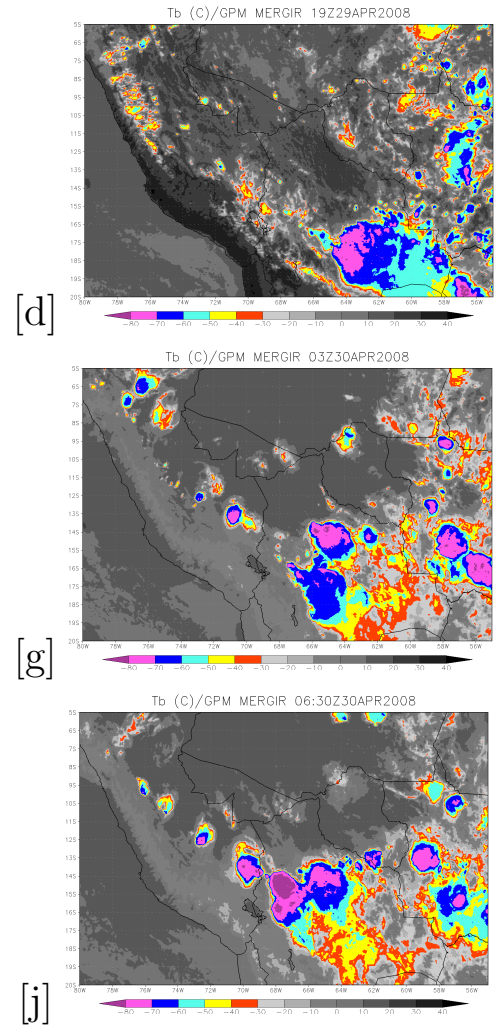

$[\mathrm{b}]$

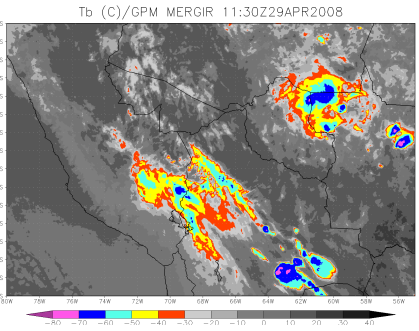

$[\mathrm{e}]$
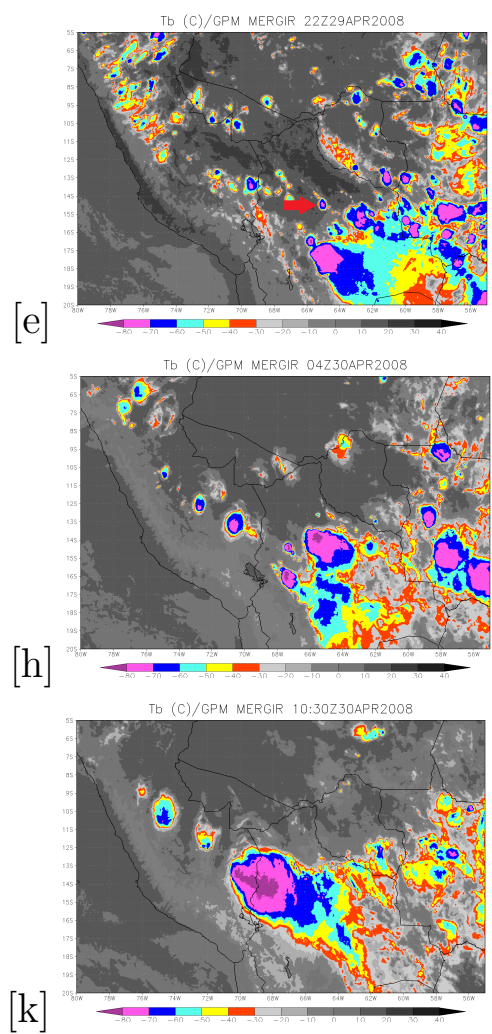
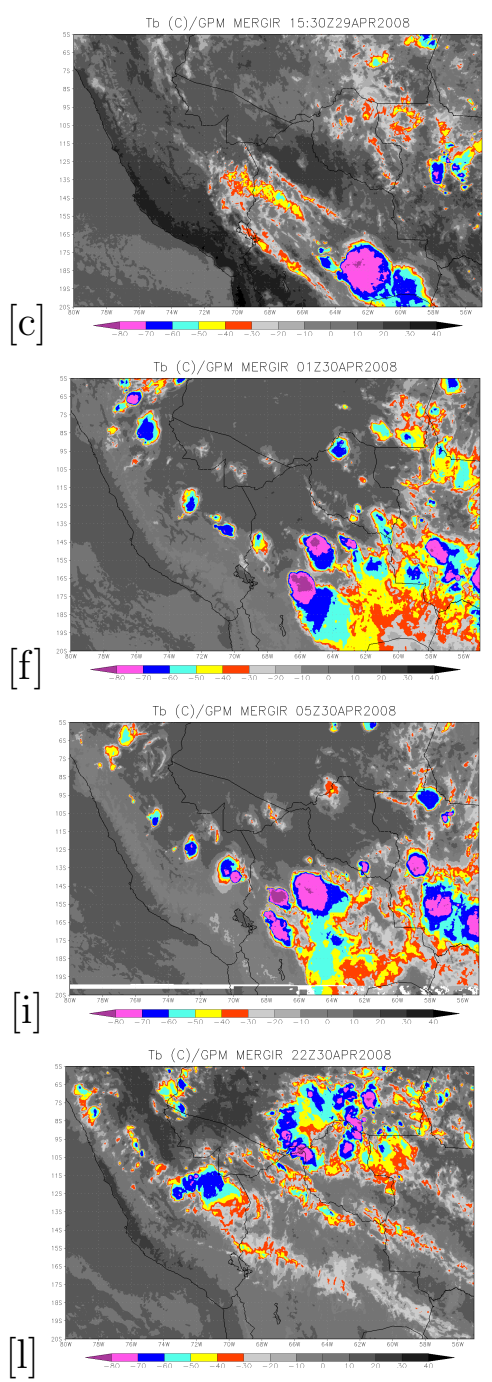

Figura 3.44: Ciclo de vida das tempestades noturnas de 30-04-2008, registradas pelo satélite TRMM por volta de 01:00 UTC em $14,1^{\circ} \mathrm{S}-64,8^{\circ} \mathrm{W}$ e $15,9^{\circ} \mathrm{S}-66,3^{\circ} \mathrm{W}$ ilustrado pela temperatura de brilho $\left({ }^{\circ} \mathrm{C}\right)$ do conjunto GPM-MERGIR para: a) 09:00 UTC (dia anterior ao registro); b) 11:30 UTC (dia anterior ao registro); c) 15:30 UTC (dia anterior ao registro); d) 19:00 UTC (dia anterior ao registro); e) 22:00 UTC (dia anterior ao registro); f) 01:00 UTC (horário aproximado do registro de ambas as tempestades); g) 03:00 UTC (dia de registro); h) 04:00 UTC (dia de registro); i) 05:00 UTC (dia de registro); j) 06:30 UTC (dia de registro); k) 10:30 UTC (dia de registro); 1) 22:00 UTC (dia de registro). 
$[a]$

$[c]$
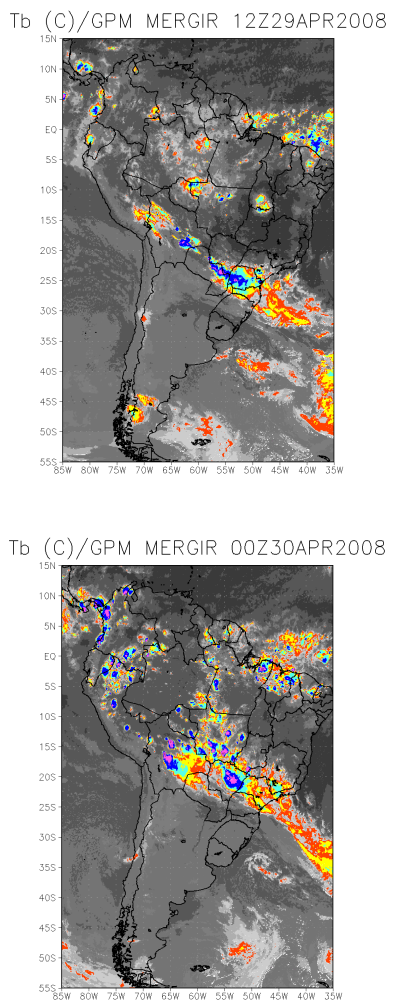

$[\mathrm{b}]$

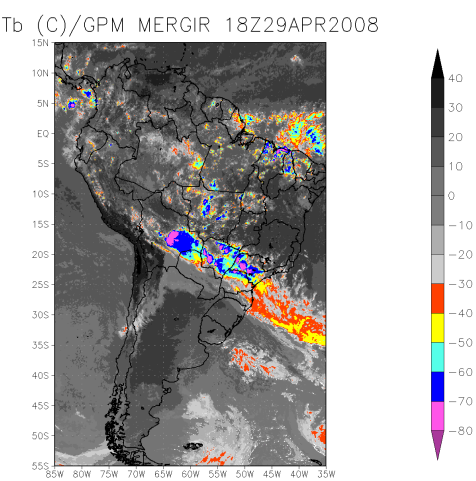

$[\mathrm{d}]$

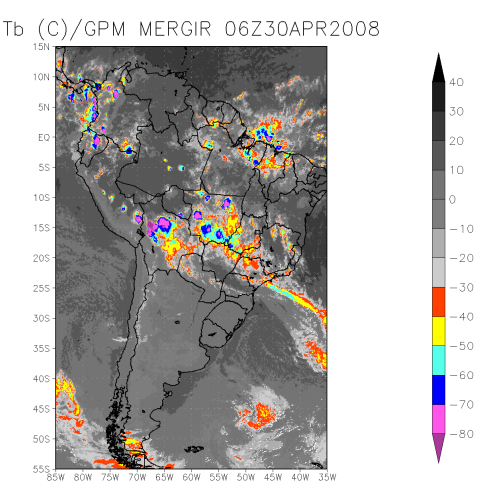

Figura 3.45: Temperatura de brilho na América do Sul ilustrando o avanço da frente fria a) 1200 UTC (29-04-2008); b) 1800 UTC (29-04-2008); c) 0000 UTC (30-04-2008); d) 16:00 UTC (30-04-2008).

O campo de superfície para este mesmo dia é mostrado na Figura 3.47, onde pressão a nível médio do mar é representada pela escala de cores (hPa), vento a $10 \mathrm{~m}$ de altura pelos vetores $(\mathrm{m} / \mathrm{s}$ ) e a precipitação (superior a $1 \mathrm{~mm}$ ) pelos contornos em azul. Novamente, os círculos em vermelho demarcam a posição onde as tempestades foram registradas pelo TRMM. Nota-se que o ciclone associado à onda frontal já se encontra no oceano Atlântico e ele aprofunda seu centro conforme desloca-se para E. Uma região de pressão baixa é observada ao longo da confluência, estendendo-se até cerca de $15^{\circ} \mathrm{S}$, com precipitação associada. Na retaguarda da frente fria atua uma região de alta pressão, proveniente do avanço do Anticiclone Subtropical do Pacífico Sul (ASPS) sobre o continente (Fig. 3.47 a) e dá origem à alta transiente pós-fontal, com pressão superior a $1020 \mathrm{hPa}$. O vento de SE/S, portanto, advém desta região de alta pressão e empurra a frente fria em direção a latitudes mais baixas. 
a) $12229 \mathrm{APR} 2008$

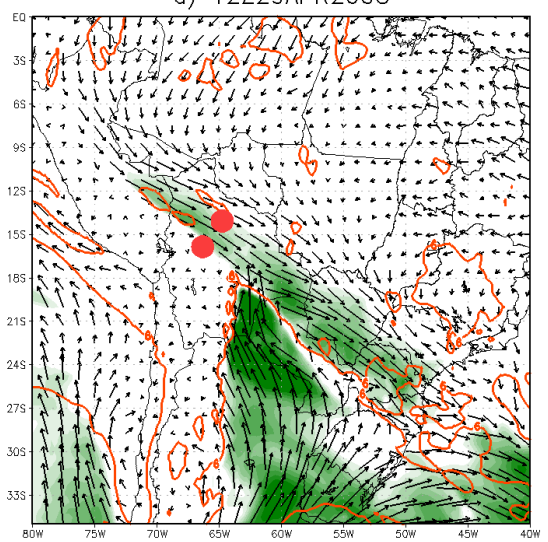

c) OOZ30APR2008 $\overrightarrow{8^{2}}$

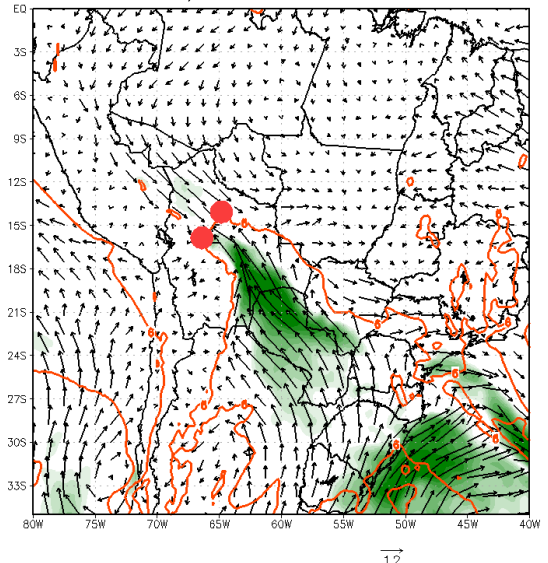

b) 18Z29APR2008

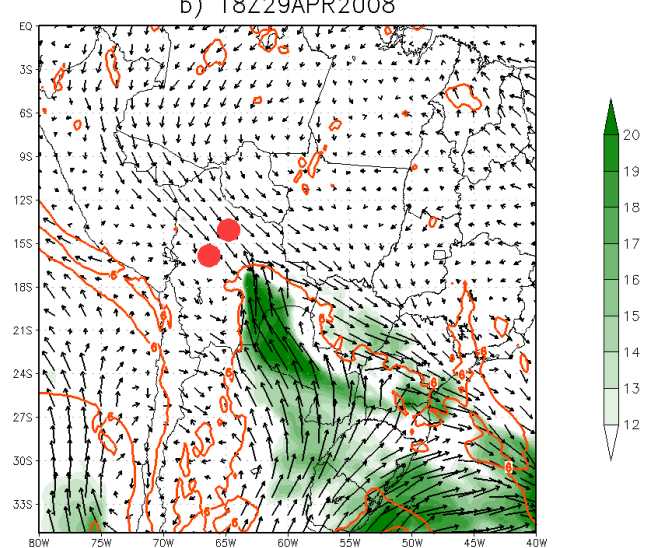

d) 06Z30APR200 $\overrightarrow{8^{2}}$

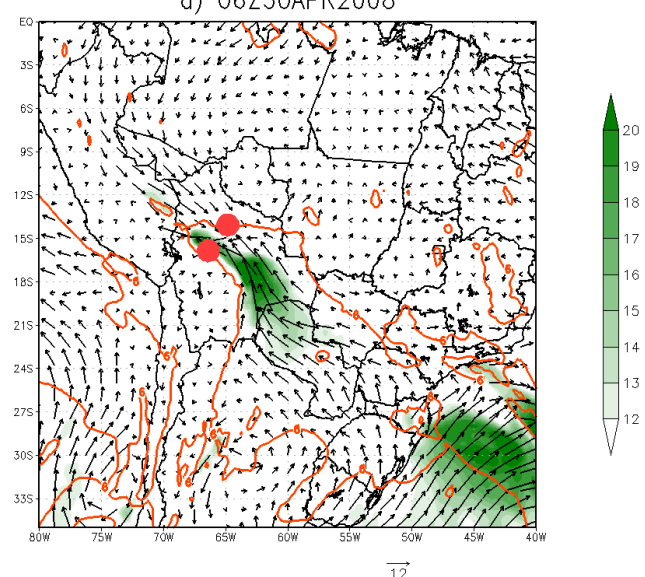

Figura 3.46: Magnitude do vento (m/s, escala de cores) superior a $12 \mathrm{~m} / \mathrm{s}$ em $850 \mathrm{hPa}$ e cisalhamento vertical do vento horizontal entre 700-850 hPa (contornos em vermelho) acima de $6 \mathrm{~m} / \mathrm{s}$ para as tempestades noturnas de 30-04-2008, registradas $\sim$ 01:00 UTC em 14, $1^{\circ} \mathrm{S}$ $64,8^{\circ} \mathrm{W}$ e $15,9^{\circ} \mathrm{S}-66,3^{\circ} \mathrm{W}$ (símbolos em vermelho) para a) 1200 UTC (dia anterior ao registro); b) 1800 UTC (dia anterior ao registro); c) 0000 UTC (dia do registro); d) 0600 UTC (dia do registro). 

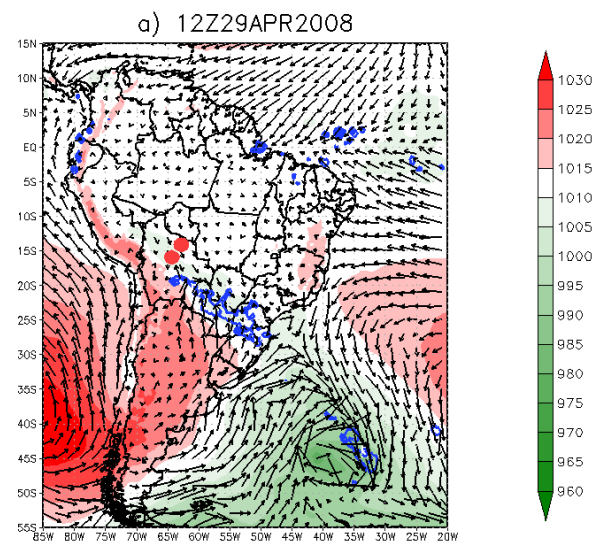

c) OOZ30APR $\overrightarrow{20} 08$

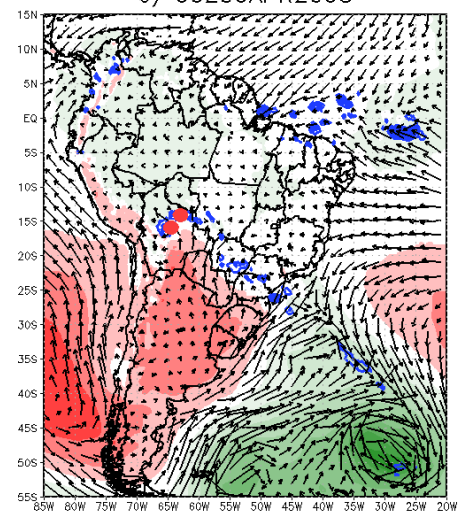

$\overrightarrow{10}$
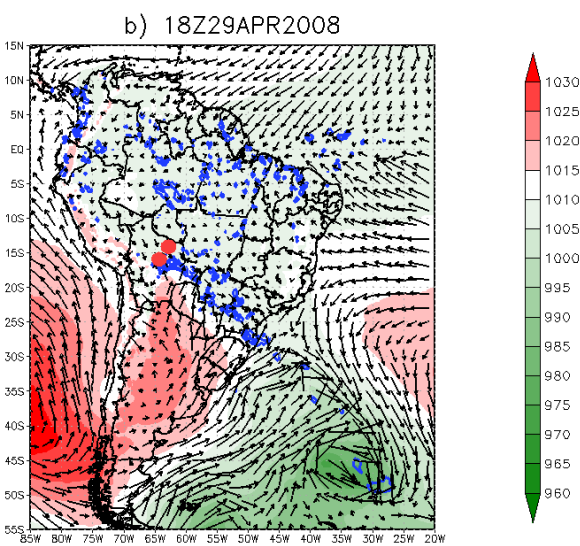

d) 06Z30APR $\overrightarrow{20} 08$
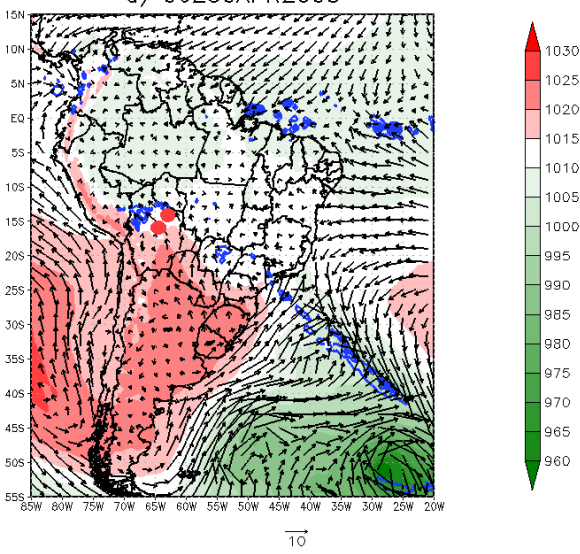

Figura 3.47: Vento horizontal em $10 \mathrm{~m}(\mathrm{~m} / \mathrm{s}$, em vetores), pressão a nível médio do mar (hPa, escala de cores) e precipitação acima de $1 \mathrm{~mm}$ (contornos em azul) para as tempestades noturnas de 30-04-2008, registradas $\sim 01: 00 \mathrm{UTC}$ em $14,1^{\circ} \mathrm{S}-64,8^{\circ} \mathrm{W}$ e $15,9^{\circ} \mathrm{S}-66,3^{\circ} \mathrm{W}$ (símbolos em vermelho) para a) 1200 UTC (dia anterior ao registro); b) 1800 UTC (dia anterior ao registro); c) 0000 UTC (dia do registro); d) 0600 UTC (dia do registro).

O terceiro caso mais intenso do conjunto de tempestades foi registrado dia 26-11-2001, às $5,04 \mathrm{UTC}$ em $8,4^{\circ} \mathrm{S}-75,9^{\circ} \mathrm{W}$, com 159,8 raios/min. Ele é um exemplo da classificação dos casos isolados na região NW do domínio, onde os ventos alísios sofrem levantamento orográfico na cordilheira dos Andes. A Figura 3.48 mostra o ciclo de vida da tempestade através da Tb. À 0000 UTC há quantidade considerável de convecção na região e 0100 UTC as primeiras células que darão origem à tempestade começam a se formar na área próxima de $7,5^{\circ} \mathrm{S}-77^{\circ} \mathrm{W}$ (seta vermelha, Fig. 3.48 a), elas evoluem em tamanho até que às 0400 UTC é possível observar dois núcleos bem definidos que se unem para, então, 0500 UTC o satélite registrar a tempestade (Fig. 3.48 a-f). Sua máxima intensidade em termos de maior área com mínima Tb é alcançada às 0730 UTC e a partir das 1000 UTC o núcleo se divide e começa a decair, quando às 1300 UTC encontra-se descaracterizada, 
embora ainda observe-se convecção. A tempestade totaliza cerca de 12 horas de duração, com mínimo deslocamento espacial.
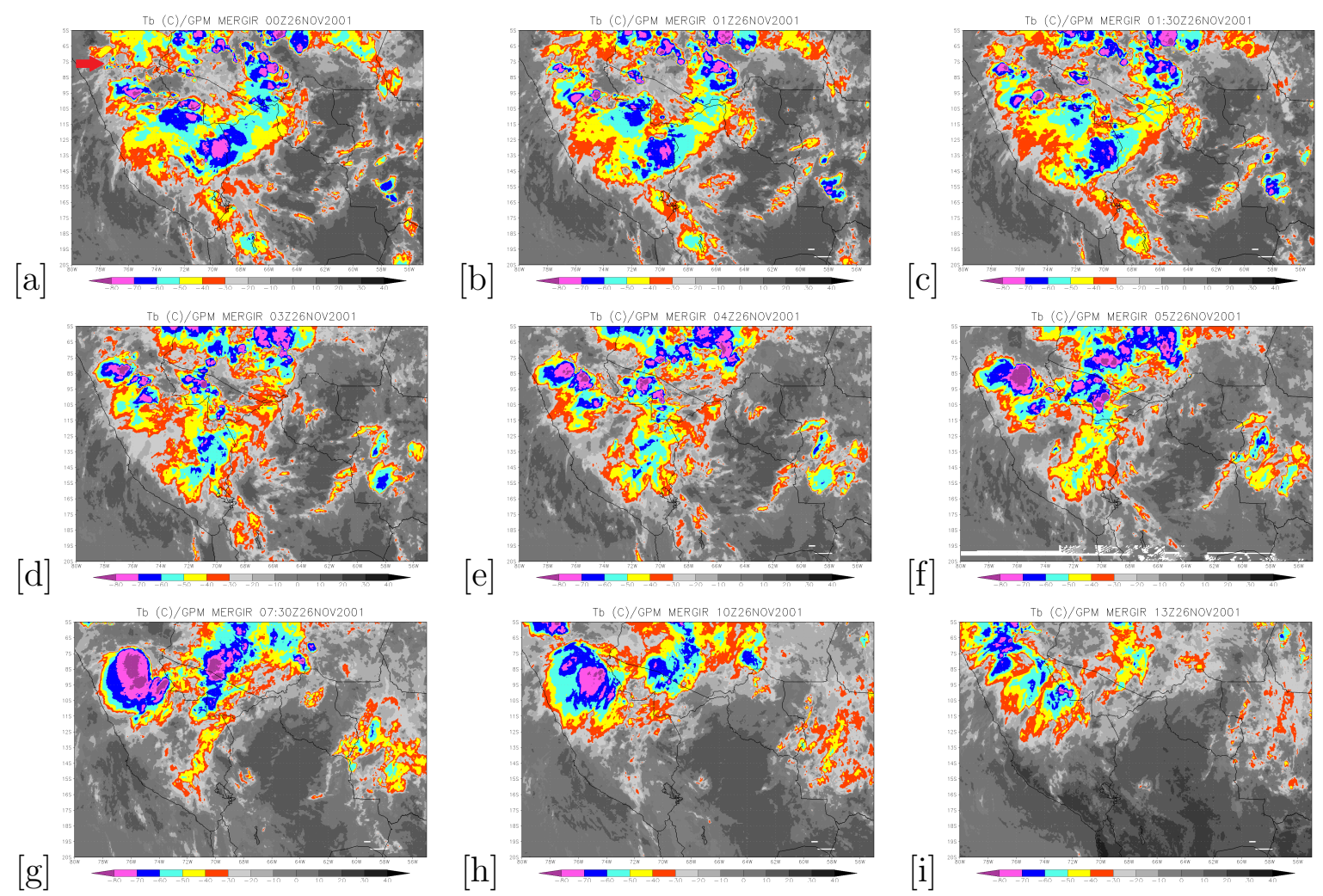

Figura 3.48: Ciclo de vida da tempestade noturna de 26-11-2001, registrada pelo satélite TRMM por 5,04 UTC em $8,14^{\circ} \mathrm{S}-75,9^{\circ} \mathrm{W}$ ilustrado pela temperatura de brilho $\left({ }^{\circ} \mathrm{C}\right)$ do conjunto GPM-MERGIR para: a) 0000 UTC; b) 0100 UTC; c) 0130 UTC; d) 0300 UTC; e) 0400 UTC; f) 0500 UTC; g) 0730 UTC; h) 1000 UTC; i) 1300 UTC.

O campo sinótico em $850 \mathrm{hPa}$ para este evento mostra que há uma confluência de ventos NW-SE, principalmente no ambiente pré-convectivo (Figura 3.49 a, b), em torno de $15^{\circ} \mathrm{S}-68^{\circ} \mathrm{W}, \sim 1000 \mathrm{~km}$ a SE de onde a tempestade atua (local identificado pelo círculo vermelho), de forma que não interfere na formação do sistema. Às 0000 UTC e 0600 UTC observa-se uma circulação ciclônica centrada aproximadamente em $12^{\circ} \mathrm{S}-62^{\circ} \mathrm{W}$, que é resposta a um vórtice ciclônico em altos níveis (VCAN) identificado no nível de 500 hPa (Figura 3.50). Este VCAN contribui para aumento de áreas de instabilidade. 

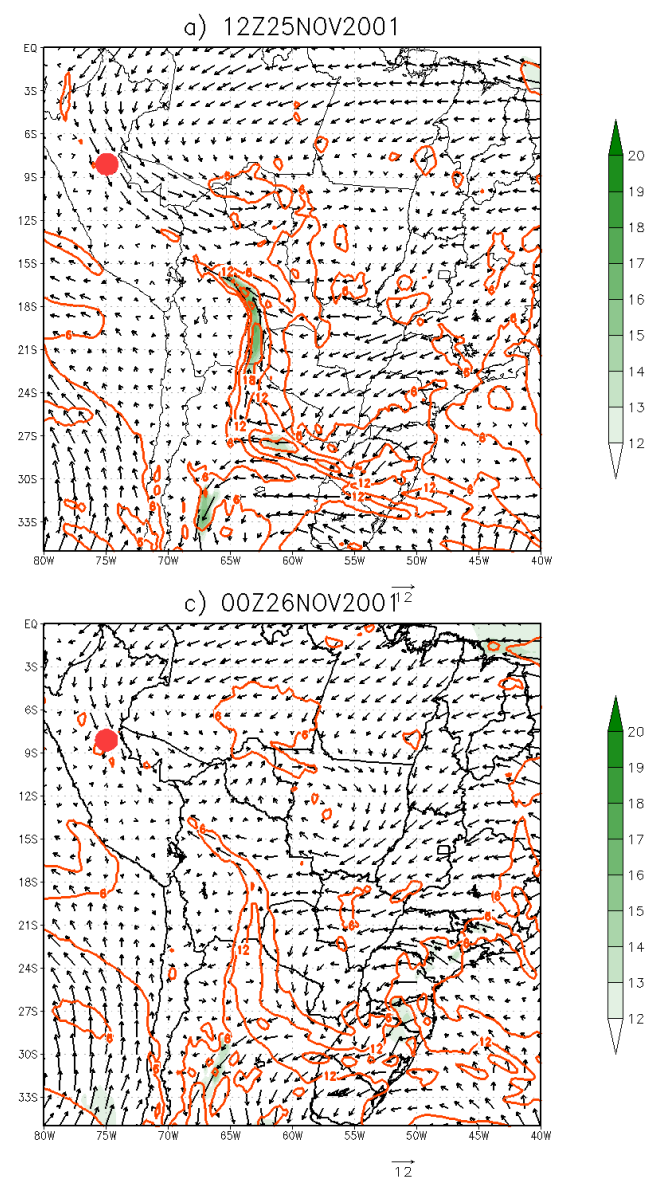

b) 18225 NOV 2001

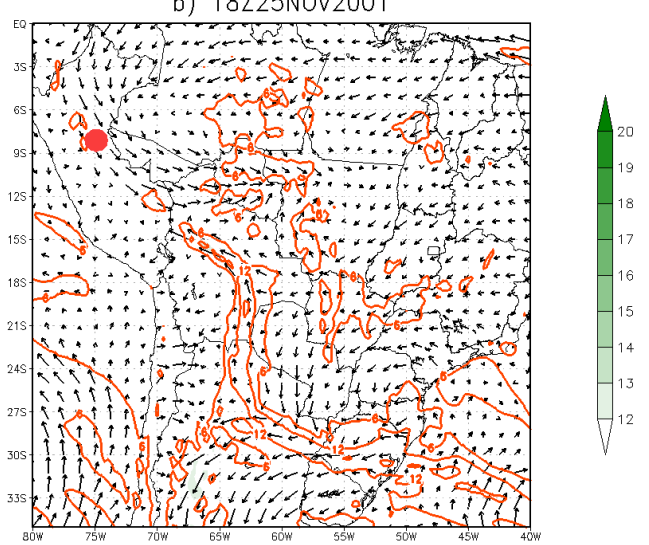

d) 06226 NOV200 $\overrightarrow{1^{12}}$

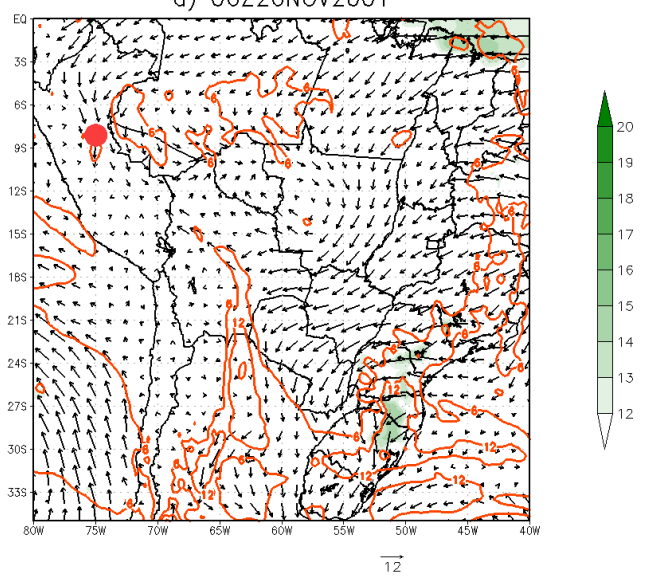

Figura 3.49: Magnitude do vento (m/s, escala de cores) superior a $12 \mathrm{~m} / \mathrm{s}$ em $850 \mathrm{hPa}$ e cisalhamento vertical do vento horizontal entre 700-850 $\mathrm{hPa}$ (contornos em vermelho) acima de $6 \mathrm{~m} / \mathrm{s}$ para a tempestade noturna de 26-11-2001, registrada $\sim 05: 00$ UTC em 8,14 ${ }^{\circ} \mathrm{S}-$ $75,9^{\circ} \mathrm{W}$ (símbolo em vermelho) para a) 1200 UTC (dia anterior ao registro); b) 1800 UTC (dia anterior ao registro); c) 0000 UTC (dia do registro); d) 0600 UTC (dia do registro).

A Figura 3.51 mostra um recorte da topografia na região de atuação da tempestade noturna acima mencionada e evidencia a complexidade do relevo no qual ela se desenvolve, matura e decai. As primeiras células iniciam onde os alísios são forçados a subir cerca de $1500 \mathrm{~m}$ de altitude na inclinação da cordilheira, condensando vapor d'água e ativando os processos microfísico de crescimento de gotas e formação de gelo. Símbolo preto indica local de formação, símbolo vermelho local de registro. 

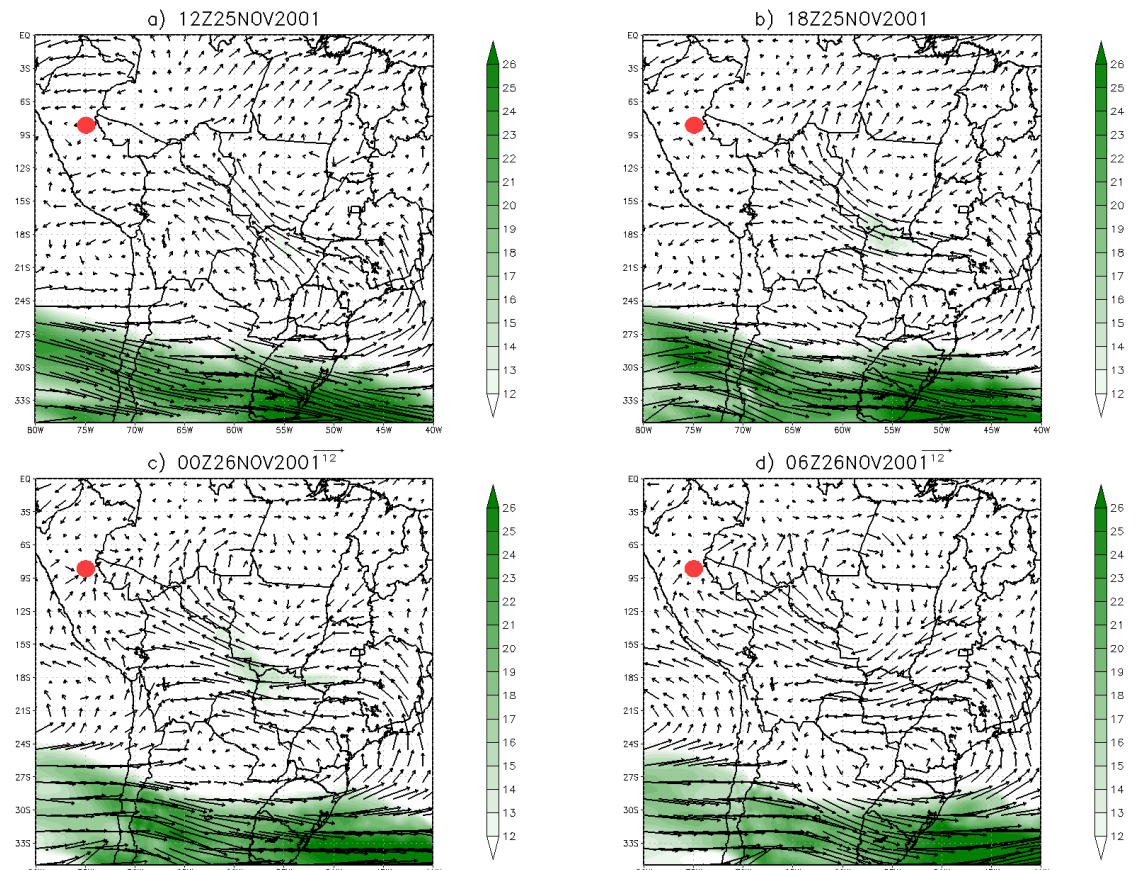

Figura 3.50: Magnitude do vento (m/s, escala de cores) superior a $12 \mathrm{~m} / \mathrm{s}$ em $500 \mathrm{hPa}$ para a tempestade noturna de 26-11-2001, registrada $\sim 0500 \mathrm{UTC}$ em $8,14^{\circ} \mathrm{S}-75,9^{\circ} \mathrm{W}$ (símbolo em vermelho) para a) 1200 UTC (dia anterior ao registro); b) 1800 UTC (dia anterior ao registro); c) $0000 \mathrm{UTC}$ (dia do registro); d) $0600 \mathrm{UTC}$ (dia do registro).

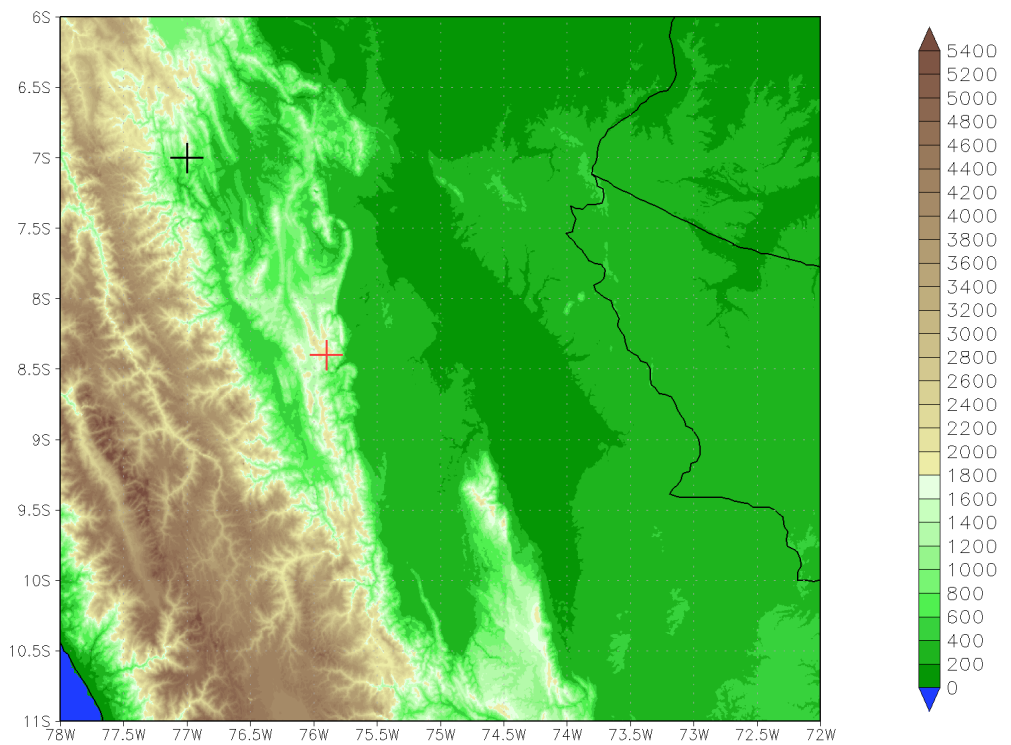

Figura 3.51: Elevação do terreno ( $\mathrm{m}$, escala de cores) na região onde atua a tempestade 26$11-2001$, registrada $\sim 0500 \mathrm{UTC}$ em $8,14^{\circ} \mathrm{S}-75,9^{\circ} \mathrm{W}$, baseada no conjunto de dados de alta resolução SRTM. Símbolo preto indica local de formação, símbolo vermelho local de registro. 
O ciclo de vida ilustrado pela Tb no painel da Figura 3.52 mostra a evolução da $16^{\mathbf{0}}$ tempestade noturna mais intensa, registrada às 0254 UTC do dia 20-10-2007 em 10,9 $9^{\circ} \mathrm{S}$ $60,04^{\circ} \mathrm{W}$, com 61,86 raios/min. Apesar da grande atividade convectiva ao longo da região, este sistema ocorre isolado de sistemas sinóticos e distante da cordilheira dos Andes, no NE do domínio de estudo onde atuam os ventos alísios de NE. As primeiras células que dão origem a este evento iniciam por volta de 2100 UTC do dia anterior ao registro, na região indicada pela seta vermelha na Figura 3.52 a. À 0000 UTC ele já está bem configurado, com formato circular e às 0200 UTC une-se a um sistema maior localizado a NW quando por volta de 0300 UTC é registrado pelo satélite TRMM (Fig. 3.52 b-d). Às 0500 UTC ele começa a decair e logo às 0700 UTC está descaracterizado, totalizando aproximadamente 10 horas de duração.

No campo de 850 hPa (Figura 3.53) nota-se que o escoamento de E-NE no ambiente préconvectivo tem cisalhamento significativo em baixos níveis (maior que $6 \mathrm{~m} / \mathrm{s}$, representado pelos contornos vermelhos) mas não é intenso em magnitude (Fig. 3.53,a,b). A partir de 0000 UTC o JBNAS encontra-se configurado próximo de $18^{\circ} \mathrm{S}-64^{\circ} \mathrm{W}$, a $\mathrm{SW}$ do registro da tempestade (símbolo vermelho), então considera-se que o evento noturno ocorre isolado de sistemas sinóticos, no escoamento dos alísios antes da deflexão na cordilheira estabelecer o JBNAS.

Ao fazer um recorte do relevo onde a tempestade se desenvolve (Figura 3.54) nota-se que a região onde as primeiras células são formadas (aproximadamente em $10,5^{\circ} \mathrm{S}-58,5^{\circ} \mathrm{W}$, símbolo preto) há elevação cerca de $500 \mathrm{~m}$ no terreno para um escoamento de $\mathrm{E} / \mathrm{NE}$, o que pode estabelecer um gatilho para o disparo da tempestade. O símbolo vermelho indica local de registro. 


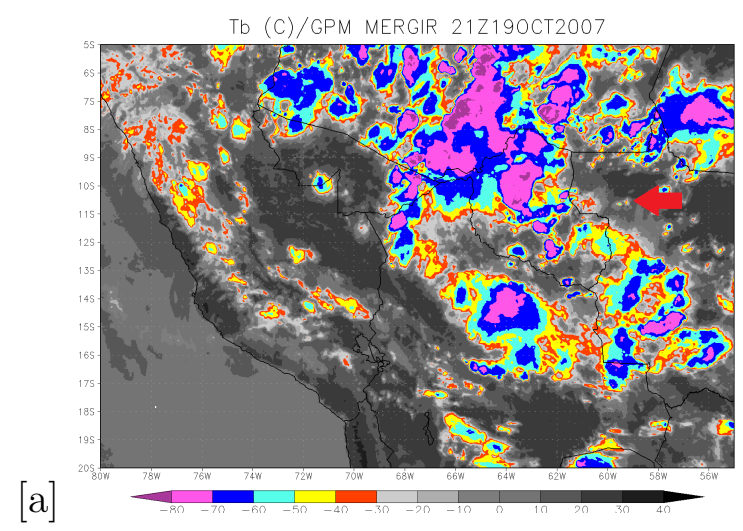

$[\mathrm{b}]$

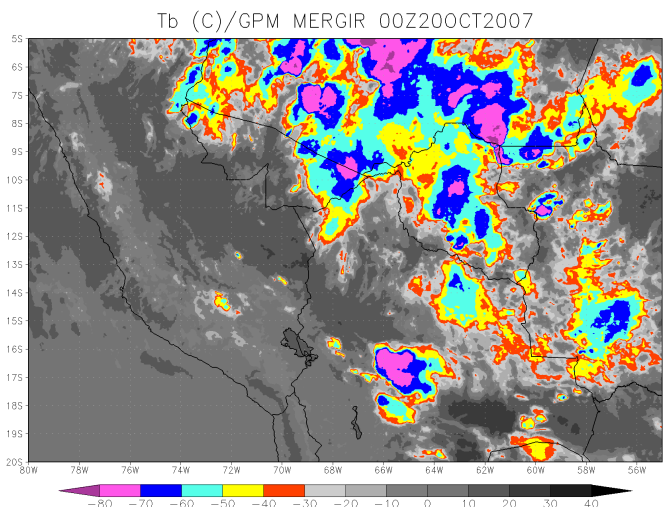

Tb (C)/GPM MERGIR 02Z200CT2007

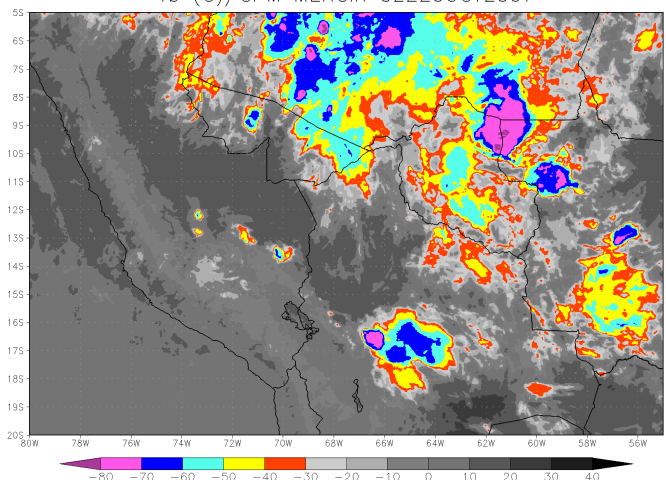

Tb (C)/GPM MERGIR 03Z200CT2007

$[c]$

Tb (C)/GPM MERGIR 05Z200CT2007

$[\mathrm{d}]$
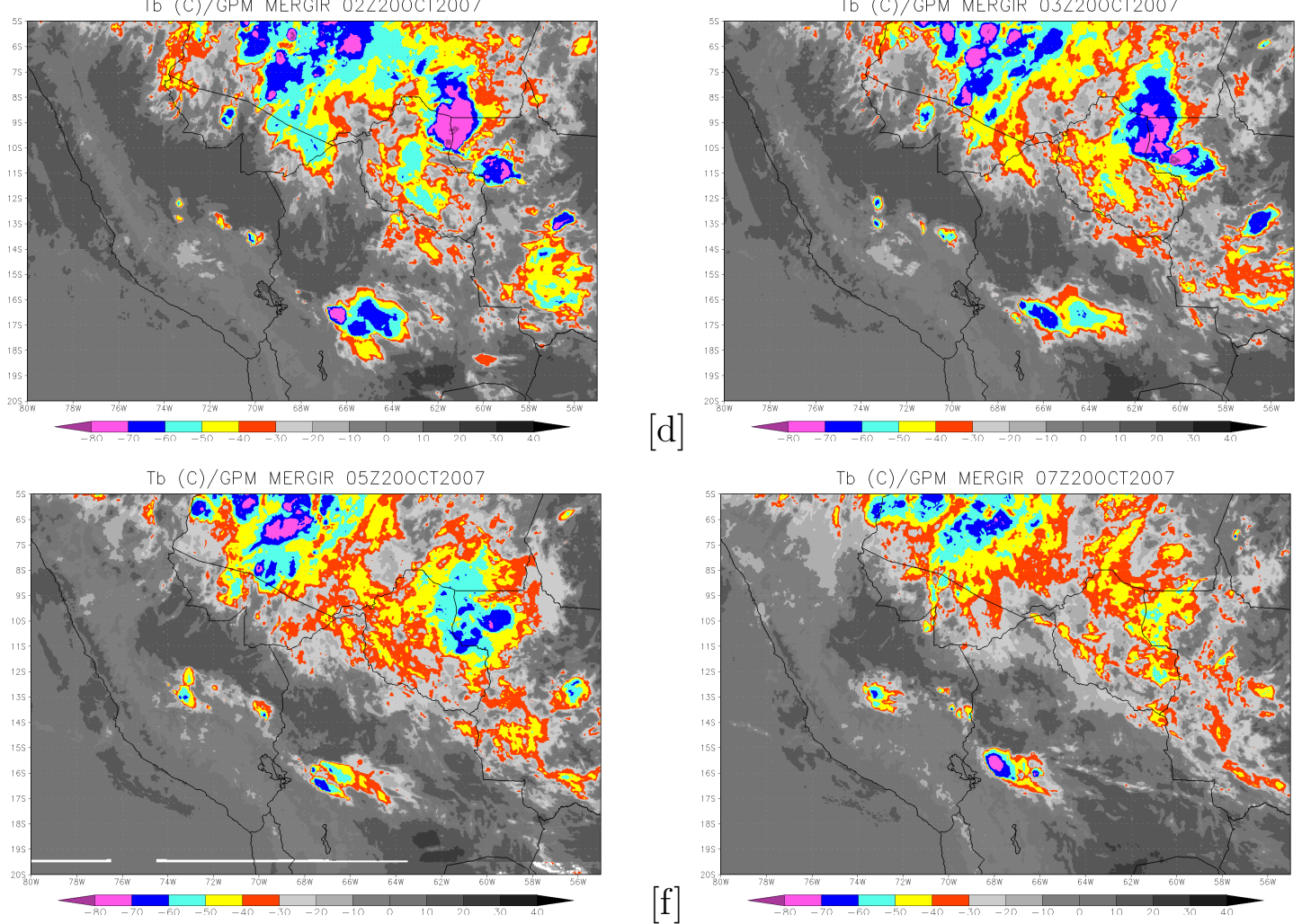

Tb (C)/GPM MERGIR 07Z200CT2007

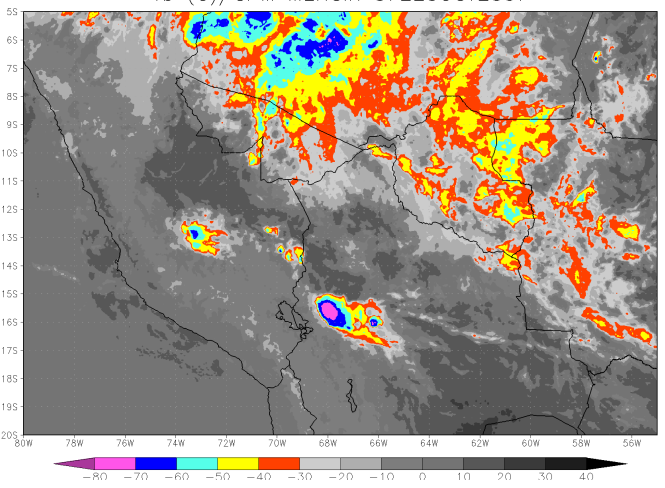

Figura 3.52: Ciclo de vida da tempestade noturna de 20-10-2007, registrada pelo satélite TRMM às 00254 UTC em $10,9^{\circ} \mathrm{S}-60,04^{\circ} \mathrm{W}$ ilustrado pela temperatura de brilho $\left({ }^{\circ} \mathrm{C}\right)$ do conjunto GPM-MERGIR para: a) 2100 UTC (dia anterior); b) 0000 UTC; c) 0200 UTC; d) 0300 UTC; e) 0500 UTC; f) 0700 UTC. 

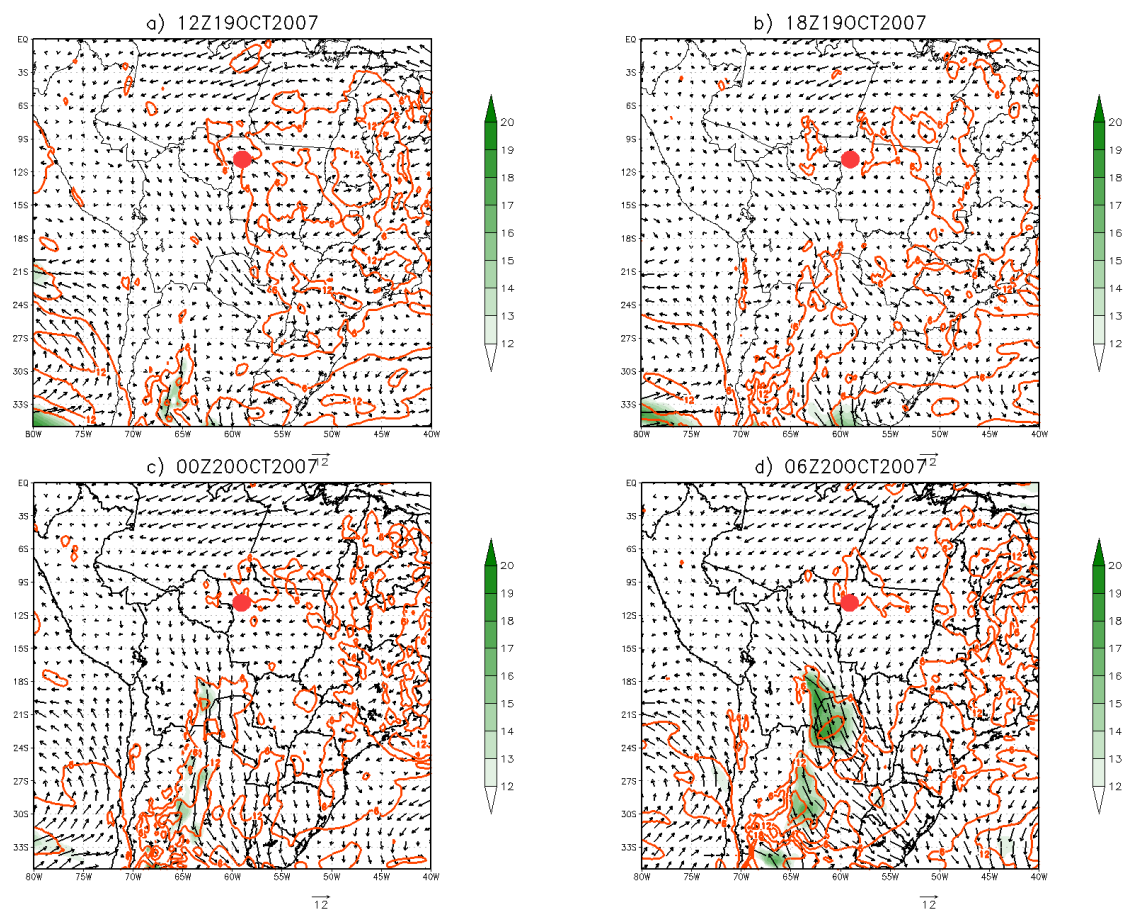

Figura 3.53: Magnitude do vento (m/s, escala de cores) superior a $12 \mathrm{~m} / \mathrm{s}$ em $850 \mathrm{hPa}$ e cisalhamento vertical do vento horizontal entre 700-850 hPa (contornos em vermelho) acima de $6 \mathrm{~m} / \mathrm{s}$ para a tempestade noturna de 20-10-2007, registrada $\sim 0300$ UTC em 10,9 $9^{\circ} \mathrm{S}-$ $60,04^{\circ} \mathrm{W}$ (símbolo em vermelho) para a) $1200 \mathrm{UTC}$ (dia anterior ao registro); b) 1800 UTC (dia anterior ao registro); c) 0000 UTC (dia do registro); d) 0600 UTC (dia do registro).

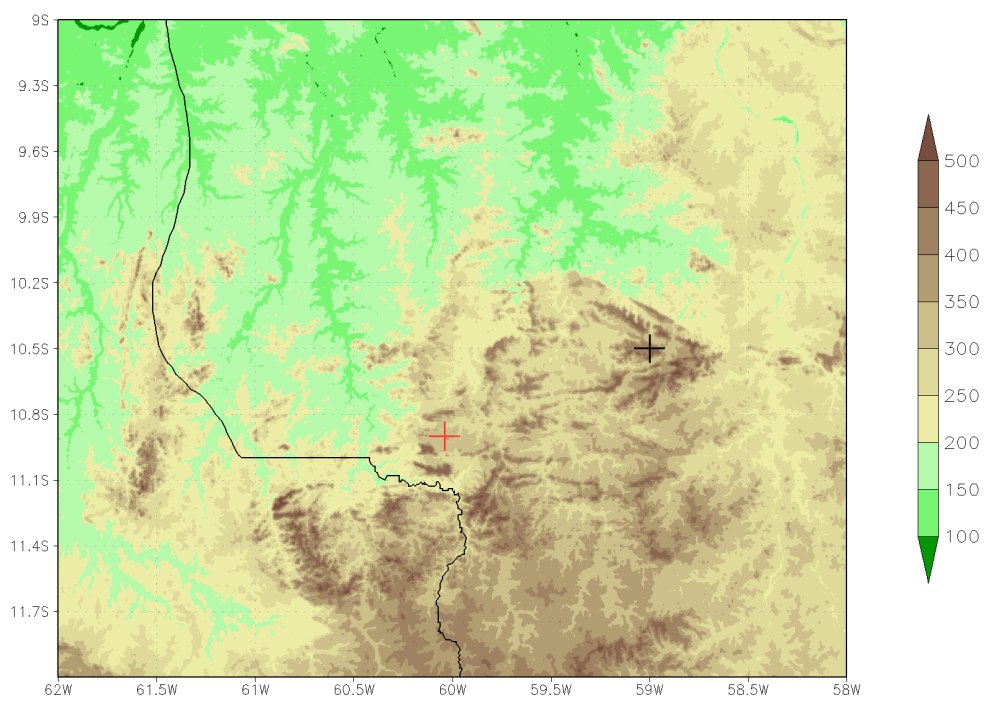

Figura 3.54: Elevação do terreno (m, escala de cores) na região onde atua a tempestade 2010-2007, registrada $\sim 0300 \mathrm{UTC}$ em $10,9^{\circ} \mathrm{S}-60,04^{\circ} \mathrm{W}$, baseada no conjunto de dados de alta resolução SRTM. Símbolo preto indica local de formação, símbolo vermelho local de registro. 
A tempestade noturna mais intensa do conjunto foi registrada no dia 25-12-2013 às $0150 \mathrm{UTC}$ em $16,16^{\circ} \mathrm{S}-63,42^{\circ} \mathrm{W}$, com uma taxa de 275,14 raios/min durante o tempo de observação do TRMM. Sua formação está relacionada ao escoamento da ZCAS, como será mostrado a seguir, e o painel da Figura 3.55 ilustra seu ciclo de vida através da Tb.
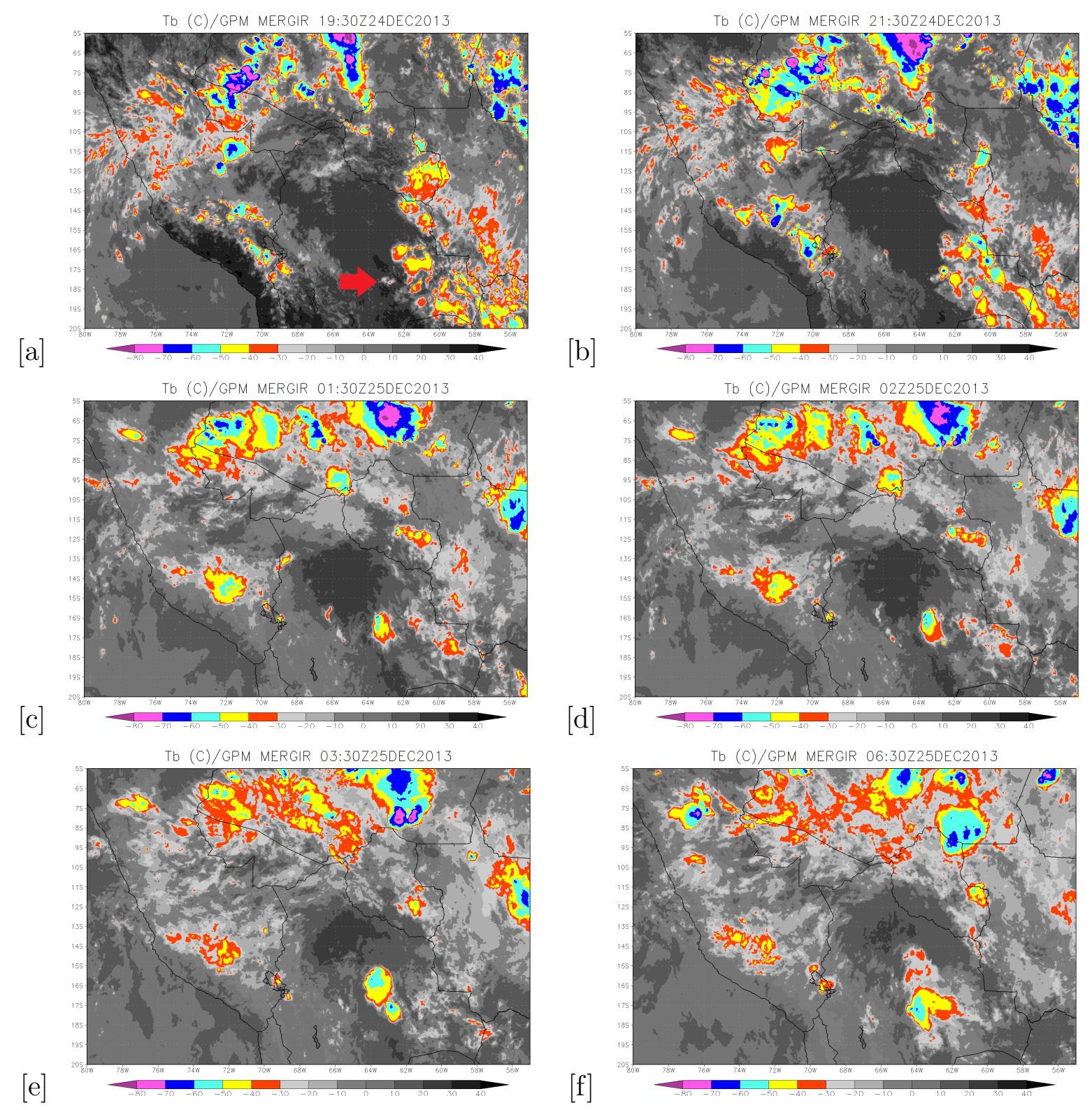

Figura 3.55: Ciclo de vida da tempestade noturna de 25-12-2013, registrada pelo satélite TRMM às 0150 UTC em $16,16^{\circ} \mathrm{S}-63,42^{\circ} \mathrm{W}$ ilustrado pela temperatura de brilho $\left({ }^{\circ} \mathrm{C}\right)$ do conjunto GPM-MERGIR para: a) 1930 UTC (dia anterior); b) 2130 UTC (dia anterior); c) 0130 UTC; d) 0200 UTC (próximo ao horário de registro); e) 0330 UTC; f) 0630 UTC. Símbolo preto indica local de formação, símbolo vermelho local de registro.

As primeiras células deste sistema têm início por volta de 1930 UTC do dia anterior, 
no local indicado pela seta vermelha da Figura 3.55 a, aproximadamente $17,6^{\circ} \mathrm{S}-62,8^{\circ} \mathrm{W}$. O sistema cresce adquirindo forma praticamente circular às 2130 UTC (Fig. 3.55 b), deslocando-se ligeiramente para $\mathrm{NE}$, com $\mathrm{Tb}$ inferior a $-60^{\circ} \mathrm{C}$. O sistema, então, cresce deslocando-se para NO, quando próximo de 0200 UTC (Fig. 3.55 d) é registrado pelo satélite. Seu núcleo começa perder intensidade enquanto o sistema se expande e decai, quando às 0630 UTC está descaracterizada (Fig. 3.55e, f), totalizando 11 horas de duração.

Quando se comparam as propriedades desta PF com os valores máximos e mínimos do conjunto de estudo (Tabela 3.3) verificamos que ela se destaca por:

1. Taxa de 275,14 raios/min absolutamente superior ao restante do conjunto, representando sozinha o percentil de $99 \%$ (não mostrado, mas para valores de outros percentis ver Tabela 3.1), uma vez que a segunda tempestade mais intensa apresenta 210,71 raios/min (Tabela 3.2);

2. Elevada altura máxima do nível de $40 \mathrm{dBZ}$ de $12,5 \mathrm{Km}$, indicando se tratar de um núcleo convectivo profundo: quanto mais elevada a altura deste eco mais forte se presume a corrente ascendente na nuvem. Apenas 4 tempestades têm valor igual ou superior e $20 \%$ tempestades têm entre 10 - $15 \mathrm{Km}$;

3. Sua área total de $8375 \mathrm{Km}^{2}$ é pequena, o que representa cerca de $12 \%$ da área máxima do conjunto $\left(67075 \mathrm{Km}^{2}\right)$ e apenas 4 vezes a área mínima $\left(2100 \mathrm{Km}^{2}\right)$;

4. Em relação às mínimas $\mathrm{PCTs}$ nos canais de 85 e $37 \mathrm{GHz}$ os respectivos valores de 89,41 K e 189,35 K não são os mais extremos do conjunto porém estão dentro da faixa de valores das 0,09\% tempestades mais extremas do globo segundo Zipser et al., 2006.

Segundo o Boletim Climanálise (CPTEC-INPE) um episódio clássico de ZCAS esteve bem configurado entre os dias 11 e 26-12-2013 sobre as regiões Sudeste, Centro-Oeste, Norte e Nordeste do Brasil, com sua região de convergência de umidade associada a um cavado invertido em 850 hPa, na parte central do país, e suporte dinâmico de um VCAN em $500 \mathrm{hPa}$. A Figura 3.56 mostra os campos médios que caracterizaram o evento de ZCAS: Tb, vento e divergência de umidade em $850 \mathrm{hPa}$, vento e velocidade vertical em $500 \mathrm{hPa}$ e precipitação acumulada (Fig. 3.56 a, b, c, d, respectivamente), evidenciando sua área de atuação. 
No horário aproximado do registro da tempestade noturna (02:00 UTC) é possível notar a banda de nebulosidade associada com a atuação da ZCAS através da Tb (GPMMERGIR) na Figura 3.57. Como destacado pelo círculo vermelho, a tempestade ocorre a W desta linha de nebulosidade, encontrando-se isolada do sistema sinótico.

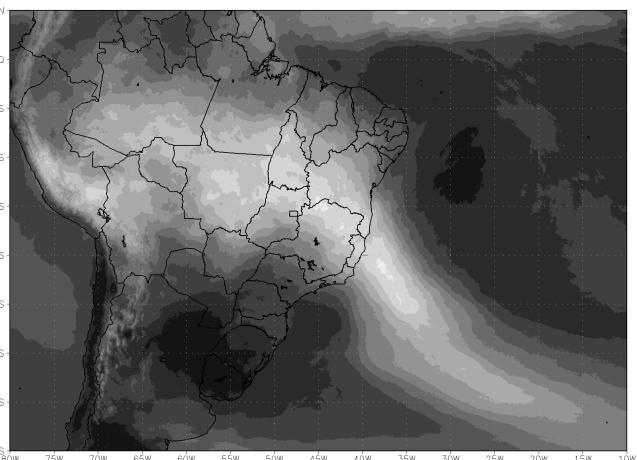

[a]

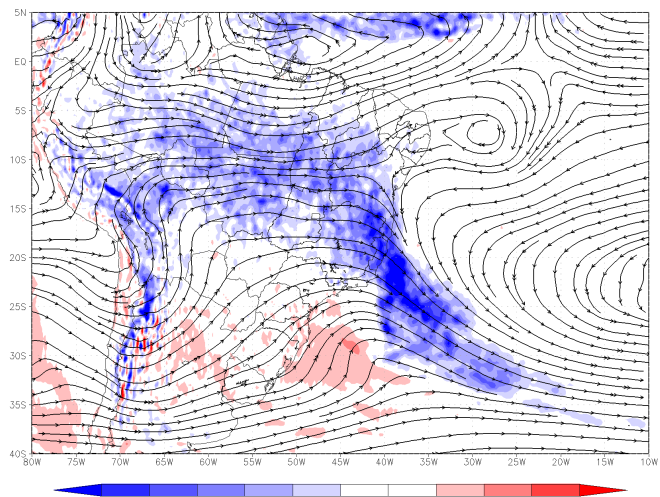

$[\mathrm{b}]$
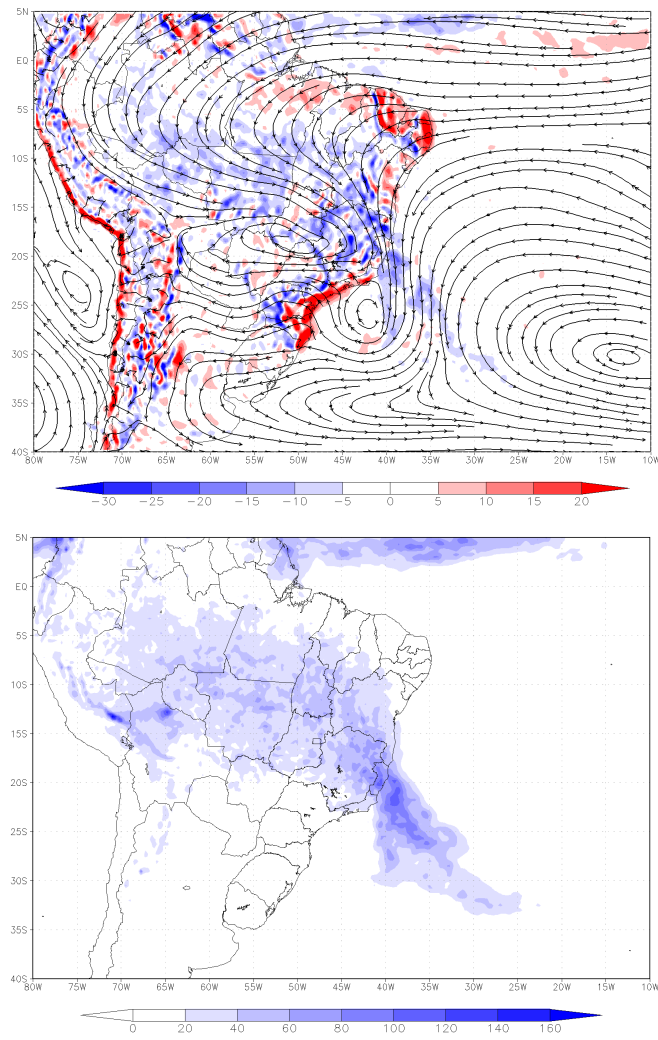

$[\mathrm{d}]$

Figura 3.56: Campos médios do evento de ZCAS registrado entre 11 e 26-12-2013 de: a) Tb (GPMMERGIR); b) linhas de corrente e divergência de umidade no nível de $850 \mathrm{hPa}\left(10^{-8} \mathrm{Kg} s^{-1}\right.$, ERA5); c) linhas de corrente e velocidade vertical em $500 \mathrm{hPa}\left(10^{-3} \mathrm{~Pa} s^{-1}\right.$, ERA5); d) precipitação acumulada (mm, ERA5). 


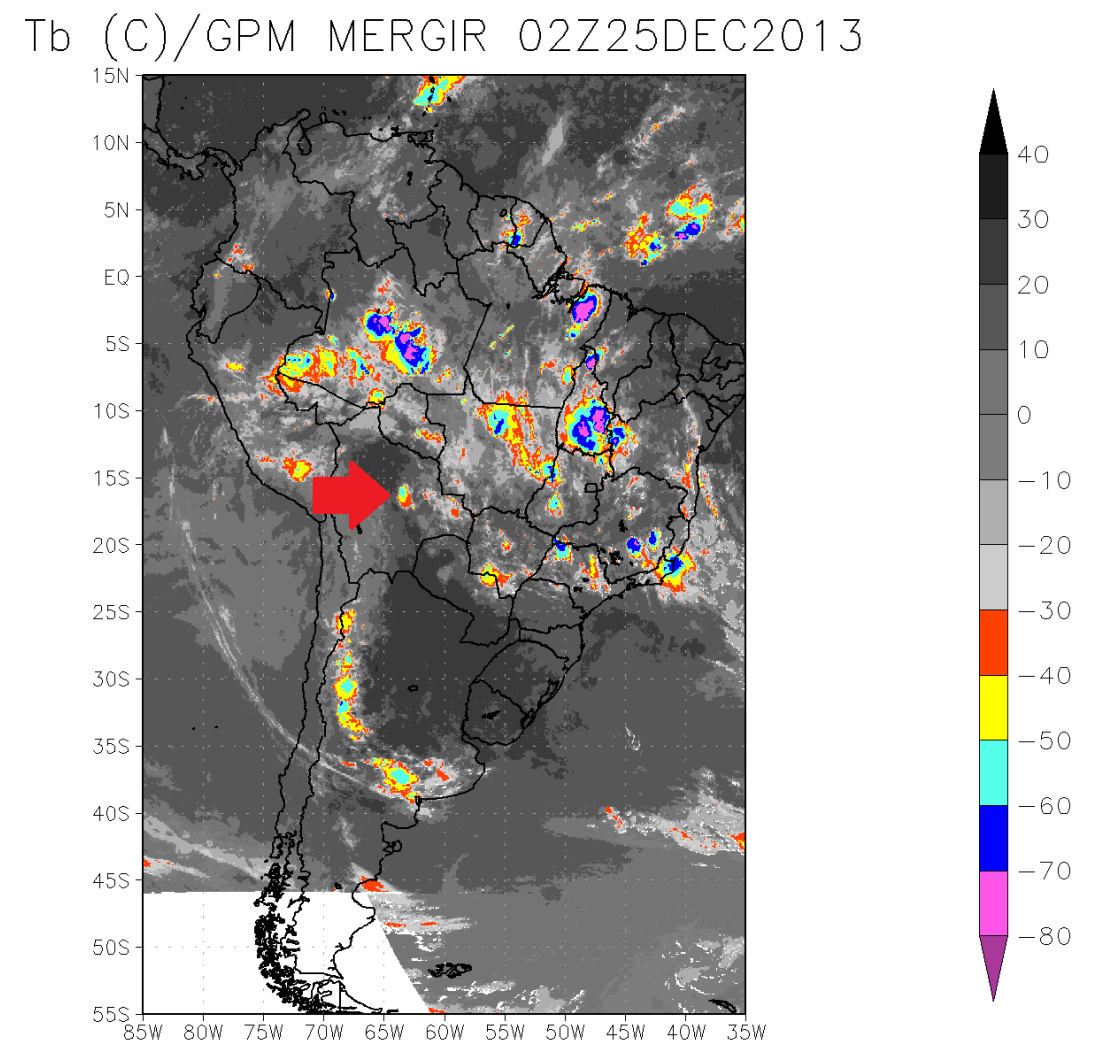

Figura 3.57: Temperatura de brilho para horário aproximado do registro da tempestade noturna de 25-12-2013 (0200 UTC), registrada pelo satélite TRMM em $16,16^{\circ} \mathrm{S}-63,42^{\circ} \mathrm{W}$, indicada pelo círculo vermelho.

Os campos de vento no nível de 500 hPa (Figura 3.58) mostram atuação do VCAN praticamente concêntrico com a região onde a tempestade atua (símbolo preto) desde os horários pré-convectivos do evento noturno. Além disso observa-se que há um transporte de ar seco e frio de S para N na borda ocidental da circulação ciclônica, uma vez que a escala de cores representa a umidade relativa $(\%)$ e os contornos em branco temperatura $\left({ }^{\circ} \mathrm{C}\right)$. O entranhamento de ar seco em níveis médios é ingrediente para severidade de tempestades, uma vez que causa evaporação do vapor d'água, resfriando o ar e acelerando as correntes descendentes dentro da nuvem. 
a) 12:00 UTC - dia anterior

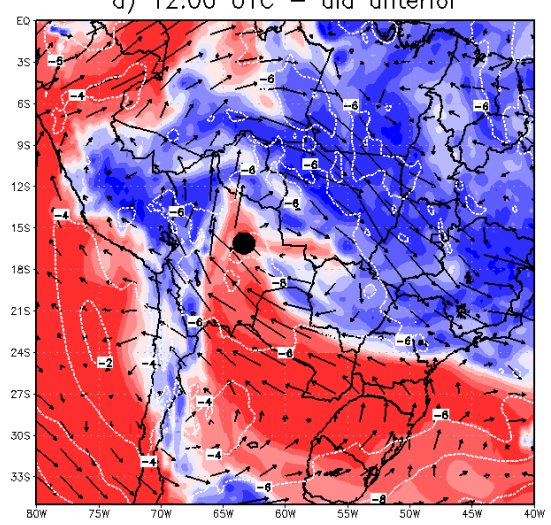

c) 00:00 UTC - d $\overrightarrow{\mathrm{i}^{2}}$

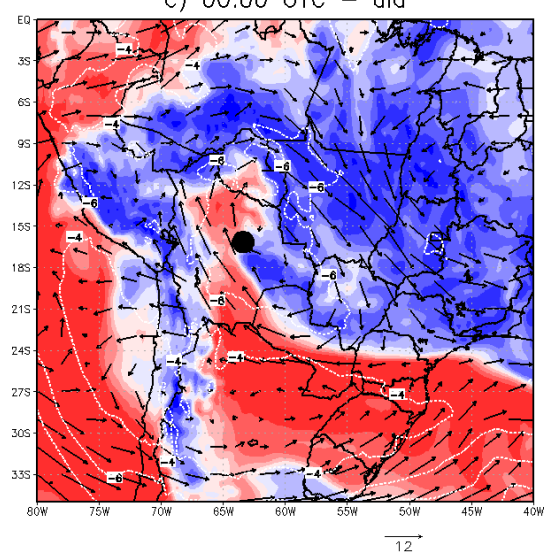

b) 18:00 UTC - dia anterior

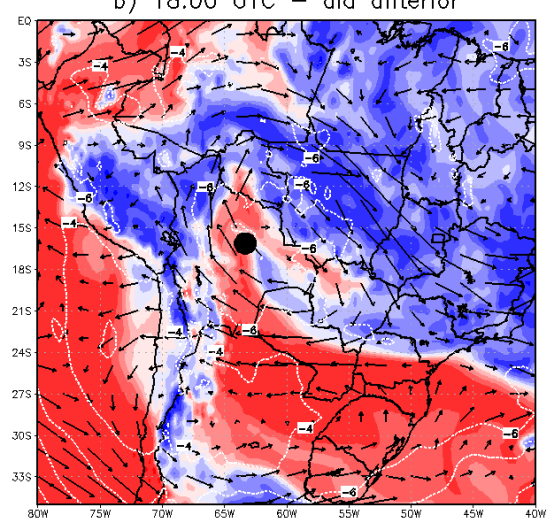

d) 06:00 UTC - di $\overrightarrow{a^{3}}$

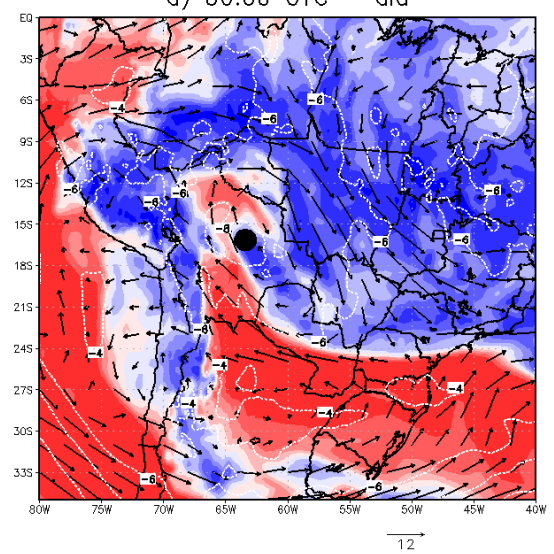

Figura 3.58: Vento horizontal (vetores) em $500 \mathrm{hPa}$, umidade relativa (\%, escala de cores) e temperatura (contornos em branco) para a tempestade noturna de 25-12-2013, registrada $0150 \mathrm{UTC}$ em $16,16^{\circ} \mathrm{S}-63,42^{\circ} \mathrm{W}$ (símbolo preto) para a) $1200 \mathrm{UTC}$ (dia anterior ao registro); b) 1800 UTC (dia anterior ao registro); c) 0000 UTC (dia do registro); d) 0600 UTC (dia do registro).

Em $850 \mathrm{hPa}$ os campos de vento apresentados na Figura 3.59 indicam que o JBNAS se estabelece a E do centro da tempestade (símbolo vermelho), na mesma região de convergência de umidade da ZCAS mostrada na Fig 3.56. b. Aqui também se observa que a circulação ciclônica de níveis médios supracitada se reflete em baixos níveis, de forma que a tempestade tenha início em um escoamento de $\mathrm{SE} / \mathrm{E}$ em baixos níveis, referente à borda austral desta circulação. Com base nos campos aqui expostos, considerou-se que a tempestade mais intensa do conjunto de dados é isolada de sistemas sinóticos, mas seu desenvolvimento tem suporte do escoamento relacionado à ZCAS. 

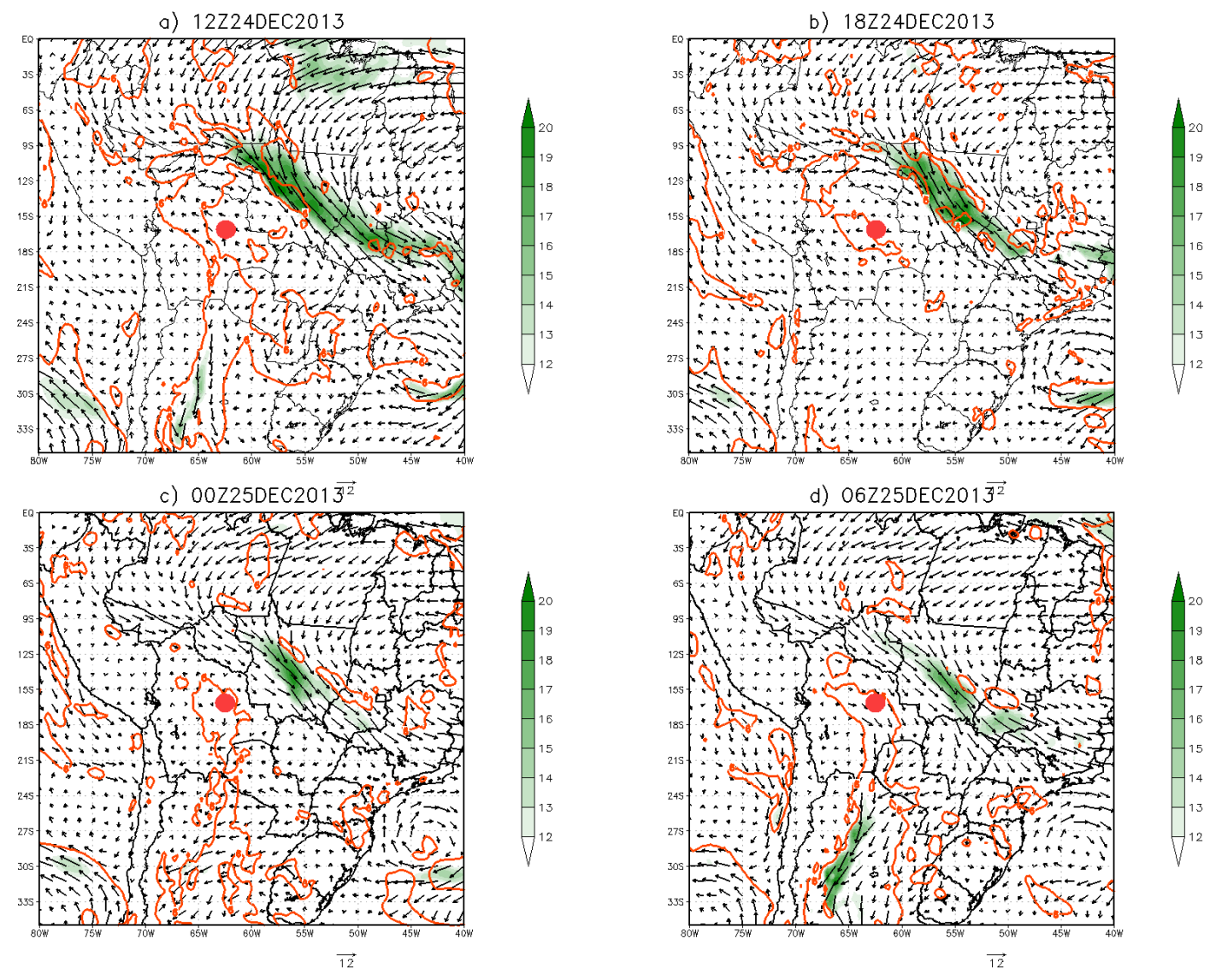

Figura 3.59: Magnitude do vento (m/s, escala de cores) superior a $12 \mathrm{~m} / \mathrm{s}$ em $850 \mathrm{hPa}$ e cisalhamento vertical do vento horizontal entre $700-850 \mathrm{hPa}$ (contornos em vermelho) acima de $6 \mathrm{~m} / \mathrm{s}$ para a tempestade noturna de 25-12-2013, registrada $\sim 0150$ UTC em $16,16^{\circ} \mathrm{S}-$ $63,42^{\circ} \mathrm{W}$ (símbolo em vermelho) para a) $1200 \mathrm{UTC}$ (dia anterior ao registro); b) $1800 \mathrm{UTC}$ (dia anterior ao registro); c) 0000 UTC (dia do registro); d) 0600 UTC (dia do registro).

\subsubsection{Ciclo de vida}

O rastreamento manual das tempestades noturnas permitiu uma estimativa a respeito do horário de início dos eventos e sua duração. O horário de início foi considerado como aquele onde surgem as primeiras células que evoluem em tamanho e profundidade para formar as tempestades registradas pelo TRMM, e não limiares de área e temperatura como nos métodos automatizados. Já o tempo de vida é contabilizado desde o surgimento destas primeiras células até o momento que o sistema se encontra descaracterizado. Devido à grande atividade convectiva na região de estudo, há casos onde não é possível identificar o fim de uma tempestade, uma vez que a evolução pode incluir diversas divisões de um sistema assim como fusões com outras células.

Com o objetivo de estabelecer se as tempestades se desenvolvem de fato no período 
noturno da região de registro opta-se por analisar o início das tempestades através da hora local, padronizando a subtração de 5 horas em relação a hora de Greenwich (UTC), uma vez que o domínio de estudo possui dois fusos horários diferentes e que a maioria das tempestades se encontre mais a oeste. Considerou-se os intervalos ]00-06], ]06-12], ]12-18] e ]18-24] respectivamente como madrugada, manhã, tarde e noite (hora local).

A maioria absoluta das tempestades noturnas inicia após 1200 hora local, mas principalmente à noite: praticamente metade dos casos tem início entre 1800-0000 hora local, como pode ser visto no histograma da Figura 3.60. Este resultado é coerente com o primeiro e terceiro picos de gênese de SCMs na bacia amazônica identificados por Rehbein, Ambrizzi e Mechoso (2018): entre 1700-2000 UTC (1200-1500 hora local) e entre 0200-0400 UTC (2100-2300 hora local). Salio, Nicolini e Zipser (2007) bem como Pereira Filho et al. (2015) também encontram resultados similares.

O tempo de vida dos sistemas é mostrado no histograma da Figura ??. O critério de início dos sistemas utilizado no presente estudo resulta em sistemas com tempos de vida médios mais longos que o encontrado por outros autores, inclusive para as latitudes subtropicais (como em Sakamoto, 2009, por exemplo, $>12 \mathrm{~h}$ ), que costumam ter maiores durações que os SCMs na Amazônia (Velasco e Fritsch, 1987; Machado et al., 1998; Rehbein, Ambrizzi e Mechoso, 2017; Anselmo et al., 2021). O tempo médio de vida das tempestades noturnas no SW Amazônia é de 16,6 h, enquanto Salio, Nicolini e Zipser (2007) encontram valores entre 6 e $9 \mathrm{~h}$ para SCMs tropicais, Rehbein, Ambrizzi e Mechoso (2018) $6 \mathrm{~h}$ em média para SCMs continentais na Amazônia e Anselmo et al. (2021) calculam 6,5 h para SCMs rastreados em toda a bacia amazônica. Quase metade das tempestades noturnas tem duração entre 7,5 e 15 horas, sendo o intervalo de 15 a 22,5 horas o segundo preferencial. Duas tempestades têm a duração mínima de 7,5 horas, elas são essencialmente isoladas, não intensas e sem atuação de JBNAS: uma no NE do domínio (90 caso, 04-04-2005) e uma com suporte do escoamento da ZCAS (77ํㅜ caso, 13-03-2006). 


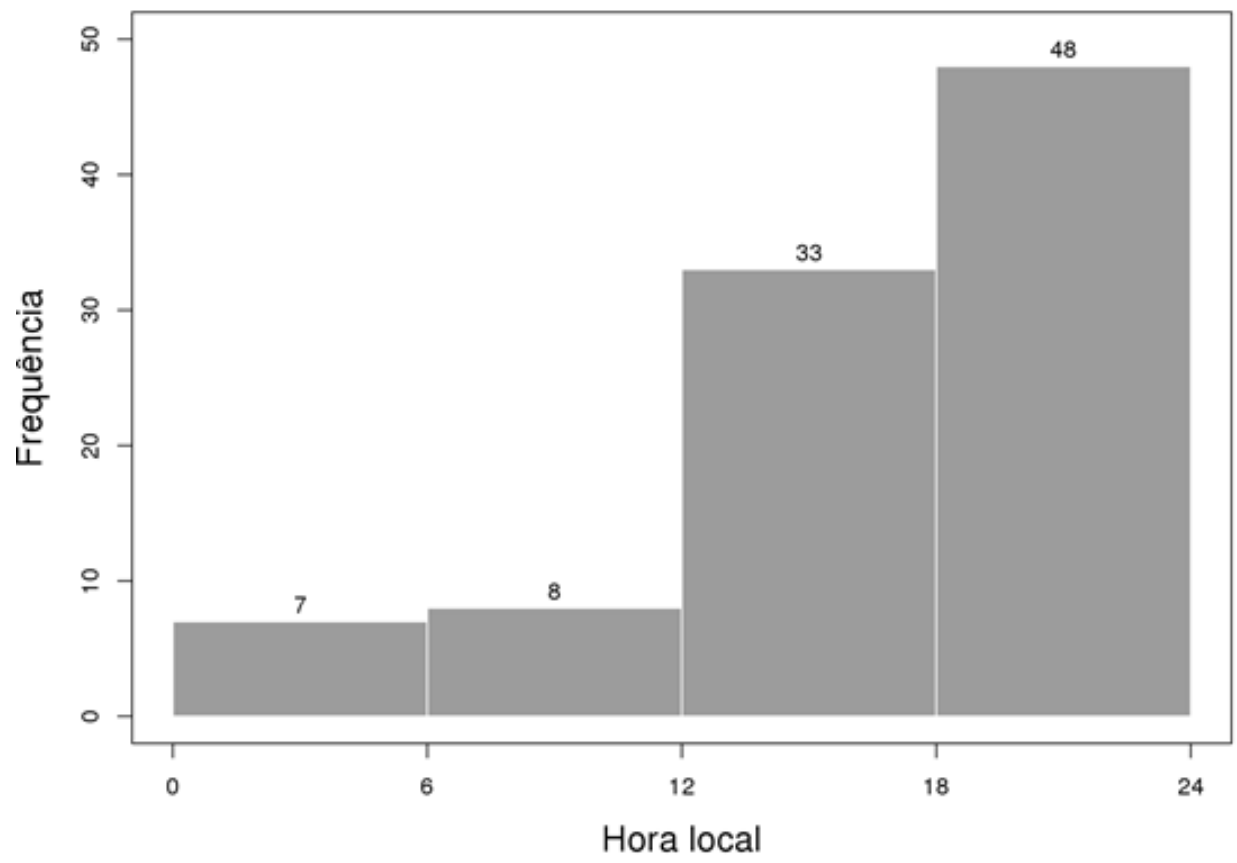

Figura 3.60: Histograma da hora local de início das tempestades noturnas.

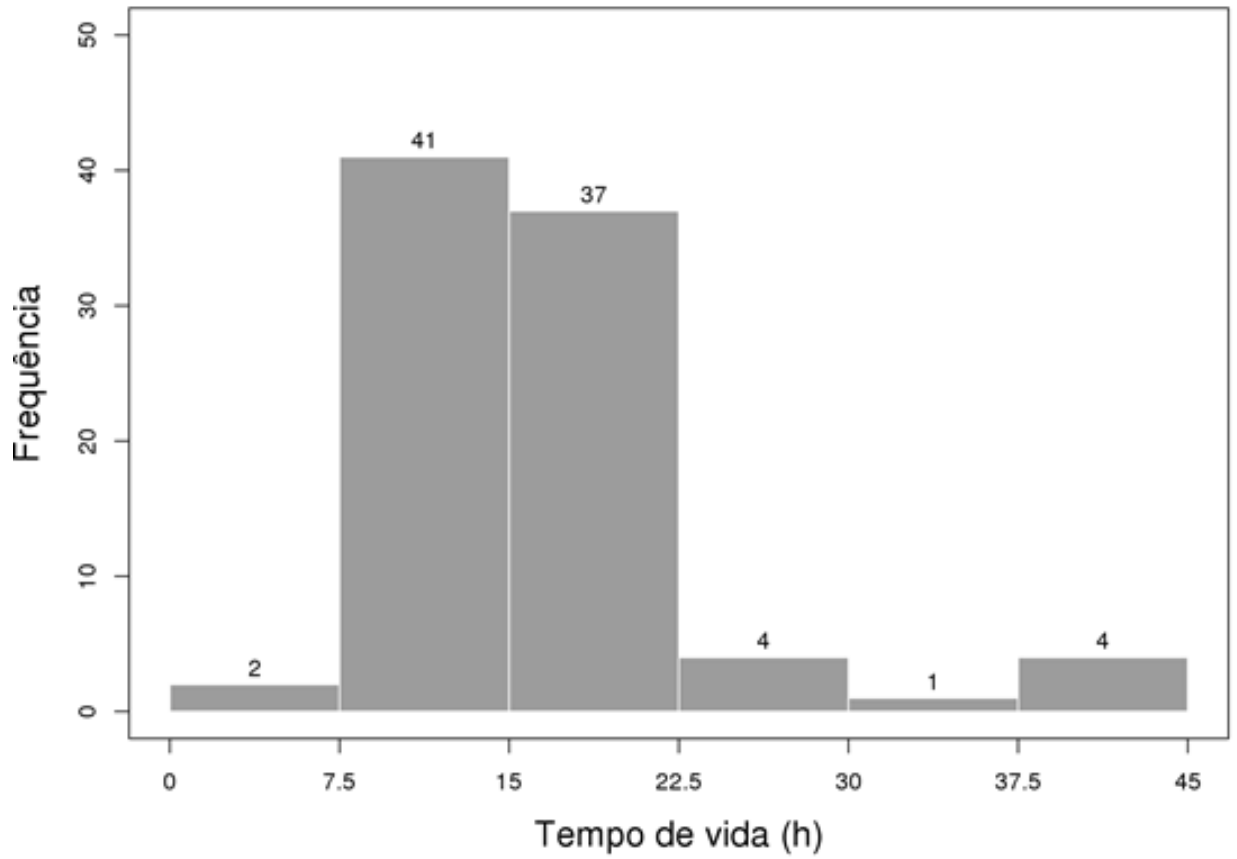

Figura 3.61: Histograma do tempo de vida das tempestades noturnas. 
A duração máxima de 42 horas, novamente, é devido ao critério de início dos sistemas, uma vez que tempestade do dia $11-11-2011$ foi registrada em aproximadamente $13^{\circ} \mathrm{S}-62^{\circ} \mathrm{W}$ às 0945 UTC mas seu núcleo se desenvolve na dianteira de um sistema disparado às 1900 UTC do dia 09-11-2011 (dois dias antes) na Argentina, em $29^{\circ} \mathrm{S}-60^{\circ} \mathrm{W}$. Este sistema cresce enquanto avança para NE junto com a frente fria até que 2100 UTC do dia 10-11-2011 se desprende do sistema frontal e avança em direção à Amazônia, regenerando seu núcleo e incorporando células convectivas em seu caminho. Por volta de 0530 UTC do dia do registro surgem, na dianteira do sistema, as últimas células que serão incorporadas para formar o núcleo do evento noturno identificado pelo TRMM.

O painel de Tb da Figura 3.62 mostra a evolução deste sistema desenvolvido junto a frente fria, com local de início indicado pela seta vermelha na Figura 3.62 a e sua subsequente evolução em tamanho e deslocamento para NE, quando às 2100 UTC do dia 10-11-2011 desconecta-se do sistema frontal e avança como um sistema isolado em direção à da Amazônia (Fig. 3.62 b - f, respectivamente). As outras três tempestades com duração estimada em 40 horas ocorrem de forma muito semelhante (04-03-2004, 12-11-2004, 14-032005) e são classificadas como embebidas em sistema frontal.

\subsubsection{Ingredientes de severidade: tempestades intensas e não intensas}

Como mostrado até aqui, o pré-condicionamento para a convecção severa noturna no SW Amazônia é proveniente do escoamento de grande escala, dado substancialmente pela atuação do JBNAS e por uma confluência associada a sistemas frontais. Embora tenham sido encontrados estes padrões sinóticos eles não explicam totalmente a severidade, uma vez que o total de casos intensos (e extremos) entre eles é semelhante. Neste tópico, portanto, avalia-se separadamente o ambiente de sistemas intensos e não intensas (limiar de $32 \mathrm{raios} / \mathrm{min}$ ) olhando para os ingredientes de severidade numa escala local.

Analisa-se agora valores pontuais dos parâmetros termodinâmicos e cinemáticos indicativos de severidade, sendo eles CAPE, CIN, cisalhamento em baixos níveis e WCD (mencionado na seção 2.2), utilizando informações da reanálise ERA5 extraídas no ponto de grade mais próximo à localização das tempestades. Especificamente nesta análise não está inclusa a informação de 0600 UTC do dia de registro, uma vez que ao olhar para o ciclo de vida, no tópico anterior, entende-se que a maior parte das tempestades noturnas já estava estabelecida neste horário. 
$[a]$

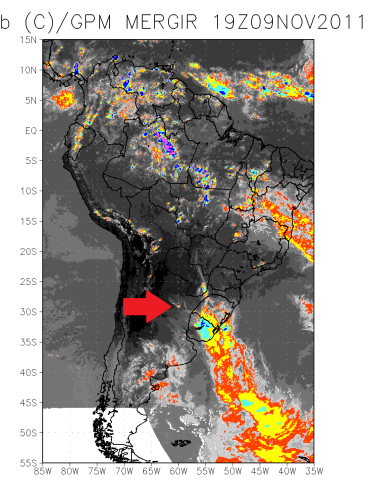

Tb (C)/GPM MERGIR O5Z10NOV2011

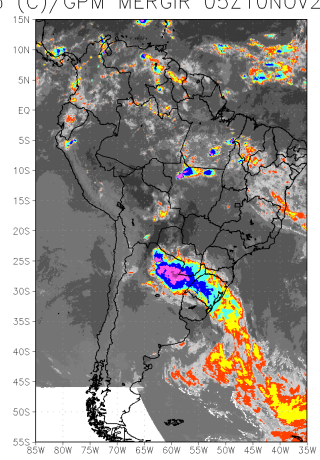

[c]

[e]

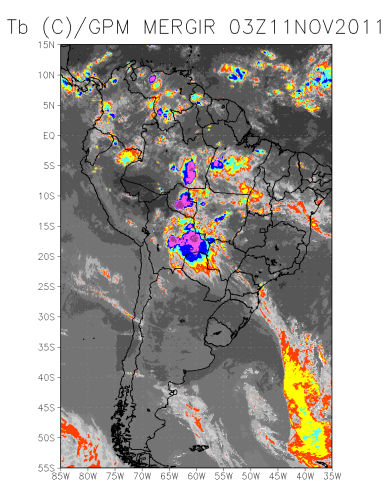

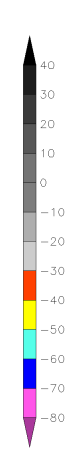

[b]

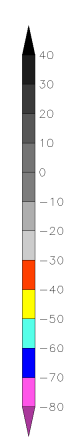

[d]

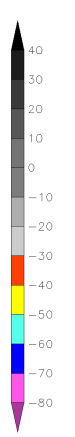

$[\mathrm{f}]$
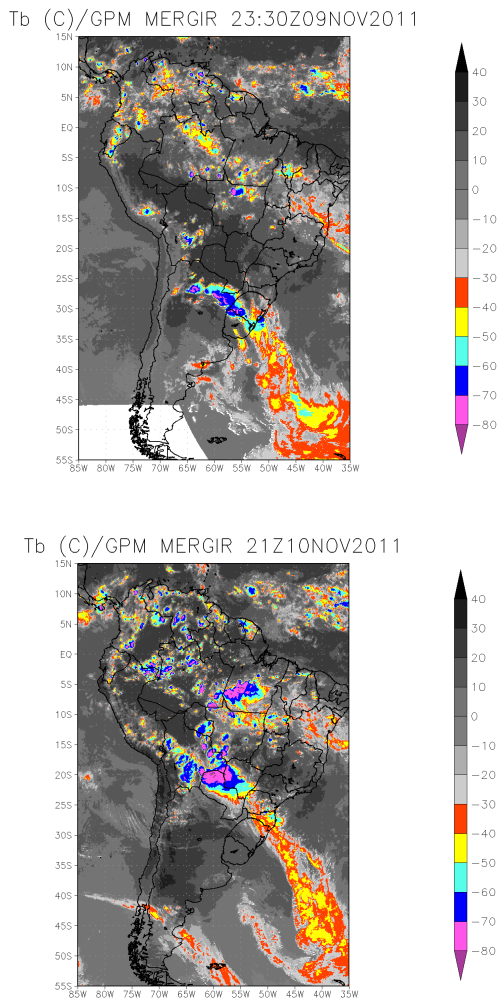

Tb (C)/GPM MERGIR 09:30Z11NOV2011
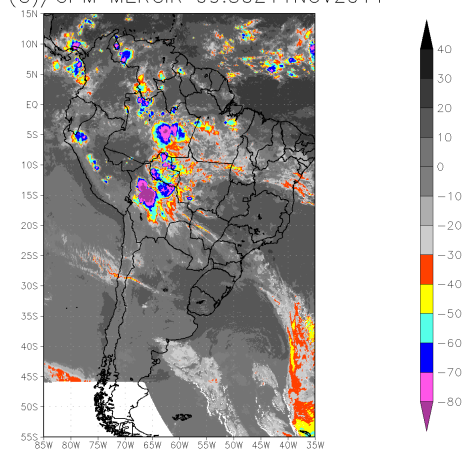

Figura 3.62: Temperatura de brilho (GPM-MERGIR) para a) 1900 UTC, dia 09-11-2011, seta vermelha indicando início do sistema; b) 2330 UTC, dia 09-11-2011; c) 0500 UTC, dia 10-11-2011; d) 2100 UTC, dia 10-11-2011; e) 0300 UTC, dia 11-11-2011 e f) 0930 UTC, horário de registro, dia 11-11-2011.

A Figura 3.63 mostra a posição das tempestades noturnas intensas em comparação com cinco lugares identificados por Albrecht et al. (2016) como os locais com mais raios na América do Sul contidos no presente domínio de estudo. Os símbolos em preto, vermelho e azul indicam respectivamente tempestades noturnas intensas com padrão de circulação P1, com padrão P2 e os locais com mais raios de Albrecht et al. (2016). Os triângulos em azul fazem parte de uma lista de 500 de locais com mais raios ao redor do globo encontrados por Albrecht et al. (2016), através do cálculo da densidade de taxa de raios observados pelo 
TRMM entre $1998-2013$, sendo aquele próximo de $17^{\circ} \mathrm{S}-65^{\circ} \mathrm{W}$ correspondente ao oitavo lugar com mais raios na América do Sul. Destaca-se a contribuição das tempestades noturnas intensas para este máximo de raios.
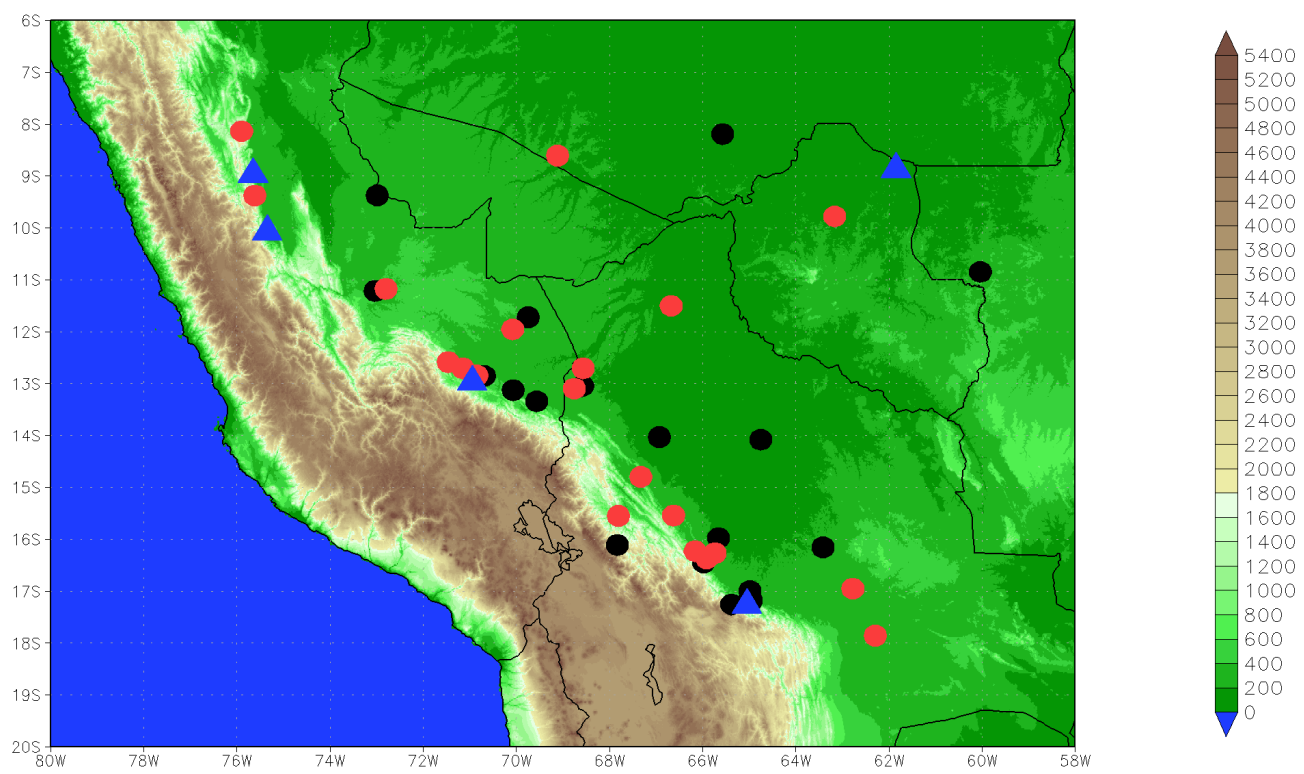

Figura 3.63: Localização das tempestades noturnas intensas com padrão P1 (símbolos em preto), com padrão P2 (símbolos em vermelho) e dos focos de raios de Albrecht et al. (2016) pertencentes ao domínio do presente estudo (símbolos em azul).

Olhando mais uma vez para as propriedades médias das PFs as tempestades noturnas intensas (não intensas) ocorrem ligeiramente mais cedo (tarde), com taxa de $71 \mathrm{raios} / \mathrm{min}$ (15 raios/min), MINPCT8GHz da ordem de 86 K (90 K) e MINPCT37GHz de $204 \mathrm{~K}$ (213 K) e MAXHT40 de 9,7 Km (8 Km). Elas também são maiores (menores) em área total, com cerca de 14 mil $\mathrm{Km}^{2}\left(8\right.$ mil $\left.\mathrm{Km}^{2}\right)$, e na área do núcleo mais frio $250 \mathrm{Km}^{2}\left(150 \mathrm{Km}^{2}\right)$, apresentando ainda maior (menor) taxa de precipitação em superfície, de $108 \mathrm{~mm} / \mathrm{h}$ (90 $\mathrm{mm} / \mathrm{h}$ ). Os sistemas intensos, portanto, têm valores marcantes em todos os parâmetros comumente utilizados para caracterizar severidade.

Liu et al. (2019), investigando relações entre variáveis termodinâmicas individuais e combinadas, e a probabilidade que as CFs registradas pelo TRMM têm de serem intensas (maior taxa de raios), concluem que uma combinação de CAPE, CIN, cisalhamento em baixos níveis e WCD tem a melhor performance em identificar tempestades intensas, justificando a presente análise. Todavia, como eles propriamente reforçam, mesmo que 
o ambiente seja favorável a tempestades não quer dizer que elas vão ocorrer, já que os mecanismos de disparo da convecção podem depender de fatores locais não captados por reanálise.

O estudo de Stolz et. al (2015) sugere que a convecção profunda nos trópicos é mais intensa quando o WCD é mais raso. Tanto a densidade total de raios (do inglês total lightning density, TLD) quanto a altura média do eco de refletividade de $30 \mathrm{dBZ}$ (do inglês average height of $30 \mathrm{dBZ}$ echoes, AVGHT30) mostraram variabilidade considerável com respeito a variações de WCD. Ambas TLD e AVGHT30 variam inversamente com WCD, tal que seus valores máximos são encontrados para uma combinação de CAPE alto, altas concentrações de núcleos de condensação de nuvens com diâmetros grandes e WCD rasos.

Os valores de WCD (em metros) para as tempestades noturnas são apresentados no eixo y do gráfico na Figura 3.64, onde o eixo x representa as 97 tempestades noturnas em ordem decrescente de severidade, de forma que 1 refere-se a tempestade mais intensa e 97 a menos intensa. A linha azul representa os valores obtidos para às 1200 UTC, enquanto a laranja àqueles para as 1800 UTC e cinza à 0000 UTC.

É notável que os valores mais baixos de WCD (ou seja, mais propensos ao desenvolvimento de tempestades intensas) ocorrem às 1800 UTC, o que corresponde ao início da tarde em termos de hora local. As tempestades mais intensas tendem a registrar WCDs mais rasos e essa tendência de aprofundamento de WCD para as tempestades menos intensas do conjunto é observada para todos os horários. Em termos médios têm-se WCD de aproximadamente 4749 m, 4314 m e 4904 m para 1200, 1800 e 0000 UTC, respectivamente, o que indica uma diminuição média de 430 m entre 1200 e 1800 UTC, podendo representar um ingrediente importante na previsibilidade dos sistemas. Valores mínimos (máximos) para os respectivos horários da análise são aproximadamente 4085 (5376), 3185 (5430) e 4230 (5573) metros. 


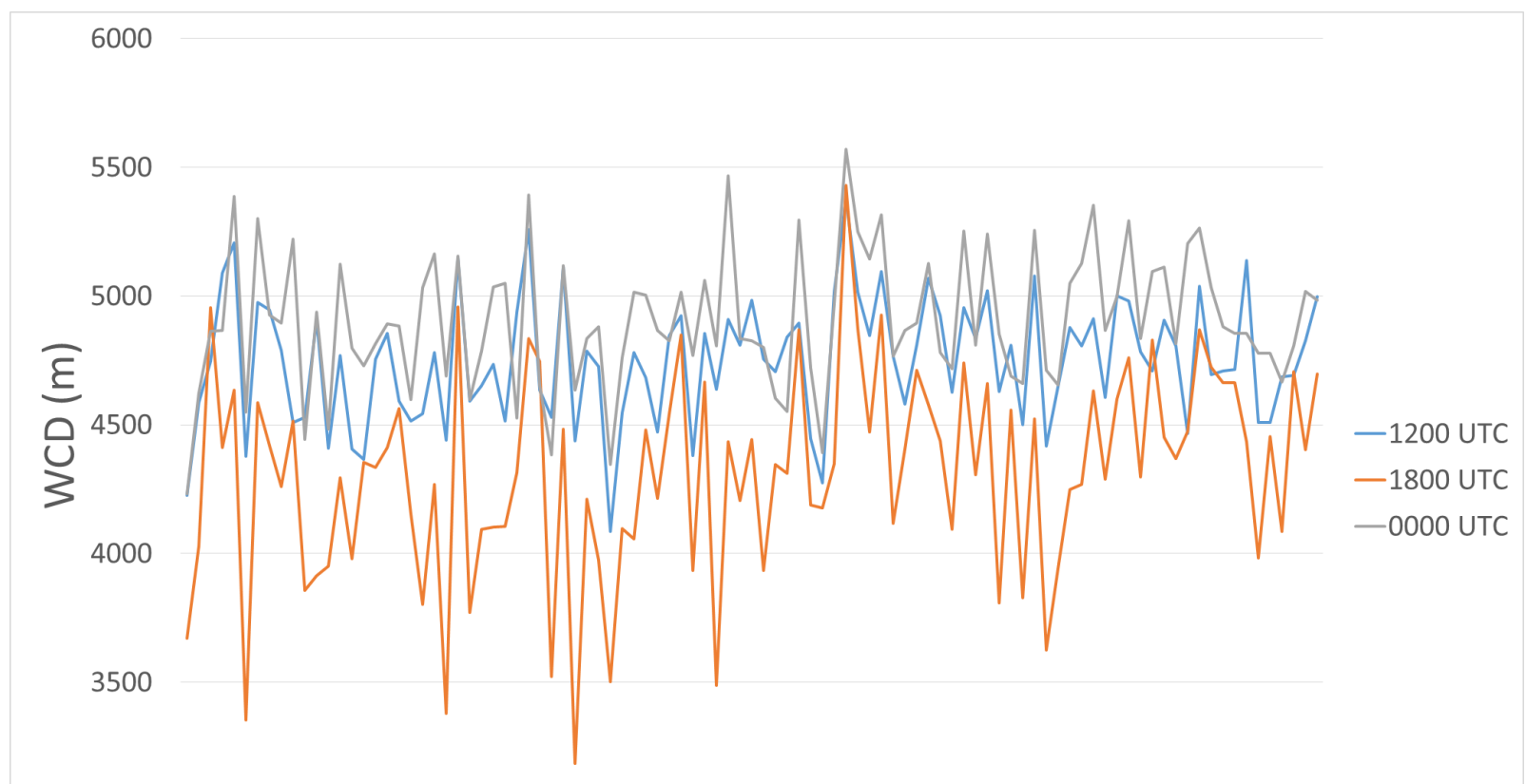

3000

147101316192225283134374043464952555861646770737679828588919497

Tempestades noturnas por ordem decrescente de severidade

Figura 3.64: WCD (eixo y, em metros) calculado a partir da reanálise ERA5 para às 1200 UTC e 1800 UTC do dia anterior às tempestades e 0000 UTC do dia de registro (linha azul, laranja e cinza, respectivamente). No eixo x, 1 refere-se à tempestade mais intensa e 97 a menos intensa.

A Figura 3.65 mostra uma comparação dos ingredientes de severidade médios para tempestades intensas e não intensas (barras em cinza e preto, respectivamente). Analisando WCD (Fig 3.65.a), ambos os grupos mostram mesmo comportamento onde o WCD diminui entre 1200 e 1800 UTC, horário em que alcança mínimos valores, e então torna a aprofundar. No caso das tempestades intensas a diferença é de mais de $500 \mathrm{~m}$ nos dois primeiros horários, e, comparando o valor mínimo entre intensas e não intensas às 1800 UTC a diferença é de mais de $250 \mathrm{~m}$. A tendência de WCD mais profundo para tempestades não intensas é observado em todos os horários. Os valores encontrados aqui estão, em geral, ligeiramente acima da média global (WCD é naturalmente mais elevado para os trópicos) encontrada em Stolz et al. (2015) para as CFs, em torno de 4200 m, porém, estão abaixo da média para a região SW Amazônia, em torno de 5000 m. Este ingrediente pode ser importante para previsibilidade de tempestades noturnas.

Outro parâmetro que claramente diferencia as tempestades noturnas intensas e não intensas é o CAPE, cujos valores médios podem ser vistos na Fig.3.65.b. Enquanto as 
tempestades não intensas mostram um aumento contínuo ao longo dos horários de análise, as tempestades intensas têm um salto de mais de $1000 \mathrm{~J} / \mathrm{Kg}$ entre 1200 e 1800 UTC. Neste horário CAPE é máximo para tempestades intensas e quase $1000 \mathrm{~J} / \mathrm{Kg}$ mais elevado do que não intensas, embora permaneça com valores altos às 0000 UTC.

Os valores de CIN extraídos da reanálise ERA5 são provavelmente superestimados, com valores médios acima de $100 \mathrm{~J} / \mathrm{Kg}$ (Fig 3.65.c). Para as tempestades não intensas, CIN aumenta progressivamente com o tempo, alcançando média maior que $200 \mathrm{~J} / \mathrm{Kg}$ às 0000 UTC. Para o conjunto de tempestades intensas, pelo contrário, CIN diminui entre 1200 e 1800 UTC. Um decréscimo no CIN somado a aumento de CAPE pode ser um fator chave no disparo de sistemas (Liu et al. 2019, 2020).

O cisalhamento vertical do vento horizontal foi calculado entre 700-1000 hPa, para representar a camada entre 1-3 Km. Ao contrário dos outros ingredientes analisados até aqui que têm um comportamento mais marcante no horário de 1800 UTC, o cisalhamento tem maior destaque às 1200 UTC, quando é mais intenso (Fig.3.65.d). Enquanto para as tempestades não intensas o cisalhamento diminui progressivamente com o tempo, para as tempestades noturnas intensas diminui entre 1200 e 1800 UTC, tornando a aumentar ligeiramente às 0000 UTC. Valores médios de cisalhamento em baixos níveis são maiores para as tempestades intensas nos três horários, o que corrobora com Liu et al. (2020).

Avalia-se agora o ambiente no qual as tempestades noturnas intensas e não intensas estiveram embebidas, através de composições centradas nas tempestades noturnas, utilizando em uma caixa de $6^{\circ} \times 6^{\circ}$ ao redor delas. As Figuras 3.66 a 3.77 mostram os campos analisados, onde o símbolo no centro das caixas representa o centro das tempestades e os valores de -6 a 6 são as latitudes e longitudes relativas à área selecionada ao redor dos sistemas. Em baixos níveis nota-se, como reflexo da topografia, uma clara divisão diagonal com orientação NW-SE no centro das caixas. Aqui avalia-se q, T e vento horizontal em $950 \mathrm{hPa}$; UR, T e vento horizontal em $850 \mathrm{hPa}, 700 \mathrm{hPa}$ e $500 \mathrm{hPa}$; CAPE e CIN da camada mais instável bem com o cisalhamento vertical do vento horizontal em baixos e médios níveis. 


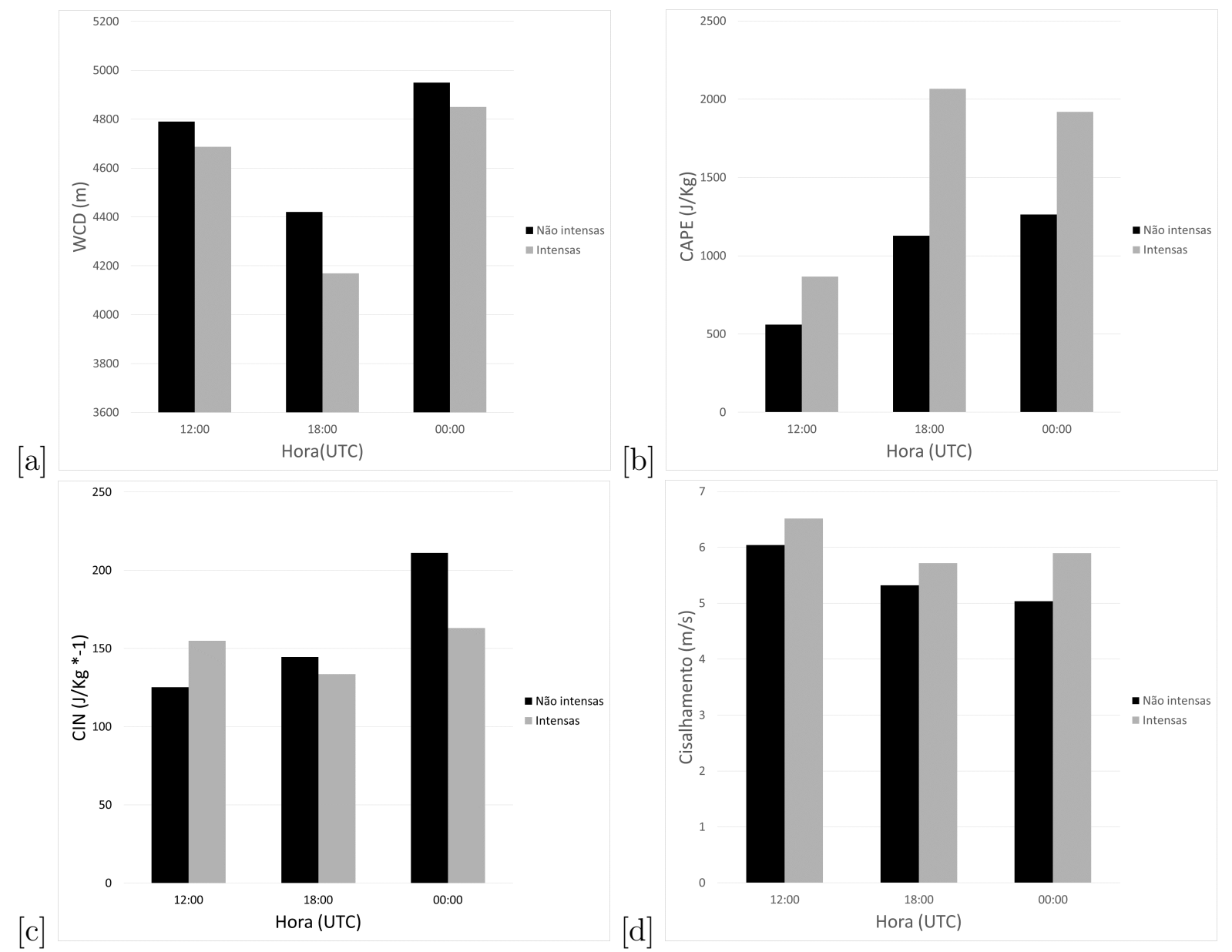

Figura 3.65: Ingredientes de severidade médios para tempestades não intensas (barras em preto) e intensas (barras em cinza), às 1200 UTC e 1800 UTC do dia anterior às tempestades e 0000 UTC do dia de registro das tempestades, sendo a) WCD (eixo y, em metros); b) CAPE (J/Kg); c) CIN (J/Kg); d) Cisalhamento em baixos níveis $(\mathrm{m} / \mathrm{s})$.

O escoamento do vento no ambiente de baixos níveis $(950 \mathrm{hPa})$ das composições para tempestades intensas e não intensas (Fig. 3.66 e Fig. 3.67) é similar: predominantemente de NW na metade NE da caixa, principalmente às 1200 e 1800 UTC, enquanto às 0000 e 0006 UTC tem uma componente de N mais marcada. Para tempestades intensas há escoamento mais forte de SE/S no sul da região central a partir de 1800 UTC que se fortalece no horário seguinte, similar ao padrão P2, sendo que o ambiente é ligeiramente mais quente (com aumento de $4^{\mathrm{O}} \mathrm{C}$ no período pré-convectivo) e tem maior contraste horizontal de umidade (entre SW e NE). Para tempestades não intensas, o contraste de umidade é menor e q máximo é generalizado ao longo da caixa analisada. 


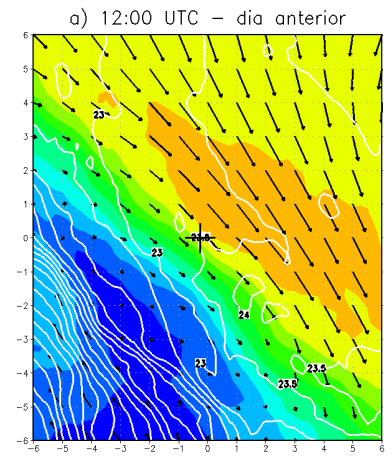

c) 00:00 UTC $-\overrightarrow{\text { dia }}$

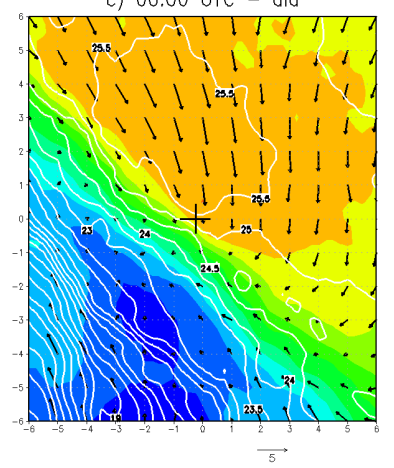

b) 18:00 UTC - dia anterior

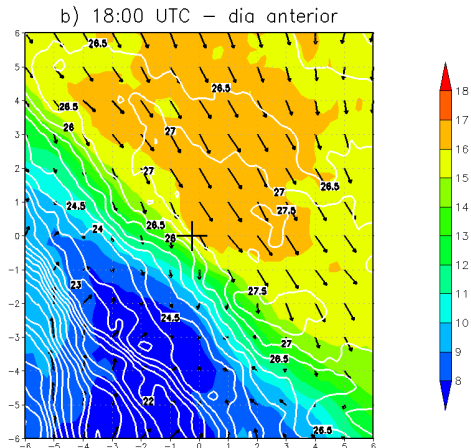

d) 06:00 UTC - Fdia

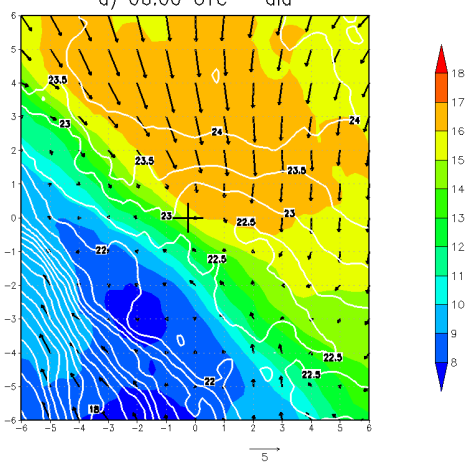

Figura 3.66: Composição de $950 \mathrm{hPa}$ centrada nas tempestades intensas onde escala de cores representa umidade específica $(\mathrm{g} / \mathrm{Kg})$, contornos a temperatura $\left({ }^{\circ} \mathrm{C}\right)$ e vetores o vento horizontal utilizando reanálise ERA5.

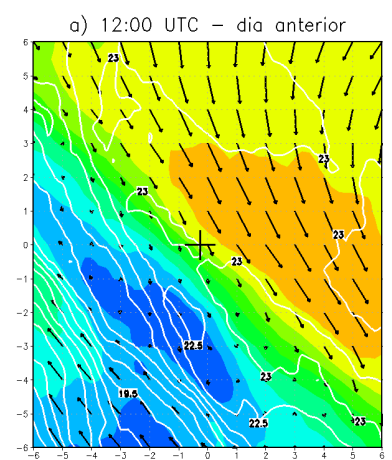

c) 00:00 UTC - जdia

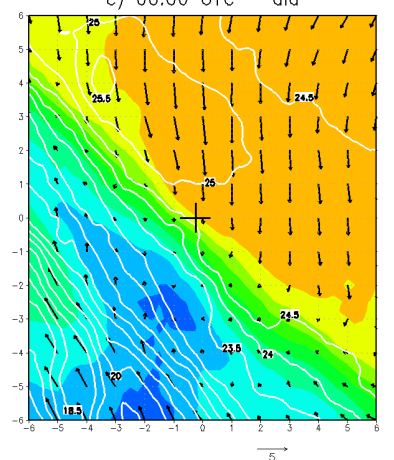

b) 18:00 UTC - dia anterior

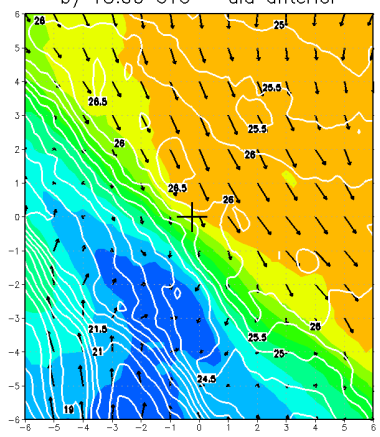

d) 06:00 UTC $-\overrightarrow{\text { sdia }}$

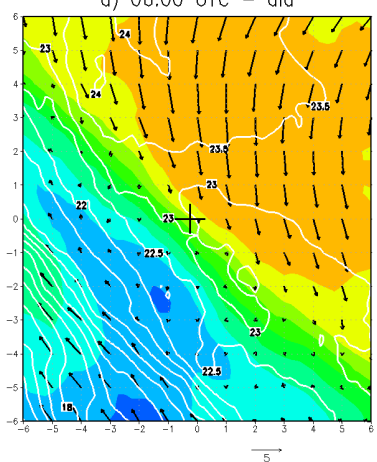

Figura 3.67: O mesmo que na Figura 3.66 mas para tempestades não intensas. 
Em $850 \mathrm{hPa}$ o contraste de UR entre o ambiente das tempestades intensas (Fig. 3.68) e não intensas (Fig. 3.69 também é evidente, assim como a confluência NO-SE ao S das tempestades intensas, mais marcante às 0000 UTC. O vento horizontal é predominante de NO para os dois ambientes pré-convectivos, mas é mais úmido para tempestades não intensas, que tem maior UR na região central, enquanto as tempestades intensas têm um núcleo mais úmido ligeiramente a $\mathrm{SE}$ do seu centro. Nos dois casos $\mathrm{T}$ aumenta cerca de $2^{\circ} \mathrm{C}$ entre 1200 e 1800 UTC e é mais elevada no sul do domínio. Valores máximos de T são maiores para tempestades intensas. Às 1800 UTC o escoamento de S está no centrosul do ambiente das tempestades intensas (Fig. 3.68.b), confluindo não somente com o escoamento de NW como também com escoamento seco de $\mathrm{W}$, provavelmente oriundo da Cordilheira, na porção sul do domínio. Para o mesmo horário no ambiente de tempestades não intensas há confluência de NW-NE nesta região, sem sinal de vento de S. Às 0600 UTC o escoamento de SE persiste no sul do domínio para tempestades intensas.

Para o nível de 700 hPa o escoamento é predominantemente de NW no ambiente das tempestades intensas e não intensas (Fig 3.70 e 3.71), sendo relativamente mais seco para o primeiro grupo. O gradiente de T é maior às 1800 UTC em ambos os ambientes, onde as temperaturas mais altas são encontradas a SW do centro das tempestades (Fig.3.70.b e Fig 3.71.b). Assim como em $850 \mathrm{hPa}$, aqui também se observa confluência NW-NE no centro-sul do ambiente de tempestades não intensas, mas não é mais observado o escoamento de $\mathrm{SE} / \mathrm{S}$ ao sul das tempestades intensas.

Uma circulação anticiclônica é observada em $500 \mathrm{hPa}$ tanto para tempestades intensas quanto não intensas (Figuras 3.72 e 3.73 , respectivamente), sendo que este escoamento é menos intenso e mais seco no ambiente pré-convectivo das tempestades intensas. Às 0000 UTC o vento é basicamente de S na região central de ambas composições, sendo mais frio e mais seco no NW das tempestades intensas (Fig. 3.72 c). Entranhamento de ar frio e seco em 500 hPa é ingrediente para severidade, uma vez que a evaporação acelera correntes descendentes nas nuvens. Como mencionado anteriormente, Romatschke e Houze (2010) discutem que esta circulação carregando ar mais seco de S para N em 500 hPa está relacionada a borda oriental da alta da Bolívia é típica de verão (Fig 3.24), que deve ter tido comportamento captado aqui devido a maior parte dos sistemas noturnos ocorrerem entre outubro e março. 


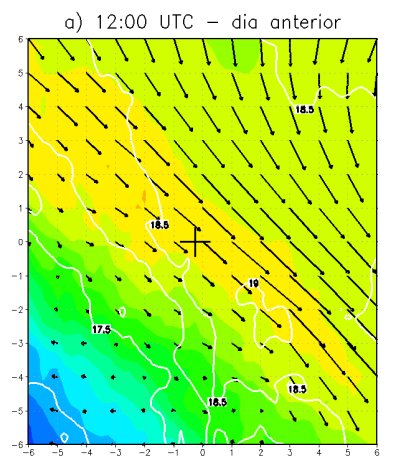

c) 00:00 UTC $-\overrightarrow{5 \mathrm{dia}}$

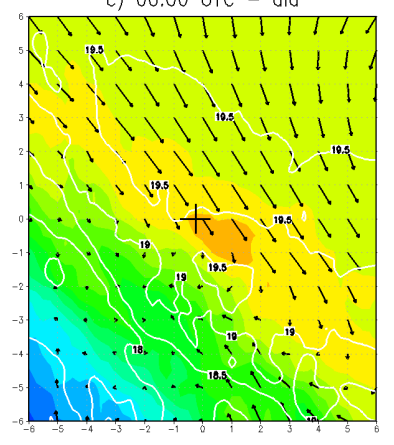

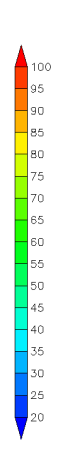

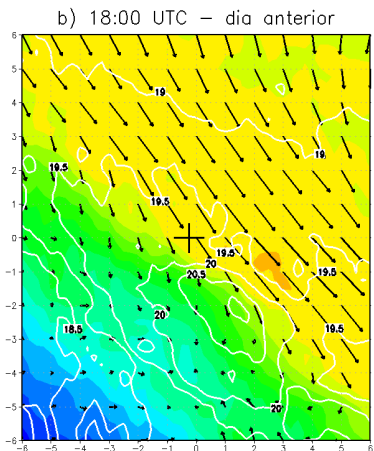

d) 06:00 UTC $-\overrightarrow{\text { dia }}$

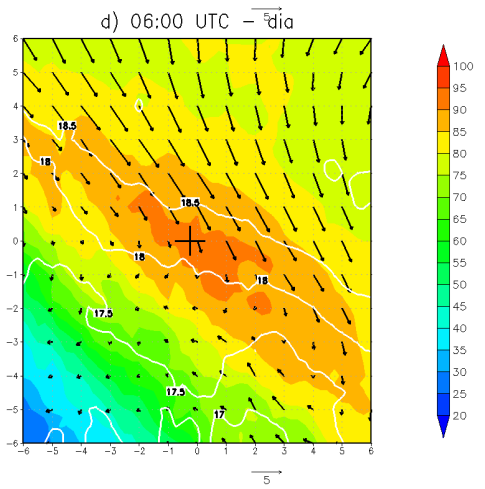

Figura 3.68: Composição de $850 \mathrm{hPa}$ centrada nas tempestades intensas onde escala de cores representa umidade relativa $(\%)$, contornos a temperatura $\left({ }^{\circ} \mathrm{C}\right)$ e vetores o vento horizontal utilizando reanálise ERA5.

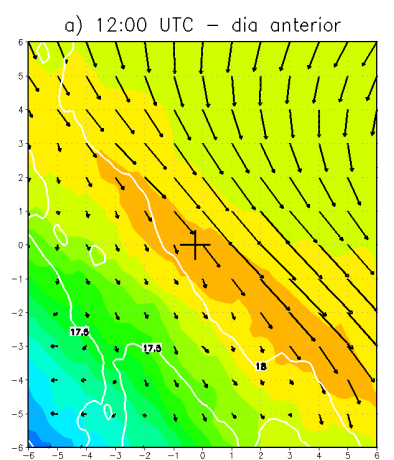

c) 00:00 UTC $-\overrightarrow{\mathrm{gio}}$

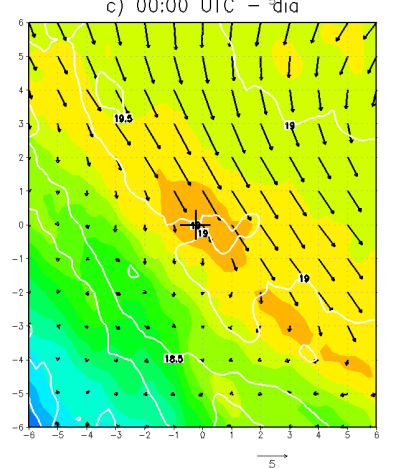

b) 18:00 UTC - dia anterior

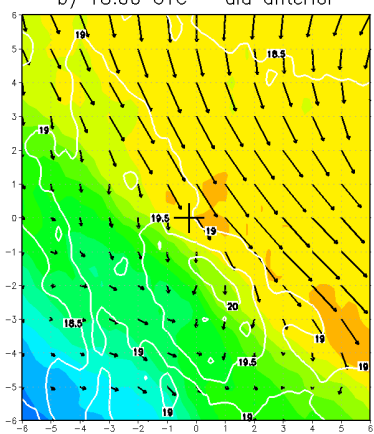

d) 06:00 UTC - sdia

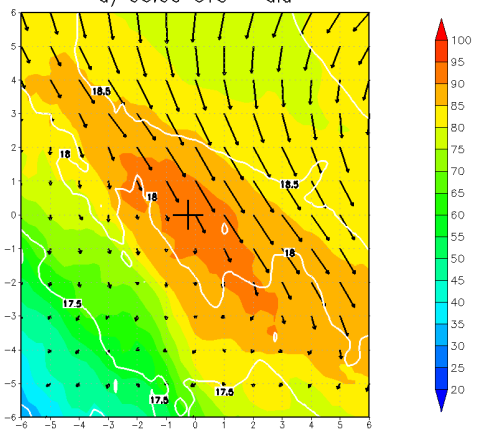

Figura 3.69: O mesmo que na Figura 3.68 mas para tempestades não intensas. 


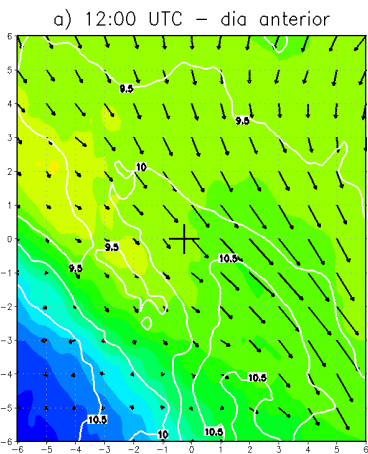

c) 00:00 UTC $-\overrightarrow{\text { dia }}$

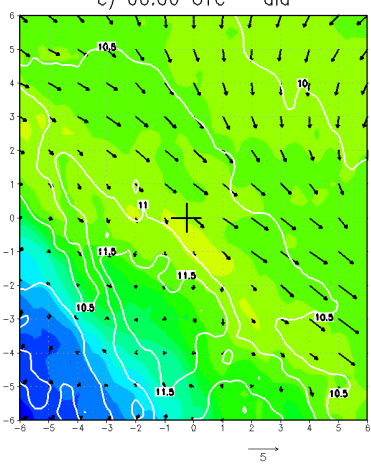

b) 18:00 UTC - dia anterior

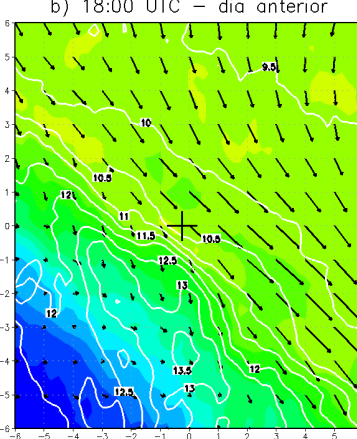

d) 06:00 UTC $-\overrightarrow{5 d i c}$

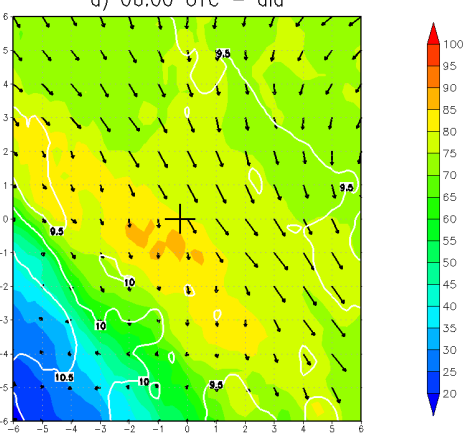

Figura 3.70: Composição de $700 \mathrm{hPa}$ centrada nas tempestades intensas onde escala de cores representa umidade relativa $(\%)$, contornos a temperatura $\left({ }^{\circ} \mathrm{C}\right)$ e vetores o vento horizontal utilizando reanálise ERA5.

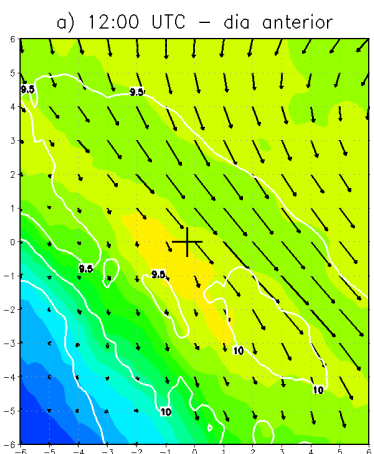

c) 00:00 UTC $-\overrightarrow{\text { dio }}$

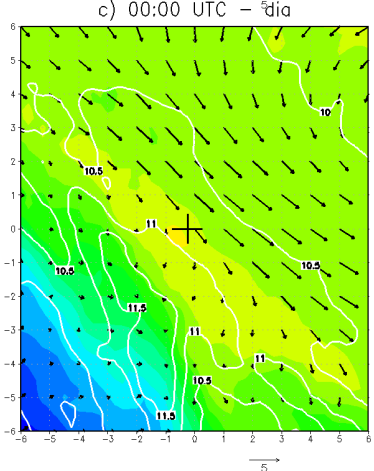

b) 18:00 UTC - dia anterior

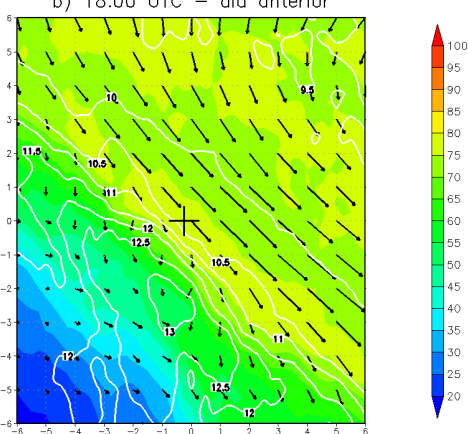

d) 06:00 UTC - Fdia

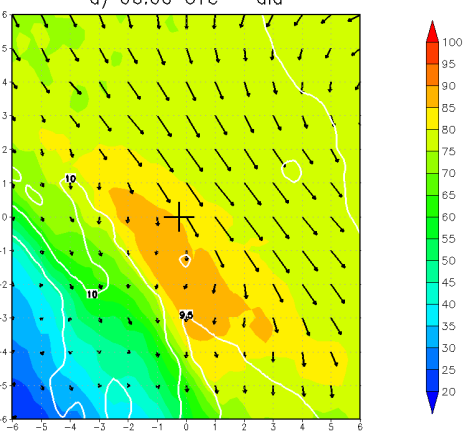

Figura 3.71: O mesmo que na Figura 3.70 mas para tempestades não intensas. 


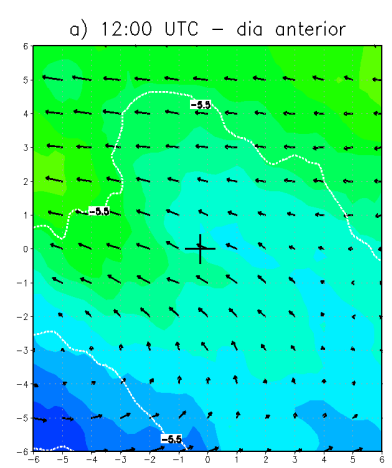

c) 00:00 UTC $-\overrightarrow{\mathrm{g}_{\mathrm{dia}}}$

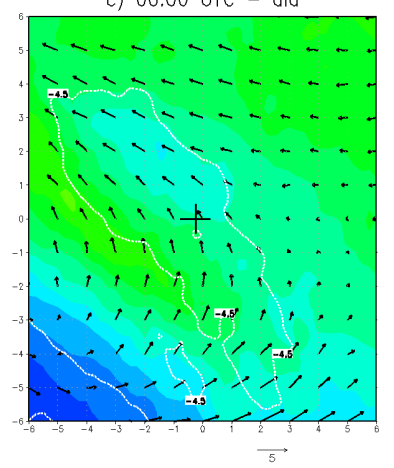

b) 18:00 UTC - dia anterior
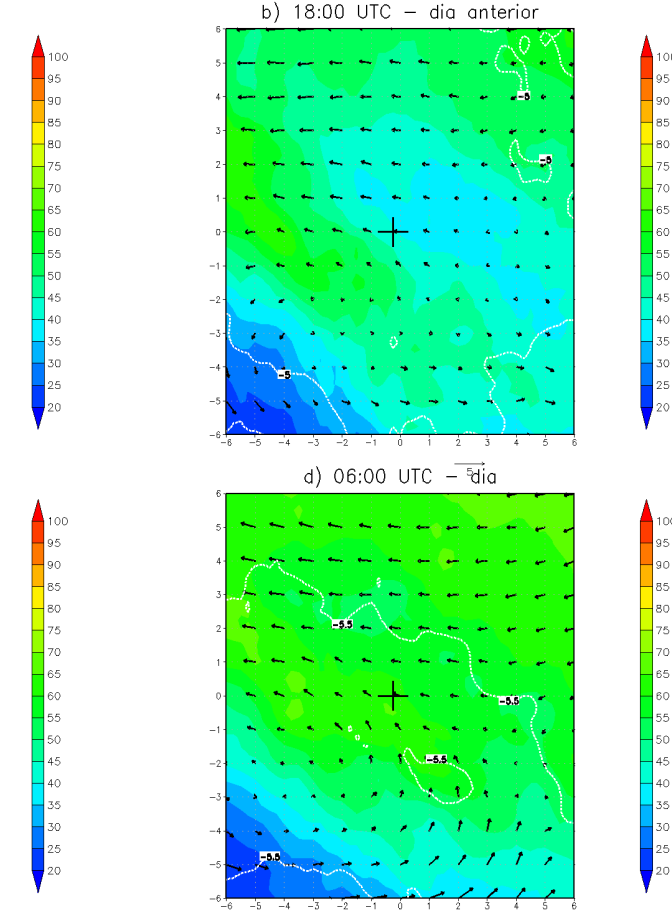

d) 06:00 UTC $-\overrightarrow{\text { dia }}$

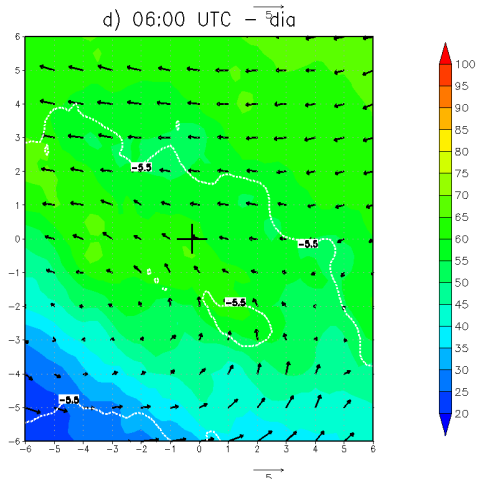

Figura 3.72: Composição de $500 \mathrm{hPa}$ centrada nas tempestades intensas onde escala de cores representa umidade relativa $(\%)$, contornos a temperatura $\left({ }^{\circ} \mathrm{C}\right)$ e vetores o vento horizontal utilizando reanálise ERA5.

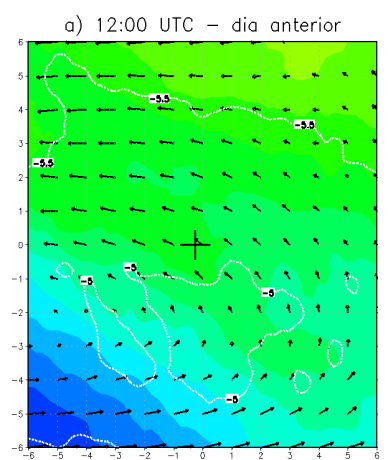

c) 00:00 UTC $-\overrightarrow{{ }^{2} \mathrm{dia}}$

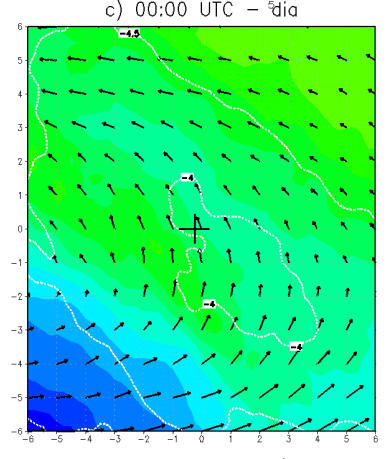

$\overrightarrow{5}$
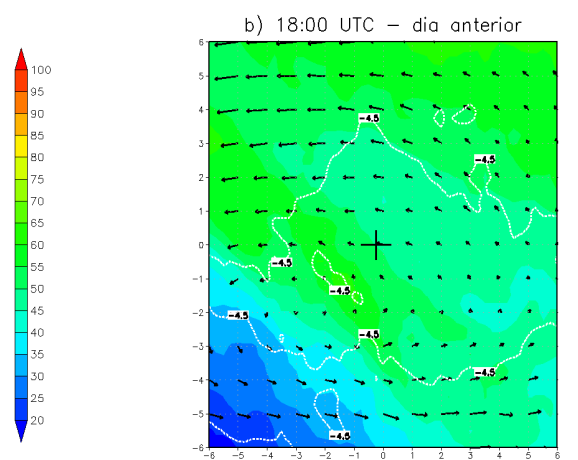

d) 06:00 UTC - vila

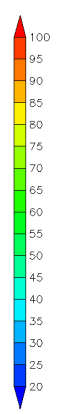

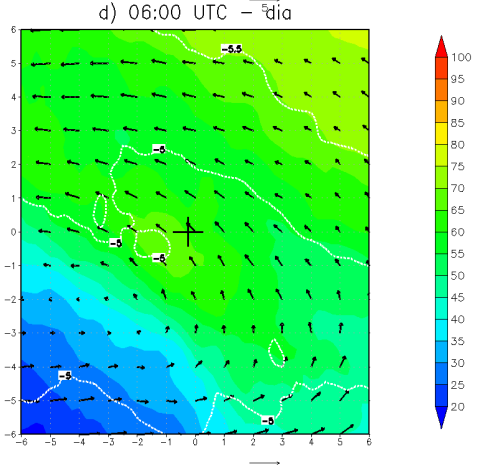

Figura 3.73: O mesmo que na Figura 3.72 mas para tempestades não intensas. 
Uma das diferenças mais marcantes entre o ambiente de tempestades noturnas intensas e não intensas é o valor de CAPE, principalmente às $1800 \mathrm{UTC}$, cerca de $600 \mathrm{~J} / \mathrm{Kg}$ mais elevado na região central e NE das tempestades intensas (Fig 3.74.b). CAPE aumenta progressivamente entre 1200 e 0000 UTC, quando tem valores máximos em ambos os ambientes (1900 J/Kg para tempestades intensas e $1700 \mathrm{~J} / \mathrm{Kg}$ para não intensas, Fig 3.74.c e Fig 3.76,c, respectivamente). O CIN também é maior para tempestades intensas e tem mesmo comportamento nos dois ambientes: diminui cerca de $50 \mathrm{~J} / \mathrm{Kg}$ entre 1200 e 1800 UTC, permitindo que a convecção seja disparada por algum mecanismo de gatilho. As tempestades intensas estão centradas em uma região limítrofe onde CAPE é alto e CIN diminui.

O cisalhamento vertical do vento horizontal, principalmente o de baixos níveis, tem valores e comportamentos semelhantes para tempestades intensas e não intensas (escala de cores, Figuras 3.75 e 3.77, respectivamente). A distribuição espacial, no entanto, é diferente: enquanto para tempestades intensas o núcleo de maior cisalhamento está no SE da caixa, para tempestades não intensas está imediatamente a E do centro dos sistemas. Às 1800 UTC este núcleo tem valores máximos mais elevados para tempestades intensas. O cisalhamento em médios níveis é ligeiramente maior para tempestades não intensas, mas comporta-se e distribui-se de maneira semelhante nos dois ambientes.

Resumidamente as tempestades noturnas intensas possuem como características marcantes: confluência NW-SE/S na porção sul do centro das tempestades em baixos níveis, $\mathrm{T}$ relativamente mais alta e CAPE consideravelmente mais elevado do que tempestades não intensas; maior contraste de umidade horizontal e vertical: escoamento mais seco sobreposto a escoamento mais úmido. Hipotetiza-se que este ambiente relativamente mais seco seja importante para a severidade dos eventos noturnos, como também é observado em regiões de tempestades severas ao redor do globo (como Argentina e centro dos EUA). Padrões de vento e umidade para tempestades noturnas intensas são similares àqueles do padrão P2. Destaca-se que tempestades noturnas intensas têm WCD mais raso, CAPE e cisalhamento em baixos níveis mais alto, com CIN ligeiramente menor do que nas tempestades não intensas. O horário de 1800 UTC (dia anterior) é marcante com WCD mínimo (e cerca de 500 m mais raso), CAPE máximo (e aproximadamente $1000 \mathrm{~J} / \mathrm{Kg}$ mais alto), com ligeira diminuição de CIN e do cisalhamento em baixos níveis. A combinação de WCD raso com CAPE alto parece desempenhar papel importante nas tempestades noturnas intensas. 

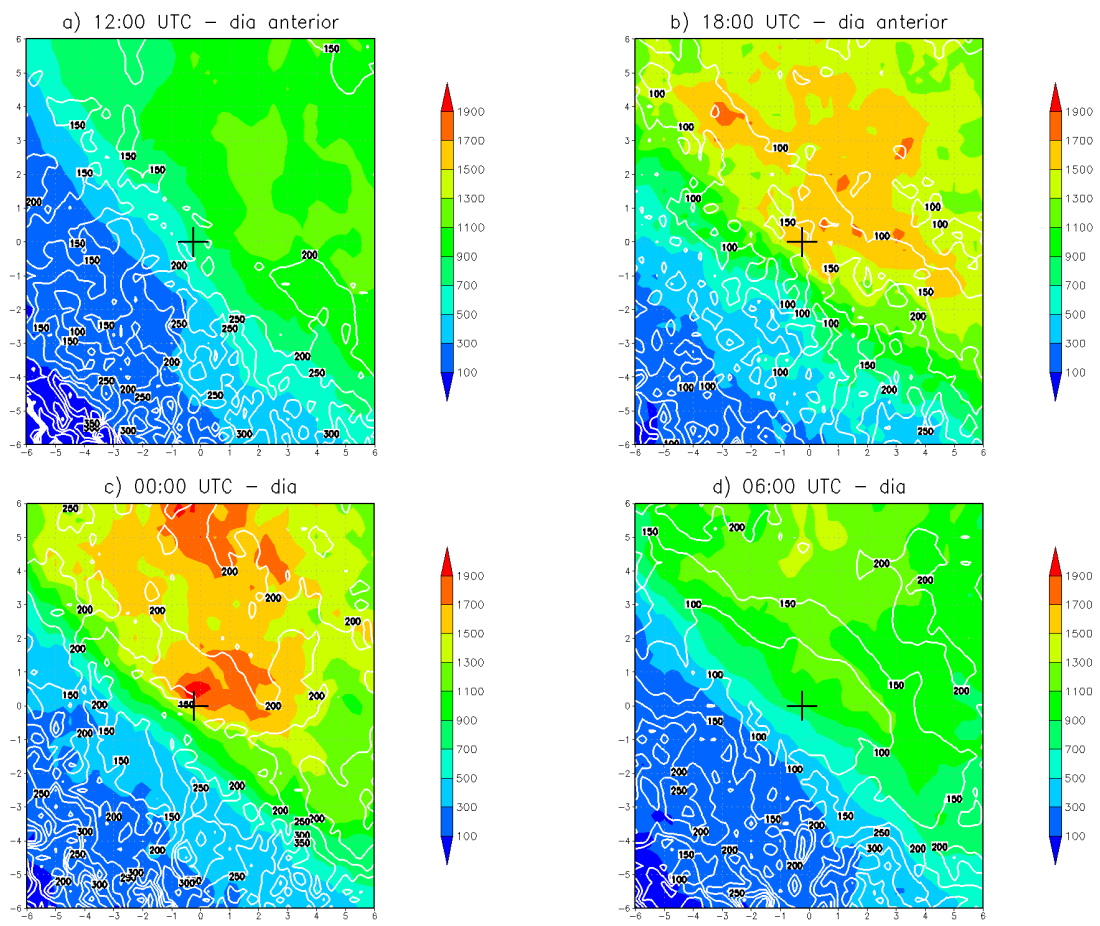

Figura 3.74: Composição de CAPE (escala de cores, J/Kg) e CIN (contornos, J/Kg) para tempestades intensas, utilizando reanálise ERA5.

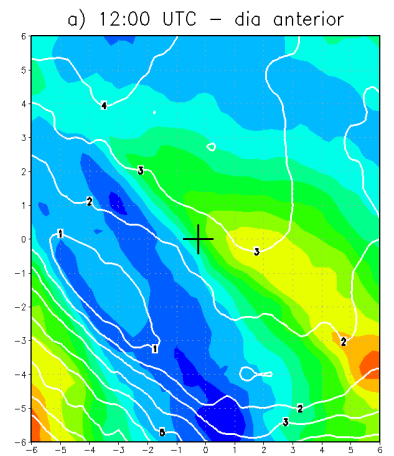

c) 00:00 UTC - dia

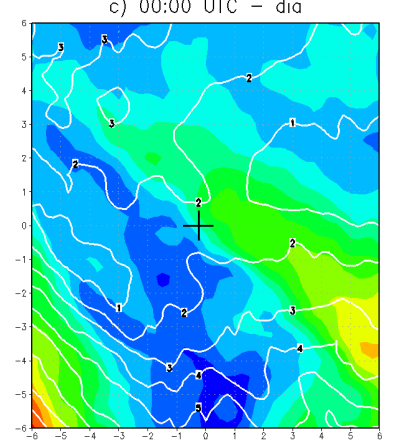

b) 18:00 UTC - dia anterior
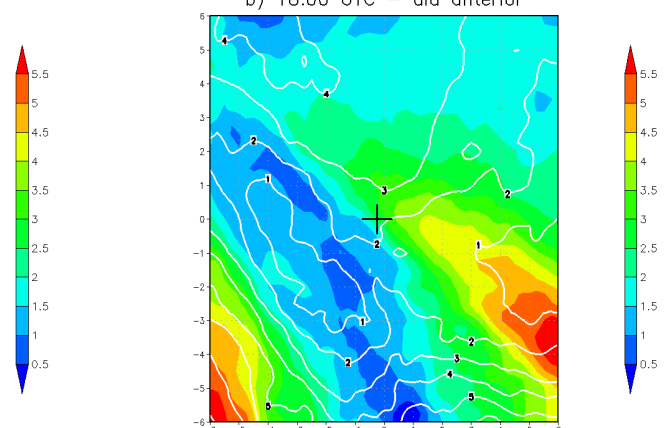

d) 06:00 UTC - dia
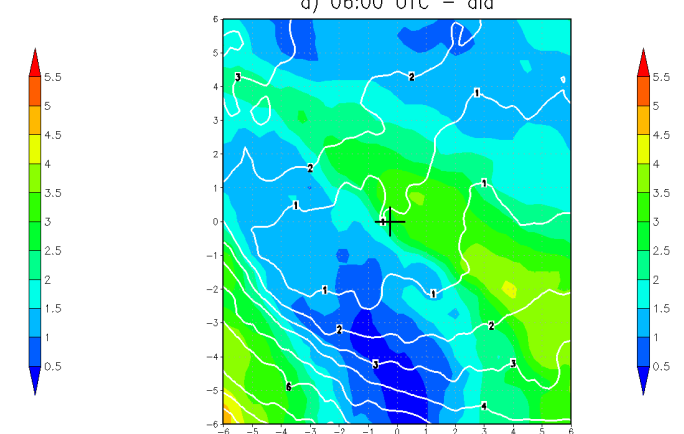

Figura 3.75: Composição do cisalhamento em baixos (escala de cores, m/s) e médios níveis (contornos, $\mathrm{m} / \mathrm{s}$ ) para tempestades intensas, utilizando reanálise ERA5. 

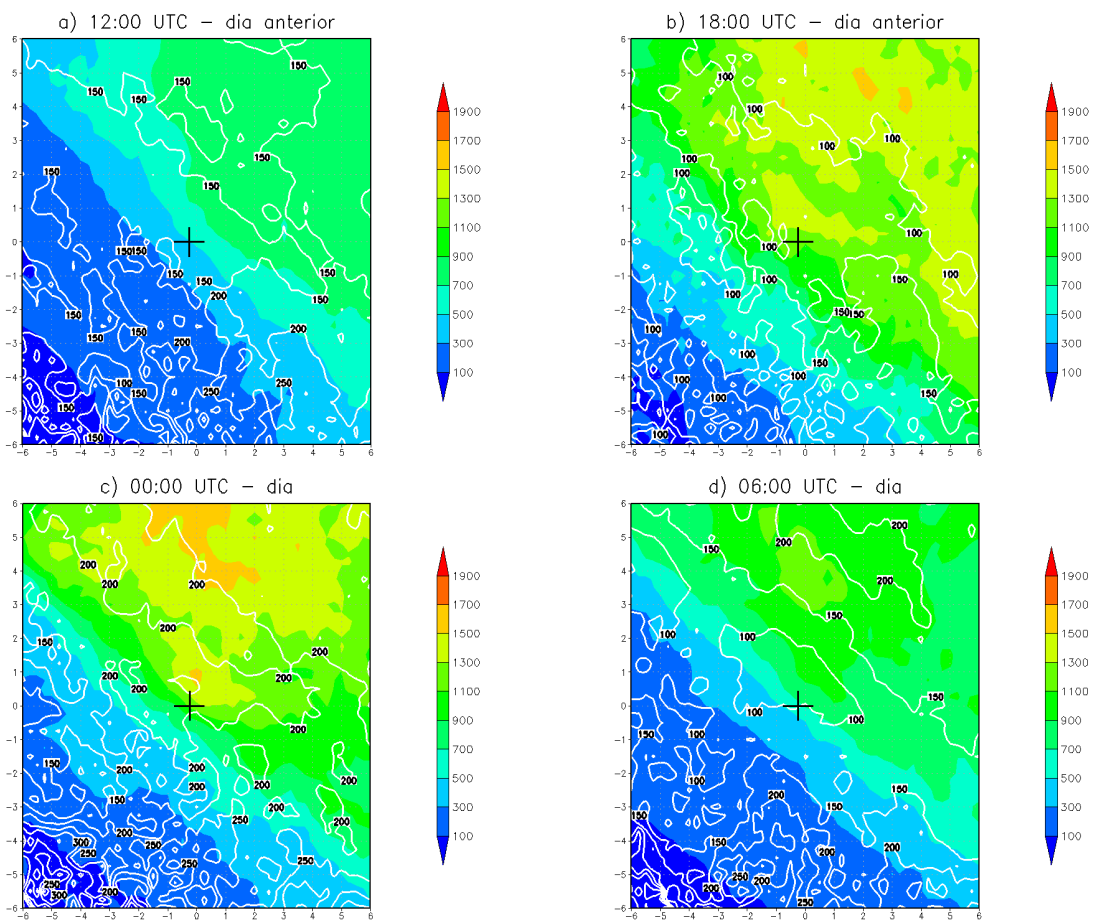

1900
-1700
-1500
-1300
-1100
-900
-700
-500
-500
100

Figura 3.76: O mesmo que na Figura 3.72 mas para tempestades não intensas.

a) 12.00 UTC - dia anterior

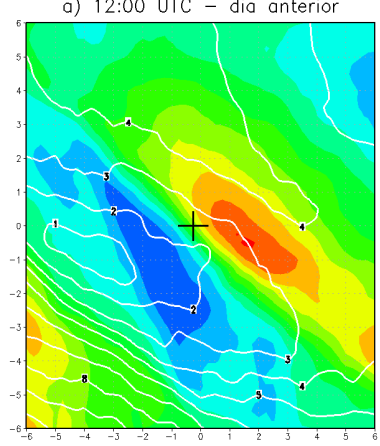

c) 00:00 UTC - dia

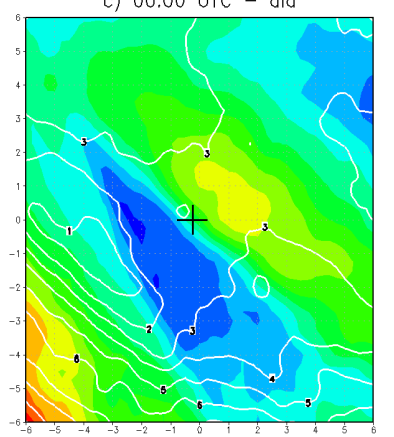

b) $18: 00$ UTC - dia anterior
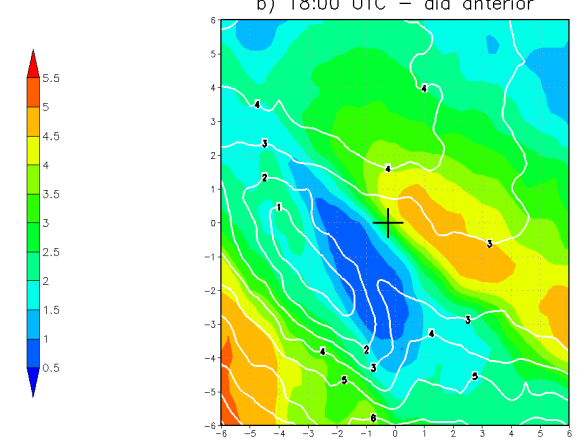

\begin{tabular}{l}
$\boldsymbol{l}_{5.5}$ \\
-5 \\
-4.5 \\
\hline-4 \\
-3.5 \\
-3 \\
-2.5 \\
-2 \\
\hline 1.5 \\
\hline 1 \\
\hline 0.5
\end{tabular}

d) 06:00 UTC - dia
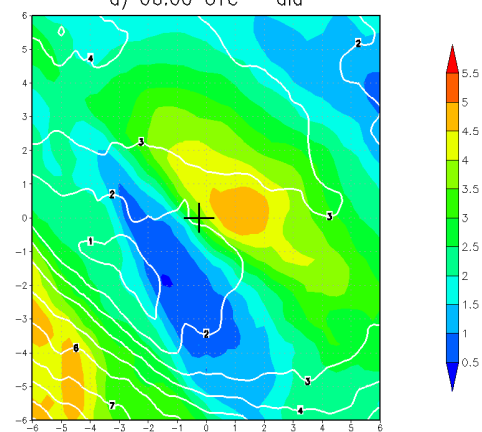

Figura 3.77: O mesmo que na Figura 3.75 mas para tempestades não intensas. 


\subsection{Simulações numéricas}

\subsubsection{Cordilheira dos Andes e circulações locais}

O objetivo das simulações numéricas no presente estudo é explorar o possível papel das circulações locais, relacionadas à complexa topografia da região andina, na formação das tempestades. Afinal, dada uma tempestade simulada nas vizinhanças de seu registro pelo satélite, é possível observar o desenvolvimento das circulações locais? Foram realizados alguns testes de familiarização com o modelo BRAMS (não mostrados) a respeito dos tipos de inicialização, aninhamento de grades, níveis de complexidade de umidade e parametrizações, tamanhos de grade, dentre outros, reforçando aquilo que foi apresentado até agora: o quão complexas são as interações entre um relevo acidentado e a atmosfera (e consequentemente suas reproduções via modelagem numérica).

A tempestade registrada no dia 26/11/2001, terceira na classificação de severidade e ilustrada na seção 3.1.5, foi escolhida para ser avaliada, uma vez que, como já mencionado, esta tempestade é entendida como uma isolada no NW do domínio de estudo, tendo sua origem relacionada ao levantamento orográfico dos alísios na cordilheira dos Andes.

Para tal, a configuração da simulação tem início às 0000 UTC do dia 26/11/2001, duração de 24 horas e inicialização heterogênea, feita a partir do conjunto de dados atmosféricos do NCEP FNL (Final) Analysis, que possui resolução espacial de $1^{\circ} \mathrm{x} 1^{\circ}$ e temporal de 6 h. Ressalta-se que a presente configuração de entrada não recebe dados para assimilação em mesoescala e que, portanto, a localização exata da tempestade não deve ser prevista.

São utilizadas duas grades com interação one-way, onde a grade aninhada, com resolução mais fina, recebe informações da grade mais grosseira, configuradas com $16 \mathrm{Km}$ e $8 \mathrm{Km}$ de espaçamento horizontal (grade 1 e grade 2, respectivamente) e concêntricas com o centroide da tempestade, em $8,14^{\mathrm{O}} \mathrm{S}-75,9^{\mathrm{O}} \mathrm{W}$. Com 300 pontos em x e 200 pontos em y, a grade 1 totaliza $4800 \times 3200 \mathrm{Km}$, enquanto a grade 2 possui 200 pontos em x e $150 \mathrm{em}$ y, com tamanho de 1600 x $1200 \mathrm{Km}$ (Figura 3.78). O domínio vertical estende-se por 20 $\mathrm{Km}$, tem 45 níveis verticais com espaçamento de $100 \mathrm{~m}$ a $600 \mathrm{~m}$ e razão de estiramento de 1,1. O passo de tempo de integração é de $10 \mathrm{~s}$, sendo que a parte química do modelo é desligada. A Tabela 3.5 resume as configurações principais do experimento.

A simulação considera que a radiação interage com as nuvens (parametrização de ra- 


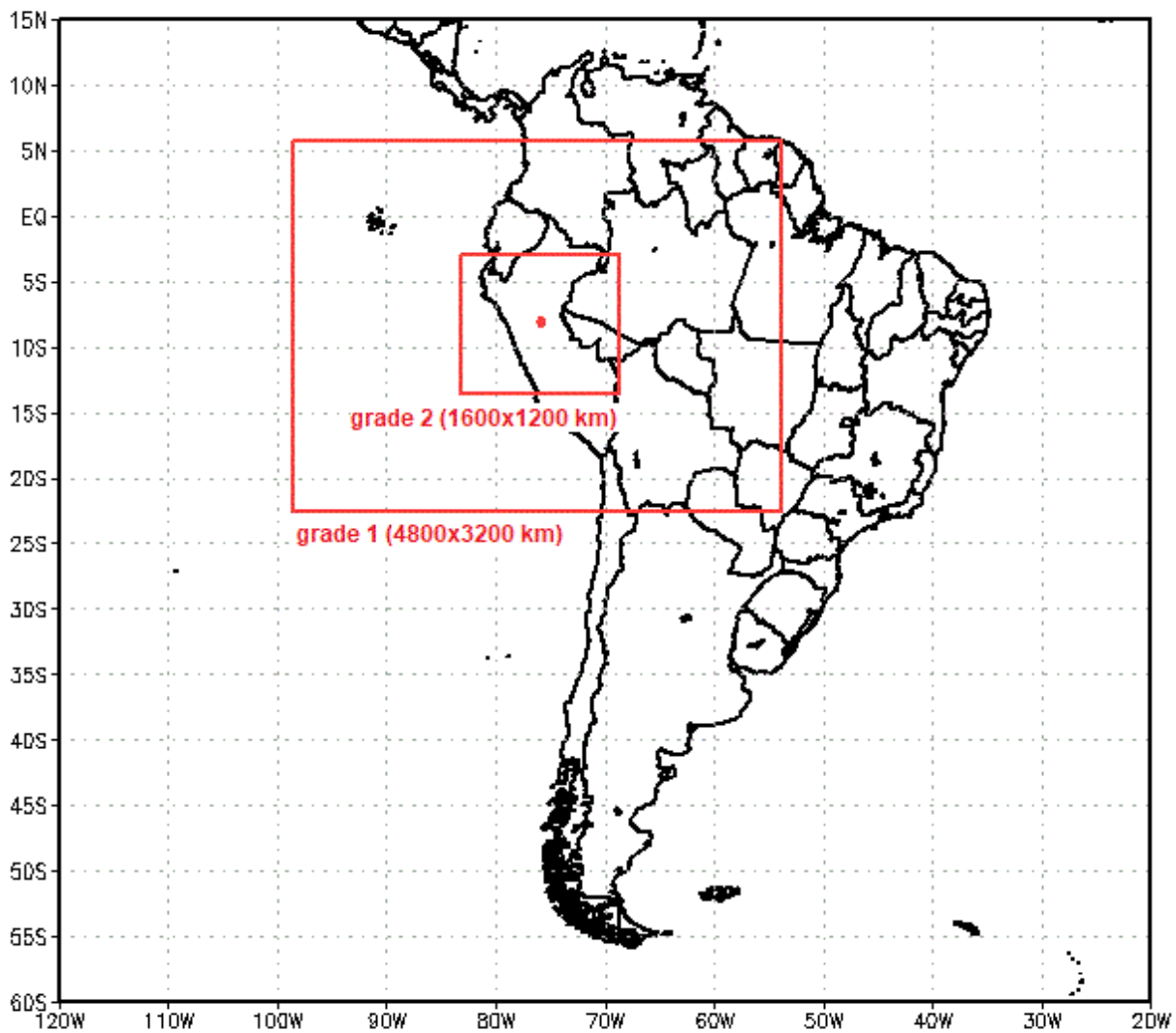

Figura 3.78: Domínios utilizados na simulação indicados pelos retângulos vermelhos. O ponto vermelho indica a localização da tempestade do dia 26/11/2001 simulada.

diação de Chen and Cotton, 1987) e que as velocidades das ondas de gravidade que passam livremente pela fronteira lateral (condição de contorno) têm valores típicos de 10-30 m/s (esquema de Klemp and Wilhelmson, 1978), objetivando que estas ondas não sejam refletidas para o interior do domínio. O nível de complexidade da umidade configurado como 3, ativa a parametrização microfísica bulk, que inclui água de nuvem, chuva, gelo puro, neve, agregados, pristine e granizo, ou alguns subconjuntos destes, e suas concentrações são prognosticadas (e não fixas). Este nível de complexidade inclui o processo de precipitação. A parametrização de turbulência utilizada (Mellor and Yamada, 1982) emprega uma previsão da energia cinética turbulenta na escala subgrade, onde os coeficientes de difusão turbulenta verticais são parametrizados pela equação da energia cinética turbulenta na escala da grade. Já a parametrização convectiva Grell para a convecção profunda, utilizada somente na grade 1, tem o fechamento tipo 'ensemble', ou seja, calcula o escoamento de massa 
Tabela 3.5 - Configurações principais da simulação da tempestade noturna ocorrida em 26/11/2001, localizada em $8,14^{\circ} \mathrm{S}-75,9^{\circ} \mathrm{W}$.

\begin{tabular}{c|c}
\hline Configuração & Especificação \\
\hline Número de pontos para o nudging na borda lateral & 10 \\
Escala de tempo do nudging para a borda lateral & $300 \mathrm{~s}$ \\
Escala de tempo do nudging para o topo do domínio & $300 \mathrm{~s}$ \\
Condição de contorno lateral & Klemp and Wilhelmson (1978) \\
Parametrização da radiação de onda curta/longa & Chen and Cotton (1987) \\
Parametrização de turbulência & Mellor and Yamada (1982) \\
Parametrização convectiva (somente grade 1) & Grell \\
Nível de complexidade de umidade & 3 \\
\hline
\end{tabular}

na base da nuvem de diversas formas (fechamentos) como com a utilização da velocidade omega (bar/s) na base da nuvem, a convergência de umidade na coluna, instabilidade, etc. e então faz uma média destes valores. A parametrização convectiva é utilizada em grades mais grosseiras, a fim de redistribuir calor e umidade verticalmente.

Tendo sido identificado o nível de $850 \mathrm{hPa}$ como importante para as tempestades noturnas, a Figura3.79 compara a saída da simulação para a grade 2 e o campo sinótico dado pela reanálise ERA5 para 0000 UTC e 0600 UTC. É possível notar que a simulação homogeneizou a umidade no domínio: subestimou em continente e superestimou na região W dos Andes. Além disso, a temperatura também é superestimada. O comportamento do vento é bem representado: ventos de N/NE no sopé oriental da cordilheira dos Andes e ventos de SE no SE do domínio.

A Figura 3.80 mostra o vento horizontal em superfície $(\mathrm{m} / \mathrm{s})$, a topografia em escala de cores $(\mathrm{m})$ e a precipitação acumulada em contornos $(\mathrm{mm})$. O símbolo vermelho indica o centro da tempestade no seu horário de registro pelo satélite, enquanto a caixa preta, imediatamente a SW chama a atenção para região onde o a simulação começa a gerar precipitação próximo da região onde a tempestade atuou às 0530 UTC e ao final da simulação, 0000 UTC do dia 27/11/2001, quando acumula cerca de 150 mm (Fig.3.80,a, b, respectivamente). Assume-se que esta precipitação se refere à tempestade simulada e as circulações locais serão avaliadas através de uma seção transversal ao longo da região indicada pelo retângulo. 


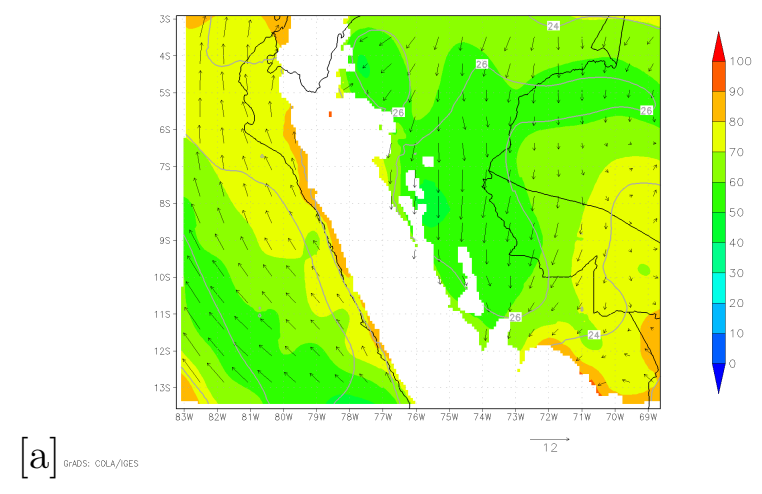

[b]
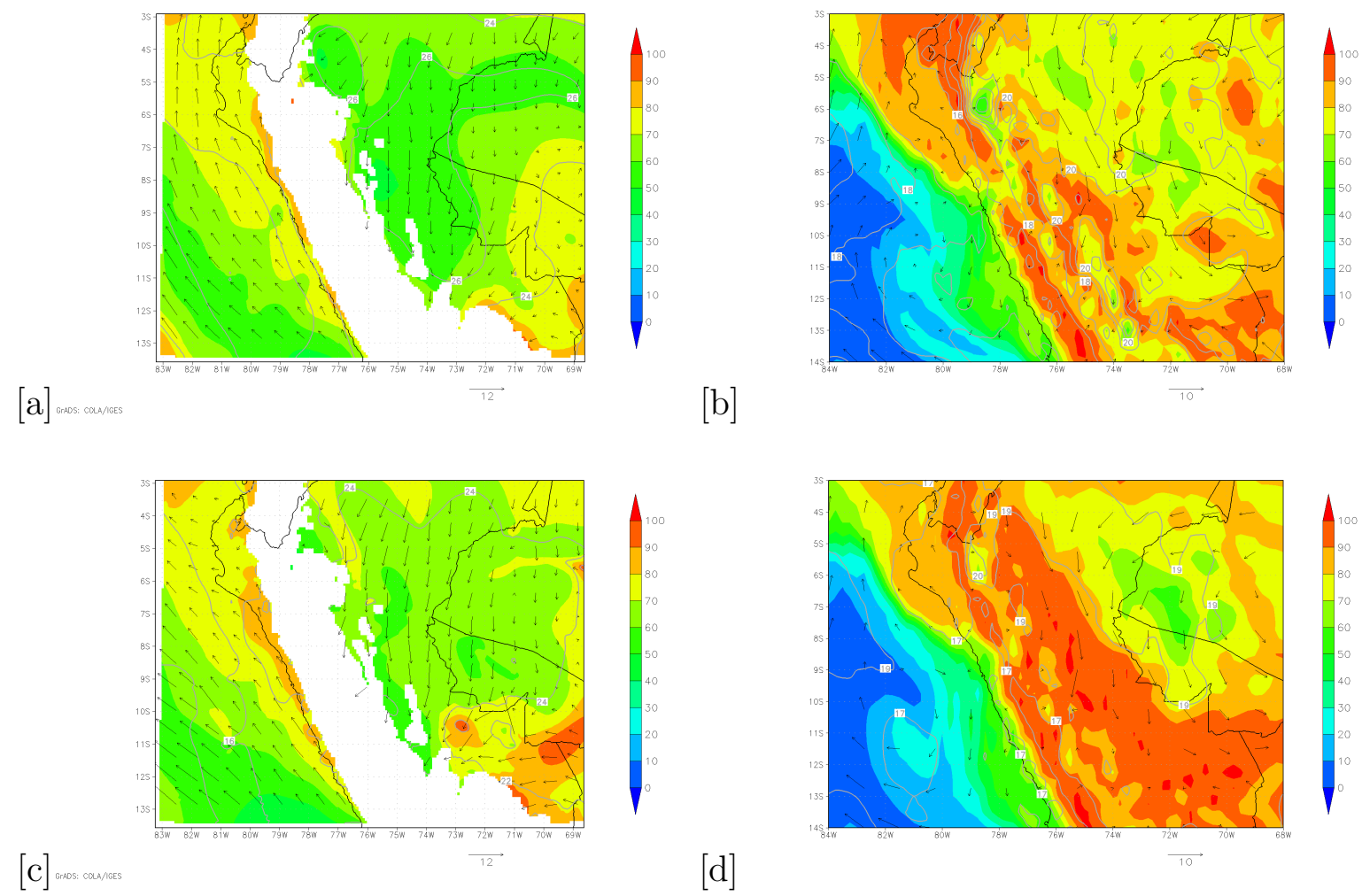

Figura 3.79: Comparação entre campos de reanalise em $850 \mathrm{hPa}$ e a grade 2 da simulação numérica para a tempestade 26/11/2001 onde a escala de cores representa a umidade relativa (\%), vetores representam o vento horizontal (m/s) e contornos a temperatura $\left({ }^{\circ} \mathrm{C}\right)$ para a) $0010 \mathrm{UTC}$, grade 2 da simulação; ) 0000 UTC da reanálise ERA5; c) 0600 UTC, grade 2 da simulação; d) 0600 UTC da reanálise ERA5.

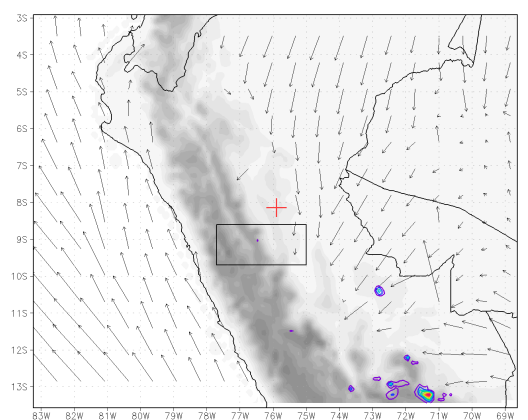

[a]

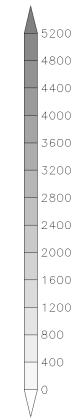

[b]

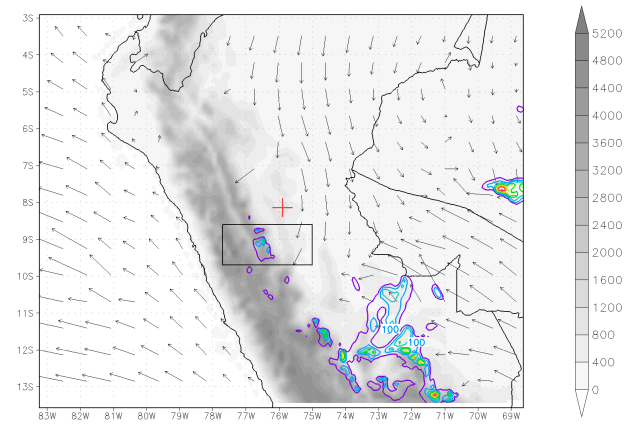

$\overline{12}$

Figura 3.80: Resultado do campo de precipitação (totpcp, $\mathrm{mm}$ ) e topografia (m) para a grade aninhada da simulação da tempestade noturna do dia 26/11/2001 onde a escala de cinza representa a elevação do terreno, os contornos a precipitação, os vetores mostram vento horizontal em $535 \mathrm{~m}$ de altura, símbolo em vermelho indica o centro da tempestade e a caixa preta a região onde a análise será realizada para a) 0530 UTC, início da precipitação; b) 0000 UTC, 27/11/2001, final da simulação. 
Desta forma, realiza-se o corte vertical desde a superfície até o topo do modelo em $9,2^{\circ} \mathrm{S}$, entre $77,5^{\circ}-75^{\circ} \mathrm{W}$ para observar as circulações locais desenvolvidas pela simulação. A Figura 3.81 mostra uma sequência temporal da evolução do vento vertical (componentes u e w, sendo que w está multiplicado por 10) e da razão de mistura do vapor junto à montanha, que tem sua topografia representada pela região preta.

Do início da simulação para a primeira saída (de 0000 a 0010 UTC, Fig 3.81,a,b, respectivamente) é possível observar que, enquanto na porção W da montanha, próximo à superfície, desenvolve-se uma circulação no sentido montanha abaixo (ventos de W até cerca de $76.6^{\circ} \mathrm{W}$, entendido como o movimento do ar devido ao resfriamento noturno), na porção oriental há um escoamento subindo a elevação topográfica, por volta de $76,2^{\circ} \mathrm{W}$, provavelmente devido a uma forçante de grande escala. Às 0220 UTC (Fig 3.81.c) destacase que: o escoamento subindo a montanha se fortalece, intensificando-se até a primeira grande elevação da cordilheira em $76,6^{\circ} \mathrm{W}$, onde começa a confluir com vento de $\mathrm{W}$ e, em aproximadamente $76,3^{\circ} \mathrm{W}$, nota-se escoamento montanha acima igualmente intensificado em superfície e, acima dele, escoamento no sentido montanha abaixo. Nesta localização também se observa razão de mistura do vapor começando a ser levada para níveis mais altos. Uma hora depois é possível observar que um rotor se desenvolve em $76,3^{\circ} \mathrm{W}$ entre a superfície e aproximadamente $3500 \mathrm{~m}$ (Fig.3.81, d).

No horário de registro da tempestade (0500 UTC, Fig 3.81.e) a confluência em $76,8^{\circ} \mathrm{W}$ está fortalecida até cerca de 4,5 Km, intensificando também a corrente ascendente neste ponto. Às 0620 UTC (Fig 3.81ff) a confluência é máxima tanto em velocidade quanto em profundidade (alcançando até cerca de $5 \mathrm{Km}$ ), momento em que o vento vertical também é máximo neste ponto que, a partir deste horário, começa a decair a observa-se um outro núcleo ascendente mais a $\mathrm{E}$, na primeira grande elevação montanhosa em $76,4^{\circ} \mathrm{W}$ às 0810 UTC (Fig.3.81.g). Às 1000 UTC (Fig.3.81.h) nota-se uma grande região de movimento ascendente de ar, entre $76,7-76,4^{\circ} \mathrm{W}$, como resultado da confluência do vento montanha abaixo (período noturno) com um escoamento de ar forçado a subir o terreno. Neste último horário também é possível notar que o vento reverte a direção na porção $\mathrm{W}$ da cordilheira, que agora é de E (sentido montanha acima). A partir de 2030 UTC (não mostrado) esta direção novamente começa a inverter no sentido montanha abaixo. 


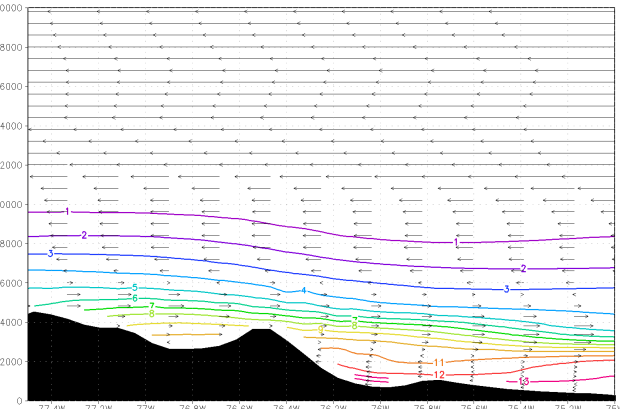

[a] was ander

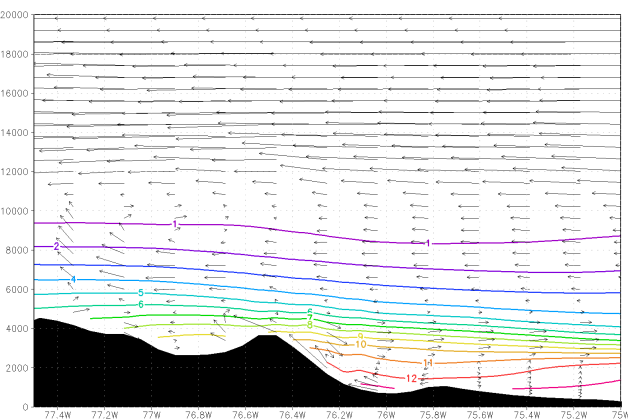

$[\mathrm{c}]_{\text {orse anuses }}$

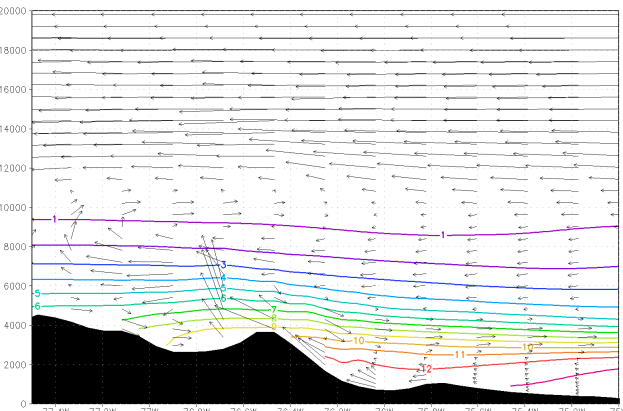

$[\mathrm{e}]_{\text {onesconses }}$

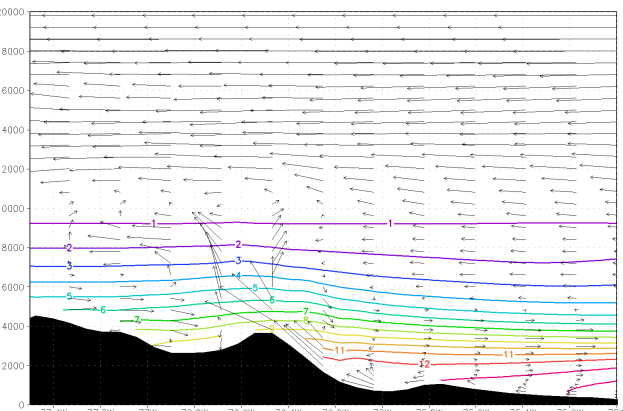

$[\mathrm{g}]$ anc anders

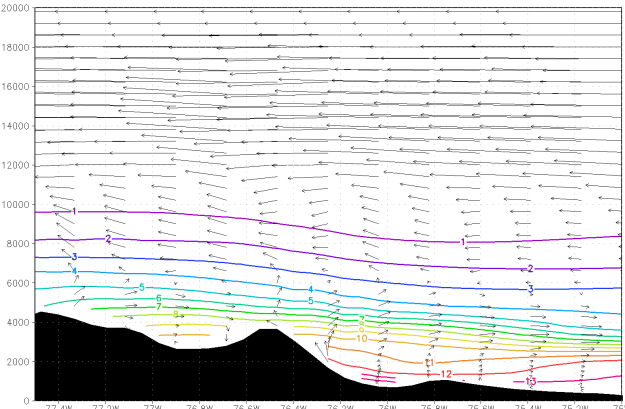

[b] woscouses

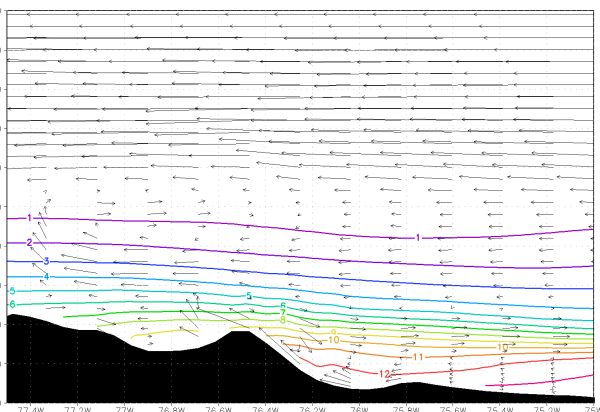

[d] wescenseses

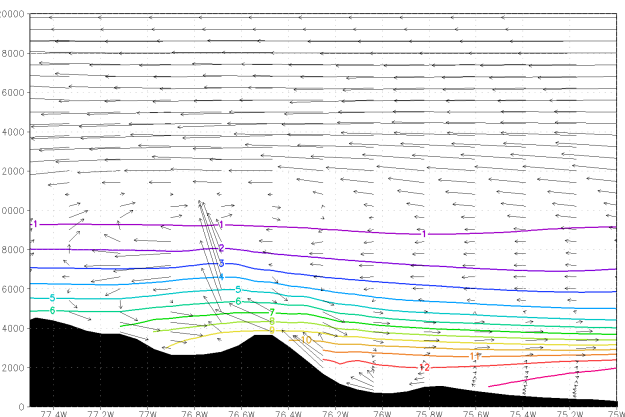

[f]

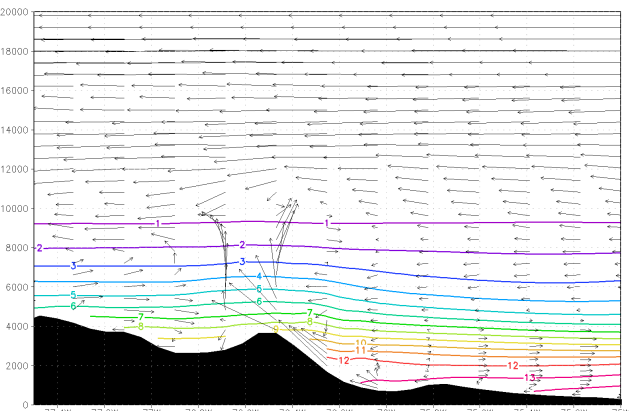

[h]

Figura 3.81: Corte vertical em $9,2^{\circ} \mathrm{S}$, entre $77,5^{\circ}-75^{\circ} \mathrm{W}$ para a grade 2 da simulação da tempestade registrada em 26/11/2001, onde a topografia é representada pela região preenchida por preto (m), os vetores representam o vento vertical (componentes u e w, sendo que w está multiplicado por 10) e da razão de mistura do vapor é mostrada pelos contornos em a) 0000 UTC, b) 0010 UTC, c) 0220 UTC, d) 0320 UTC, e) 0500 UTC, f) 0620 UTC, g) 0810 UTC, h) 1000 UTC. 
Seguindo as discussões apresentadas em Meyers et. al (1997), durante a descrição da parametrização microfísica do modelo RAMS, olha-se agora para as razões de mistura dos hidrometeoros separadamente, através de um corte transversal semelhante ao anterior, também em $9,2^{\circ} \mathrm{S}$ mas expandido longitudinalmente para melhor visualização dos campos $\left(80-74^{\circ} \mathrm{W}\right)$. A Figura 3.82 mostra, para o horário de registro da tempestade noturna, razões de mistura de a) água de nuvem, b) condensado total, c) chuva, d) pristine, e) neve, f) graupel, g) agregados, h) granizo, todas em g/Kg. É possível observar que a água de nuvem é localmente injetada no núcleo da corrente ascendente observada na primeira grande elevação da cordilheira (Fig. 3.82.a) para transformar-se nas categorias de gelo. Na localização da corrente ascendente, a razão de mistura do graupel (Fig.3.82.f) é pequena devido a maior conversão da água de nuvem em granizo (Fig 3.82,g). O pristine (Fig 3.82, d) encontra-se imediatamente acima da água de nuvem e do condensado total, com maior concentração a W da corrente ascendente. Há um núcleo com neve no topo da corrente ascendente, por volta de $6 \mathrm{Km}$, mas a maior parte deste hidrometeoro encontra-se em altitudes mais elevadas mais a W, onde há confluência E-W até cerca de $9 \mathrm{Km}$. Agregados também são observados em dois núcleos, um menor na corrente ascendente principal e outro maior na região de maior confluência. A razão de mistura de chuva (Fig 3.82.c) é observada em altitudes mais baixas, próximo a primeira inclinação oriental da cordilheira, imediatamente abaixo do granizo. Desta forma, pode-se afirmar que a água da nuvem converte-se principalmente em chuva e granizo na primeira elevação dos Andes, enquanto outros hidrometeoros de fase sólida formam-se em maior altitude, na parte mais ocidental da cordilheira, onde há confluência desde a superfície.

Os resultados da simulação da terceira tempestade noturna mais intensa do conjunto, avaliados a partir da grade aninhada com maior refinamento, permitem observar as circulações desenvolvidas no complexo terreno da Amazônia andina bem como uma distribuição de hidrometeoros consistente com uma nuvem verticalmente extensa. Desta forma, a conclusão geral é de que a tempestade foi resolvida satisfatoriamente pela simulação com o modelo regional BRAMS, podendo ser ainda ser aprimorada. 


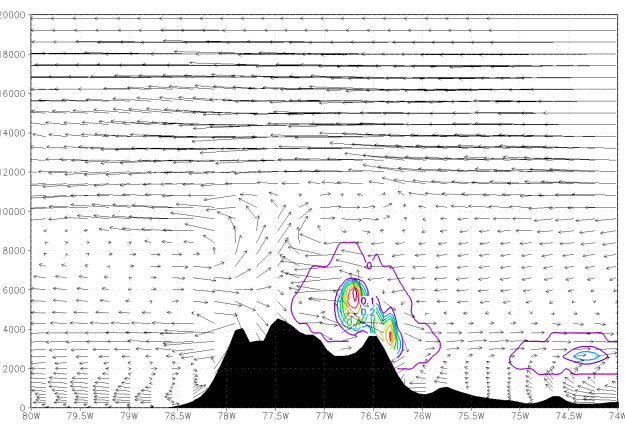

$[a]$

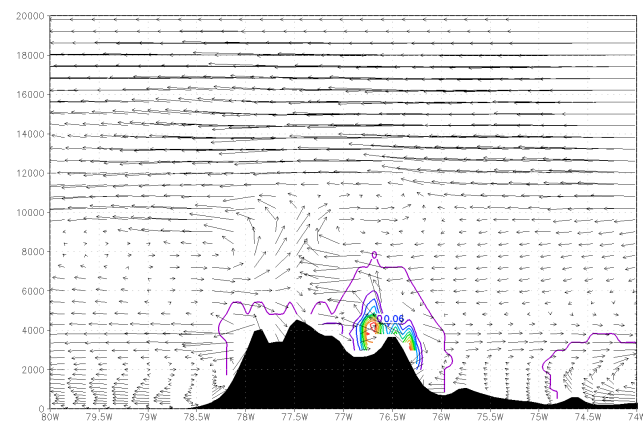

$[c]$

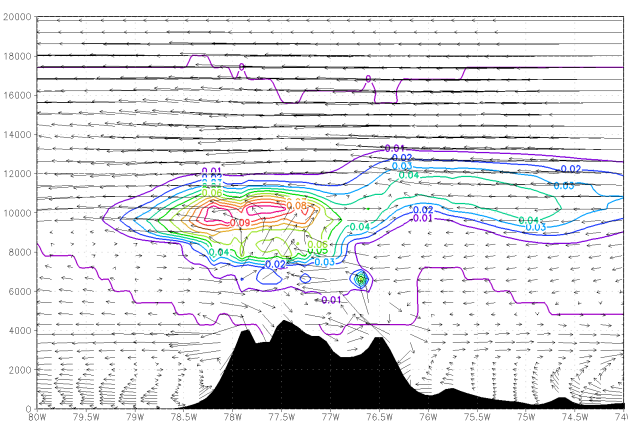

$[\mathrm{e}]$

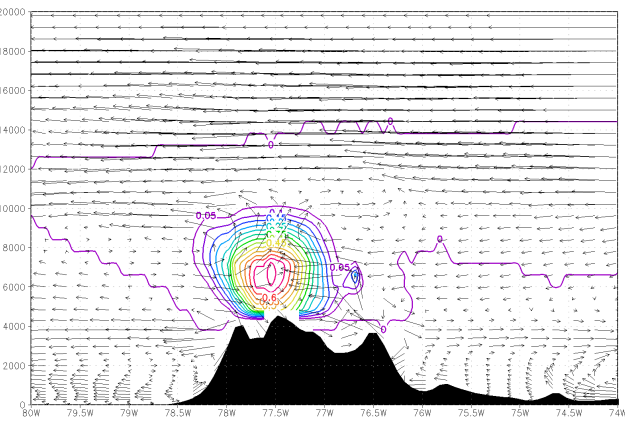

$[\mathrm{g}]$

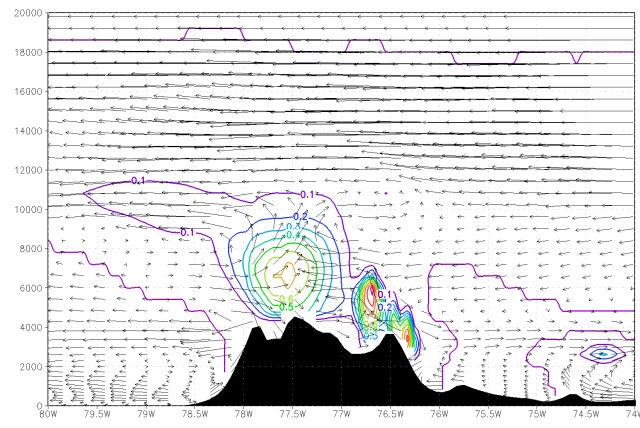

$[\mathrm{b}]$ ow

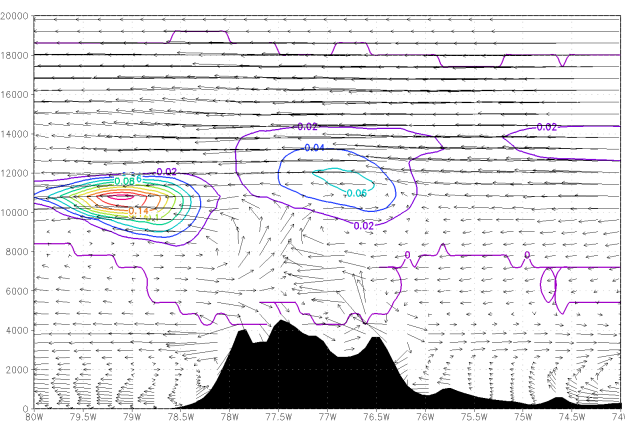

[d]

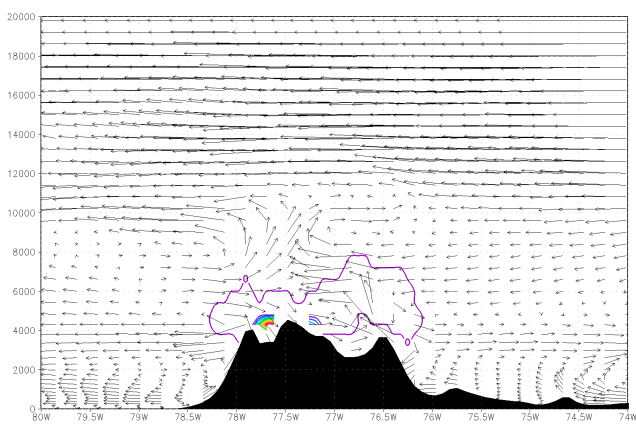

$[\mathrm{f}]$

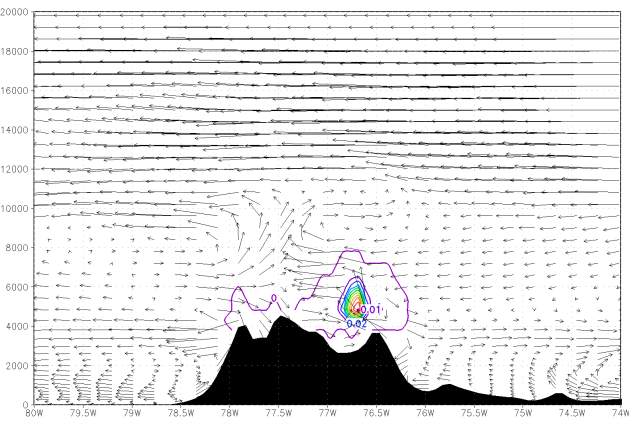

$[\mathrm{h}]$

Figura 3.82: Corte vertical em $9,2^{\circ} \mathrm{S}$ entre $80^{\circ} \mathrm{W}-74^{\circ} \mathrm{W}$, às 0500 UTC do dia $26 / 11 / 2001$, mostrando vento vertical $\left(\mathrm{u} ; \mathrm{w}^{*} 10\right)$, topografia $(\mathrm{m})$ e razão de mistura $(\mathrm{g} / \mathrm{Kg})$ de a) água de nuvem, b) condensado total, c) chuva, d) pristine, e) neve, f) graupel, g) agregados, h) granizo. 
Capítulo 4

\section{Conclusões}

O estudo de tempestades noturnas na região SW Amazônia e encosta da cordilheira dos Andes mostrou que estes sistemas possuem características que são associadas com índices de severidade em todo o mundo. Embora a maior parte das chuvas observadas na bacia amazônica não sejam severas, mas certamente abundantes, a localização especial nos trópicos meridionais perto da cordilheira dos Andes apresenta ingredientes suficientes para levar a sistemas convectivos intensos e severos. As principais características das tempestades noturnas no SW Amazônia podem ser sumarizadas ao responder aos cinco questionamentos iniciais:

1. Sob qual configuração sinótica essas tempestades noturnas ocorrem?

Dois padrões de grande escala em baixos níveis estão associados com as tempestades noturnas, um relacionado ao JBNAS (P1) e outro com a confluência associada a passagem de sistemas frontais (P2). P1 contabiliza 55 casos, dos quais 19 são intensos e 13 extremos, enquanto P2 contabiliza 42 casos, 20 intensos e 10 extremos. No padrão P1, o JBNAS desempenha papel importante intensificando o fluxo de NW, elevando a temperatura e a umidade da região. O ambiente pré-convectivo mostra CAPE alto aumentando $\sim 1000 \mathrm{~J} / \mathrm{Kg}$ enquanto CIN reduz $\sim 50 \mathrm{~J} / \mathrm{Kg}$ entre $1200 \mathrm{e}$ 1800 UTC. No padrão P2, nota-se confluência NW-SE associada com a passagem de sistemas frontais. O avanço destes sistemas, e consequentemente da confluência, para latitudes baixas é favorecido por uma configuração de altos níveis já discutida por outros autores e observada aqui: uma crista próxima à costa do Chile e um cavado no Sul do Brasil em 500 hPa, bastante evidente nos campos de anomalia.

2. Estão embebidas em sistemas maiores ou acontecem de forma isolada? 
A maioria das tempestades noturnas ocorre com suporte de sistemas sinóticos (como JBNAS, frentes frias e ZCAS) mas são essencialmente isoladas, apenas 7 foram considerados embebidas ou disparadas por sistemas frontais. Fundamentalmente identificam-se seis tipos eventos: 1) isolados, no escoamento de NW relacionado ao JBNAS; 2) isolados, em região onde há confluência NW-SE/S em baixos níveis, relacionada ao escoamento de sistema frontal; 3) embebidos ou disparados por sistemas frontais; 4) isolados no NW do domínio onde os ventos alísios sofrem levantamento na cordilheira dos Andes, antes de defletirem para S; 5) isolados, no escoamento dos alísios mas no NE do domínio, longe da cordilheira e 6) isolados com suporte do escoamento relacionado a ZCAS/ZCON.

3. Quais são as características comuns entre elas?

A localização preferencial das tempestades noturnas ocorre próximo ao sopé da cordilheira dos Andes, principalmente no trimestre OND (transição entre a estação seca e chuvosa). Cerca de 40\% dos sistemas identificados entre 1998-2013 são intensos (> $32 \mathrm{raios} / \mathrm{min}$ ) e $25 \%$ extremos (> $47 \mathrm{raios} / \mathrm{min}$ ). O horário local preferencial para o início destes sistemas é entre 18 e 00, e eles duram em média 16,6h, com a maioria tendo durações entre 7,5 e $22 \mathrm{~h}$.

4. Quais seriam os ingredientes importantes para sua intensidade e previsibilidade?

Comparando composições de campos médios centradas nas tempestades intensas e não intensas, utilizando caixas de $6^{\circ} \times 6^{\circ}$ ao redor delas, observa-se que o ambiente de tempestades noturnas intensas tem uma confluência NW-S/SE em baixos níveis, na região sul do centro dos sistemas (similar a P2), T relativamente mais alta e CAPE consideravelmente maior do que para tempestades não intensas. Além disso, há um contraste de umidade entre médios e baixos níveis, com ar mais seco sobreposto a fluxo úmido, hipotetiza-se que este ambiente relativamente mais seco seja importante para a severidade dos sistemas noturnos, como tem sido mostrado em tempestades severas que ocorrem em regiões subtropicais ao redor do globo. Destaca-se que tempestades noturnas intensas têm WCD mais raso, CAPE mais alto e cisalhamento do vento em baixos níveis e um CIN ligeiramente mais baixos do que tempestades não intensas. O horário de 1800 UTC (pré-convectivo) é notável, onde encontram-se WCD mínimo e o CAPE é máximo (500 m mais raso e $1000 \mathrm{~J} / \mathrm{Kg}$ maior em com- 
paração às não intensas), o CIN e cisalhamento do vento de baixo nível diminuem ligeiramente e aumentam novamente no horário seguinte. A combinação de WCD raso e CAPE alto parece desempenhar um papel importante no NT intenso no SW Amazônia.

5. Qual o papel dos Andes na formação dessas tempestades severas?

As simulações numéricas com o modelo regional BRAMS na região SW Amazônia, local com topografia complexa relacionada à cordilheira dos Andes, mostraram-se desafiadoras. Resultados mostram que é possível capturar padrões de circulação observados nos campos de reanálise e também observar o desenvolvimento de circulações locais relacionadas à topografia, como fluxo terreno abaixo durante a noite e terreno acima durante o dia. A simulação da tempestade do dia 26/11/2001, terceira mais intensa na classificação de severidade, mostrou que um fluxo de ar em superfície é forçado a subir a inclinação da cordilheira, resultando em um sistema intenso, verticalmente desenvolvido, devido à confluência com fluxo que descende do topo da montanha no período noturno.

O rastreamento manual das tempestades noturnas na região SW Amazônia nas imagens de satélite mostrou uma gama de outros sistemas com potencial de severidade que não foram selecionados pela filtragem realizada no banco Precipitation Features. Sugerese, desta forma, que trabalhos futuros realizem o rastreamento destes eventos noturnos na presente região em outras bases de dados, como os métodos clássicos encontrados na literatura científica que geralmente são baseados nas próprias imagens de satélite, definindo limiares de área e temperatura de brilho. Isso deve resultar em um número muito maior de sistemas convectivos para serem estudados. Outra sugestão refere-se ao aprimoramento das simulações numéricas, seja avaliando diferentes configurações de entrada para o BRAMS ou utilizando outros modelos regionais. Também é necessário ampliar o número de tempestades noturnas simuladas, principalmente àquelas consideradas isoladas junto à cordilheira, visando identificar elementos marcantes para implementar objetivamente um conjunto de informações que auxiliem na previsibilidade destes sistemas. 


\section{Referências Bibliográficas}

ALBRECHT, R. I., MORALES, C. A., SILVA DIAS, M. A. F. Electrification of precipitating systems over the Amazon: Physical processes of thunderstorm development, J. Geophys. Res., 116, D08209, doi:10.1029/2010JD014756. 2011.

AlBRECHT, R.I.; GOODMAN, S. J.; BUECHLER, D. E.; BLAKESLEE, R. J.; CHRISTIAN, H. J. Where Are the Lightning Hotspots on Earth?. Bull. Amer. Meteor. Soc., 97, 2051-2068, https://doi.org/10.1175/BAMS-D-14-00193.1. 2016.

ANGELIS, C. F.; MCGREGOR, G. R.; KIDD, C. A 3 year climatology of rainfall characteristics over tropical and subtropical South America based on tropical rainfall measuring mission precipitation radar data. Int. J. Climatol., 24: 385-399. https://doi.org/10.1002/joc.998. 2004a.

ANGELIS, C. F.; MCGREGOR, G. R.; KIDD, C. Diurnal cycle of rainfall over the Brazilian Amazon. Climate Research, 26(2), 139-149. http://www.jstor.org/stable/24868716. 2004b.

ANSELMO, E.: Morfologia das tempestades elétricas na América do Sul. Tese de doutorado em Meteorologia, Universidade de São Paulo. 2015.

ANSELmO, E. M.; SCHUMACHER, C.; MACHADO, L. A. T. The Amazonian LowLevel Jet and Its Connection to Convective Cloud Propagation and Evolution, Monthly Weather Review, 148(10), 4083-4099. 2020. 
AnSElmo, E. M.; MACHADO, L. A. T.; SCHUMACHER, C.; KILADIS, G. N. Amazonian mesoscale convective systems: Life cycle and propagation characteristics. Int J Climatol. 1- 14. https://doi.org/10.1002/joc.7053. 2021.

AWAKA, J., T. IGUCHI, H. KUMAGAI, AND K. OKAMOTO. Rain type classification algorithm for TRMM precipitation radar, in Geoscience and Remote Sensing, 1997: IGARSS '97, Remote Sensing-A Scientific Vision for Sustainable Development, vol. 4, pp. 1633-1635, Inst. of Electr. and Electron. Eng., New York, doi:10.1109/IGARSS.1997.608993. 1997.

BENDIX, J.; FRIES, A.; ZÁRATE, J.; TRACHTE, K.; ROLLENBECK, R.; PUCHACOFREP, F.; PALADINES, R.; PALACIOS, I.; ORELLANA, J.; OÑATE-VALDIVIESO, F.; NARANJO, C.; MENDOZA, L.; MEJIA, D.; GUALLPA, M.; GORDILLO, F.; GONZALEZJARAmillo, V.; DOBBERMANN, M.; CÉlleri, R.; CARRILlO, C.; ARAQUE, A.; ACHILLES S. RadarNet-Sur First Weather Radar Network in Tropical High Mountains. Bull. Amer. Meteor. Soc., 98, 1235-1254, https://doi.org/10.1175/BAMS-D-15-00178.1. 2017.

BLANCHARD, D. O. Assessing the Vertical Distribution of Convective Available Potential Energy. Weater Forecasting, 13, 870-877, https://doi.org/10.1175/1520-0434(1998)013¡0870:ATVDOC¿2.0 1998.

BONNER, W. D. Climatology of the Low Level Jet. Monthly Weather Review, 96(12): 833-850, 1968.

CAREY, L. D.; RUTLEDGE, S. A. Electrical and multiparameter radar observations of a severe hailstorm, J. Geophys. Res., 103(D12), 13979-14000, doi:10.1029/97JD02626, 1998.

CAREY, L. D.; BUFFALO, K. Environmental Control of Cloud-to-Ground Lightning Polarity in Severe Storms. AGU Fall Meeting Abstracts. 135. 10.1175/MWR3361.1. 2004. 
CECIL, D.; GOODMAN, S.; BOCCIPPIO, D.; ZIPSER, E.; NESBITT, S. Three years of trmm precipitation features. part i: Radar, radiometric, and lightning characteristics.Mon. Wea. Rev., v. 133, p. 543-566, 2005.

CECIL, D. J.; BLANKENSHIP, C. B. Toward a Global Climatology of Severe Hailstorms as Estimated by Satellite Passive Microwave Imagers. J. Climate, 25, 687-703,https://doi.org/10.1175/JC D-11-00130.12012.

CHAVEZ, S. P.; TAKAHASHI, K.: Orographic rainfall hot spots in the Andes [U+2010] Amazon transition according to the TRMM precipitation radar and in situ data, Journal of Geophysical Research: Atmospheres, 122, 11, (5870-5882), 2017.

CLIMANÁliSE: Boletim de Monitoramento e Análise Climática. Cachoeira Paulista-SP: INPE/CPTEC, 2005. v. 20. n. 9. Disponível em http://climanalise.cptec.inpe.br/ rclimanl/boletim/0905/index.html.

CLIMANÁLISE: Boletim de Monitoramento e Análise Climática. Cachoeira Paulista-SP: INPE/CPTEC, 2008. v. 23. n. 4. Disponível em http://climanalise.cptec.inpe.br/ rclimanl/boletim/index0408.shtml.

CLIMANÁLISE: Boletim de Monitoramento e Análise Climática. Cachoeira Paulista-SP: INPE/CPTEC, 2013. v. 24. n. 8. Disponível em http://climanalise.cptec.inpe.br/ $\sim$ rclimanl/boletim/index0813.shtml.

CLIMANÁliSE: Boletim de Monitoramento e Análise Climática. Cachoeira Paulista-SP: INPE/CPTEC, 2013. v. 28. n. 12. Disponível em http://climanalise.cptec.inpe.br/ rclimanl/boletim/index1213.shtml.

COHEN, J. C. P. Um estudo observacional de linhas de instabilidade na Amazônia. 121f. Dissertação de mestrado. Instituto Nacional de Pesquisas Espaciais, São José dos Campos - SP. 1989. 
COHEN, J. C. P.; SILVA DIAS, M. A. F.; NOBRE, C. A.: Aspectos 93 climatológicos das linhas de instabilidade na Amazônia. Boletim Climanálise, 4 (11), 34-40, 1989.

DOSWEL, C. A.; RASMUSSEN, E. The Effect of Neglecting the Virtual Temperature Correction on CAPE Calculations. Weather and Forecasting. 9. 10.1175/1520-0434(1994)009¡0625:TEONTV ¿2 1994.

DOSWELL, C. A.; EVANS, J. S.: Proximity sounding analysis for derechos and supercells: an assessment of similarities and differences, Atmospheric Research, Volumes 67-68, Pages 117-133, ISSN 0169-8095, https://doi.org/10.1016/S0169-8095(03)00047-4. 2003.

DYE, J. E.; WINN, W. P.; JONES, J. J.; BREED, D. W. The electrification of New Mexico thunderstorms. Part I: Rrelationship between precipitation development and the onset of electrification. Journal of Geophysical Research, 94(D6), 8643-8656. https://doi.org/10.1029/JD094iD06p0 1989.

ESCOBAR, G. C. J.; COMPAGNUCCI, R. H.; BISCHOFF, S. A. Sequence Patterns of $1000 \mathrm{hPa}$ and $500 \mathrm{hPa}$ geopotential height fields associated with cold surges in Buenos Aires. Atmosfera, 12(2): 69-89. 2004.

ESCOBAR, G. C. J.; VAZ, J. C. M.; REBOITA, M. S. Circulação atmosférica em superfície associada às friagens no Centro-Oeste do Brasil. Anuário do Instituto de Geociências, v. 42, n. 1, p. 241-254, 2019. Surface Atmospheric Circulation Associated With Friagens in Central-West Brazil. Disponível em: http://www.anuario.igeo.ufrj.br/2019_01/ 2019_1_241_254.pdf. Acesso em: 22 set. 2020.

ESPINOZA, J. C. V.; RONCHAIL, J.; GUYOT, J. L.; COCHONNEAU, G.; NAZIANO, F.; LAVADO, W.; DE OLIVEIRA, E.; POMBOSA, R.; VAUCHEL, P. Spatio-temporal rainfall variability in the Amazon basin countries (Brazil, Peru, Bolivia, Colombia, and Ecuador). Int. J. Climatol. 29, 1574-1594. 2009. 
FIGUEROA, S. N.; NOBRE, C. A. Precipitation distribution over central and western tropical South America. Climanalise 6: 36-40. 1990.

FISCH, G.; MARENGO, J. A.; NOBRE CA. Uma revisão geral sobre o clima da Amazônia. Acta Amazônica 28: 101-126. 1998.

FISHER, B. L. Climatological Validation of TRMM TMI and PR Monthly Rain Products over Oklahoma, Journal of Applied Meteorology, 43(3), 519-535. 2004.

FUNK, C. Climate Hazards Group (http://dx.doi.org/10.15780/G2RP4Q). 2015.

FREITAS, S. R.; LONGO, K. M.; SILVA DIAS, M. A. Monitoring the transport of biomass burning emissions in South America. Environmental Fluid Mechanics, 5, 135, 2005.

FRISBY, E. M.; SANSOM, H. W. Hail incidence in the tropics. J. Appl. Meteor., 6, $339-354.1967$.

GARREAUD, R. D. "Cold air incursions over subtropical South America: mean structure and dynamics". Monthly Weather Review, 128: 2544-2559. 2000.

GATLIN, P. N.; GOODMAN, S. J. A total lightning trending algorithm to identify severe thunderstorms. Journal of atmospheric and oceanic technology, v. 27, n. 1,p. 3-22, 2010.

GIRARDI, C. O. Poço dos Andes. Relatório Técnico ECA 01/83. Instituto de Atividades espaciais (CTA), São José dos Campos, 25 p. 1983.

HALLADAY, K.; MALHI, Y.; NEW, M. Cloud frequency climatology at the Andes/Amazon transition: 2. Trends and variability. J. Geophys. Res.. 117. D23103. 10.1029/2012jd017789. 2012 .

HERSBACH, H., BELL, B., BERRISFORD, P., BIAVATI, G., HORÁNYI, A., MUÑOZ SABATER, J., NICOLAS, J., PEUBEy, C., RADU, R., ROZUM, I., SCHEPERS, D., 
SIMMONS, A., SOCI, C., DEE, D., THÉPAUT, J-N.: ERA5 hourly data on pressure levels from 1979 to present. Copernicus Climate Change Service (C3S) Climate Data Store (CDS). (Acessado em 2018, 2019, 2020), 10.24381/cds.bd0915c6. 2018.

HERSBACH, H., BELL, B., BERRISFORD, P., BIAVATI, G., HORÁNYI, A., MUÑOZ SABAter, J., NICOlAS, J., PEUBEy, C., RADU, R., ROZUM, I., SCHEPERS, D., SIMMONS, A., SOCI, C., DEE, D., THÉPAUT, J-N. (b): ERA5 hourly data on single levels from 1979 to present. Copernicus Climate Change Service (C3S) Climate Data Store (CDS). (Accessed on ; DD-MMM-YYYY ¿), 10.24381/cds.adbb2d47. 2018.

HOREL J. D.; HAHMANN A. N.; GEISLER J. E. An investigation of the annual cycle of convective activity over the tropical Americas. Journal of Climate 2: 1388-1403. 1989.

HOUZE, R. A. JR.; WILTON, D. C.; SMUlL, B. F. Monsoon convection in the Himalayan region as seen by the TRMM Precipitation Radar, Q. J. R. Meteorol. Soc., 133, 1389-1411. 2007.

HOUZE, R. A. JR. Orographic effects on precipitating clouds. Reviews of Geophysics, 50, RG1001. https://doi.org/10.1029/2011RG000365. 2012.

HOUZE, R. A.; RASMUSSEN, K. L.; ZULUAGA, M. D.; BRODZIK, S. R. The variable nature of convection in the tropics and subtropics: A legacy of 16 years of the Tropical Rainfall Measuring Mission satellite, Rev. Geophys., 53, 994- 1021, doi:10.1002/2015RG000488. 2015.

IMAOKA, K.; SPENCER, R. W. Diurnal Variation of Precipitation over the Tropical Oceans Observed by TRMM/TMI Combined with SSM/I, Journal of Climate, 13(23), 4149-4158. 2000.

JARVIS, A.; REUTER, H. I.; NELSON, A.; GUEVARA, E. Hole-filled seamless SRTM data V4, International Centre for Tropical Agriculture (CIAT), available from ¡https://srtm.csi.cgiar.orgi. 
Accessed in 17 February 2017. 2008.

JANOWIAK, J.; JOYCE, B.; XIE, P. NCEP/CPC L3 Half Hourly 4km Global (60S - 60N) Merged IR V1, Edited by Andrey Savtchenko, Greenbelt, MD, Goddard Earth Sciences Data and Information Services Center (GES DISC), Accessed in June/2019 10.5067/P4HZB9N27EKU. 2017.

JOHNS, R. H.; AND DOSWELL, C. A. (1992). Severe local storm forecasting. Weather Forecast. 7, 588-612.

JOHNSON, R.H.; MAPES, B.E. Mesoscale Processes and Severe Convective Weather. In Severe Convective Storms; Meteorological Monographs; Doswell, C.A., III, Ed.; American Meteorological Society: Boston, MA, USA. Volume 28, pp. 71-122. 2001.

JUNQUAS, C.; TAKAHASHI, K.; CONDOM, T. Understanding the influence of orography on the precipitation diurnal cycle and the associated atmospheric processes in the central Andes. Clim. Dyn. 50: 3995. https://doi.org/10.1007/s00382-017-3858-8. 2018.

KOUSKY, V. E.; KAYANO, M. T.; CAVALCANTI, I. F. A. A review of the southern oscillation: oceanic, atmospheric circulation changes and related anomalies. Tellus 36A: 490-504. 1984.

KUMmEROW, C.; BARNES, W.; KOZU, T.; SHIUE, J.; SIMPSON, J. The Tropical Rainfall Measuring Mission (TRMM) sensor package. J. Atmos. Oceanic Tech.,. 15, 809-817. 1998.

KUMMEROW, C.; SIMPSON, J.; THIELE, O.; BARNES, W.; CHANG, A. T. C.; STOCKER, E.; ADLER, R. F.; HOU, A.; KAKAR, R.; WENTZ, F.; ASHCROFT, P.; KOZU, T.; HONG, Y.; OKAMOTO, K.; IGUCHI, T.; KUROIWA, H.; IM, E.; HADDAD, Z.; HUFFMAN, G.; FERRIER, B.; OLSON, W. S.; ZIPSER, E.; SMITH, E. A.; WILHEIT, T. T.; NORTH, G.; KRISHnAMURTI, T.; NAKAMURA, K. The status of the Tropical Rainfall Measuring Mission (TRMM) after two years in orbit. J. Appl. Meteor., 39, 
1965-1982. 2000.

LIU, C., ZIPSER, E. J., CECIL, D. J., NESBITT, S. W., AND SHERWOOD, S. A Cloud and precipitation feature database from nine years of TRMM observations. J. Appl. Meteorol. Climatol. 47, 2712-2728. doi: 10.1175/2008JAMC1890.1. 2008.

LIU, N.; LIU, C.; TISSOT, P. E. A Bayesian-like approach to describe the regional variation of high $[\mathrm{U}+2010]$ flash rate thunderstorms from thermodynamic and kinematic environment variables. Journal of Geophysical Research: Atmospheres, 124, 12507-12522. https://doi.org/10.1029/2019JD031254. 2019.

LIU, N.; LIU, C.; CHEN, B.; ZIPSER, E. What Are the Favorable Large-Scale Environments for the Highest-Flash-Rate Thunderstorms on Earth?, Journal of the Atmospheric Sciences, 77(5), 1583-1612. Retrieved Jan 5, 2021, from https://journals.ametsoc.org/view/journals/atsc/7 d-19-0235.1.xml. 2020.

LONGO, M.; SILVA DIAS, M. A. F.; CAMARGO, R. de. 2004. Análise das características dinâmicas e sinóticas de um evento de friagem durante a estação chuvosa no sudoeste da Amazônia In Revista Brasileira de Meteorologia. v.19, 59-72.

MACGORMAN, D. R., BURGESS, D. W.; MAZUR, W. V.; RUST, D.; TAYLOR, W. L.; JOHNSON, B. C. Lightning Rates Relative to Tornadic Storm Evolution on 22 May 1981. J. Atmos. Sci., 46, 221-251.doi: http://dx.doi.org/10.1175/1520-0469(1989)046¡0221:LRRTTS¿2.0.CO;2, 1989.

MACHADO, L. A. T.; ROSSOW, W. B.; GUEDES, R. L.; WALKER, A. W. Life Cycle Variations of Mesoscale Convective Systems over the Americas, Monthly Weather Review, 126(6), 1630-1654. 1998.

MACHADO, L.; LAURENT, H.; DESSAY, N.; MIRANDA, I. Seasonal and diurnal variability of convection over the Amazonia: a comparison of different vegetation types and large scale forcing, Theoretical and Applied Climatology 78(1): 61-77. 2004. 
MAPES, B. E.; HOUZE, R. A. Cloud clusters and superclusters over the oceanic warm pool. Mon. Wea. Rev., 121, 1398-1415. 1993.

MOHR, K. I.; ZIPSER, E. J.: Mesoscale convective systems defined by their 85-GHz ice scattering signature: Size and intensity comparison over tropical oceans and continents. Monthly Weather Review, 124, 2417-2437, 1996.

MOHR, K. I.; TORACINTA, E. R.; ZIPSER, E. J.; ORVILLE, R. E. A comparison of WSR-88D reflectivities, SSM/I brightness temperatures, and lightning for mesoscale convective systems in Texas. Part II: SSM/I brightness temperatures and lightning. J. Appl. Meteor., 35, 919-931. 1996.

MAREnGO, J. A.; Nobre, C. A.; Culf, A. D. Climatic Impacts of Friagens in forested and deforested areas of the Amazon Basin. Journal of Applied Meteorology, 36: 15531566. 1997.

MAREnGO, J. A.; DOUGLAS, M. W.; SILVA DIAS, P. L. "The South American lowlevel jet east of the Andes during the 1999 LBA-TRMM and LBA-WET AMC campaign. Journal of Geophysics. Res.,107,8079,doi:10.1029/2001JD001188. 2002.

MARENGO, J. A.; SOARES, W. R.; SAULO, C.; NICOLINI, M. Climatology of the LowLevel Jet East of the Andes as Derived from the NCEP-NCAR Reanalysis: Characteristics and Temporal Variability, Journal of Climate, 17 (12), 2261-2280. https://journals. ametsoc.org/view/journals/clim/17/12/1520-0442_2004_017_2261_cotlje_2.0.co_. 2.xml. 2004.

Martin, S. T.; ARTAXO, P.; MAChadO, L. A. T.; MAnZI, A. O.; SOUZA, R. A. F.; SCHUMACHER, C.; WANG, J.; ANDREAE, M. O.; BARBOSA, H. M. J.; FAN, J.; FISCH, G.; GOLDSTEIN, A. H.; GUENTHER, A.; JIMENEZ, J. L.; PÖSCHL, U.; SILVA DIAS, M. A.; SMITH, J. N.; WENDISCH, M.: Introduction: Observations and Modeling of the Green Ocean Amazon (GoAmazon2014/5), Atmos. Chem. Phys., 16, 4785-4797, https://doi.org/10.5194/acp-16-4785-2016, 2016. 
MILLS, G. A.; AND CONQUHOUN, J. R. Objective prediction of severe thunderstorm environments: preliminary results linking a decision tree with an operational regional NWP model. Weather Forecast. 13, 1078-1092. 1998.

MUGNAI, A.; SMITH, E. A.; TRIPOLI, G. J. Foundations for statistical-physical precipitation retrieval from passive microwave satellite measurements. Part II: Emission source and generalized weighting function properties of a time dependent cloud-radiation model. J. Appl. Meteor., 32, 17-39. 1993.

MÜlleR, G. V.; COMPAGNUCCI, R.; NUÑEZ, M. N.; SALLES, A. Surface circulation associated with frost in the wet pampas. International Journal of Climatology, 23(8): 943-961. 2003.

NASCIMENTO, E. L. (2005). Previsão de tempestades severas utilizando-se parâmetros convectivos e modelos de mesoescala: uma estratégia operacional adotável no Brasil. Rev. Bras. Meteorol. 20, 121-140.

NASCIMENTO, E. L.; FOSS, M.; FERREIRA, V.; BROOKS, H. E. "An updated and expanded climatology of severe weather parameters for subtropical South America as derived from upper air observations and cfsr-cfsv2 data". 28th Conference on Severe Local Storms - American Meteorological Society 7-11 November 2016, Portland/OR. (https://ams.confex.com/ams/28SLS/webprogram/Paper300887.html). 2016.

NATIONAL AERONAUTICS AND SPACE ADMINISTRATION.Goodbye to TRMM, First Rain Radar in Space. 2014. Dispon’1vel em: ¡https://gpm.nasa.gov/missions/TRMM/goodbyetrmm-first-rain-radar-space ¿. Acesso em: 20 abr. 2021.

NATIONAL AERONAUTICS AND SPACE ADMINISTRATION. TRMM Comes to an End after 17 Years. 2015. Disponível em: ¡https://gpm.nasa.gov/missions/trmm/missionendi. Acesso em: 20 abril 2021. 
NEGRI, A. J.; BELL, T. L.; XU, L. Sampling of the Diurnal Cycle of Precipitation Using TRMM, Journal of Atmospheric and Oceanic Technology, 19(9), 1333-1344. 2002.

NESBITT, S. W.; ZIPSER, E. J.; CECIL, D. J. A Census of Precipitation Features in the Tropics Using TRMM: Radar, Ice Scattering, and Lightning Observations. J. Climate, 13, 4087-4106, https://doi.org/10.1175/1520-0442(2000)013¡4087:ACOPFI¿2.0.CO;2. 2000.

NICOLINI, M.; SAULO, A. C. ETA characterization of the 1997-98 warm season Chaco jet cases. Preprints, Sixth Int. Conf. on Southern Hemisphere Meteorology and Oceanography, Santiago, Chile, Amer. Meteor. Soc., 330-331. 2000.

NICOLINI, M.; SAULO, A. C. Modeled Chaco low-level jets and related precipitation patterns during the 1997-1998 warm season. Meteor. Atmos. Phys., 94 , 129-143. 2006.

NOBRE, C. A.; SELlERS, P.; SHUKLA, J. Amazonian deforestation and regional climate change. Journal of Climate 4: 957-988. 1991.

NOBRE, C. A. et al. Characteristics of amazonian climate: Main features. GEOPHYSICAL MONOGRAPH SERIES, p. 149-162, 2009.

NUneS, A. M. P.; SILVA DIAS, M. A. F.; ANSElmO, E. M.; MORAlES, C. A. Severe Convection Features in the Amazon Basin: A TRMM-Based 15-Year Evaluation. Frontiers in Earth Science, 4. doi:10.3389/feart.2016.00037. 2016.

OLIVEIRA, M. I.; NASCIMENTO, E. L.; KANNENBERG, C. A. New Look at the Identification of Low-Level Jets in South America, Monthly Weather Review, 146(7), 2315-2334. https://doi.org/10.1175/MWR-D-17-0237.1. (2018).

PEREIRA FILHO, A. J., CARBOnE, R.E., TUTTLE, J.D., KARAM, H.A. Convective rainfall in Amazonia and adjacent tropics. Atmos. Clim. Sci. 5:137-161. https://doi.org/10.4236/acs.20 2015. 
PIElKE, R. E.; COTTON, W. R.; WALKO, R. L.; TREMBACK, C. J.; LYONS, W. A.; GRASSO, L. D.; NICHOLLS, M. E.; MORAN, M. D.; WESLEY, D. A.; LEE, T. J.; COPELAND, J. H. A Comprehensive Meteorological Modeling System - RAMS. Metero. Atmos. Phys.. 49, 69-91. 1992.

PIERCE, E. Some Topics in atmospheric electricity - Recent advances in a atmopheric eletrecity. Pergamon press, London, 1958.

RASMUSSEN, K. L.; HOUZE, R. A. JR. Orogenic convection in subtropical South America as seen by the TRMM satellite, Mon. Weather Rev., 139(8), 2399-2420, doi:10.1175/ MWR-D-10-05006.1. 2011.

RASMUSSEN, K. L., HOUZE, R. A., Jr. Convective Initiation near the Andes in Subtropical South America, Monthly Weather Review, 144(6), 2351-2374. DOI: https://doi . org/10.1175/MWR-D-15-0058.1. 2016.

RATISBOnA, L. R. The climate of Brazil. Climates of Central and South America, World Survey of Climatology, Vol. 12. Elsevier Scientific Publishing Company; New York, 219-293, chap. 5. 1976.

REHBEIN, A., AMBRIZZI, T.; MECHOSO, C. R., Mesoscale convective systems over the Amazon basin. Part I: climatological aspects. Int. J. Climatol, 38: 215-229. https://doi.org/10.1002/joc.517 2018.

REBOITA, M. S.; ESCOBAR, G. C. J.; LOPES, V. Climatologia sinótica de eventos de ondas de frio sobre a região sul de Munas Gerais. Revista Brasileira de Climatologia, 16: 72-92. 2015.

RICARTE, R. M. D. Climatologia de eventos de friagem no sul da região Amazônica. Instituto Nacional de Pesquisas Espaciais, São José dos Campos, Tese de doutorado, 119p. 2012 .

RICKENBACH, T. M. Nocturnal cloud systems and the diurnal cariation of clouds and 
rainfall in Southwestern Amazonia. Mon. Weather Rev. 132, 1201-1219. doi: 10.1175/15200493(2004)132¡1201:NCSATD¿2.0.CO;2. 2004.

ROMATSCHKE, U.; HOUZE, R. A. JR. Extreme summer convection in South America, J. Clim., 23, 3761-3791, doi:10.1175/2010JCLI3465.1. 2010.

ROMATSCHKE, U.; HOUZE, R. A. JR. Characteristics of precipitating convective systems in the premonsoon season of South Asia, J. Hydrometeorol., 12, 157-180, doi:10.1175/2010JHM13 2011a.

ROMATSCHKE, U.; HOUZE, R. A. JR. Characteristics of precipitating convective systems in the South Asian monsoon, J. Hydrometeorol., 12, 3-26, doi:10.1175/2010JHM1289.1. $2011 b$.

ROMATSCHKE, U.; MEDINA, S.; HOUZE JR, R. A. Regional, seasonal, and diurnal variations of extreme convection in the South Asian region, J. Clim., 23, 419-439, doi:10.1175/2009JCLI3140.1. 2010.

ROSENFELD, D.; WOODLEY, W. L. Closing the 5-year circle: From cloud seeding to space and back to climate change through precipitation physics. Cloud Systems, Hurricanes, and the Tropical Rainfall Measuring Mission (TRMM), Meteor. Monogr., No. 51, Amer. Meteor. Soc., 59-80. 2003.

ROTUNNO, R.; KLEMP, J.B.; WEISMAN, M. L. A Theory for Strong, Long-Lived Squall Lines. J. Atmos. Sci., 45, 463-485. 1988.

SALIO, P.; NICOLINI, M.; SAULO, A. C. Chaco low level jet events characterization during the austral summer season by ERA reanalysis. J. Geophys. Res., 107 .4816, doi:10.1019/2001JD00 2002 .

SALIO, P.; NICOLINI, M.; ZIPSER, E. J. Mesoscale Convective Systems over Southeastern South America and Their Relationship with the South American Low-Level Jet, 
Monthly Weather Review, 135(4), 1290-1309. 2007.

SAKAMOTO, M. S. Mesoscale Convective Systems Observed in Subtropics of South America during SALLJEX. Tese de doutorado, Departamento de Ciências Atmosféricas, Universidade de São Paulo, 281 pp. http://www. iag.usp.br/pos/sites/default/files/d eiry $_{\text {ss }}$ akamoto.pdf.2009.

SALATI, E.; MARQUEZJ.; MOLIONL.C.OrigemedistribuicãodaschuvasnaAmazônia.Interciencia3 200-205.1978.

SALIO, P., NICOLILNI, M., ZIZPSER, E.J.Mesoscaleconvectivesystemsover southeasternSouthAn leveljet.Mon.WeatherRev.135 : 1290-1309.https : //doi.org/10.1175/MW R3305.1.2007.

SANTOSNETO, L.A.AnáliseObservacionaldasLinhasdeInstabilidadeFormadasnaCostaNorteNordestedaAméricadoSul.TrabalhodeConclusãodeCursodoCursodeGraduaGãoemMeteorologiadaUnive

SAULO, A.; NICOLINI, M.; CHOU, S.ModelcharacterizationoftheSouthAmericanlowlevel flowduringthe1997-1998spring-summerseason.ClimateDynamics16, 867-881.Doi : 2000.

SILVA DIAS, M. A. F.; RUTLEDGE, S.; KABAT, P.; SILVA DIAS, P. L.; NOBRE, C.; FISCH, G.; DOLMAN, A. J.; ZIPSER, E.; GARSTANG, M.; MANZI, A. O.; FUENTES, J. D.; ROCHA, H. R.; MARENGO, J.; PLANA-FATTORI, A.; SÁ, L. D. A.; AlvalÁ, R. C. S.; ANDREAE, M. O.; ARTAXO, P.; GIELOW, R.; GATTI, L. "Cloud and Rain Processes in Biosphere-Atmosphere Interaction Context in the Amazon Region". Journal of Geophysical Research, $\mathrm{n}^{\mathrm{O}}$ 107, 2002.

SIMPSON, J.; ADLER, R.; NORTH, G. A proposed tropical rainfall measuring mission (TRMM) satellite. J. Atmos. Oceanic Technol., v. 69, p. 278-295, 1988.

SCHUltZ, C. J.; PETERSEN, W. A.; CAREY, L. D. Lightning and severe weather: A comparison between total and cloud-to-ground lightning trends. Weather and forecasting, v. 26, n. 5, p. 744-755, 2011. 
SMITH, E. A.; MUGnAI, A.; COOPER, H. J.; TRIPOLI, G. J.; XIANG, X. Foundations for statistical-physical precipitation retrieval from passive microwave satellite measurements. Part I: Brightness-temperature properties of a time-dependent cloud-radiation model. J. Appl. Meteor., 31, 506-531. 1992.

SOUTO, R.; SILVA DIAS, P. L.; VIGILANT, F. Parallel Performance Analysis of a Regional Numerical Weather Prediction Model in a Petascale Machine. 145-150. 10.1007/9783-319-26928-311. 2015.

SPENCER, R. W. A satellite passive 37-GHz scattering-based method for measuring oceanic rain rates. J. Appl. Meteorol. 25, 754-766. 1986.

SteEge, H. T.; Pitman, N. C.; SABATIER, D.; BARAlOtO, C.; SAlOMÃO, R. P.; GUEVARA, J. E.; ET AL. Hyperdominance in the Amazonian tree flora. Science 342, 1243092. doi: 10.1126/science.1243092. 2013.

STEINER, M.; HOUZE, R. A. JR.; YUTER, S. E. Climatological characterization of three-dimensional storm structure from operational radar and rain gauge data. J. Appl. Meteorol. 1995, 34, 1978-2007.

STENSRUD, D. J. Importance of Low-Level Jets to Climate: A Review. Journal of Climate, 9(8), 1698-1711. 1996.

STOLZ, D. C.; RUTLEDGE, S. A.; PIERCE, J. R. Simultaneous influences of thermodynamics and aerosols on deep convection and lightning in the tropics, J. Geophys. Res. Atmospheres, 120(12), 6207-6231, doi:10.1002/2014JD023033. 2015.

Stolz, D. C., RUtledge, S. A., PIERCE, J. R., AND VAN DEN HEEver, S. C. A global lightning parameterization based on statistical relationships among environmental factors, aerosols, and convective clouds in the TRMM climatology, J. Geophys. Res. Atmos., 122, 7461- 7492, doi:10.1002/2016JD026220. 2017. 
TANG, S.; XIE, S.; ZHANG, Y.; ZHANG, M.; SCHUMACHER, C.; UPTON, H.; JENSEN, M. P.; JOHNSON, K. L.; WANG, M.; AHLGRIMM, M. et al. Large-scale vertical velocity, diabatic heating and drying profiles associated with seasonal and diurnal variations of convective systems observed in the GoAmazon2014/5 experiment, Atmospheric Chemistry and Physics 16(22): 14249. 2016.

TRACHTE, K.; ROLLENBECK, R.; BENDIX, J. Nocturnal convective cloud formation under clear-sky conditions at the eastern Andes of south Ecuador. Journal of Geophysical Research, vol. 115, no. D24203. 2010.

TRIPOLI, G. J.; COTTON, W. R. The Colorado State University three-dimensional cloud mesoscale model, 1982: PartI: General theoretical framework and sensitivity experiments. J. de Rech. Atmos.. 16, 185-220. 1982.

VERA, C.; BAEZ, J.; DOUGLAS, M.; EMMANUEL, C. B.; MARENGO, J.; MEITIN, J.; NICOlini, M.; NOGUES-PAEGle, J.; PAEGLE, J.; PENALBA, O.; SAliO, P.; SAULO, C.; SILVA DIAS, M. A.; DIAS, P. S.; ZIPSER, E. "The South American LowLevel Jet Experiment", Bulletin of the American Meteorological Society, 87(1), 63-78. doi: 10.1175/BAMS-87-1-63. 2006.

WALKO R.; BAND L.; BARON J.; KITTEL F.; LAMMERS R.; LEE T.; OJIMA D.; PIELKE R.; TAYLOR C.; TAGUE C.; TREMBACK C.; VIDALE P. Coupled AtmosphereBiophysics-Hydrology Models for Environmental Modeling. J Appl Meteorol 39: (6) 931$944,2000$.

WEISMAN, M. L.; KLEMP, J. B. Characteristics of isolated convective storms. Mesoscale Meteorology and Forecasting, P. S. Ray, Ed., Amer. Meteor. Soc., 331-358. 1986.

WEISMAN, M. L.; ROTUnNO, R. A Theory for Strong Long-Lived Squall Lines. Revisited. J. Atmos. Sci., 61, 361-382. 2004. 
WHITEMAN, C. D.; XINDI, B.; SHIYUAN, Z. Low-level Jet Climatology from Enhanced Rawinsonding Observations at a Site in the Southern Great Plains. Journal of Applied Meteorology, 36(10): 1363-1376. 1997.

WILLIAMS, L. Hail and its distribution. Studies of the Army Aviation (V/STOL Environment), Army Engineer Topographic Laboratories Rep. 8, ETL-SR-73-3, 27 pp. 1973.

WILLIAMS M.; Houze, R. A. Satellite-observed characteristics of winter monsoon cloud clusters. Mon. Wea. Rev., 115, 505-519. 1987.

WILliAMS, E.; BOLDI, B.; MATLIN, A. WEBER, M.; HODANISH, S.; SHARP, D.; GOODMAN, S.; RAGHAVAN, R.; BUECHLER, D. The behavior of total lightning activity in severe florida thunderstorms. Atmospheric Research, Elsevier, v. 51, n. 3, p. 245-265, 1999.

WILliAMS, E. R.; ROSENFELD, D.; MADDEN, N.; GERLACH, J.; GEARS, N.; ATKINSON, L.; DUNNERMANN, N.; FROSTOM, G.; ANTONIO, M.; BIAZON, B.; CAMARGO, R.; FRANCA, H.; GOMES HELD, A.; LIMA, M. Contrasting convective regimes over the Amazon: Implications for cloud electrification. Journal of Geophysical Research. 107. 50.1-50.19. 10.1029/2001JD000380. 2002.

WILLIAMS, E.R. Lightning and climate: a review. Atmos. Res. 76, 272-287. 2005.

ZAMBRANO-BIGIARINI, M.; NAUDITT, A.; BIRKEL, V.; VERBIST, K.; RIBBE, L. Temporal and spatial evaluation of satellite-based rainfall estimates across the complex topographical and climatic gradients of Chile; Hydrol. Earth Syst. Sci., 21, 1295-1320, https://doi.org/10.5194/hess-21-1295-2017. 2017.

ZIPSER, E. J.; LIU, C.; CECIL D. J., NESBITT, S. W.; YORTY, D. P. Where are the most intense thunderstorms on Earth? Bulletin of the American Meteorological Society, Volume 87, Issue 8 (August 2006) pp. 1057-1071, 2006. 
Apêndice 



\section{Apêndice A}

\section{Apêndice A}

\section{A.1 Classificação de severidade das tempestades noturnas}

A Tabela A.1 apresenta a classificação das 97 tempestades noturnas por ordem de severidade, como mencionado na seção 3.1.2. 
Tabela A.1 - : Classificação das 97 tempestades através da taxa de raios, em ordem decrescente. Coluna 1: ordem de classificação de severidade; Coluna 2: data de ocorrência; Coluna 3: taxa de raios (flashes/min); Coluna 4: horário de registro do sistema pelo satélite TRMM (UTC); Coluna 5: latitude do sistema no horário de registro; Coluna 6: longitude do sistema no horário de registro; Coluna 7: área total do sistema (número de pixels com PCT85GHz;250 K*área do pixel), em $\mathrm{Km}^{2}$; Coluna 8: área do núcleo do sistema (número de pixels com PCT85GHzj100 K*área do pixel), em $\mathrm{Km}^{2}$; Coluna 9: mínima temperatura de brilho do sistema no canal de $85 \mathrm{GHz}$, em K; Coluna 10: mínima temperatura de brilho do sitema no canal de $37 \mathrm{GHz}$, em K; Coluna 11: máxima taxa de precipitação na superfície $(\mathrm{mm} / \mathrm{h})$; Coluna 12: máxima altura do nível de $40 \mathrm{dBZ}(\mathrm{Km})$.

\begin{tabular}{|c|c|c|c|c|c|c|c|c|c|c|c|}
\hline 1 & 2 & 3 & 4 & 5 & 6 & 7 & 8 & 9 & 10 & 11 & 12 \\
\hline $1^{\mathrm{O}}$ & $25 / 12 / 2013$ & 275,14 & 1,84 & 16,16 & $-63,42$ & 8375 & 275 & 89,41 & 189,35 & 85,6 & 12,5 \\
\hline $2^{\underline{\mathrm{O}}}$ & $24 / 10 / 2007$ & 210,71 & 0,77 & $-16,27$ & $-65,74$ & 26575 & 850 & 70,56 & 163,41 & 110,6 & 10,75 \\
\hline $3^{\mathrm{O}}$ & $26 / 11 / 2001$ & 159,8 & 5,04 & $-8,14$ & $-75,9$ & 32550 & 200 & 84,55 & 198,82 & 105,1 & 9,25 \\
\hline $4^{\mathrm{O}}$ & 09/08/2013 & 144,34 & 8,29 & $-17,19$ & $-64,96$ & 14125 & 125 & 86,56 & 195,57 & 138,3 & 10 \\
\hline $5^{\mathrm{O}}$ & $30 / 11 / 2012$ & 125,65 & 7,31 & -17 & $-64,99$ & 11325 & 1250 & 66,95 & 169,95 & 194,9 & 9,75 \\
\hline $6^{\mathrm{o}}$ & 03/09/2009 & 115,99 & 7,2 & $-15,98$ & $-65,66$ & 10725 & 375 & 81,77 & 177,15 & 80,5 & 9,25 \\
\hline $7^{\underline{O}}$ & $22 / 11 / 2001$ & 89,57 & 7,18 & $-16,46$ & $-65,98$ & 3850 & 50 & 83,65 & 212,23 & 54,8 & 10,5 \\
\hline $8^{\mathrm{O}}$ & $24 / 10 / 2012$ & 77,97 & 2,16 & $-9,38$ & $-75,62$ & 6000 & 450 & 69,19 & 195,32 & 96,6 & 13,5 \\
\hline $9^{\underline{O}}$ & $03 / 11 / 2009$ & 72,81 & 9,67 & $-13,13$ & $-70,07$ & 22675 & 125 & 82,79 & 208,71 & 105,8 & 9,25 \\
\hline $10^{\mathrm{o}}$ & $11 / 10 / 2003$ & 72,17 & 4,24 & $-12,59$ & $-71,46$ & 12600 & 300 & 90,98 & 213,89 & 271,6 & 9 \\
\hline $11^{\underline{\mathrm{o}}}$ & $30 / 10 / 2008$ & 71,52 & 3,79 & $-16,96$ & $-62,78$ & 75 & 75 & 95,9 & 67 & 82,5 & 10,25 \\
\hline $12^{\mathrm{O}}$ & $12 / 11 / 2004$ & 70,88 & 8,88 & $-11,18$ & $-72,8$ & 67 & 75 & 97,74 & 206,65 & 84,9 & 8,25 \\
\hline $13^{\mathrm{O}}$ & $10 / 11 / 2003$ & 67,66 & 2,73 & $-9,78$ & $-63,17$ & 34950 & 175 & 90,57 & 206,64 & 117,2 & 6,75 \\
\hline $14^{\mathrm{O}}$ & $21 / 10 / 2009$ & 67,01 & 6,95 & $-12,86$ & $-70,69$ & 20950 & 150 & 83,86 & 212,47 & 194,2 & 8 \\
\hline $15^{\mathrm{o}}$ & $25 / 09 / 2003$ & 64,44 & 2,71 & $-14,8$ & $-67,33$ & 4000 & 175 & 81,33 & 216,95 & 53,6 & 10,5 \\
\hline $16^{\mathrm{o}}$ & $20 / 10 / 2007$ & 61,86 & 2,89 & $-10,85$ & $-60,04$ & 12275 & 50 & 95,08 & 212,95 & 51,6 & 7,75 \\
\hline $17^{\mathrm{O}}$ & 10/09/1999 & 56,06 & 0,17 & $-15,56$ & $-67,81$ & 4975 & 75 & 99,97 & 182,1 & 126,6 & 11 \\
\hline $18^{\underline{O}}$ & $03 / 02 / 2013$ & 55,42 & 7,72 & $-13,1$ & $-68,76$ & 21025 & 225 & 88,94 & 209,6 & 133,7 & 11,25 \\
\hline $19^{\mathrm{O}}$ & $10 / 10 / 2000$ & 52,19 & 1,78 & $-17,26$ & $-65,38$ & 4525 & 25 & 97,68 & 193,1 & 99,1 & 9,25 \\
\hline $20^{\mathrm{o}}$ & $12 / 11 / 2007$ & 52,19 & 6,17 & $-11,22$ & $-73,04$ & 16275 & 275 & 95,3 & 216,4 & 78,1 & 9,5 \\
\hline
\end{tabular}


Tabela A.2 - Continuação Tabela A.1

\begin{tabular}{|c|c|c|c|c|c|c|c|c|c|c|c|}
\hline $21^{\mathrm{O}}$ & $6 / 02 / 2007$ & 50,9 & 7,76 & 3,05 & $-68,58$ & 7125 & 150 & 4,97 & 209,3 & 131 & 7,25 \\
\hline $22^{\mathrm{O}}$ & $2 / 11 / 2001$ & 3,33 & 7,16 & 3,35 & $-69,57$ & 8950 & 200 & 0,81 & 219,9 & 121,6 & 10,5 \\
\hline $23^{\mathrm{O}}$ & $28 / 10 / 2012$ & 7,04 & 0,12 & 1,73 & 9,75 & 500 & 300 & 89,43 & 228,91 & 36,7 & 8 \\
\hline $24^{\mathrm{O}}$ & $14 / 03 / 2013$ & , 39 & 2,75 & 6,38 & $-65,92$ & 5575 & 50 & 7,76 & 5,08 & 119,1 & 7,5 \\
\hline $25^{\mathrm{O}}$ & /1090 & ,39 & 3,1 & 96 & 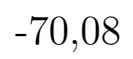 & 50 & 150 & 15 & 04,79 & 87,3 & 9 \\
\hline $26^{\mathrm{o}}$ & $02 / 0$ & $x$ & {$[0,10$} & & $r$ & 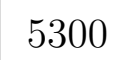 & 175 & & & 300 & 8,75 \\
\hline $27^{\mathrm{O}}$ & $12 / 12 / 2001$ & 45,11 & 6,62 & $-12,71$ & $-71,15$ & 10575 & 825 & 74,32 & 188,23 & 88,8 & 9,25 \\
\hline $28^{\underline{\mathrm{O}}}$ & $17 / 01 / 2008$ & 44,46 & 5,7 & $-16,12$ & $-67,83$ & 22250 & 150 & 96,88 & 217,24 & 147,4 & 10,5 \\
\hline $29^{\mathrm{O}}$ & $/ 2008$ & 43,82 & 1,14 & $-14,09$ & $-64,76$ & 9525 & 225 & 79,95 & 210,47 & 97,7 & 7 \\
\hline $30^{\mathrm{O}}$ & $/ 2004$ & 43,17 & 8,05 & $-17,19$ & $-65,01$ & 14050 & 400 & 89,71 & 215,1 & 74,2 & 10,5 \\
\hline $31^{\mathrm{O}}$ & $26 / 10 / 2012$ & 42,53 & 0,34 & $-8,2$ & 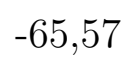 & 75 & 200 & 75,47 & 8,72 & 35,8 & 15,5 \\
\hline $32^{\mathrm{O}}$ & $21 / 12 / 2013$ & 1 & 3,92 & $-17,86$ & & 50 & 100 & & & 64,3 & 8,5 \\
\hline $33^{\mathrm{O}}$ & 5 & & 4 & & 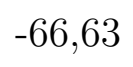 & & 7 & & & $1:$ & 7 \\
\hline $34^{\mathrm{O}}$ & 002 & & {$[0,12$} & & & & 175 & & & 0 & 14,75 \\
\hline $35^{\mathrm{O}}$ & 07 & 02 & 4 & - & - & 0 & 550 & & & 117,7 & 11 \\
\hline $36^{\mathrm{o}}$ & 005 & ,08 & 4,57 & 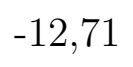 & 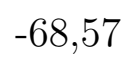 & 75 & 325 & & & 82,6 & 0 \\
\hline $37^{\underline{0}}$ & $26 / 09 / 2005$ & 5,08 & 1,22 & $-11,51$ & $-66,68$ & 12525 & 125 & 93,97 & 78,18 & 79,7 & 10 \\
\hline $38^{\mathrm{O}}$ & 03/12/2004 & 34,15 & 7,47 & $-14,04$ & -66 & 650 & 250 & 87 & 2,03 & 44,8 & - \\
\hline $39^{\mathrm{O}}$ & $22 / 10 / 2002$ & 33,51 & 5,95 & $-12,85$ & $-70,85$ & 4650 & 75 & 92,03 & 223,43 & 121 & 10 \\
\hline $40^{\mathrm{O}}$ & $19 / 02 / 2004$ & 31,57 & 9,17 & $-15,32$ & $-66,16$ & 13525 & 150 & 90,02 & 210,55 & 54,5 & 8,75 \\
\hline $41^{\mathrm{O}}$ & $21 / 10 / 1998$ & 30,29 & 0,49 & $-9,48$ & $-61,86$ & 25 & 375 & 85,1 & & 66,9 & 9,5 \\
\hline $42^{\mathrm{O}}$ & $15 / 0$ & 29,64 & 3,98 & $-8,09$ & $-62,7$ & 55 & 175 & 7 & 18 & 3 & 10 \\
\hline $43^{\mathrm{O}}$ & $12 / 0$ & 29,64 & 6,5 & $-15,88$ & 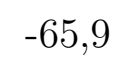 & 16425 & 150 & 89,22 & 207,07 & 79,8 & 8,5 \\
\hline $44^{\mathrm{O}}$ & $16 / 0$ & 29 & 1,03 & & & & 75 & & & 76,1 & 9,75 \\
\hline $45^{\mathrm{O}}$ & $\mid 10 / 12 / 2012$ & 29 & (1) & $-9,59$ & $-74,67$ & 000 & 125 & & 220,45 & 147,6 & 9,5 \\
\hline $46^{\mathrm{O}}$ & 03/03/2009 & 27,06 & 3,81 & $-9,68$ & $-63,81$ & 4750 & 100 & 85,69 & 209,89 & 72 & 9 \\
\hline $47^{\mathrm{O}}$ & $22 / 10 / 2008$ & 27,06 & 7,96 & $-17,39$ & $-64,47$ & 3175 & 300 & 84,54 & 200,86 & 85,4 & 12,5 \\
\hline $48^{\mathrm{O}}$ & 09/11/2009 & 25,77 & 7,36 & $-9,83$ & $-74,91$ & 2875 & 150 & 98,81 & 208,51 & 136,5 & 9,75 \\
\hline $49^{\underline{O}}$ & $17 / 02 / 2010$ & 25,13 & 4,89 & $-8,75$ & $-75,4$ & 13725 & 150 & 92,81 & 212,85 & 141,9 & 7,75 \\
\hline $50^{\mathrm{O}}$ & $10 / 01 / 2002$ & 24,49 & 6,03 & $-10,49$ & $-69,34$ & 16575 & 75 & 98,9 & 218,37 & 171,7 & 8,5 \\
\hline
\end{tabular}


Tabela A.3 - Continuação Tabela A.1

\begin{tabular}{|c|c|c|c|c|c|c|c|c|c|c|c|}
\hline $1^{\mathrm{O}}$ & $2 / 02 / 1999$ & 24,49 & 9,05 & $-11,28$ & $-73,27$ & 7175 & 150 & 85,08 & 205,57 & 175 & 8,5 \\
\hline $52^{\mathrm{O}}$ & $03 / 07 / 2000$ & 23,2 & 5,08 & $-16,65$ & $-65,14$ & 5425 & 250 & 83,65 & 196,61 & 174,3 & 7 \\
\hline $53^{\mathrm{o}}$ & 11/11/1998 & 22,55 & 4,22 & $-13,14$ & $-70,78$ & 9150 & 225 & 78,22 & 202,56 & 198,9 & 7,5 \\
\hline $54^{\mathrm{o}}$ & $13 / 10 / 2011$ & 21,91 & 0,51 & $-10,8$ & $-61,81$ & 10775 & 50 & 90,4 & 207,47 & 81,2 & 8,25 \\
\hline $55^{\mathrm{o}}$ & $06 / 12 / 2011$ & 21,91 & 6,25 & $-16,66$ & $-62,37$ & 7675 & 50 & 91,47 & 214,43 & 51,4 & 7,75 \\
\hline $56^{\mathrm{o}}$ & $17 / 05 / 2007$ & 21,26 & 9,7 & $-14,8$ & $-66,48$ & 4400 & 50 & 94,32 & 216,5 & 38,2 & 8,75 \\
\hline $57^{\mathrm{O}}$ & $30 / 01 / 2007$ & 20,62 & 7,19 & $-17,41$ & $-64,64$ & 11425 & 125 & 91,23 & 209,04 & 184,3 & 7,5 \\
\hline $58^{\mathrm{o}}$ & $15 / 04 / 2004$ & 19,98 & 4,82 & $-16,34$ & $-66,02$ & 4100 & 125 & 77,59 & 210,88 & 48,4 & 10,5 \\
\hline $59^{0}$ & 11/11/1998 & 19,98 & 4,24 & $-13,64$ & $-67,98$ & 2650 & 300 & 68,91 & 184,26 & 62,4 & 8,75 \\
\hline $60^{\circ}$ & $09 / 02 / 2008$ & 19,33 & 9,08 & $-17,16$ & $-64,88$ & 7750 & 175 & 91,43 & 218,31 & 90,5 & 10,25 \\
\hline $61^{\mathrm{o}}$ & 02/03/2008 & 19,33 & 8,24 & $-8,67$ & $-75,91$ & 10850 & 100 & 98,25 & 205,01 & 55,9 & 8 \\
\hline $62^{\mathrm{o}}$ & $15 / 01 / 2000$ & 18,69 & 6,82 & $-11,9$ & $-72,46$ & 10675 & 275 & 86,15 & 191,05 & 125 & 7,75 \\
\hline $63^{\mathrm{o}}$ & $03 / 02 / 2003$ & 18,69 & 1,38 & $-11,51$ & $-70,91$ & 4200 & 125 & 92,09 & 214,12 & 64,3 & 8 \\
\hline $64^{\mathrm{o}}$ & $21 / 10 / 2001$ & 18,69 & 8,89 & $-11,92$ & $-71,89$ & 4075 & 25 & 98,46 & 214,34 & 44,4 & 8 \\
\hline $65^{\circ}$ & $12 / 01 / 2012$ & 17,4 & 3,09 & $-9,24$ & $-75,34$ & 7275 & 325 & 83,44 & 200,01 & 109,4 & 9,75 \\
\hline $66^{\mathrm{o}}$ & $09 / 04 / 2000$ & 17,4 & 1,07 & $-11,94$ & $-70,32$ & 4075 & 125 & 93,07 & 208,99 & 107,2 & 8,5 \\
\hline $67^{\mathrm{o}}$ & $29 / 11 / 2010$ & 16,75 & 3,22 & $-16,61$ & $-66,26$ & 3075 & 75 & 99,15 & 221,28 & 34 & 8 \\
\hline $68^{\mathrm{o}}$ & $22 / 06 / 2012$ & 16,11 & 2,26 & $-13,23$ & $-68,91$ & 5675 & 325 & 90,91 & 207,44 & 48,5 & 6,5 \\
\hline $69^{\mathrm{o}}$ & $16 / 01 / 2005$ & 15,46 & 9,34 & $-13,64$ & $-70,24$ & 26100 & 125 & 95,86 & 229,93 & 261,4 & 7,5 \\
\hline $70^{\mathrm{o}}$ & $01 / 01 / 2000$ & 13,53 & 4,32 & $-12,19$ & $-71,02$ & 6375 & 125 & 91,91 & 212,91 & 92,3 & 9,25 \\
\hline $71^{\mathrm{O}}$ & $03 / 02 / 2003$ & 12,89 & 1,39 & $-12,79$ & $-69,43$ & 8900 & 150 & 96,28 & 233,99 & 97,7 & 6,75 \\
\hline $72^{\mathrm{O}}$ & $22 / 11 / 2011$ & 12,89 & 4,48 & $-13,5$ & $-61,28$ & 8000 & 100 & 86,32 & 218,29 & 62,4 & 7,75 \\
\hline $73^{\mathrm{O}}$ & $07 / 01 / 2003$ & 12,24 & 0,15 & $-15,49$ & $-66,63$ & 2850 & 25 & 92,85 & 220,07 & 81,6 & 7 \\
\hline $74^{\mathrm{O}}$ & $18 / 03 / 2001$ & 12,24 & 0,36 & $-10,75$ & $-62,69$ & 3975 & 250 & 91,44 & 228,23 & 42,6 & 7 \\
\hline $75^{\mathrm{o}}$ & $11 / 11 / 2011$ & 12,24 & 9,78 & $-13,39$ & $-62,12$ & 18175 & 100 & 98,26 & 217,19 & 90,8 & 6,25 \\
\hline $76^{\mathrm{o}}$ & $12 / 11 / 2004$ & 11,6 & 8,88 & $-9,5$ & $-74,97$ & 3125 & 150 & 80,27 & 218,04 & 28,8 & 7,25 \\
\hline $77^{\mathrm{o}}$ & $13 / 03 / 2006$ & 9,67 & 3,05 & $-15,59$ & $-68,44$ & 6750 & 100 & 92,42 & 216,75 & 55,6 & 7,5 \\
\hline $78^{\circ}$ & $21 / 04 / 2012$ & 9,67 & 8,89 & $-17,54$ & $-64,9$ & 26025 & 125 & 80,81 & 200,53 & 116,9 & 7,5 \\
\hline $79^{\mathrm{o}}$ & $13 / 10 / 2007$ & 9,67 & 7,7 & $-8,29$ & $-76,3$ & 17100 & 175 & 94,42 & 210,59 & 59,1 & 8,25 \\
\hline $80^{\mathrm{o}}$ & $04 / 03 / 2004$ & 9,02 & 2,7 & $-13,39$ & $-69,87$ & 3125 & 225 & 82,55 & 216,58 & 55,1 & 6,75 \\
\hline
\end{tabular}


Tabela A.4 - Continuação Tabela A.1

\begin{tabular}{|c|c|c|c|c|c|c|c|c|c|c|c|}
\hline $81^{\mathrm{O}}$ & $16 / 01 / 1998$ & 7,73 & 0,2 & $-16,25$ & $-66,14$ & 2450 & 225 & 79,07 & 196,79 & 92,8 & 8,25 \\
\hline $82^{\mathrm{O}}$ & $27 / 04 / 2008$ & 7,73 & 3,88 & $-9,22$ & $-75,46$ & 3625 & 75 & 99,83 & 224,71 & 58,7 & 7,75 \\
\hline $83^{\mathrm{O}}$ & 09/12/2011 & 7,73 & 5,09 & $-16,37$ & $-66,18$ & 9675 & 125 & 94,93 & 222,16 & 167,5 & 8,75 \\
\hline $84^{\mathrm{O}}$ & $21 / 04 / 2001$ & 7,09 & 6,19 & $-17,33$ & $-64,61$ & 2550 & 100 & 97,11 & 210,44 & 70,8 & 8,25 \\
\hline $85^{\mathrm{o}}$ & $30 / 10 / 2013$ & 7,09 & 6,1 & $-10,02$ & $-75,34$ & 3275 & 50 & 96,82 & 227,26 & 53,9 & 6,75 \\
\hline $86^{\mathrm{o}}$ & $17 / 10 / 2012$ & 6,44 & 5,44 & $-16,2$ & $-63,46$ & 2100 & 75 & 96,47 & 214,48 & 16,4 & 10 \\
\hline $87^{\underline{0}}$ & $12 / 11 / 2009$ & 6,44 & 4,6 & $-17,11$ & $-65,52$ & 3325 & 175 & 99,31 & 231,91 & 25,4 & 7,75 \\
\hline $88^{\underline{O}}$ & $23 / 12 / 2001$ & 6,44 & 1,33 & $-9,03$ & $-70,11$ & 7700 & 125 & 84,29 & 214,33 & 107,2 & 6,5 \\
\hline $89^{\underline{0}}$ & $29 / 11 / 1998$ & 5,8 & 5,06 & $-9,74$ & $-75,44$ & 2475 & 150 & 86,41 & 220,59 & 58,3 & 8 \\
\hline $90^{\mathrm{O}}$ & $04 / 04 / 2005$ & 5,15 & 7,66 & $-8,28$ & $-64,14$ & 7525 & 150 & 84,23 & 215,39 & 111,2 & 6,5 \\
\hline $91^{\mathrm{O}}$ & $30 / 04 / 2008$ & 5,15 & 1,13 & $-15,88$ & $-66,33$ & 2850 & 250 & 81,12 & 208,25 & 75,4 & 6,75 \\
\hline $92^{\mathrm{O}}$ & $14 / 04 / 2000$ & 3,87 & 7,98 & $-12,65$ & $-71,43$ & 3725 & 225 & 88,1 & 206,32 & 78,1 & 7,25 \\
\hline $93^{\mathrm{O}}$ & $11 / 04 / 2008$ & 3,22 & 0,77 & -8 & $-62,46$ & 3450 & 125 & 87,66 & 228,67 & 147,1 & 6,5 \\
\hline $94^{\mathrm{O}}$ & 25/12/1999 & 3,22 & 7,91 & $-11,27$ & $-72,73$ & 5200 & 100 & 92,34 & 218,14 & 59,1 & 7 \\
\hline $95^{\mathrm{o}}$ & $21 / 12 / 2013$ & 3,22 & 3,87 & -13 & $-69,97$ & 13700 & 300 & 82,14 & 226,73 & 86,7 & 5,75 \\
\hline $96^{\underline{\mathrm{O}}}$ & $20 / 04 / 2001$ & 2,58 & 7,38 & $-13,24$ & $-70,35$ & 6425 & 150 & 98,83 & 244,16 & 114,1 & 7 \\
\hline $97^{\mathrm{O}}$ & $14 / 04 / 2011$ & 1,29 & 6,75 & $-13,04$ & $-70,93$ & 3750 & 25 & 94,36 & 226,36 & 88,6 & 6,25 \\
\hline
\end{tabular}

\section{A.2 Normais climatológicas e anomalias}

Esta seção destina-se às figuras citadas na Seção 3.1.4, que se referem aos campos das normais climatológicas e recorte no domínio de estudo mostrando anomalias para os padrões P1 e P2 de escoamento. 

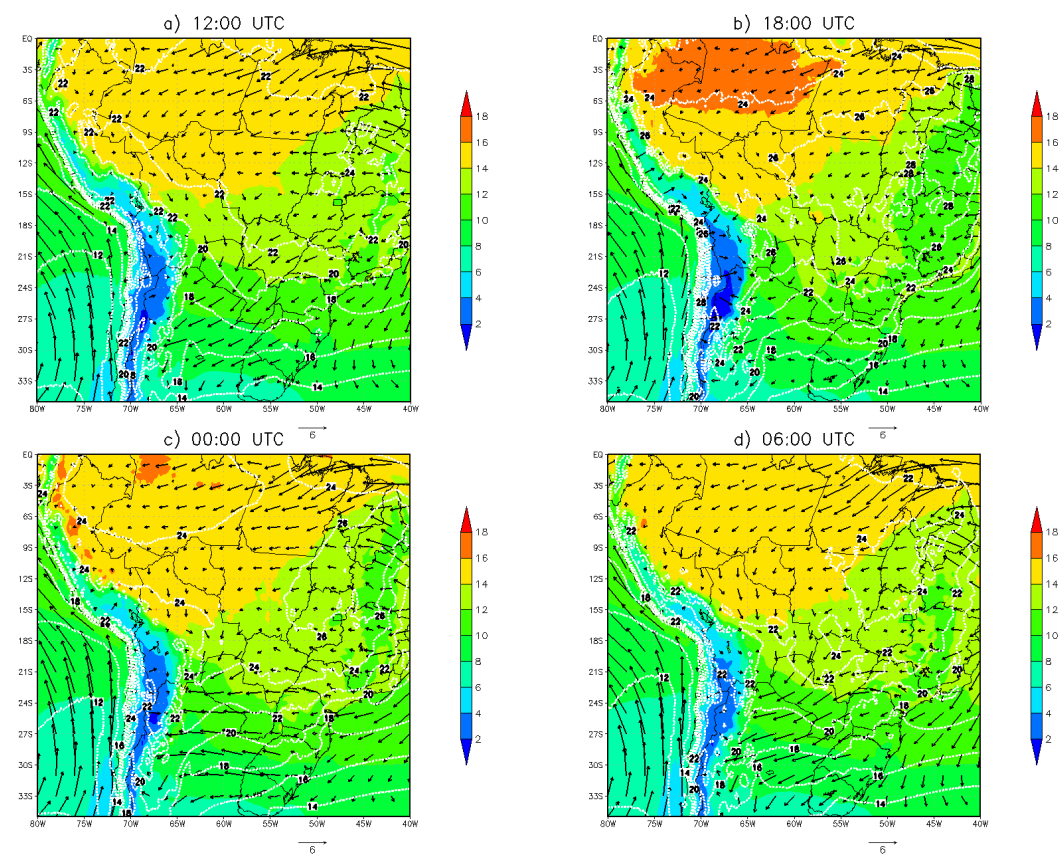

Figura A.1: Normais climatológicas (1981-2010) para o nível de $950 \mathrm{hPa}$, onde vetores representam vento horizontal $(\mathrm{m} / \mathrm{s})$, escala de cores representa umidade específica $(\mathrm{g} / \mathrm{Kg})$ e contornos a temperatura $\left({ }^{\circ} \mathrm{C}\right)$ às a) 12:00 UTC, b) 18:00 UTC, c) 00:00 UTC, d) 06:00 UTC.

a) 12:00 UTC

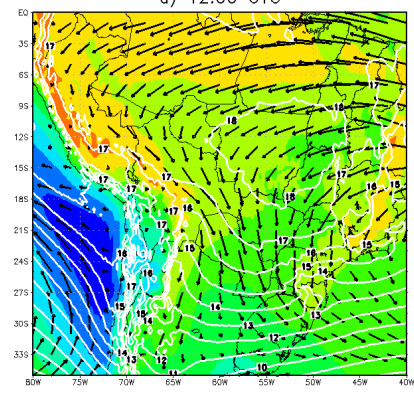

c) $00: 00$ UTC 8

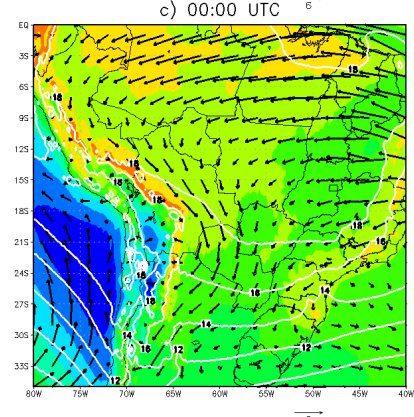

b) 18:00 UTC

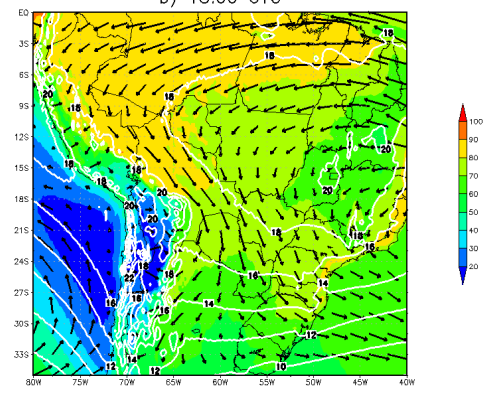

d) 06:00 UTC

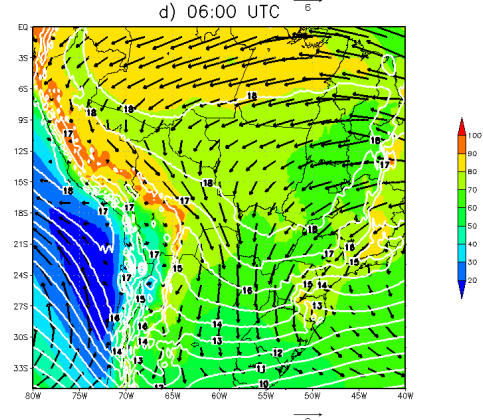

Figura A.2: Normais climatológicas (1981-2010) para o nível de 850 hPa, onde vetores representam vento horizontal $(\mathrm{m} / \mathrm{s})$, escala de cores representa umidade relativa (\%) e contornos a temperatura $\left({ }^{\circ} \mathrm{C}\right)$ às a) 12:00 UTC, b) 18:00 UTC, c) 00:00 UTC, d) 06:00 UTC. 

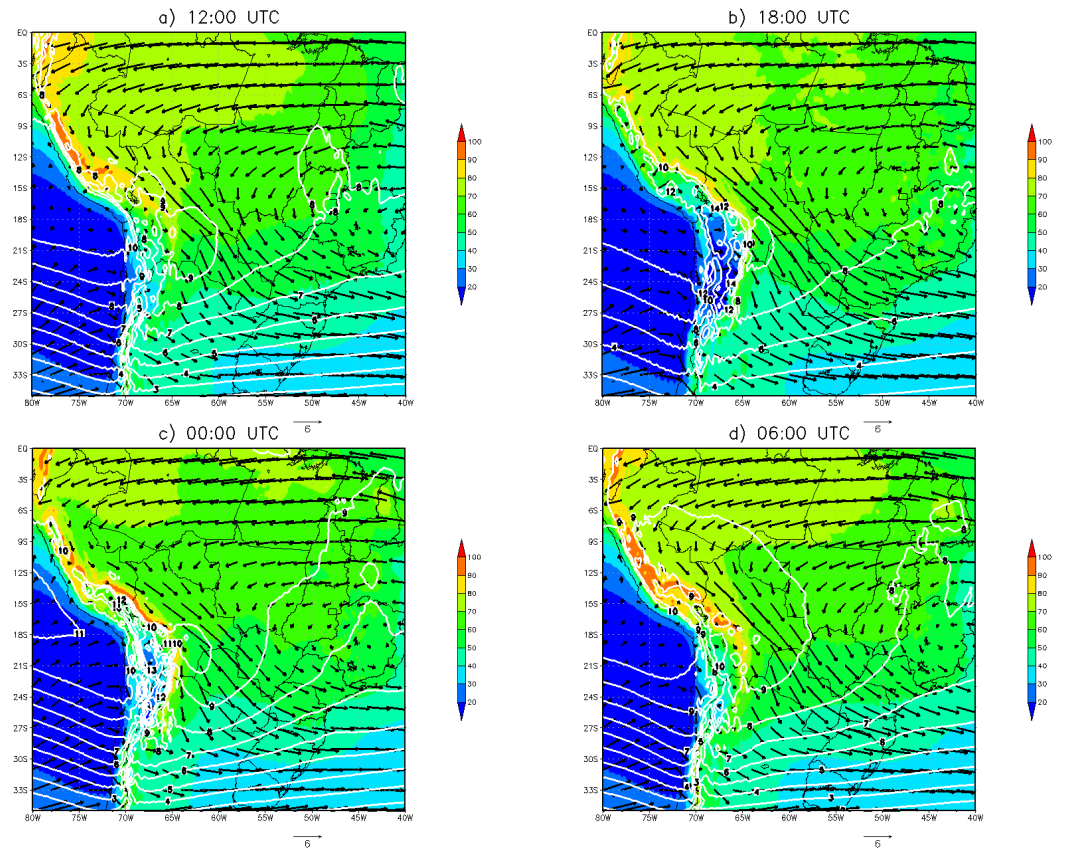

Figura A.3: Normais climatológicas (1981-2010) para o nível de $700 \mathrm{hPa}$, onde vetores representam vento horizontal $(\mathrm{m} / \mathrm{s})$, escala de cores representa umidade relativa $(\%)$ e contornos a temperatura $\left({ }^{\circ} \mathrm{C}\right)$ às a) 12:00 UTC, b) 18:00 UTC, c) 00:00 UTC, d) 06:00 UTC.
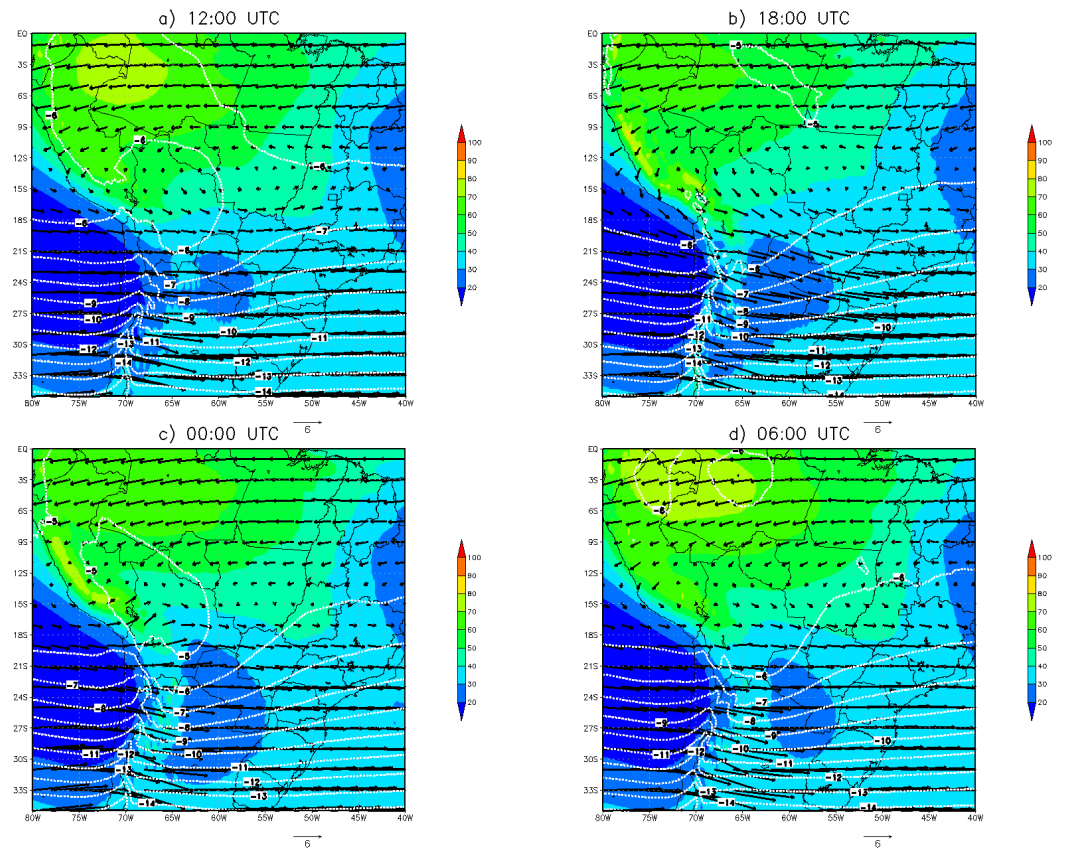

Figura A.4: Normais climatológicas (1981-2010) para o nível de $500 \mathrm{hPa}$, onde vetores representam vento horizontal $(\mathrm{m} / \mathrm{s})$, escala de cores representa umidade relativa $(\%)$ e contornos a temperatura $\left({ }^{\circ} \mathrm{C}\right)$ às a) 12:00 UTC, b) 18:00 UTC, c) 00:00 UTC, d) 06:00 UTC. 

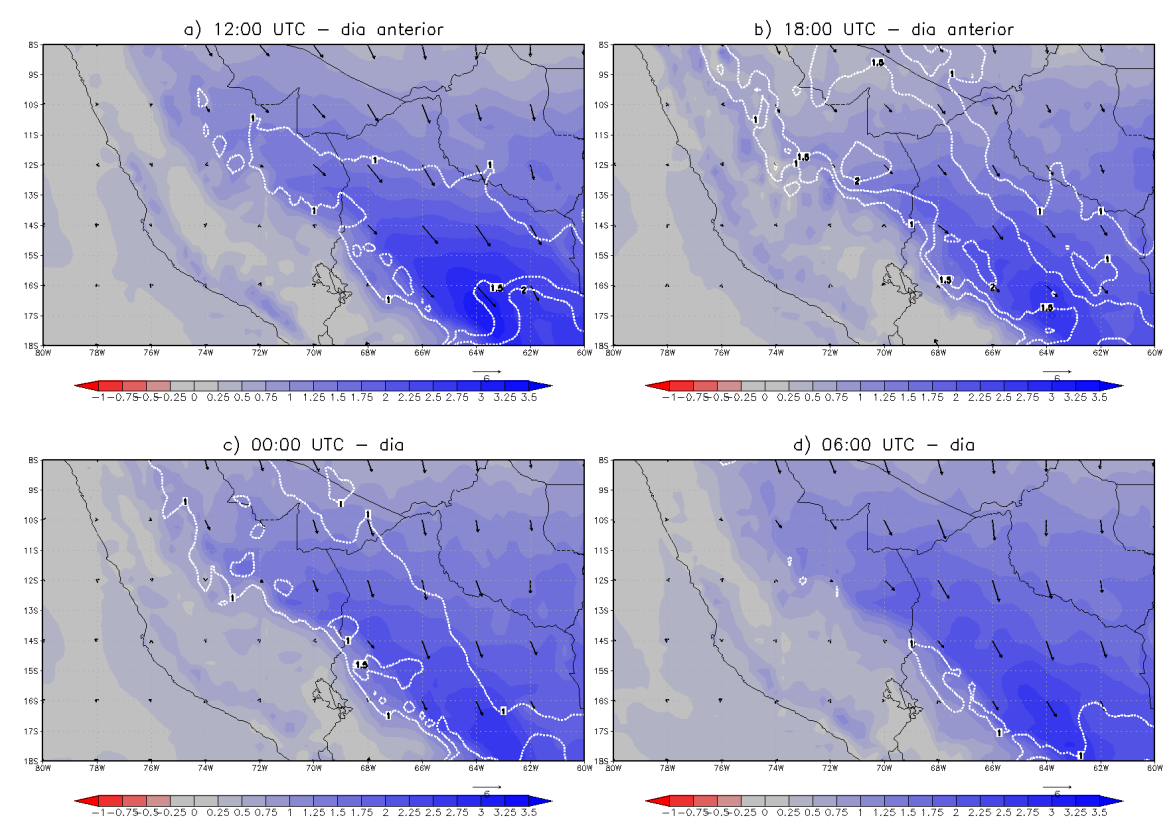

Figura A.5: Recorte da região SO da Amazônia mostrando anomalia do escoamento P1 para o nível de $950 \mathrm{hPa}$, onde vetores representam vento horizontal $(\mathrm{m} / \mathrm{s})$, escala de cores representa umidade específica $(\mathrm{g} / \mathrm{Kg})$ e contornos a temperatura $\left({ }^{\circ} \mathrm{C}\right)$ às a) 12:00 UTC, b) 18:00 UTC, c) 00:00 UTC, d) 06:00 UTC.
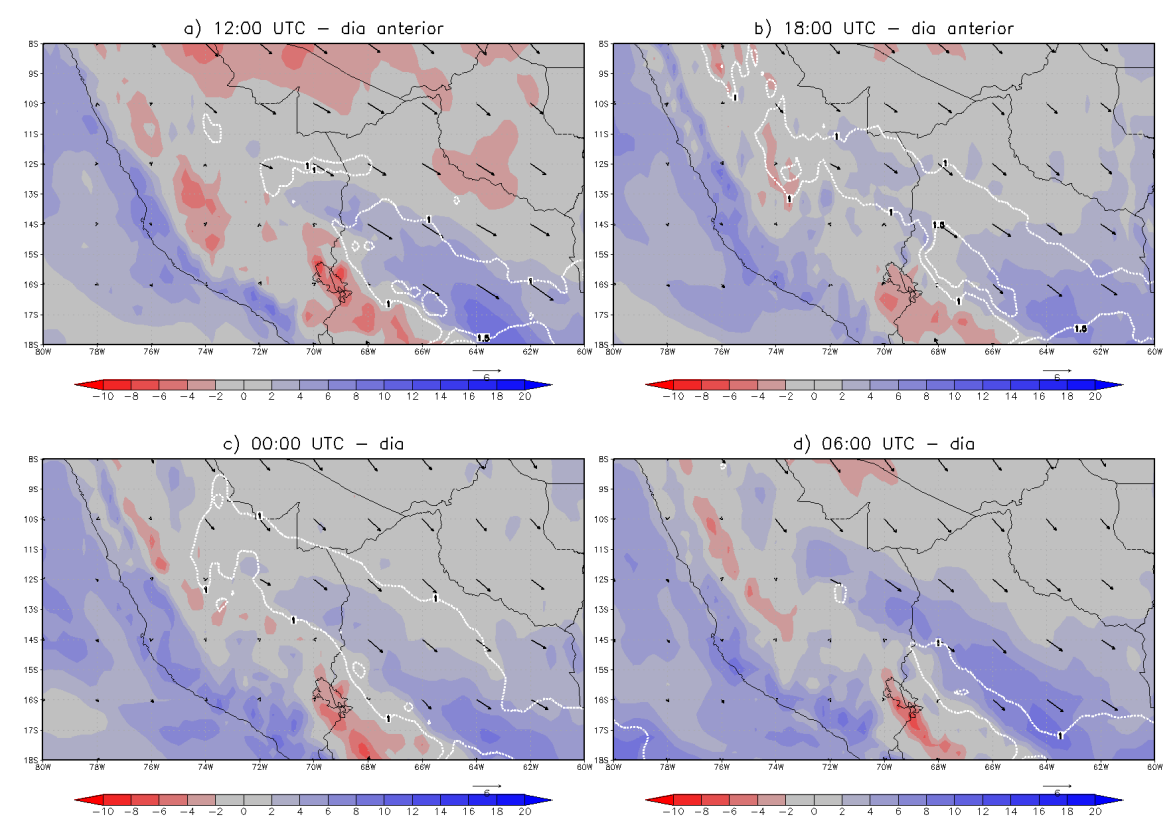

Figura A.6: Recorte da região SO da Amazônia mostrando anomalia do escoamento P1 para o nível de $850 \mathrm{hPa}$, onde vetores representam vento horizontal $(\mathrm{m} / \mathrm{s})$, escala de cores representa umidade relativa $(\%)$ e contornos a temperatura $\left({ }^{\circ} \mathrm{C}\right)$ às a) 12:00 UTC, b) 18:00 UTC, c) 00:00 UTC, d) 06:00 UTC. 

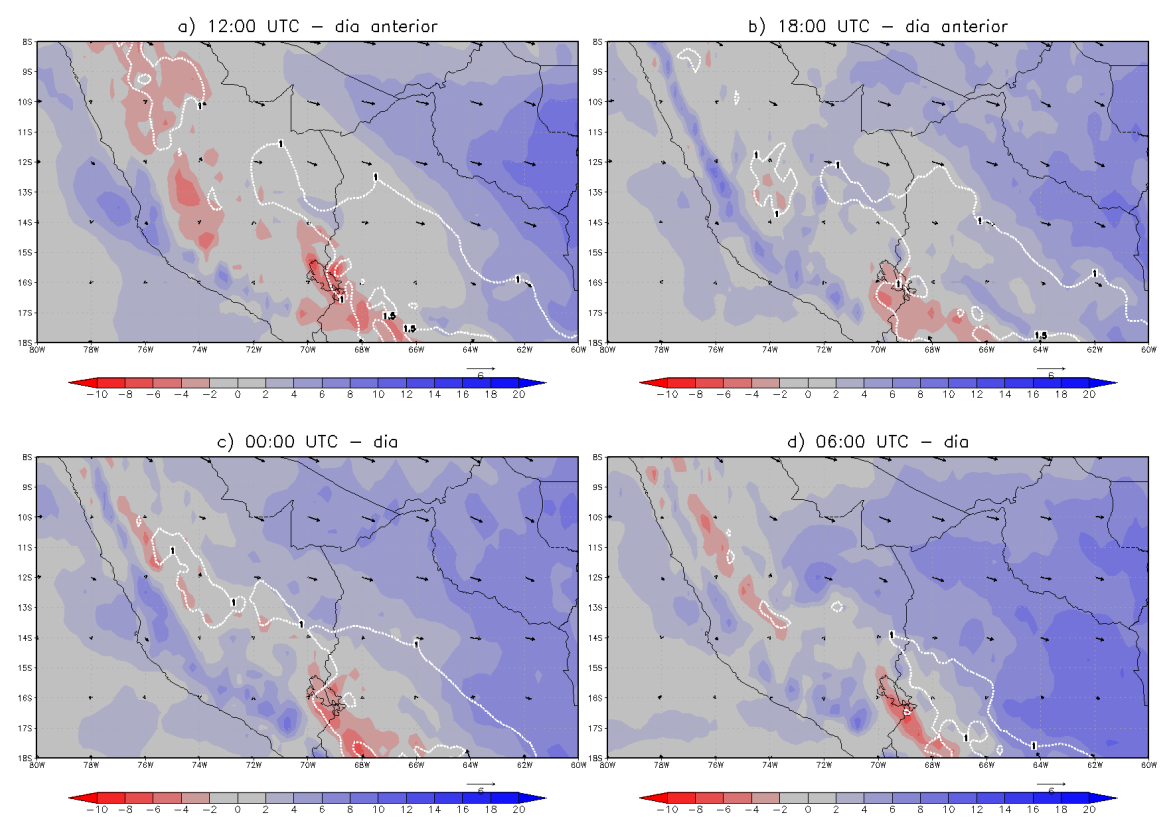

Figura A.7: Recorte da região SO da Amazônia mostrando anomalia do escoamento P1 para o nível de $700 \mathrm{hPa}$, onde vetores representam vento horizontal $(\mathrm{m} / \mathrm{s})$, escala de cores representa umidade relativa (\%) e contornos a temperatura $\left({ }^{\circ} \mathrm{C}\right)$ às a) 12:00 UTC, b) 18:00 UTC, c) 00:00 UTC, d) 06:00 UTC.
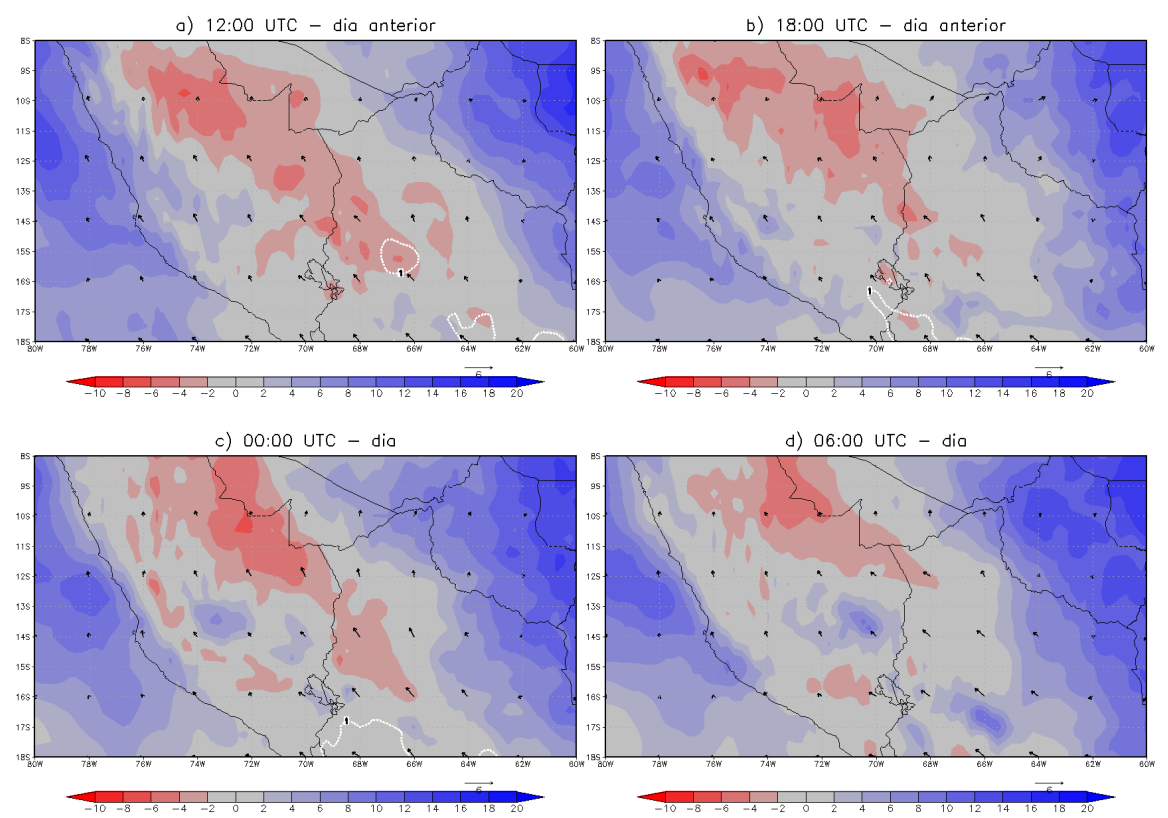

Figura A.8: Recorte da região SO da Amazônia mostrando anomalia do escoamento P1 para o nível de $500 \mathrm{hPa}$, onde vetores representam vento horizontal $(\mathrm{m} / \mathrm{s})$, escala de cores representa umidade relativa $(\%)$ e contornos a temperatura $\left({ }^{\circ} \mathrm{C}\right)$ às a) 12:00 UTC, b) 18:00 UTC, c) 00:00 UTC, d) 06:00 UTC. 

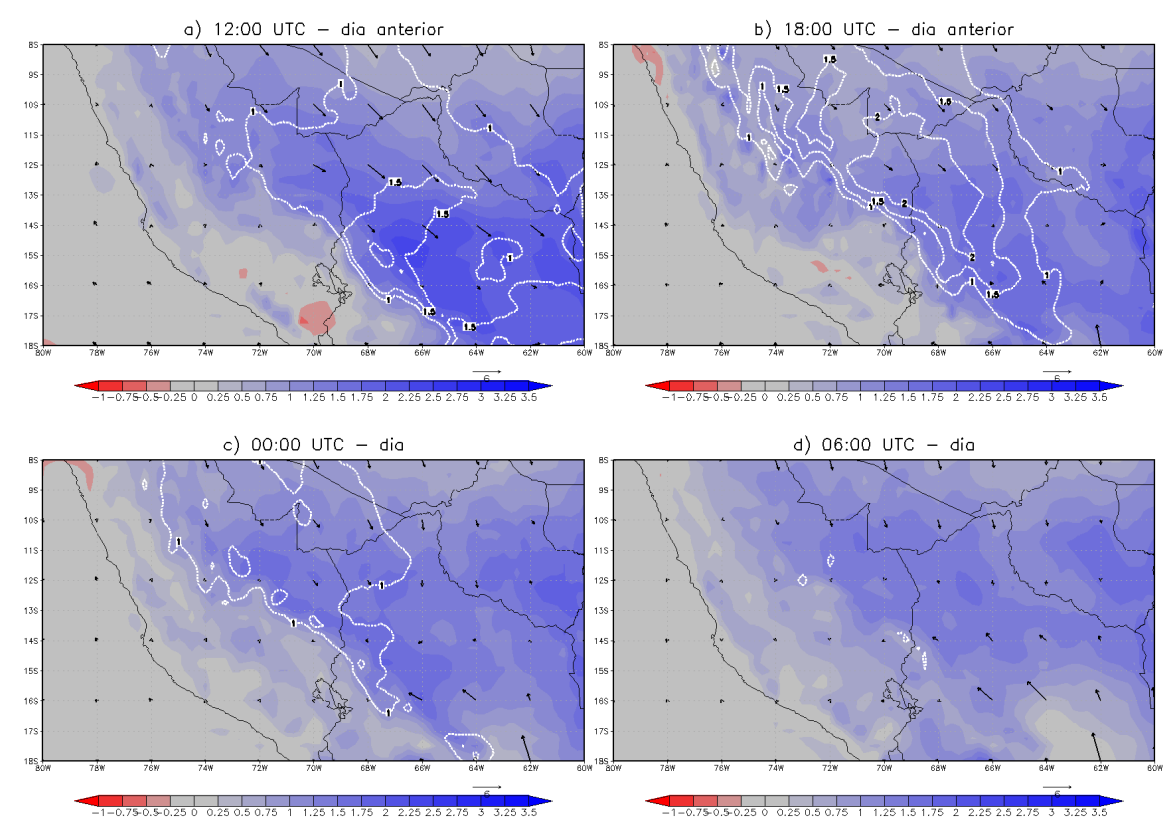

Figura A.9: Recorte da região SO da Amazônia mostrando anomalia do escoamento P2 para o nível de $950 \mathrm{hPa}$, onde vetores representam vento horizontal $(\mathrm{m} / \mathrm{s})$, escala de cores representa umidade específica $(\mathrm{g} / \mathrm{Kg})$ e contornos a temperatura $\left({ }^{\circ} \mathrm{C}\right)$ às a) 12:00 UTC, b) 18:00 UTC, c) 00:00 UTC, d) 06:00 UTC.
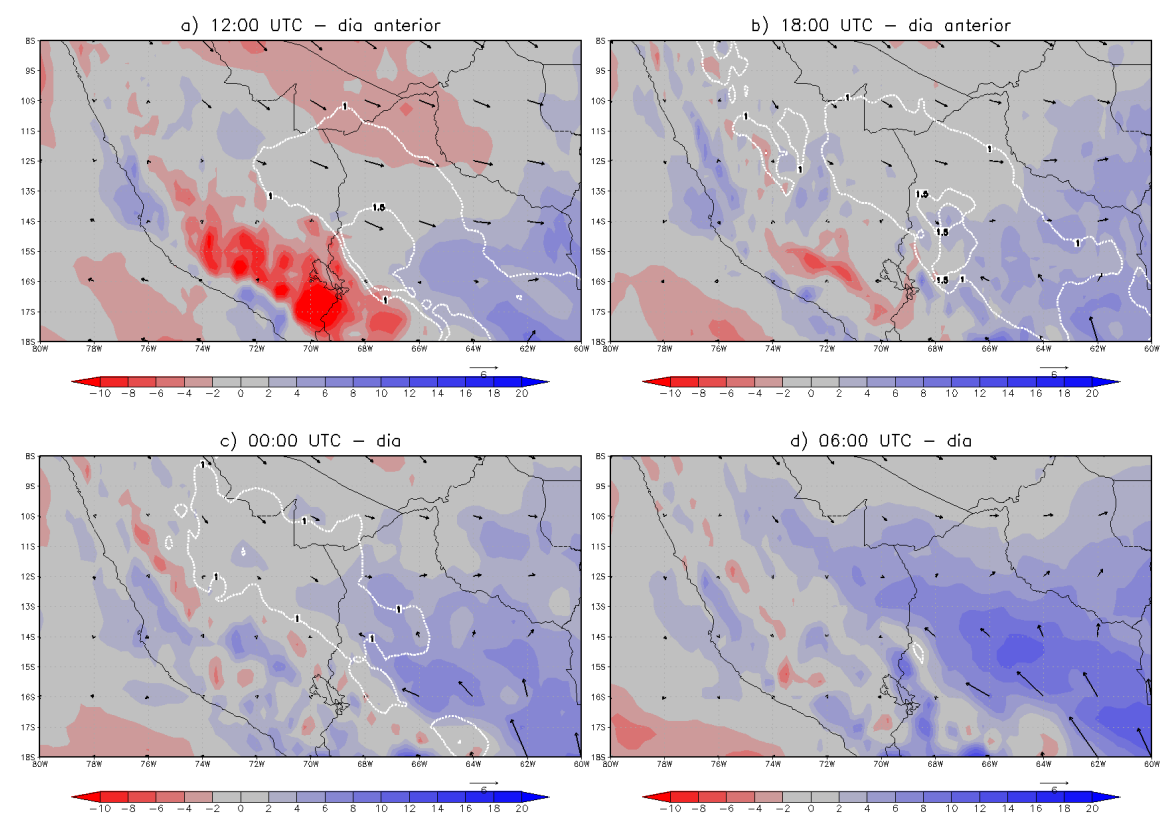

Figura A.10: Recorte da região SO da Amazônia mostrando anomalia do escoamento P2 para o nível de $850 \mathrm{hPa}$, onde vetores representam vento horizontal $(\mathrm{m} / \mathrm{s})$, escala de cores representa umidade relativa $(\%)$ e contornos a temperatura $\left({ }^{\circ} \mathrm{C}\right)$ às a) 12:00 UTC, b) 18:00 UTC, c) 00:00 UTC, d) 06:00 UTC. 


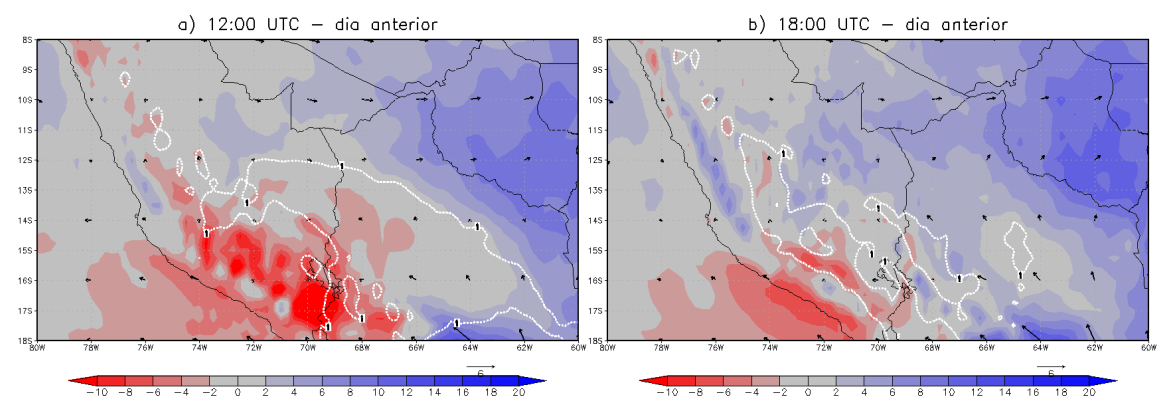

c) 00:00 UTC - dio

d) 06:00 UTC - dia

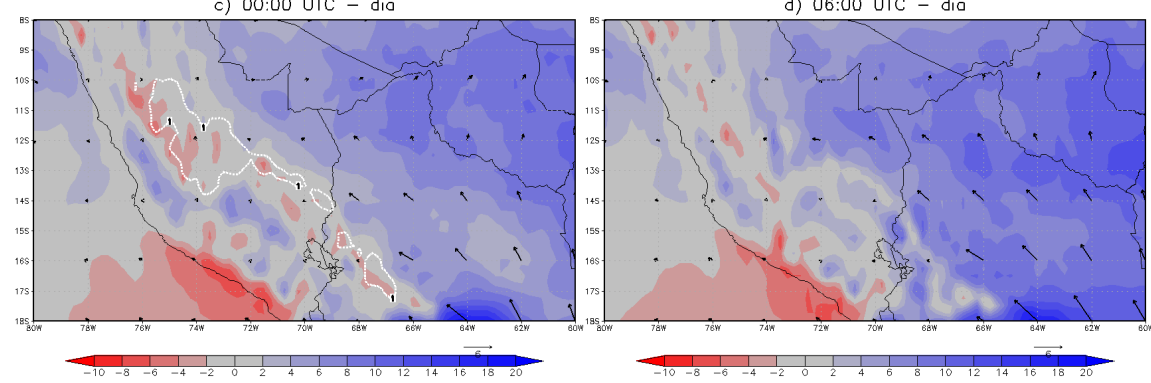

Figura A.11: Recorte da região SO da Amazônia mostrando anomalia do escoamento P2 para o nível de $700 \mathrm{hPa}$, onde vetores representam vento horizontal $(\mathrm{m} / \mathrm{s})$, escala de cores representa umidade relativa $(\%)$ e contornos a temperatura $\left({ }^{\circ} \mathrm{C}\right)$ às a) 12:00 UTC, b) 18:00 UTC, c) 00:00 UTC, d) 06:00 UTC.

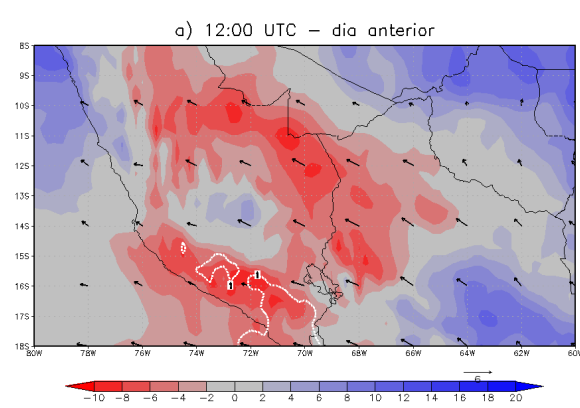

c) 00:00 UTC - dia

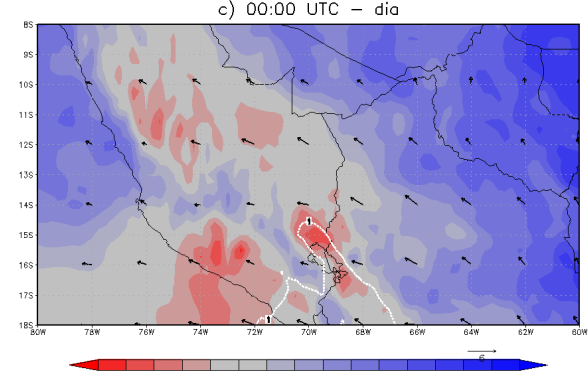

b) 18:00 UTC - dio anterior

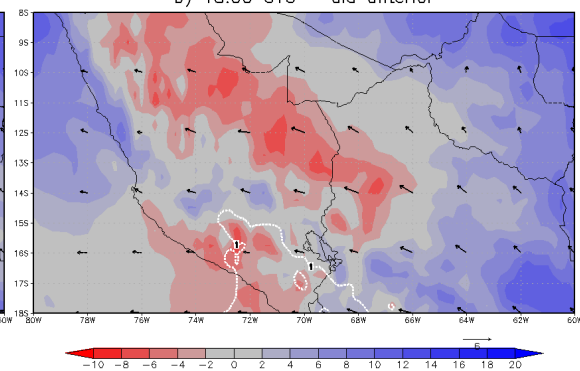

d) 06:00 UTC - dio
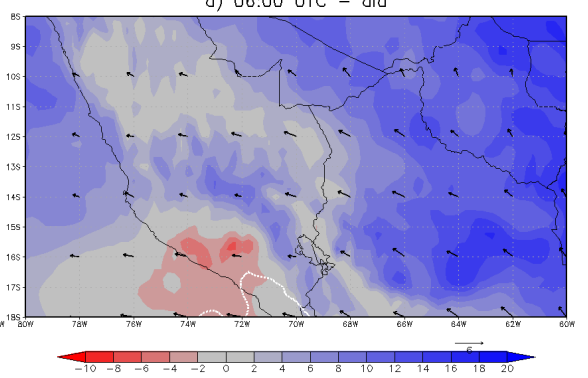

Figura A.12: Recorte da região SO da Amazônia mostrando anomalia do escoamento P2 para o nível de $500 \mathrm{hPa}$, onde vetores representam vento horizontal $(\mathrm{m} / \mathrm{s})$, escala de cores representa umidade relativa $(\%)$ e contornos a temperatura $\left({ }^{\circ} \mathrm{C}\right)$ às a) 12:00 UTC, b) 18:00 UTC, c) 00:00 UTC, d) 06:00 UTC. 